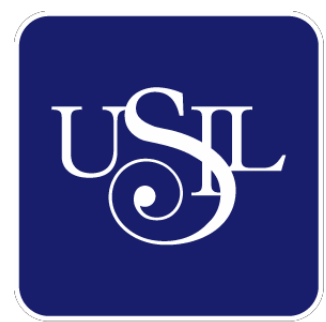

UNIVERSIDAD

SAN IGNACIO

DE LOYOLA

ESCUELA DE POSTGRADO

Maestría En Dirección De Marketing Y Gestión Comercial

\title{
PLAN DE MARKETING DEL PROGRAMA MULTIDENT KIDS PARA LAS SEDES ATE Y SANTA ANITA DE LA CLÍNICA MULTIDENT PARA EL AÑO 2018
}

Tesis para optar el grado de Maestro en Dirección de Marketing y Gestión Comercial

\section{GUISELLA EGÚSQUIZA CÁCERES \\ XIOMARA HUERTA MUNAYA \\ KARINA MOLINA NEYRA}

\author{
Asesor \\ Dr. José Miguel Solano Morales \\ Lima - Perú \\ 2018
}





\section{PLAN DE MARKETING}

\section{DEL PROGRAMA MULTIDENT KIDS PARA LAS SEDES ATE Y SANTA ANITA DE LA CLÍNICA MULTIDENT PARA EL AÑO 2018}




\section{RESUMEN EJECUTIVO}

El presente plan está enfocado en el programa Multident Kids de la Clínica Multident, quienes señalan el interés por potenciar el área de odontopediatría en sus dos nuevas sedes de los distritos de Santa Anita y Ate.

Mientras el sector salud en el que se encuentra la empresa está en crecimiento, el programa Multident Kids no crece en el mismo ritmo y está perdiendo posicionamiento en la zona.

En el análisis externo detectamos oportunidades interesantes que la empresa no utiliza en la actualidad, así como amenazas para las cuáles se han propuesto acciones que las disminuirán. Asimismo, identificamos los factores críticos de éxito, las fortalezas y debilidades.

La investigación de mercado nos ha servido para identificar los atributos que más valoran los padres en los centros odontológicos, además de determinar la intención de uso del servicio con algunas características adicionales.

Y tomando en consideración el crecimiento del país y del sector odontológico se han propuesto estrategias y acciones que responden a las preferencias de los padres de familia de la zona.

Para asegurar el éxito del plan hemos propuesto un calendario de ejecución de acciones y responsables por cada de ellas, así como el cuadro de control que permitirá el monitoreo constante de cada una de las estrategias y el plan de 
contingencia que minimizará el efecto de los imprevistos o eventos negativos que puedan surgir y por último la evaluación financiera del plan. 


\section{ÍNDICE}

INTRODUCCIÓN.................................................................................18

\section{CAPÍTULO I}

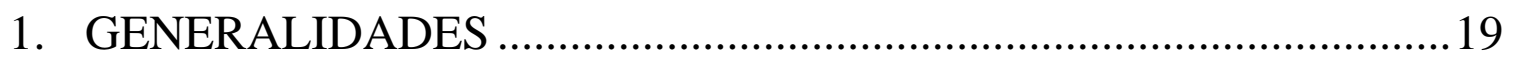

1.1. Antecedentes de la investigación......................................................19

1.2. Determinación del problema u oportunidad......................................21

1.3. Justificación del proyecto..............................................................22

1.4. Objetivos generales y específicos.....................................................24

1.5. Alcances y limitaciones de la investigación.......................................25

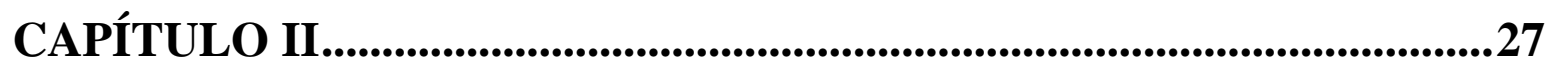

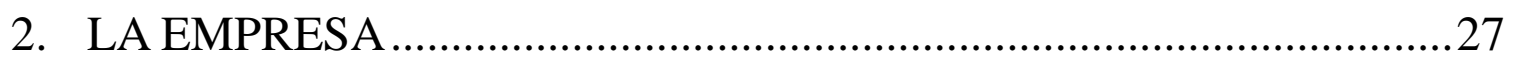

2.1. Antecedentes de la empresa …………………………………….........

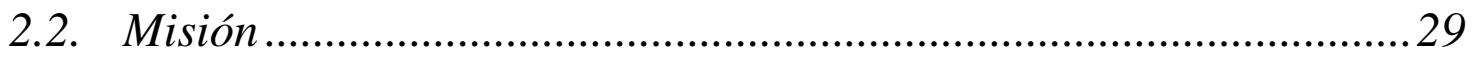

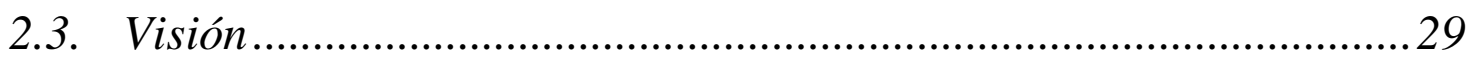

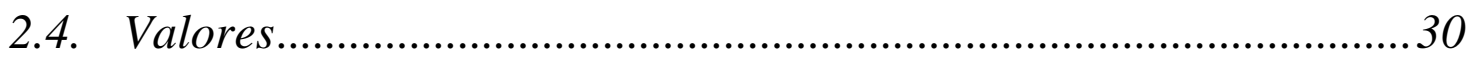


3. ANÁLISIS DE LA SITUACIÓN DE LA EMPRESA .............................33

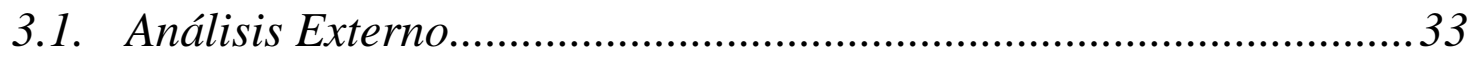

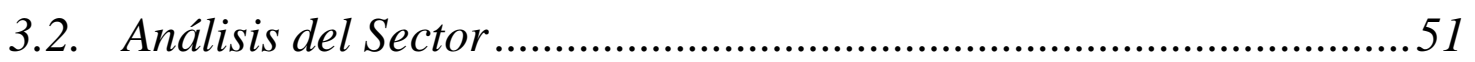

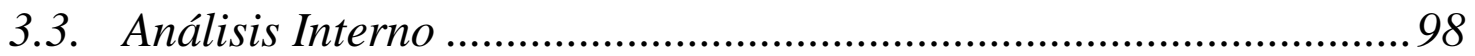

CAPÍTULO IV ......................................................................................117

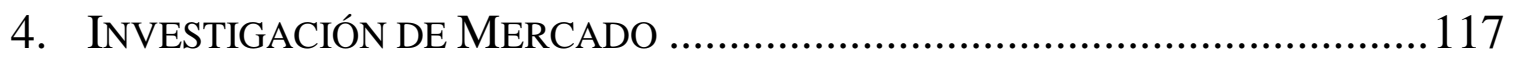

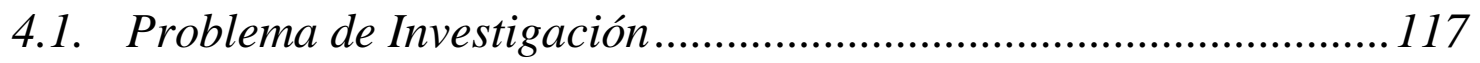

4.2. Necesidades de Información ....................................................... 118

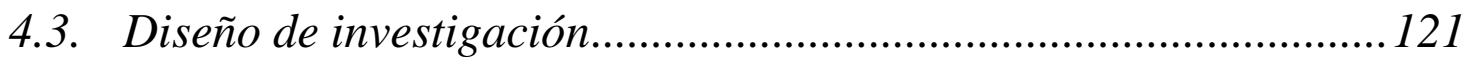

4.4. Método de investigación cualitativa .............................................. 122

4.5. Método de investigación Cuantitativo........................................... 132

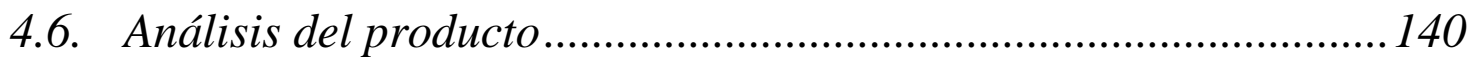

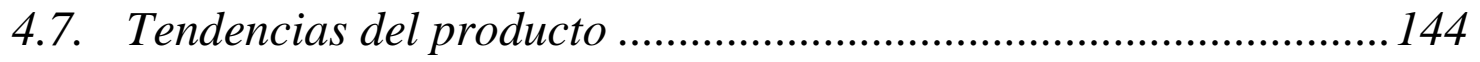

4.8. Tendencias del Comportamiento del Consumidor ......................... 146

4.9. Tendencia de medios, distribución, precio.....................................151

4.10. Segmentos del mercado que compran el producto ......................... 153 
4.11. Análisis DAFO.

155

CAPÍTULO V ................................................................................................. 148

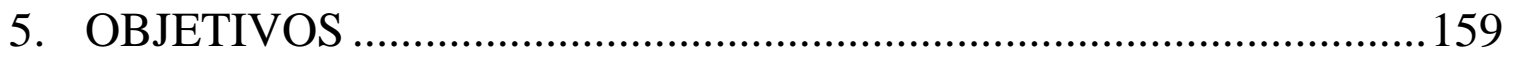

5.1. Relación entre el Plan estratégico y el Plan de marketing .............159

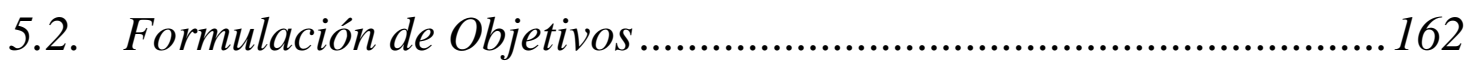

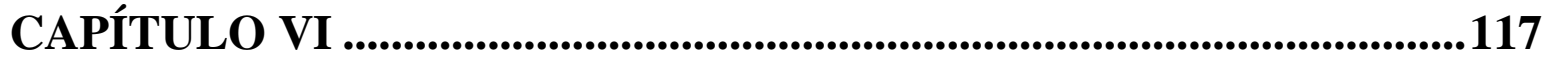

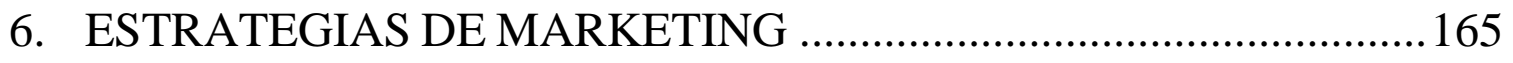

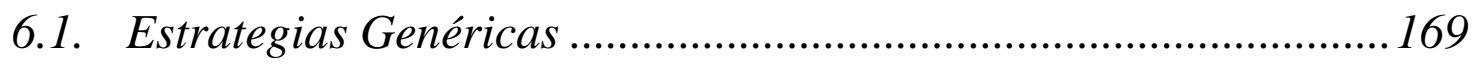

6.2. Estrategias de Cartera .............................................................. 170

6.3. Estrategias de Segmentación......................................................... 173

6.4. Estrategias de Posicionamiento ................................................... 175

6.5. Estrategias de Fidelización ........................................................... 176

6.6. Estrategia de Posición de mercado (LRS) ..................................... 179

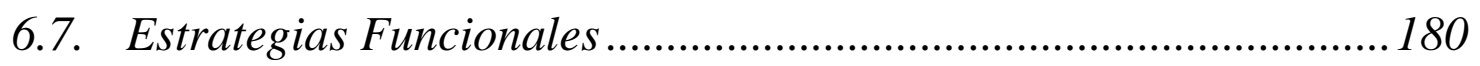


7. EJECUCIÓN DE LA ESTRATEGIA ..................................................182

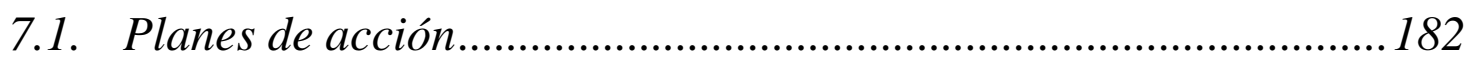

A1. "Plan de seguimiento" ....................................................................185

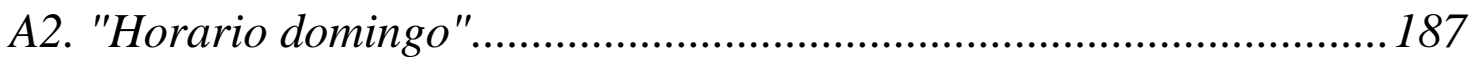

A3. "Experiencia Multident Kids" .......................................................... 189

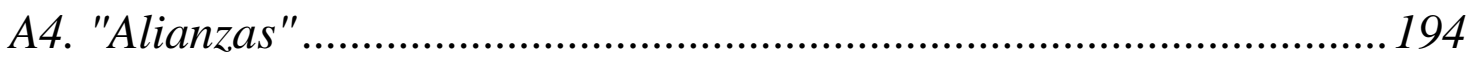

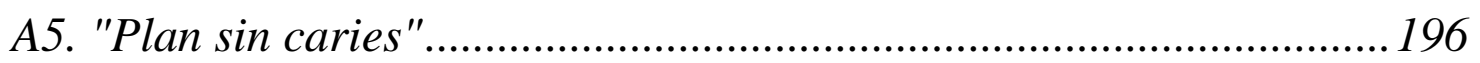

A6. "Programa Guerra a las Caries".......................................................199

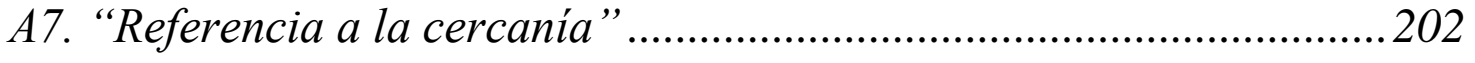

A8. "Potenciar Multident Card" ............................................................204

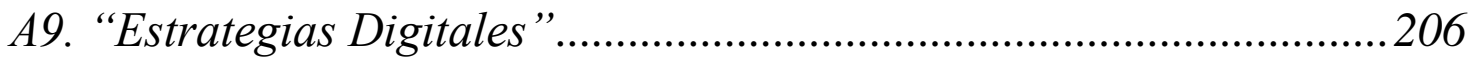

7.2. Calendario de ejecución del Plan ..................................................211

7.3. Presupuesto de Marketing.............................................................2212

7.4. Estado de Resultados..................................................................213

CAPÍTULO VIII .......................................................................................218

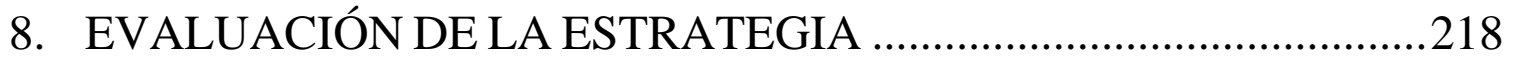

8.1. Sistema de Información y Control....................................................218

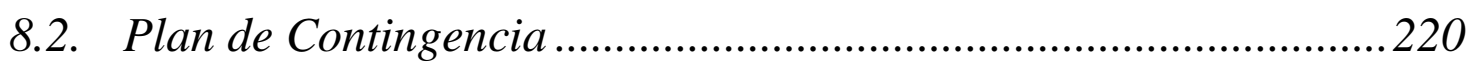


8.3. Evaluación Financiera.

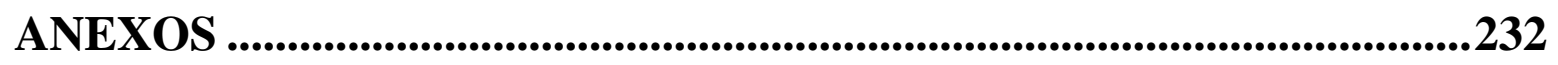

ANEXO 1: LISTA DE EMPRESAS CON CONVENIOS CORPORATIVOS VIGENTES. 232

ANEXO 2: NIVEL DE SATISFACCIÓN DEL CLIENTE INTERNO .........................233

ANEXO 3: NIVEL DE SATISFACCIÓN DEL CLIENTE EXTERNO..........................234

ANEXO 4: RESUlTADO DE TRABAJO DE CAMPO DE COMPETENCIA DIRECTA .235

ANEXO 5: ENTREVISTAS A PROFUNDIDAD A PROFESIONAL ODONTÓLOGO ....236

ANEXO 6: ENTREVISTAS A PROFUNDIDAD A PROFESIONAL RELACIONADO ...238

ANEXO 7: ENTREVISTAS A PROFUNDIDAD A PADRES DE FAMILIA .................239

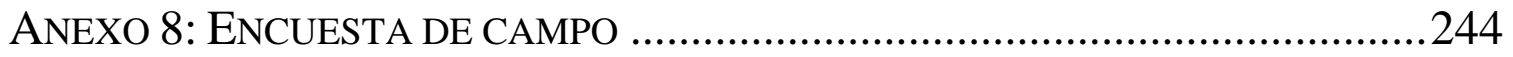

ANEXO 9: CRONOGRAMA DE VIDEOS EN VIVO PARA ESTRATEGIA DIGITAL EN

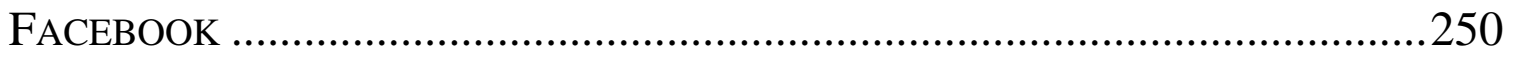

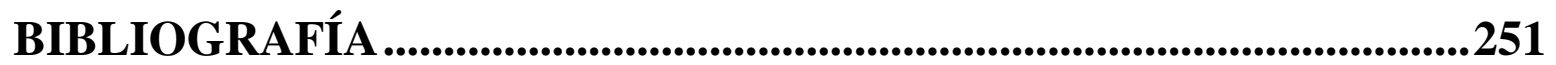




\section{ÍNDICE DE TABLAS}

Tabla 1. Proyección de variables macroeconómicas del Perú ..........................35

Tabla 2. Clasificación de empresas por Cantidad de trabajadores...................37

Tabla 3. Instituciones educativas en Santa Anita y Ate...................................38

Tabla 4. Servicios médicos otras especialidades ...........................................39

Tabla 5.Indicadores Demográficos 2015 - 2050 ..........................................42

Tabla 6.Uso de Redes Sociales en el Perú .......................................................45

Tabla 7. Penetración de Internet en NSE A,B,C+........................................46

Tabla 8. Proyección de Penetración Medios Online Zona 5 NSE A,B,C+......47

Tabla 9. Proyecciones Macroeconómicas del País y del Sector .......................57

Tabla 10. Proyecciones PBI por Sector ........................................................59

Tabla 11. Presupuesto Público por Sector .......................................................61

Tabla 12. Proyección de Gastos e Ingresos Zona 5 NSE A, B, C+ .................64

Tabla 13. Proyección de afiliación a los sistemas de salud en Lima

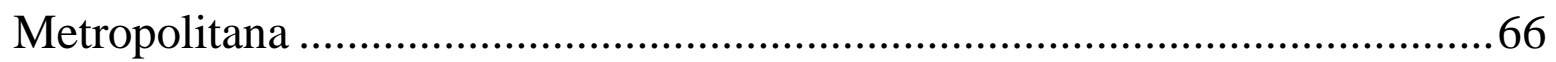

Tabla 14. Gasto Promedio de la Salud Bucal Perú, Chile, Colombia..............67

Tabla 15. Gastos de atención odontológica de niños con caries de infancia

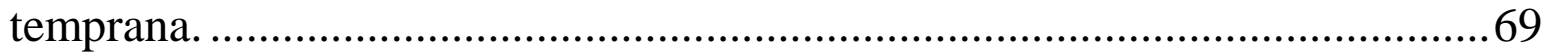

Tabla 16. Distribución de pacientes del 2012-2017.........................................71

Tabla 17. Actividades realizadas por el área de Marketing en el año 2017. ...74 
Tabla 18. Gasto promedio anual de pacientes vs Gasto promedio del sector en

los NSE A,B,C+ en Lima Este 87

Tabla 19. Tarifario de tratamientos más comunes ......................................... 106

Tabla 20.Estructura Distribución Muestral ....................................................125

Tabla 21. Índices Utilizados para el cálculo del Mercado Potencial ..............134

Tabla 22. Cálculo del Mercado Potencial ......................................................135

Tabla 23.Mercado Potencial............................................................................. 136

Tabla 24. Muestra gestantes entre 25 y 45 años, NSE A, B, C+ de Ate, Santa

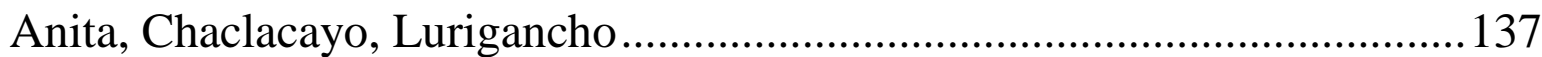

Tabla 25. Muestra Familias (padres entre 25 y 45 años) con hijos entre 0 y 12

años, NSE A, B, C+ de Ate, Santa Anita, Chaclacayo, Lurigancho..............137

Tabla 26. Distribución de la muestra para madres gestantes .........................138

Tabla 27. Distribución de la muestra para padres con niños de 0 a 12 años .138

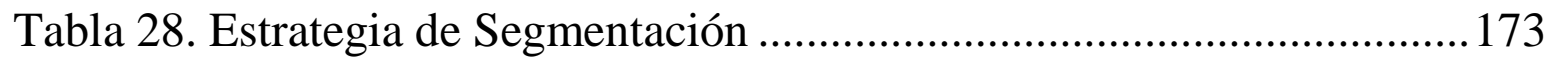

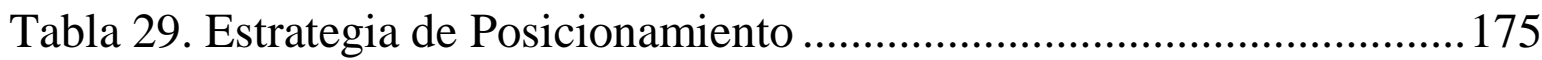

Tabla 30. Evaluación de calidad percibida ..................................................176

Tabla 31. Evaluación del coste/precio percibido ............................................ 177

Tabla 32.Tarifario comparativo de precios regulares y con tarjeta Multident

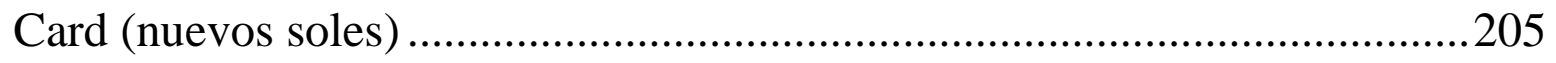

Tabla 33. Proyección de Ventas sin plan de marketing propuesto ................213 
Tabla 34. Previsión de Ventas del plan de marketing propuesto ...................213

Tabla 35. Resumen previsión de ventas ......................................................215

Tabla 36. Proyección de Estado de Ganancias y Pérdidas del programa ......216

Tabla 37. Indicadores de Control y Plan de Contingencia.............................221

Tabla 38. Flujo de Fondos.....................................................................224

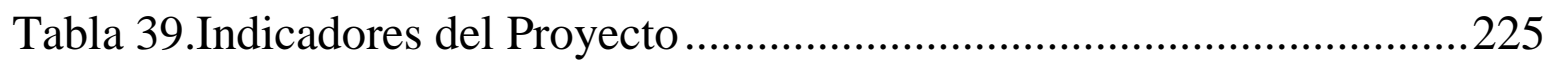




\section{ÍNDICE DE FIGURAS}

Figura 1.Porcentaje de facturación por especialidades odontológicas. 21

Figura 2. Mapa de ubicación de sedes Ate y Santa Anita en Lima 26

Figura 3. Esfuerzos de modernización del Estado ............................................34

Figura 4. Clasificación de empresas por Cantidad de Trabajadores .................37

Figura 5. Distribución de centros educativos en Ate y Santa Anita según

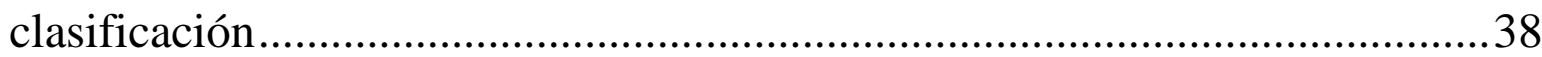

Figura 6: Creación de puestos de trabajo formales ........................................40

Figura 7. Pilares de Crecimiento Económico para el 2018...............................41

Figura 8. Estrategia de las Empresas para el 2018.......................................49

Figura 9. Anuncios de inversión privada en el sector salud ...........................55

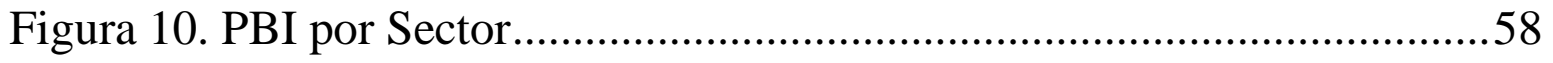

Figura 11. Presupuesto Público 2018 por sector en porcentajes......................60

Figura 12. Distribución por NSE Zona 5 Lima Metropolitana .........................62

Figura 13. Mapa de ubicación de centros odontológicos en Santa Anita .........84

Figura 14.Mapa de ubicación de centros odontológicos en Ate .......................84

Figura 15. Precios de competencia respecto a MULTIDENT.........................85

Figura 16. Gasto anual paciente Multident Kids vs Gasto anual del sector ....88

Figura 17. Fuerzas de Porter - Multident (Ate, Santa Anita) ..........................93

Figura 18. Mapa de Lima Este de Guía de Calles de Lima ............................98 


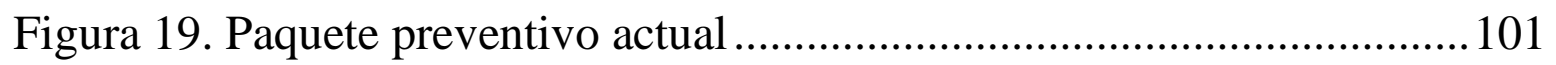

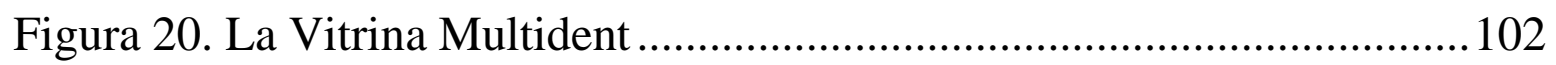

Figura 21. Participación de ventas por tipo de tratamiento ........................... 103

Figura 22. Ciclo de vida de las especialidades odontológicas en Multident .104

Figura 23. Fotografías de infraestructura actual ....................................... 112

Figura 24. Actividades del equipo de trabajo ............................................ 113

Figura 25. Preferencia de programas dentales para Multident Kids ..............141

Figura 26. Preferencia para sala de espera para niños de 0-2 años................ 142

Figura 27. Preferencia para sala de espera para niños de 3-5 años................ 143

Figura 28. Preferencia para sala de espera para niños de 6-12 años.............. 143

Figura 29. Preferencia sobre horarios de atención .......................................... 144

Figura 30. Preferencia de servicios adicionales esperados .......................... 145

Figura 31.Aspectos valorados en un centro odontológico ............................146

Figura 32. Motivo por el que llevó a su hijo a su última atención.................147

Figura 33. Cantidad de veces que llevó a su hijo al dentista en el último año

Figura 34. Motivo de elección del centro odontológico ................................. 148

Figura 35.Lugar de la última atención dental ............................................149

Figura 36. Padres cuyos hijos concluyen sus tratamientos ............................150

Figura 37. Motivos de abandono del tratamiento .........................................150 
Figura 38.Recordación de la marca "Multident"

Figura 39. Reconocimiento de la marca "Multident" en Ate y Santa Anita..151

Figura 40. Medio preferido para mantener comunicación ..............................152

Figura 41. Preferencia sobre planes propuestos y sus características ............153

Figura 42. Edades de los padres en la aceptación de las propuestas .............154

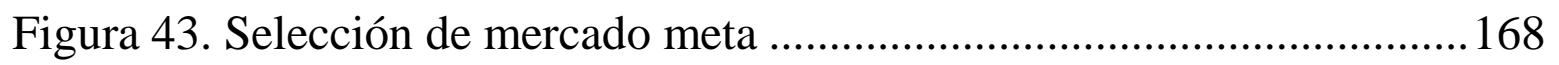

Figura 44. Matriz estrategias genéricas de Porter ............................................169

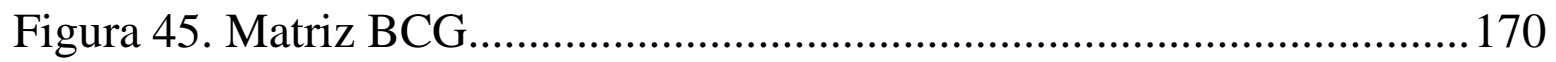

Figura 46. Matriz priorización Líneas de productos ......................................171

Figura 47. Mapa del Valor para el Cliente..................................................178

Figura 48. Worflow propuesto para Plan de Seguimiento ............................. 186

Figura 49. Propuesta para actividades adicionales para atención en domingos 188

Figura 50. Propuesta de afiche para atención dominical .............................. 188

Figura 51. Propuesta de anuncios para actividades......................................190

Figura 52. Propuesta de publicación de experiencia en Facebook .................193

Figura 53. Empresas propuestas para alianzas ............................................. 196

Figura 54. Empresas propuestas para convenios de Plan Sin Caries............. 198

Figura 55. Propuesta de muñeco en material mdf para juegos en centro comerciales. 
Figura 56. Prototipo de Banner relativa a la cercanía. ..................................203

Figura 57. Proyección de Resultados ............................................................217

Figura 58. Evaluación Financiera ….........................................................226 


\section{INTRODUCCIÓN}

La presente tesis del plan de marketing tiene como finalidad investigar las necesidades del mercado de salud dental para bebés y niños, de manera proponer estrategias que permitan el posicionamiento del programa Multident Kids para las sedes de Ate y Santa Anita.

Creemos necesario investigar la situación actual de la salud dental, el análisis de necesidades del cliente y consumidores potenciales, en este caso padres e hijos; evaluar las competencias de Multident Kids y el análisis del micro y macro entorno para proponer las estrategias de cartera, segmentación, fidelización, posicionamiento y funcionales que permitan a los padres reconocer a la clínica como el mejor aliado en la salud dental de sus hijos y a los niños como una experiencia amigable, generando en ambos cliente y consumidor final, un clima de gran confianza.

Asimismo, el plan de marketing está alineado a la visión de la empresa, lo cual permitirá concretar los objetivos que se plantean en este estudio.

Finalmente, creemos que los padres de familia hoy en día tienen mayor acceso a la información sobre el cuidado de la salud y las alternativas que existen en el mercado, asimismo su capacidad adquisitiva ha crecido, los padres conscientes de proteger la salud de sus hijos asisten periódicamente al dentista, de manera que se evite el riesgo de incidentes, infecciones y enfermedades bucales. 


\section{CAPítUlO I}

\section{GENERALIDADES}

\subsection{Antecedentes de la investigación.}

De acuerdo a la Organización Mundial de la Salud, el concepto de salud no sólo se concibe como ausencia de síntomas, sino también el disfrute del bienestar psicológico y social, por tanto, es necesario propiciar los mecanismos para que cada miembro de la familia lo obtenga.

La salud dental está estrechamente vinculada con el bienestar general. Las enfermedades bucales representan la segunda causa de morbilidad en consultas externas y deterioran la salud en general, la autoestima, la calidad de vida y desarrollo integral de las personas. La atención dental genera altos costos tanto en el sector público como privado.

Probablemente, la atención odontológica de niños y adolescentes es una de las situaciones en la cual el odontólogo enfrenta los mayores desafíos, en su contribución hacia el logro de una sociedad sana, en el campo de la salud dental. 
La respuesta al tratamiento dental de un niño genera estrés que proviene del miedo y la ansiedad que se tiene ante lo desconocido. La información previa que los padres tengan en el tratamiento, las técnicas de manejo de conducta del profesional y el entorno físico-psicológico que brinde los centros odontológicos son aspectos fundamentales en la salud bucal del niño. 


\subsection{Determinación del problema u oportunidad.}

Desde el año 2012 Multident tiene presencia en Lima Este y cuenta con el programa Multident Kids que brinda los servicios de odontopediatría, sin embargo, este no ha crecido sostenidamente en la Clínica como sí lo han conseguido otras especialidades tales como: implantes, ortodoncia y estética dental.

Inicialmente el programa contaba con un $8 \%$ de la facturación de la empresa $\mathrm{y}$, en la actualidad el porcentaje ha decrecido a un 5\% como se muestra en la figura 1, dado el mayor énfasis puesto por la empresa en las especialidades de mayor ticket promedio.

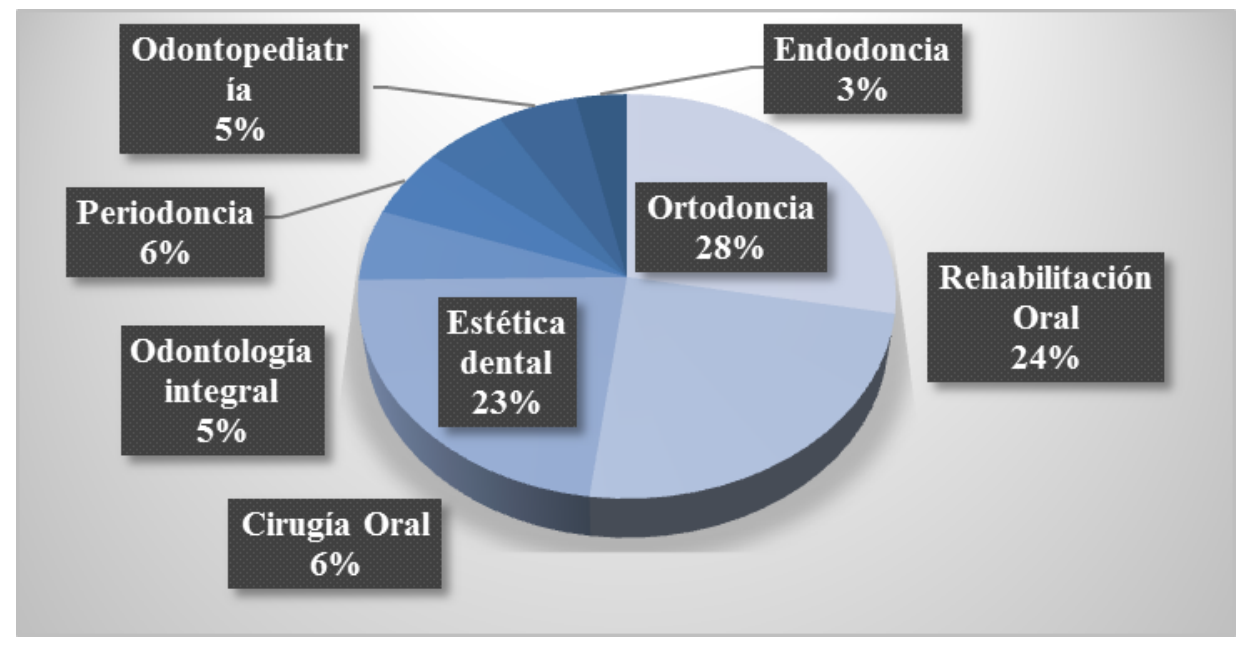

Figura 1.Porcentaje de facturación por especialidades odontológicas. 
En una entrevista con el director médico de Lima Este de Multident manifestó su preocupación por el programa ya que, a pesar de poner esfuerzos en el área de marketing, los resultados no reflejan un importante incremento en las ventas para Multident Kids. Sin embargo, dada las oportunidades que presenta el sector, el mercado de Lima Este y las fortalezas de la clínica, consideramos que presenta potencial para crecer, además que puede significar el primer paso para que toda una familia considere atenderse en Multident y retribuya al crecimiento de toda la empresa.

Consideramos que el reto está en acceder de una forma más eficiente al público objetivo, identificar las preferencias tanto de los padres y niños, logrando que Multident Kids sea el servicio diferenciado que valoran accediendo al mismo.

\subsection{Justificación del proyecto.}

La salud dental es parte fundamental en el bienestar integral de las personas y es la salud un tema de interés social y de gran responsabilidad. Las instituciones involucradas como el Ministerio de Salud (MINSA) y el Colegio Odontológico del Perú, entre otros, juegan un rol importante en crear las estrategias multidisciplinarias para que exista un plan preventivo.

La salud dental preventiva, es una planificación que se inicia en los hogares de las familias peruanas, al ser la familia el núcleo y eje de la sociedad. 
Son principalmente los afiliados del SIS, Essalud y los no asegurados dados la deficiencia del servicio de salud público quienes acuden a centros privados para satisfacer estas necesidades. La demanda representada por los gastos de bolsillo de los peruanos se ha incrementado en un $4 \%$ en los dos últimos años y de éstos el $43 \%$ representa los gastos por atención en prestadoras de servicio privado.

El crecimiento económico de los distritos periféricos se evidencia en el mejoramiento de la capacidad adquisitiva de las familias, que pueden acceder a diferentes servicios de mejor calidad, preocupación de la salud integral en la familia propiciada principalmente en padres jóvenes con hijos pequeños, tanto en sus necesidades emocionales, físicas y psicológicas. Pero además existe un crecimiento informal o poco fiscalizado en cuanto a la calidad de los servicios que se otorgan.

En este sentido, Multident, una marca reconocida en Lima por la calidad y confianza en los servicios odontológicos que presta, apuesta por incentivar el desarrollo del servicio de odontología pediátrica en Lima Este, respondiendo a la demanda insatisfecha de un servicio de calidad adecuada y lo que valora este mercado.

El equipo de tesis escogió este programa y las zonas por su gran potencial de crecimiento, por tener un concepto que aún no ha sido totalmente explotado. Y resaltamos también que el programa elegido es de alto interés para la empresa porque representa el primer eslabón de la cadena de pacientes dentro de un núcleo familiar.

Además, tenemos la certeza que con las ideas desarrolladas en el presente Plan de Marketing el crecimiento de la marca tendrá un mayor impacto en la empresa y en la sociedad. 


\subsection{Objetivos generales y específicos.}

El objetivo estratégico de Multident es incrementar la participación de mercado a $27 \%$ para el cierre del año 2018, manteniendo un margen de utilidad neta superior o igual al $5 \%$.

Esencialmente, la marca pretende tener una presencia en todo el país con un total de 55 sedes.

A nivel de Lima Este, la marca busca posicionar las sedes de Ate y Santa Anita como un servicio de confianza y diferenciado por su avanzada tecnología y un equipo integrado por odontólogos de primer nivel, técnicos y administrativos, comprometidos con el mejoramiento contínuo.

Para el 2018 se tiene como objetivos específicos para el programa Multident Kids:

- Incrementar las ventas de Multident Kids en 59\% para el año 2018.

- Mantener el margen de utilidad sobre las ventas como mínimo en 5\% para el 2018.

- Incrementar en 25\% el número de pacientes en tratamiento en el 2018.

- Incrementar la facturación promedio anual por paciente en 25\% para el 2018.

- Ampliar la cobertura de convenios con presencia en 3\% de empresas en Lima Este para el 2018. 
- Aumentar la notoriedad de la marca en Ate y Santa Anita de 33\% a 50\% pensando en nuestros clientes (padres) y consumidores (bebés, niños y adolescentes) en el 2018.

\subsection{Alcances y limitaciones de la investigación.}

El presente plan de marketing centra su atención en los padres con hijos comprendidos en las edades de 0 a 12 años y madres gestantes que viven en Ate y Santa Anita y en los distritos aledaños como Chaclacayo y Lurigancho, por cercanía y afluencia de vías principales como la Carretera Central, es importante precisar que estos distritos están unidos por esta vía y ambas sedes de la Clínica están a metros de la misma. Considera a los padres y madres gestantes perteneciente a un NSE A, B y C+ dado el precio accesible para estos.

Los distritos mencionados están comprendidos en la Zona 5 de acuerdo con APEIM y fueron elegidos en base al radio de acción definida por la Corporación para cada sede. La ubicación de las sedes de Ate y Santa Anita en Lima se muestra en la figura 2. 


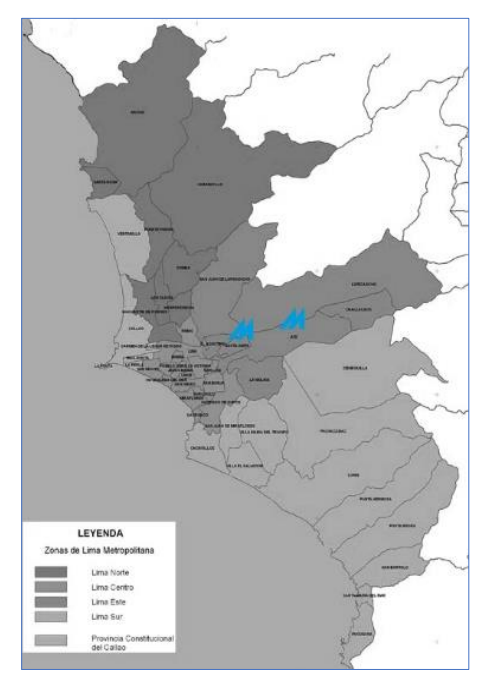

Figura 2. Mapa de ubicación de sedes Ate y Santa Anita en Lima

Existe una sola visión para la marca Multident, ofrecen los mismos servicios en todas sus sedes, sin embargo, las estrategias se pueden adaptar según el sector geográfico donde se desarrolle la empresa.

Dada la proliferación de empresas informales que ejercen la actividad de servicios odontológicos en la zona, existen limitaciones en cuanto a la exactitud de la información, consideraremos proyecciones macroeconómicas del sector, aproximaciones sobre cantidad de centros odontológicos y otros relacionados a la salud y servicios ofrecidos a niños, que para el análisis de competencia podemos apoyarnos con la investigación de campo. 


\section{CAPÍTULO II}

\section{LA EMPRESA}

\subsection{Antecedentes de la empresa}

Multident es una cadena de clínicas odontológicas con presencia en Perú. La empresa nace en Lima el 20 de agosto de 1993, su fundador el Dr. Jesús Ochoa Zavaleta es académico, profesor, clínico y empresario. La trayectoria y el prestigio del doctor en el rubro odontológico es una fortaleza para la marca, es por eso y por todo el esfuerzo del equipo odontológico y administrativo que hoy es reconocida como una clínica líder en el país.

Cuando la empresa empezó con su red de clínicas que tiene hoy en día, inició sus operaciones en los distritos más modernos con 3 sedes: Chorrillos, San Isidro y Lince, en el año 1998 se inauguró la sede Miraflores, el año 2000 la sede San Borja, a fines del 2004 las sede La Molina, en el 2006 la sede San Miguel y el 2008 la sede Av. Arequipa donde se concentraba la mayor parte del movimiento financiero, laboral y de entretenimiento. A partir del 2009, se detectó un crecimiento de distritos periféricos de manera que la empresa decidió iniciar actividades en todos los distritos sin temor. El resultado fue bueno pues en cada uno de los distritos se encontró un porcentaje de personas que sí estaban dispuestas a invertir un poco más en su salud a cambio de un servicio de calidad. 
Debido a las nuevas tendencias y estilos de vida, el dentista ya no se considera visitarlo únicamente cuando se presenta algún dolor y con temor; sino que, muchos de los pacientes que acuden a Multident lo hacen con la finalidad de mejorar su imagen y calidad de vida.

Es por eso, que la empresa desde sus inicios ha trabajado mucho para mantenerse pionero y líder en estética dental, gestión de la calidad, infraestructura, trayectoria y programas de protección.

A la fecha la empresa cuenta con 33 sedes en Lima y 4 en provincias. La rápida expansión en todo Lima ha sido porque a partir de la octava sede fueron trabajadas bajo la modalidad de franquicia. Cada una de las sedes cuenta con los lineamientos de la sede central, similar infraestructura, proveedores y con todas las especialidades en odontología que garantiza una igual y adecuada atención al paciente: Estética dental, Endodoncia, Periodoncia, Ortodoncia, Rehabilitación Oral, Cirugía Oral, Implantología y Odontopediatría.

Multident ha recibido múltiples premios a lo largo de los años que refleja el liderazgo que presenta en el rubro odontológico y además la confianza que depositan las empresas de rubros totalmente distintos a través del programa corporativo el cual le otorga una atención preferencial a su gran plantel de trabajadores y familiares directos en cualquiera de las sedes. 
Dentro de los servicios más resaltantes que ofrece en todo Lima y que no lo tienen diseñado otras clínicas son: Emergencias dentales 24 horas, un programa de financiamiento conocido como "Sonrisa Perfecta", un programa de asegurados "Plan dental", una tarjeta de beneficios y descuentos llamada "Multident Card" y los programas diseñados para niños "Multident Kids" y para novias "Multident Novias".

\subsection{Misión}

Es brindar atención dental de calidad y un servicio de excelencia a nuestros pacientes y a las personas cuya protección de salud nos ha sido confiada.

\subsection{Visión}

Ser el sistema de atención dental líder en el País, con la más avanzada tecnología, en manos de un equipo integrado por odontólogos de primer nivel, técnicos y administrativos, comprometidos con el mejoramiento continuo en busca de un país que sonría sanamente. 


\subsection{Valores}

Multident la Clínica Dental líder del país, busca desbordar las expectativas de nuestros pacientes, cumpliendo con los requisitos, promoviendo un mejoramiento continuo, elevando el nivel profesional y manteniendo a la vanguardia de la tecnología.

Multident promueve y practica la cultura de valores, honestidad, veracidad, laboralidad, lealtad y respeto. Esta es una parte fundamental de la familia Multident.

Multident está comprometida con la defensa del medio ambiente y la cultura de vida sana; la protección del menor, la mujer desvalida, y el adulto mayor, participando activamente en campañas y programas de ayuda social a nivel nacional. 


\subsection{Estructura Organizacional de la empresa}

El personal administrativo de Multident se encuentra organizado de la siguiente forma:

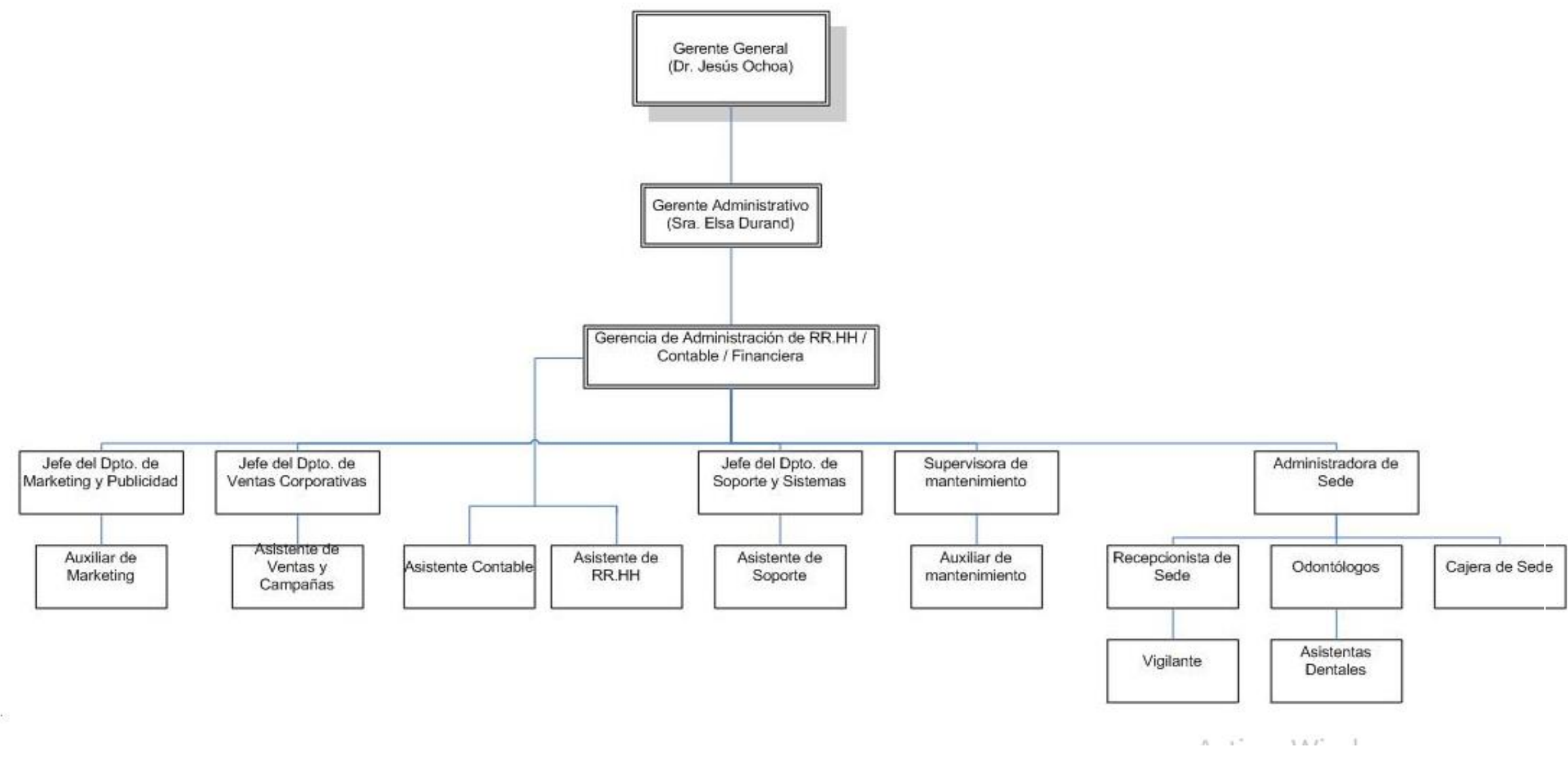




\section{Gerente General}

2. Gerente Administrativo

3. Director Médico

4. Administradora de Recursos Humanos

5. Asistente de Recursos Humanos

6. Contador General y Finanzas

7. Asistente Contable

8. Jefe de Ventas Corporativas

9. Asistente de Ventas Corporativas

10. Jefe de Relaciones Públicas - Marketing

11. Jefe de Logística y Mantenimiento

12. Jefe del Departamento de Sistemas y Soporte Técnico

13. Administradora de Sede

14. Asistente Administrativa de Sede

15. Recepcionista de Sede

16. Cajera de Sede

17. Radiólogo

18. Vigilancia de Sede y Mantenimiento 


\section{CAPÍTULO III}

\section{ANÁLISIS DE LA SITUACIÓN DE LA EMPRESA}

\subsection{Análisis Externo}

\subsubsection{Análisis político-legal}

El 2017 fue un año difícil para el Perú que llevaron a paralizar obras públicas importantes, actos de corrupción acontecidos como el caso de Odebrecht y Lavajato, los cuales han generado un clima de conflictos en el escenario político.

Es importante resaltar que aún así, el Perú reporta el riesgo país más bajo (0.99 puntos porcentuales) dentro de la región, seguido de Colombia (1.64 puntos) y México (1.81 puntos). Este indicador El EMBI+ Perú proporcionado por el Banco JP Morgan se mide en función a la diferencia del rendimiento promedio de los títulos soberanos peruanos frente al rendimiento del bono del Tesoro Estadounidense. Así se estima el riesgo político y la posibilidad de que un país pueda incumplir con sus obligaciones de pago a los acreedores internacionales (Gestión, 08 de enero del 2018).

El sector salud será uno de los más beneficiados en el Presupuesto General de la República para el 2018, el Poder Ejecutivo ha destinado S/. 16,027 millones, lo que implica un crecimiento del $16 \%$ en relación con el año anterior, según la Ley $\mathrm{N}^{\circ}$ 30693 aprobada para el presupuesto del año fiscal 2018. El presupuesto será destinado principalmente al aseguramiento y sistema integrado de salud, a la mejora de la infraestructura y equipamiento de los servicios, a la modernización de los 
establecimientos de salud, al fortalecimiento de las capacidades profesionales de trabajadores del sector y a potenciar el desarrollo infantil temprano, según informes presentados por el Ministerio de Salud - MINSA.

A nivel nacional, existe un proyecto de modernización de la gestión pública como se resume en la figura 3 , el cual recae en uno de los ejes transversales de la política nacional de modernización y gobierno electrónico para mejorar los servicios ofrecidos en los órganos de la administración pública. Las plataformas digitales de SUNAT, PRODUCE y la RENIEC permitirán el cruce de información de las Empresas (Pymes y Mypes).
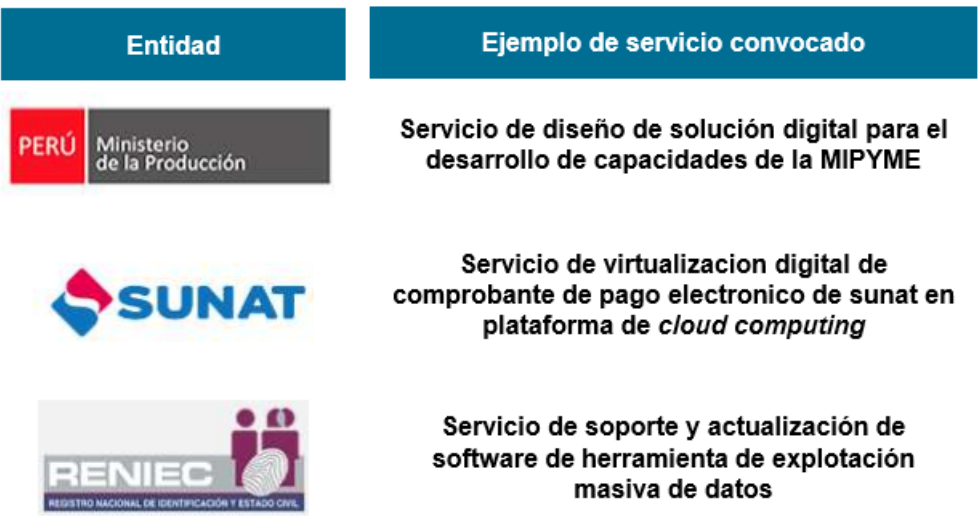

Resultado

Adjudicado por $<$ S/100 000

Adjudicado por US\$12 millones

Declarado desierto

Figura 3. Esfuerzos de modernización del Estado 


\subsubsection{Económico-Demográfico}

El Perú es un país con una larga historia, abundantes recursos y culturas. Es el séptimo productor minero, el cuarto caladero mundial, convirtiéndose en una de las naciones con mayor biodiversidad y enorme potencial de desarrollo.

La inversión prevista de US\$ 5 mil millones para la construcción de la mina Quellaveco en Moquegua ha logrado generar gran expectativa, así también se avizora el inicio de la reconstrucción de Mina Justa en Ica y Michiquillay en Cajamarca a fines del 2018.

Según el Informe de Actualización de Proyecciones Macroeconómicas publicado por el Ministerio de Economía y Finanzas (MEF), entre las principales proyecciones tenemos los siguientes indicadores macroeconómicos que se muestran en la tabla 1:

Tabla 1. Proyección de variables macroeconómicas del Perú

\begin{tabular}{|l|l|l|l|l|}
\hline \multicolumn{1}{|c|}{ Variables } & 2016 & 2017 & 2018 & 2019 \\
\hline PBI & $3,5 \%$ & $2.8 \%$ & $4.0 \%$ & $4,0 \%$ \\
\hline Inversión Privada & $6.1 \%$ & $2.5 \%$ & $3.5 \%$ & $3.5 \%$ \\
\hline Inversión Pública & $4.7 \%$ & $5.0 \%$ & $5.8 \%$ & $5.8 \%$ \\
\hline Brecha Fiscal & $2.6 \%$ & $1.8 \%$ & $1.3 \%$ & $1.2 \%$ \\
\hline
\end{tabular}

Elaboración propia

Fuente: Marco Macroeconómico Multianual 2018-2021- MEF, Agosto 2017

Diario Gestión, 2017 
De acuerdo con el Informe macroeconómico, entre el 2017 y 2020, se destinará US\$ 6400 millones de dólares a la reconstrucción del país y la proyección de crecimiento económico para este año 2018 es consistente con la recuperación gradual de la brecha del producto $\mathbf{y}$ un crecimiento del PBI potencial aproximado del $4,0 \%$.

En el sector de la salud privada, las familias de clase media de Lima y provincias permanecen desatendidas, más del 30\% de la población perteneciente al NSE C no cuenta con ningún seguro de salud, según estudio efectuado por el SAE y Apoyo Consultoría, diciembre 2018.

Cabe notar que en Lima Este se viene desarrollando una serie de obras, una de las más importantes es el Proyecto de la línea 2 del Metro de Lima, obra financiada por el Banco Mundial y otras instituciones internacionales. La gran ventaja es que, a futuro, permitirá la movilización de más de 2 millones de personas desde zonas industriales del Este hacia el Callao y viceversa.

Santa Anita tiene entre sus zonas comerciales más importantes el Mercado de Mayoristas, el Mercado de Productores, el Ovalo Santa Anita, Mall Aventura Plaza; y Ate es el tercer distrito más poblado de Lima, tiene dentro del sector comercial comprometidos S/.694.1 millones, seguido del sector industrial S/.139.2 millones y del educativo S/93.9 millones. En Ate se encuentra el Real Plaza Santa Clara, la zona comercial de Ceres y todos los supermercados importantes. 
En la zona 5 de Lima Metropolitana encontramos un total de 5,295 empresas productoras en diferentes rubros y clasificaciones como se muestra en la tabla 2. Están divididas entre micro, pequeñas, medianas y grandes empresas.

Tabla 2. Clasificación de empresas por Cantidad de trabajadores

\begin{tabular}{|l|r|}
\hline Clasificación por trabajadores & Cantidad \\
\hline 1 a 50 trabajadores & 2921 \\
\hline 50 a 500 trabajadores & 2351 \\
\hline 500 a más trabajadores & 23 \\
\hline Total & 5295 \\
\hline Elaboración propia
\end{tabular}

Fuente: Base de datos del Ministerio de Producción 2017

Un porcentaje mayor de empresas son micro y pequeñas empresas que están conformadas por menos de 50 trabajadores como se muestra en la figura 4.

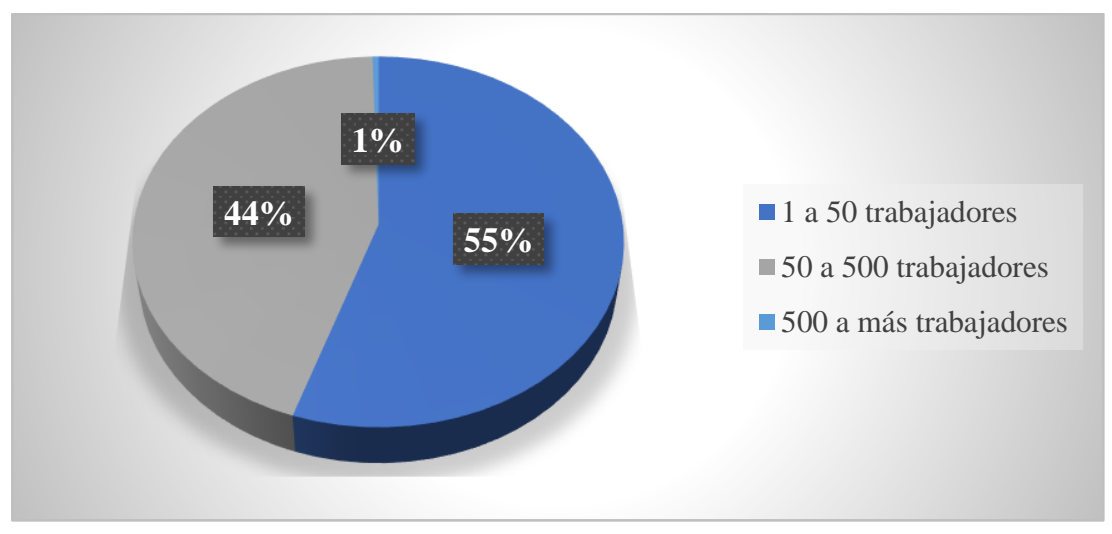

Figura 4. Clasificación de empresas por Cantidad de Trabajadores 
Un total de 1,030 centros educativos desde niveles preescolares hasta secundaria que demuestra un movimiento comercial importante. La clasificación de las instituciones se muestra en la tabla 3 y su participación en la figura 5.

Tabla 3. Instituciones educativas en Santa Anita y Ate

\begin{tabular}{|l|r|}
\hline Clasificación centros educativos & Cantidad \\
\hline Centros prescolares - E. Inicial & 333 \\
\hline Educación primaria & 296 \\
\hline Educación secundaria & 401 \\
\hline Total & 1030 \\
\hline
\end{tabular}

Elaboración propia

Fuente: Base de Colegios de UGEL 062016

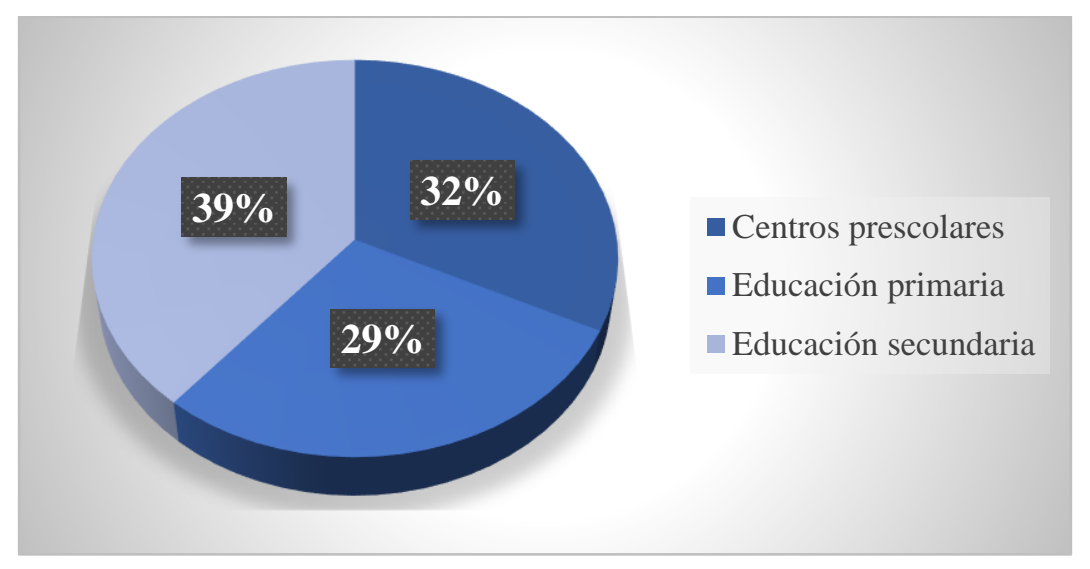

Figura 5. Distribución de centros educativos en Ate y Santa Anita según clasificación 
Servicios profesionales de otras especialidades médicas para niños y madres gestantes con un total de 57 consultorios, la clasificación se muestra en la tabla 4.

Tabla 4. Servicios médicos otras especialidades

\begin{tabular}{|l|r|}
\hline Clasificación por trabajadores & Cantidad \\
\hline Pediatras & 11 \\
\hline Centro de terapia para niños & 28 \\
\hline Centros ginecológicos & 18 \\
\hline Total & 57 \\
\hline \multicolumn{2}{|l|}{ Elaboración propia }
\end{tabular}

Fuente: Reporte Área de Convenios Multident

De acuerdo con los datos estadísticos del INEI, en el último trimestre agostooctubre 2017, se crearon 88,300 nuevos empleos en Lima Metropolitana. En este sentido, el empleo en la población de 25 a 44 años se ha incrementado en $0.6 \%$ respecto al trimestre del año 2016, siendo más notable el incremento de la población de 45 a más años, que tienen mayor experiencia laboral, el cual aumentó en $6.4 \%$ en relación con el año anterior. (Diario Gestión, 15 de noviembre 2017).

Es así como abordamos un tema actual de importancia, la informalidad laboral, tanto de los empleados dependientes como de los trabajadores independientes. En el Perú, existe un $70 \%$ de empleos informales a nivel nacional, "La formalización no representa sobrecostos laborales, genera una mayor productividad empresarial y por ende beneficios para los trabajadores $\mathrm{y}$ empleadores", indicó la Sunafil. 
El crecimiento del empleo para el presente año será de $2.1 \%$ según cifras de Apoyo Consultoría y el MTPE como se muestra en la figura 6.

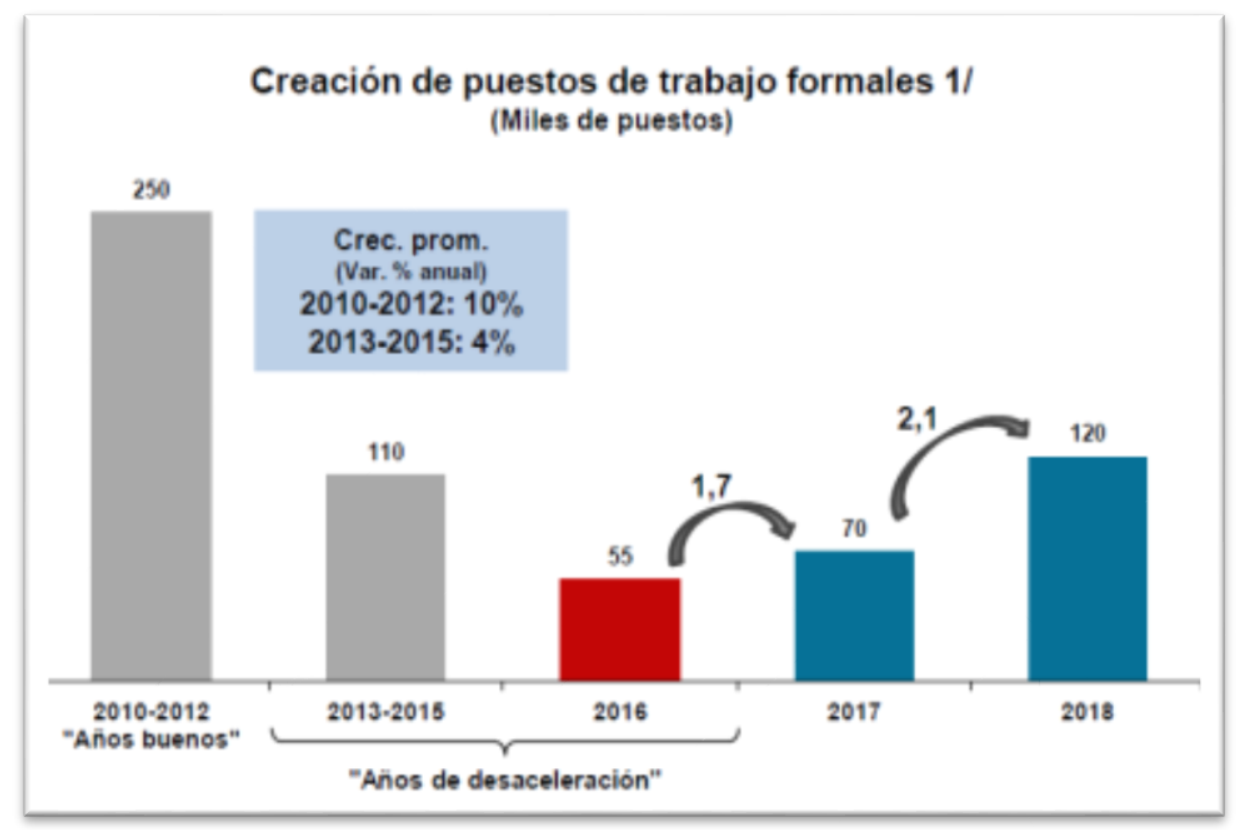

Figura 6: Creación de puestos de trabajo formales 
Los principales pilares de crecimiento económico se muestran en la figura 7 , siendo los más relevantes el gasto público, infraestructura, minería e hidrocarburos y el consumo de familias.

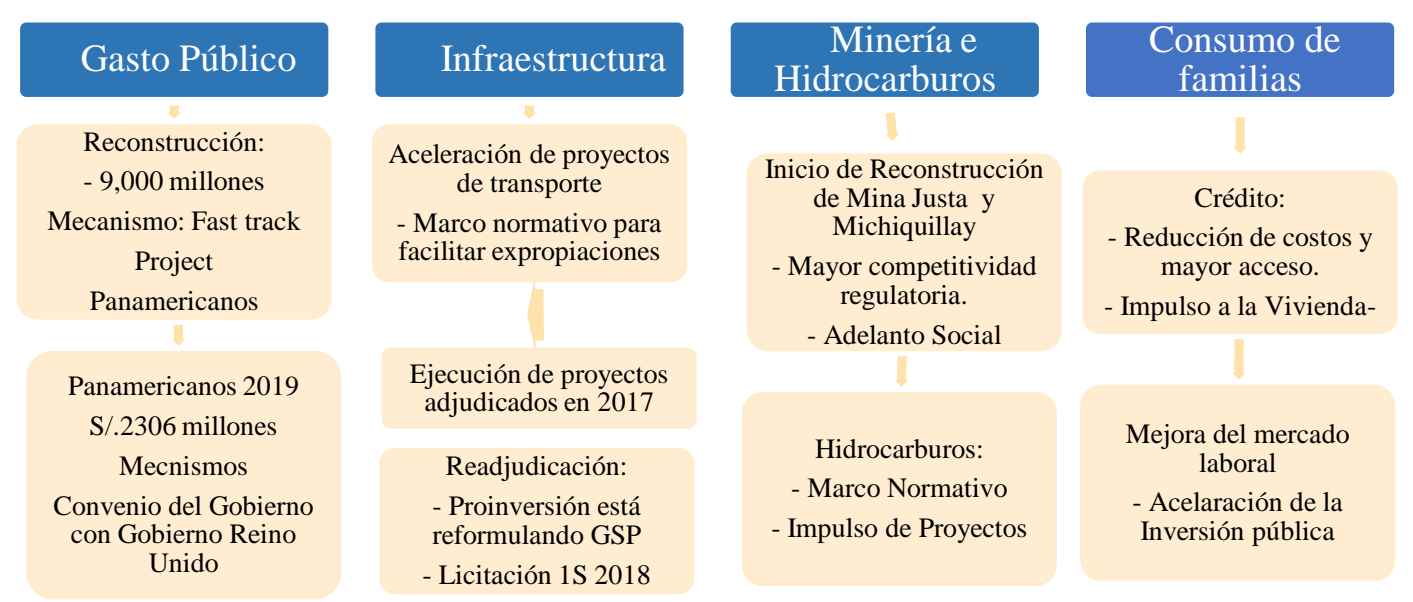

Figura 7. Pilares de Crecimiento Económico para el 2018

Elaboración propia:

Fuente MEF, agosto 2017

Por otro lado, en el aspecto demográfico podemos revisar indicares demográficos que se muestran en la tabla 5 , se precisa que la tasa de crecimiento de la población peruana presenta una desaceleración de $1.6 \%$ a $1.1 \%$ en el presente año. La tasa de natalidad va en descenso, en el 2015 era de 2.5 hijos por mujer y se espera que para el 2020 sea 2.3 hijos. Finalmente, la población infantil menor a 14 años, para el 2018 representará el 28,8 \% de la población total y para el 2020 se proyecta el $26.1 \%$ según las estadísticas del INEI. 
Según los resultados de la Encuesta Demográfica y de Salud Familiar (Endes) 2016 las mujeres de 15 a 49 años tienen en promedio 2.5 hijos y en el área urbana el número promedio de hijos por mujer es de 2.3 hijos.

Tabla 5.Indicadores Demográficos 2015 - 2050

\begin{tabular}{|c|c|c|c|c|c|}
\hline INDICADOR & 2015 & 2018 & 2020 & 2035 & 2050 \\
\hline Población total & $31,151,643.00$ & $32,162,184.00$ & $32,284,358.00$ & $37,243,725.00$ & $40,111,393.00$ \\
\hline $\begin{array}{l}\text { Crecimiento anual } \\
\text { absoluto }\end{array}$ & $337,995.00$ & $327,663.28$ & $325,675.00$ & $247,825.00$ & $124,593.00$ \\
\hline $\begin{array}{l}\text { Tasa de } \\
\text { crecimiento } \\
(\mathrm{x} 1000)\end{array}$ & 10.85 & 10.51 & 9.92 & 6.65 & 3.11 \\
\hline $\begin{array}{l}\text { Nacimientos } \\
\text { anuales }\end{array}$ & $578,130.00$ & $560,457.90$ & $563,344.00$ & $523,758.00$ & $484,166.00$ \\
\hline $\begin{array}{l}\text { Tasa global de } \\
\text { fecundidad }\end{array}$ & 2.29 & 2.22 & 2.15 & 1.92 & 1.84 \\
\hline $\begin{array}{l}\text { Defunciones } \\
\text { anuales }\end{array}$ & 175.59 & 181.29 & 191.41 & 263.03 & 354.96 \\
\hline $\begin{array}{l}\text { tasa de mortalidad } \\
\text { infantil }\end{array}$ & 17.56 & 17.01 & 15.71 & 11.88 & 9.55 \\
\hline $\begin{array}{l}\text { Esperanza de vida } \\
\text { (años) }\end{array}$ & 74.61 & 77.03 & 81.33 & 77.62 & 79.34 \\
\hline $\begin{array}{l}\% \text { menor de } 14 \\
\text { años }\end{array}$ & 27.90 & 27.02 & 26.10 & 21.40 & 18.50 \\
\hline $\begin{array}{l}\% \text { entre } 15 \text { y } 59 \\
\text { años }\end{array}$ & 62.40 & 64.42 & 63.00 & 62.60 & 59.70 \\
\hline$\% 60$ años y mas & 9.70 & 10.01 & 10.90 & 16.00 & 21.80 \\
\hline
\end{tabular}

Elaboración Propia

Fuente: Instituto Nacional De Estadística E Informática- Inei-Perú: Estimaciones $Y$

Proyecciones De

La Población Departamental Por Años Calendario Y Edades Simples, 1995-2025- Boletín Demográfico Especial $N^{\circ} 22$ 


\subsubsection{Socio-cultural}

Según el informe del Índice de Progreso Social Regional (IPSR) elaborado por Centrum Católica con la colaboración del Social Progress Imperative, explica el Dr. Fernando D’Alessio, director de Centrum Católica 'La importancia del crecimiento económico es innegable. No obstante, el bienestar o progreso social tiene que ver con las oportunidades que una sociedad brinda a sus ciudadanos para su desarrollo, sin importar origen, lengua, raza o género".

Actualmente, el Perú ocupa la posición 47 en el ranking mundial. El IPSR que mide 50 indicadores, incluye a 128 países, donde vive el 98\% de la población mundial. El ranking latinoamericano de IPSR está comandado, en un primer gran bloque con más de 70 puntos, por Uruguay, Chile y Costa Rica; y de otro lado está el Perú, en el segundo bloque junto con México, Ecuador y Colombia con un puntaje de 54.85; es decir, con un progreso social "medio bajo", según lo indica la Mg. Alexandra Ames, directora del Centro de Progreso Social de Centrum.

La población de Lima este en su mayoría son inmigrantes de la sierra central, Junín, Ayacucho, Apurímac y Huancavelica, los padres de familia cuentan con un perfil progresista, quiere decir que su mayor objetivo es lograr bienestar en su familia. Buscan calidad, practicidad y rendimiento en los productos o servicios que adquieren. Ellos privilegian el rendimiento antes que el precio, según estudios de Rolando Arellano. 
Una característica identificada en ellos es que buscan servicios diferentes especialmente cuando se trata de sus hijos, pues anhelan entregarles un estilo de vida y oportunidades a los que ellos no pudieron acceder por sus posibilidades limitadas.

Existe una marcada tendencia de los padres a una vida apresurada y a la necesidad de una rápida accesibilidad a la información usando innovadoras tecnologías de información y el uso de las redes sociales como se muestra en la tabla 6. Asimismo, requiere servicios con mayor asistencia, recordación y flexibilidad en horarios.

Según profesionales de la salud la preferencia por el horario es variable según las actividades del paciente, siempre demandan más opciones en su mayoría fines de semana, cuando se trata de padres primerizos y madres gestantes, los servicios de salud preventiva para sus hijos son los más requeridos, sin embargo, la mayoría de padres de la zona desconoce las diferencias entre un servicio de salud general y especializado. 


\section{Tabla 6.Uso de Redes Sociales en el Perú}

\begin{tabular}{|l|l|l|}
\hline Uso de Redes Sociales & Participación 2016 & Participación 2017 \\
\hline Facebook & $89 \%$ & $80 \%$ \\
\hline Youtube & $59 \%$ & $49 \%$ \\
\hline Whatsapp & $59 \%$ & $67 \%$ \\
\hline Google & $40 \%$ & $37 \%$ \\
\hline Twitter & $16 \%$ & $15 \%$ \\
\hline Instagram & $10 \%$ & $17 \%$ \\
\hline Snapchat & $3 \%$ & $6 \%$ \\
\hline Lindekin & $3 \%$ & $5 \%$ \\
\hline Otros & $5 \%$ & $5 \%$ \\
\hline
\end{tabular}

\section{Elaboración propia}

Fuente GFK, noviembre 2017

Encuestas realizadas a población urbana

Hay un incremento en la tendencia de uso de los móviles Smartphone por parte de la generación Y con una participación del 73\% frente a la generación X con una participación del 65\%, dado que este medio de comunicación se convierte en un punto de experiencia muy importante para ellos y sus hijos, quienes son nativos digitales.

El "WhatsApp" es la aplicación líder en América Latina, seguida de YouTube y Facebook. Spotify, Snapchat y los juegos son de las más relevantes en la población joven.

Según estudios realizados por la investigadora de mercado GFK el uso de internet tiene una participación del $93 \%$ en los NSE A, B y 76\% en el NSE C, lo cual permite la fácil accesibilidad a contenidos digitales.

Adicionalmente, La Unión Internacional de Telecomunicaciones (UIT) efectuó un estudio para analizar el Índice de Desarrollo de Tecnologías de 
Información, del cual resultó que el Perú se encuentra en el 8vo puesto dentro del ranking de Latinoamérica.

Dicho estudio evaluó 11 subindicadores distribuidos en tres subíndices: acceso, uso y habilidades para aprovechar las TIC, a partir del cual encontraron deficiencias como el escaso acceso a Internet y la brecha digital que existen entre las provincias y la capital, dado que en las primeras carecen de banda ancha.

Tabla 7. Penetración de Internet en NSE A,B,C+

\begin{tabular}{|l|r|r|r|r|}
\hline $\begin{array}{l}\text { Uso Internet } \\
\text { (Edad mayor a 18 } \\
\text { años) }\end{array}$ & $\begin{array}{c}\text { Usuarios } \\
\text { intensivos }\end{array}$ & $\begin{array}{l}\text { Usuarios } \\
\text { regulares }\end{array}$ & $\begin{array}{c}\text { Usuarios } \\
\text { esporádicos }\end{array}$ & Total Usuarios \\
\hline NSE A / B & $61 \%$ & $17 \%$ & $3 \%$ & 2382 \\
\hline NSE C & $44 \%$ & $15 \%$ & $3 \%$ & 3208 \\
\hline
\end{tabular}

Fuente: Elaboración propia

Encuestas elaboradas por GFK 2016 
Dentro de la zona 5 de Lima metropolitana observamos un uso creciente del internet y dispositivos móviles como se muestra en la tabla 8.

Tabla 8. Proyección de Penetración Medios Online Zona 5 NSE A,B,C+

\begin{tabular}{|l|l|l|l|}
\hline Indicadores de Medios Online & 2016 & 2017 & 2018 \\
\hline Celular 2/ 3/ & $95 \%$ & $95 \%$ & $96 \%$ \\
\hline Uso Internet 2/ 3/ & $67 \%$ & $73 \%$ & $74 \%$ \\
\hline $\begin{array}{l}\text { Internet para Obtener de } \\
\text { información 2/ 3/ }\end{array}$ & $87 \%$ & $85 \%$ & $87 \%$ \\
\hline $\begin{array}{l}\text { Internet para Comunicarse (e- } \\
\text { mail, chat, etc.) 2/ 3/ }\end{array}$ & $89 \%$ & $90 \%$ & $91 \%$ \\
\hline
\end{tabular}

Elaboración Propia

Fuentes:

2/ APEIM 2016: Data ENAHO 2015

3/ APEIM 2017: Data ENAHO 2016

*Zona 5 : Ate, Chaclacayo, Lurigancho, Santa Anita, San Luis, El Agustino.

Por otro lado, en el 2017 se llevó a cabo un acontecimiento importante deportivo, el pase de la selección peruana al mundial de Rusia 2018 después de 30 años, lo cual ha creado un cambio de percepción de la imagen y reputación del país al habernos convertido en protagonistas del cambio a partir del deporte. Este hecho conlleva a crearse un clima propicio para el crecimiento comercial, reactivación del mercado laboral y recuperación del consumo familiar. 


\subsubsection{Tecnológico-Natural}

Los avances de tecnología para la odontología han tenido una evolución rápida que representa un reto para el sector mantenerse al día con ellas pero que permite sin lugar a duda brindar un mejor tratamiento al paciente y comodidad para el odontólogo que lo realiza.

Las enfermedades dentales que se tratan por especialidades tienen la opción de tener equipos tecnológicos que facilitan tanto el diagnóstico como el tratamiento final.

En cuanto al diagnóstico la herramienta de mayor uso es la cámara intraoral, ya que permite mostrarle al paciente los detalles del interior de la boca para que conozca el estado de su salud bucal antes y después del tratamiento dental.

Los Rayos X digitales son una opción importante para complementar un diagnóstico y producir imágenes en un corto tiempo reduciendo la exposición a la radiación.

En cuanto a tratamientos más comunes como brackets se han desarrollado mecanismos para minimizar las molestias de los pacientes como que los brackets sean invisibles o colocados por el interior de la boca. Además, que tratamientos de rehabilitación oral y estéticos se pueden concluir en una sesión. La tecnología del Cad Cam es una de las herramientas que más contribuye a ese objetivo ya que por medio de un diseño asistido por computadora, las fabricaciones de prótesis dentales son precisas, de mayor calidad y rápidas. 
Por otro lado, para los pacientes más nerviosos existe el uso del óxido nitroso en combinación con el oxígeno para sedaciones conscientes como una alternativa en determinados procedimientos que permite una mayor comodidad en los pacientes. Así también, el uso del láser de diodos como una alternativa moderna en lugar de las herramientas clásicas como el micromotor y turbinas para minimizar el dolor o molestias ocasionados.

La importancia del uso de tecnologías novedosas no es exclusiva de empresas de salud y eso lo demuestra las últimas encuestas a emprendedores que coinciden en que la estrategia más importante es la implementación de nuevas tecnologías según el último reporte de la consultora Apoyo como se muestra en la figura 8.

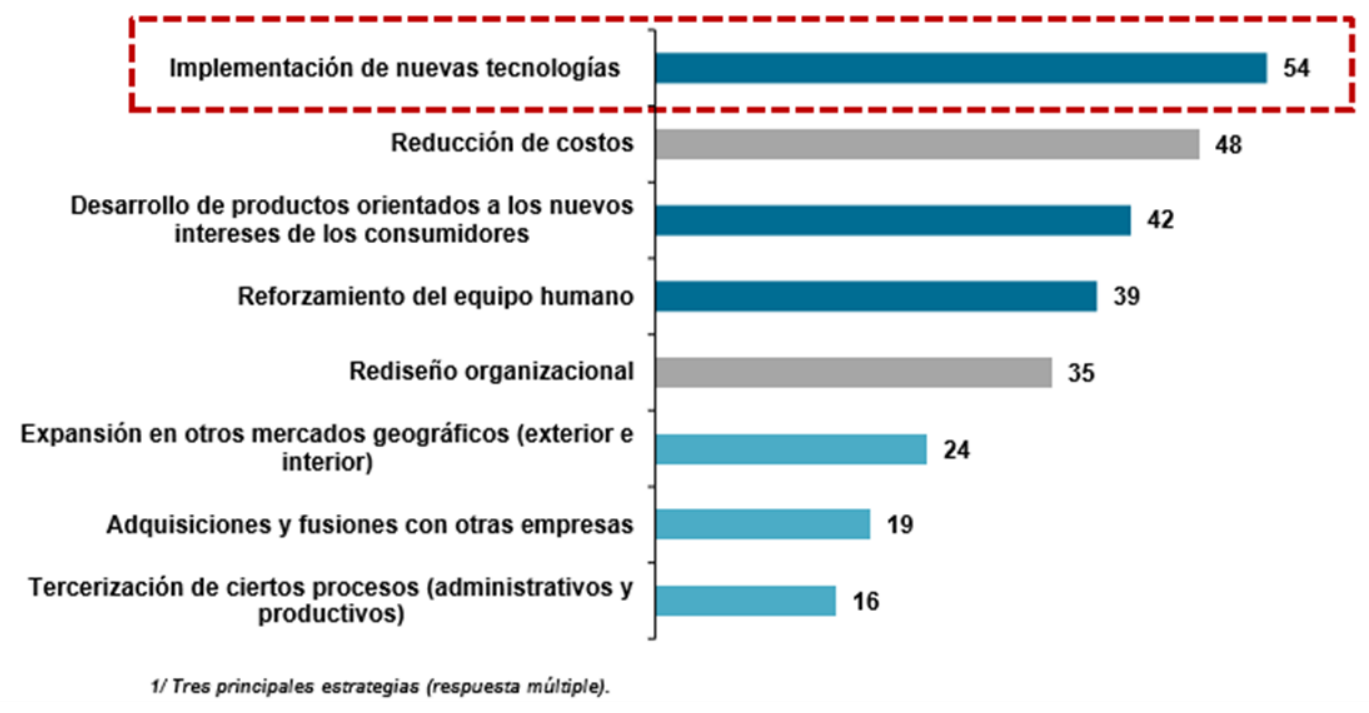

Figura 8. Estrategia de las Empresas para el 2018

Fuente: APOYO - SAE, Noviembre 2017 


\subsubsection{Conclusiones del Análisis Externo}

El crecimiento del PBI en 4 \% para el próximo 2018 y la calificación de riesgo son favorables para la economía del país. El crecimiento de la tasa de empleo formal crecerá en $2.1 \%$ y los indicadores macroeconómicos generan una mayor confianza en los inversionistas extranjeros creando un clima de respaldo económico y social en las empresas peruanas existentes.

La Ley $N^{\circ} 30693$ que aprueba el Presupuesto para el sector salud del año fiscal 2018 indica que se realizará una mayor inversión que favorece el crecimiento a nivel país.

Los padres de familia viven inmersos en un sin número de actividades en torno a la profesión, hogar, educación, salud de su familia, por lo que cuentan con un tiempo limitado y buscan acceder rápidamente a la información de salud utilizando las tecnologías de información más modernas y accesibles que les proporcionen mayor rapidez en respuesta a su necesidad.

Asimismo, el Proyecto de la línea 2 del Metro de Lima, genera una ventaja que, a futuro permitirá la movilización de más de 2 millones de personas desde zonas industriales desde Ate hacia el Callao y viceversa.

La innovación toma mayor relevancia, el 54\% de las empresas lo considera dentro de sus estrategias para el 2018 y las nuevas tecnologías en odontología son una oportunidad para incrementar la confianza y garantizar el éxito de los tratamientos en los pacientes. 


\subsection{Análisis del Sector}

\subsubsection{Definición de la Industria.}

La industria de la salud está comprendida en el sector denominado otros servicios, que además incluye las actividades inmobiliarias, educación, y servicios mercantes y no mercantes prestados a los hogares.

De acuerdo a la Ley N ${ }^{\circ} 5395$ del 30 de octubre de 1973 "Ley General de Salud"; 2 y 6 de la Ley N 5412 del 8 de noviembre de 1973 "Ley Orgánica del Ministerio de Salud" se rigen las normas de seguridad de la salud, así como los procedimientos de la Institución que representa la salud ante el estado, procura velar por la gestión eficaz de los servicios de salud que usan los habitantes del Perú.

“El Colegio Odontológico del Perú, creado en 1964 por Ley N¹5251, modificada en el año 2007 por la Ley N²9016, agremia a los miembros de la profesión odontológica como una especialidad médica, que a través de la prevención, el diagnóstico, el tratamiento y la rehabilitación, crea y está preparada para prevenir el daño, mensurar el daño, eliminar las alteraciones y recuperar la función del Sistema Estomatognático y para proveer en toda persona condiciones y calidad de vida con salud bucal, la que contribuye y se proyecta a la nación en defensa de la salud humana" (artículo 3 inc. “a” de la Ley N²9016). 
Asimismo, el Congreso de la República ha promulgado la Ley 30699 que modifica el artículo $1^{\circ}$ de la Ley 15251, que descentraliza y fortalece las acciones que realizarán los centros odontológicos en las regiones del país, vela por obligatoriedad de la colegiación y condición de habilitado y está en contra de la publicidad antiética.

Constituye ejercicio ilegal de la profesión, la práctica de la misma sin reunir los requisitos legales señalados en el Título II del D.S. 014-2008-SA. Para el ejercicio profesional de la odontología en cualquiera de sus especialidades, se requiere tener título profesional universitario, estar colegiado en el Colegio Odontológico del Perú y habilitado por el Colegio Regional respectivo.

Asimismo, el Cirujano Dentista (no especialista), que ejerza la práctica especializada deberá acreditar las competencias profesionales certificadas siempre y cuando, se trate de procedimientos de baja y mediana complejidad. Los Cirujano Dentistas pueden realizar tratamientos de su competencia bajo anestesia local en consultorios o en consultas ambulatorias. Cuando el Cirujano Dentista requiera atender a un paciente bajo anestesia general, deberá realizarlo en un ambiente hospitalario o clínico, que posea los mínimos requisitos indispensables que permitan ejecutar los referidos procedimientos, conforme lo disponen las normas sanitarias correspondientes y deberá contar con el apoyo de un médico-cirujano anestesiólogo. Cuando se requiera el uso de sedación consciente (gas, óxido nitroso u otros), el cirujano dentista deberá contar con la respectiva capacitación y certificación vigente realizando el procedimiento en un ambiente con el equipamiento adecuado. 
El cirujano dentista especialista en el cuidado de la salud dental de los niños es el Odontopediatra, especialidad que esta controlada por la Sociedad de Odontopediatría del Perú. Manejar de forma idónea la conducta del niño, es uno de los retos de la odontología pediátrica dado que conlleva gran estrés físico y emocional. Es importante que el profesional tenga la capacidad y conocimiento para detectar las causas que generan ansiedad en el niño y brindar una atención óptima integral.

"Una contribución muy importante a la reducción del estrés que se genera en las atenciones odontológicas es la integración físico-psíquica adecuada que permita al paciente estabilizarse, donde la ergonomía y el diseño van estrechamente relacionados en la planificación de espacios que debe tener una clínica odontopediátrica. Esto permite que tenga todos los servicios de calidad en un solo lugar y que el paciente sienta los beneficios y agrado de desenvolverse en un ambiente cautivante"1 (Manji 1992).

La salud dental está estrechamente relacionada con la salud y bienestar general. Las enfermedades bucales representan la segunda causa de morbilidad en consultas externas y deterioran la salud en general, la autoestima, la calidad de vida y desarrollo integral de las personas. Su atención genera altos costos tanto públicos como privados.

\footnotetext{
${ }^{1}$ Manji 1992
} 
La salud dental comprende desde medidas de promoción de salud de prevención de enfermedades hasta procedimientos de control y de rehabilitación (operatoria dental, endodoncia, prótesis, cirugía, ortopedia, ortodoncia, etc.) integrando todas la odontología preventiva y restaurativa-curativa.

La Superintendencia Nacional de Salud (SUSALUD), institución que vela por el derecho de las personas al acceso de servicios de salud, ha detectado que en el país hay 60,000 establecimientos de salud informales, esta cifra triplica al de los formales y en su mayoría se ubican en inmediaciones de grandes centros de salud. Según la investigación publicada por el Colegio Odontológico del Perú ${ }^{2}$ existe actualmente un porcentaje de ilegalidad en el ejercicio de la profesión de odontólogos en el país, solo un 55\% se encuentra colegiado, generado por una alta tasa de sub-empleo de odontólogos recién colegiados.

${ }^{2}$ Fuente: Mg. Ascanoa Olazo, Jimmy Mg. CD. Espec. Botetano Villafuerte, Raúl. (2012-2013) Apuntes sobre la Odontología en el Perú: Situación laboral de nuevos colegiados procedentes de universidades nacionales y privadas). 
De acuerdo a Apoyo Consultores, para el año 2018 las redes de clínicas concentraran su inversión en equipamiento y remodelaciones, y su expansión a través de centros médicos de baja complejidad como se muestra en la figura 9.

\section{Anuncios de inversión}

\begin{tabular}{|c|c|c|}
\hline Empresa & $\begin{array}{c}\text { Monto } \\
\text { (US\$ Millones) }\end{array}$ & Proyecto \\
\hline $\int_{\text {SANNA }}^{53}$ & 73 & $\begin{array}{l}\text { Ampliación de } \\
\text { clínicas }\end{array}$ \\
\hline (19) La Luz & 52 & $\begin{array}{c}\text { Ampliación de clínica } \\
\text { e innovación } \\
\text { tecnológica }\end{array}$ \\
\hline هil $\begin{array}{l}\text { Clínica } \\
\text { San Pablo }\end{array}$ & 73 & $\begin{array}{l}\text { Ampliación de } \\
\text { clínicas }\end{array}$ \\
\hline (O) Clínica & 14 & $\begin{array}{c}\text { Renovación de área } \\
\text { tecnológica }\end{array}$ \\
\hline 5anitioferist+ts. & 10 & $\begin{array}{l}\text { Apertura de centros } \\
\text { de salud }\end{array}$ \\
\hline + jockeysaluc & 14 & $\begin{array}{l}\text { Remodelación de } \\
\text { clínica e innovación } \\
\text { tecnológica }\end{array}$ \\
\hline
\end{tabular}

Figura 9. Anuncios de inversión privada en el sector salud 


\subsubsection{Evolución de la Demanda.}

De acuerdo con la proyección de condiciones macroeconómicas del Perú en el periodo 2016 al 2018 como se muestra en la tabla 9, tenemos que el sector se mueve entre el $11.5 \%$ a $16 \%$ del PBI.

Específicamente el gasto en salud representa en promedio alrededor de 5.3\%, de los cuales el $58.7 \%$ corresponde al gasto público en salud (GPS) y $41.2 \%$ al gasto privado. Del gasto privado el $84.7 \%$ es gasto de bolsillo.

Estas cifras están por debajo del promedio latinoamericano de gasto en salud que representa el 7.7\% de su PBI y más aún de los países de alto ingresos de $11.9 \%$ de su $\mathrm{PBI}^{3}$ (Cirujano Dentista -CD César Torres 2017).

\footnotetext{
${ }^{3}$ Publicación CD Cesar Torres 2017
} 
Tabla 9. Proyecciones Macroeconómicas del País y del Sector

\begin{tabular}{|c|c|c|c|}
\hline Proyecciones Macroeconómicas y del Sector & 2016 & 2017 & 2018 \\
\hline Tasa de crecimiento de PBI 6/ & 3.9 & 2.8 & 4 \\
\hline PBI (miles de millones)* 6/ & 501.10 & 359.76 & 513.95 \\
\hline$\%$ Sector Otros Servicios 1/ 6/ & 13.5 & 11.67 & 16.67 \\
\hline Población (millones de habitantes) 2/ & 31.49 & 31.83 & 32.16 \\
\hline PBI per cápita del Sector (miles)* & 2.15 & 0.32 & 2.66 \\
\hline Promedio Gasto Total Salud (miles de millones) $* 5 /$ & 26.56 & 19.07 & 27.24 \\
\hline Promedio Gasto Publico (miles de millones)* 5/ & 15.62 & 11.21 & 16.02 \\
\hline Promedio Gasto Privado (miles de millones) $* 5 /$ & 10.94 & 7.86 & 11.22 \\
\hline Promedio Gasto de Bolsillo (miles de millones)* 5/ & 9.27 & 6.65 & 9.51 \\
\hline
\end{tabular}

Elaboración Propia

Fuentes:

1/ Informe Técnico Nro. 02. Mayo 2017. Cuentas Nacionales año Base 2007 Instituto Nacional de Estadística e Informática con información disponible al 10-05-2017.

2/ Perú: Estimaciones y Proyecciones de Población Departamental por Años Calendario y Edades Simples, 1995-2025. Lima, Noviembre 2010. Dirección Técnica de Demografía e Indicadores Sociales. Boletín Especial $N^{\circ} 22$

5/ Matus-López M, Prieto Toledo L, Cid Pedraza C. Evaluación del espacio fiscal para la salud en Perú. Rev. Panam. Salud Pública. 2016; 40(1):64-69.

6/ Publicación Diario Gestión. Economía. 27 Agosto 2017. 
La variación del PBI para el sector salud corresponde al 3.7\% en el 2018 como se muestra en la figura $10 \mathrm{y}$ el presupuesto asignado es de 16 mil millones que representa un incremento del $16 \%$ respecto del año anterior y equivale al 10\% del presupuesto público, es el tercer sector en el que más se invertirá, tal como se muestra en las tablas 10 y 11 . Además en la figura 11 se resalta la representación del sector salud con respecto al presupuesto público.

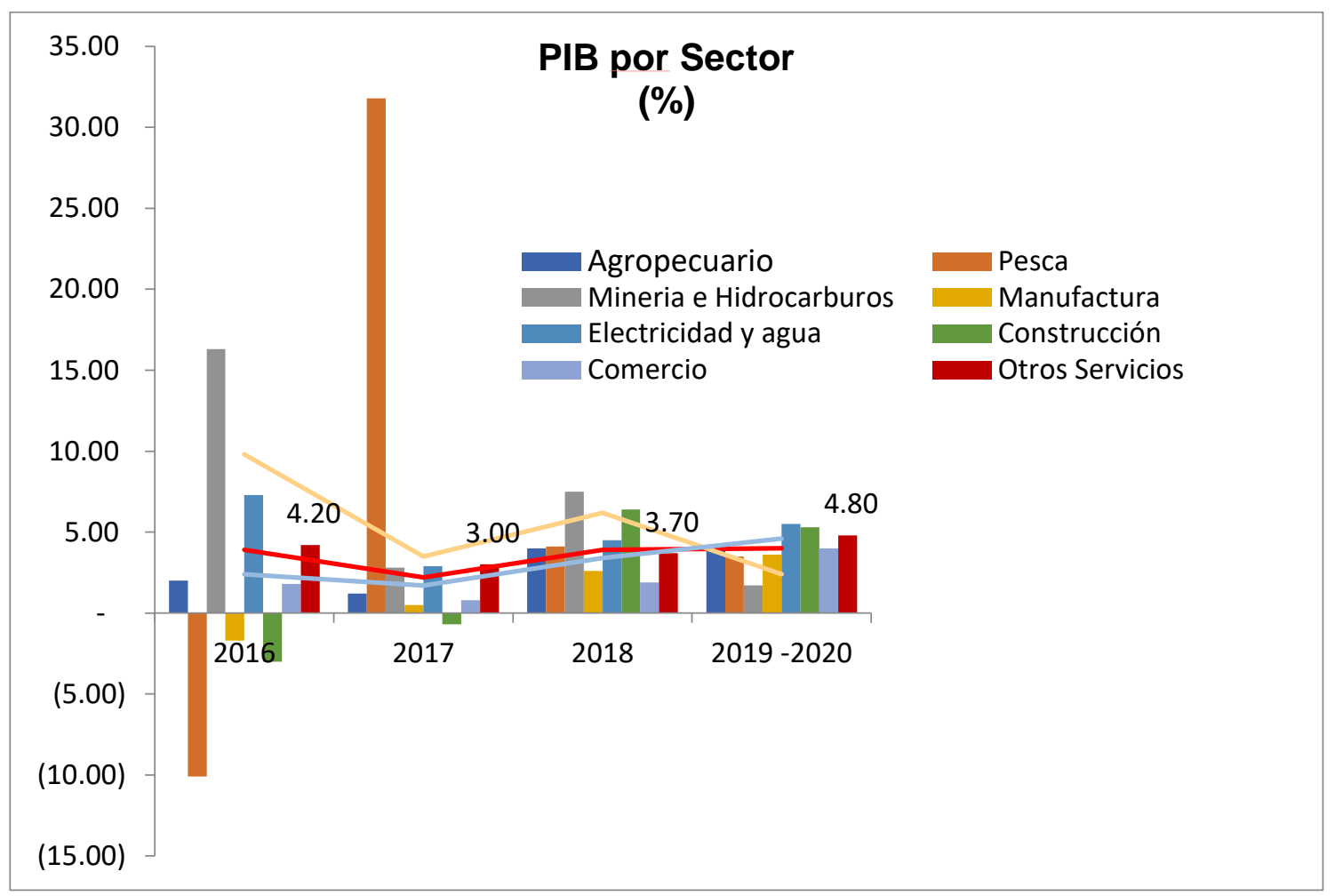

Figura 10. PBI por Sector 
Tabla 10. Proyecciones PBI por Sector

\begin{tabular}{|l|r|r|r|r|}
\hline PIB por sector & 2016 & 2017 & 2018 & $2019-2020$ \\
\hline Agropecuario & 2.00 & 1.20 & 4.00 & 4.00 \\
\hline Pesca & 10.10 & 31.80 & 4.10 & 3.50 \\
\hline Minería e Hidrocarburos & 16.30 & 2.80 & 7.50 & 1.70 \\
\hline Manufactura & 1.70 & 0.50 & 2.60 & 3.60 \\
\hline Electricidady agua & 7.30 & 2.90 & 4.50 & 5.50 \\
\hline Construcción & 3.00 & 0.70 & 6.40 & 5.30 \\
\hline Comercio & 1.80 & 0.80 & 1.90 & 4.00 \\
\hline Otros Servicios & 4.20 & 3.00 & 3.70 & 4.80 \\
\hline PIB Global & 3.90 & 2.20 & 3.90 & 4.00 \\
\hline PIB Primario & 9.80 & 3.50 & 6.20 & 2.40 \\
\hline PIB no primario & 2.40 & 1.70 & 3.40 & 4.60 \\
\hline
\end{tabular}

Elaboración Propia

Fuentes: BCRP, BBVA. Nov. 2017 


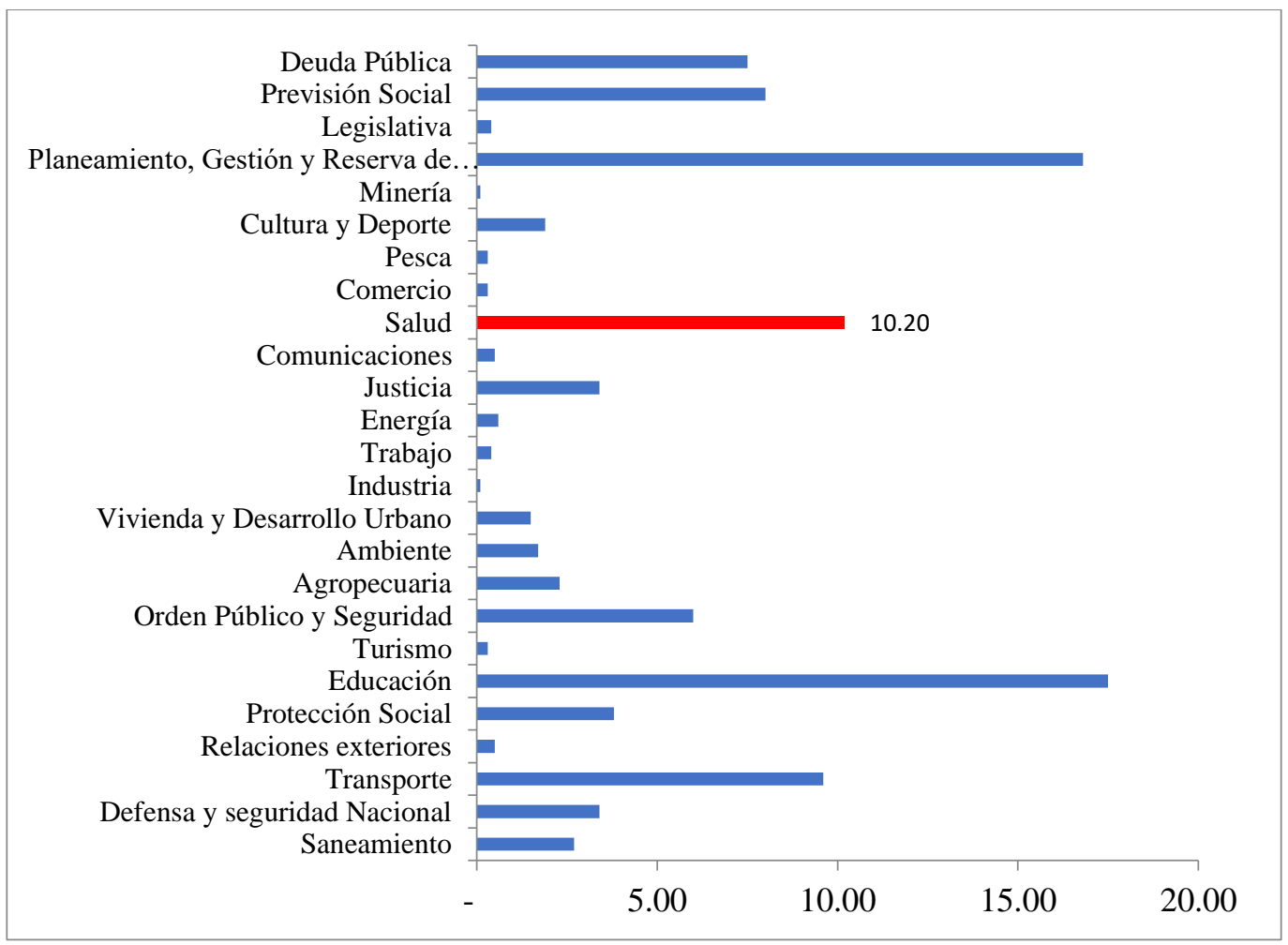

Figura 11. Presupuesto Público 2018 por sector en porcentajes 


\section{Tabla 11. Presupuesto Público por Sector}

\begin{tabular}{|l|r|r|}
\hline Presupuesto & \multicolumn{1}{l|}{ Valor } \\
\hline Saneamiento & 2.70 & 4,292 \\
\hline Defensa y seguridad Nacional & 3.40 & 5,358 \\
\hline Transporte & 9.60 & 15,111 \\
\hline Relaciones exteriors & 0.50 & 765 \\
\hline Protección Social & 3.80 & 6,028 \\
\hline Educación & 17.50 & 27,430 \\
\hline Turismo & 0.30 & 527 \\
\hline Orden Público y Seguridad & 6.00 & 9,366 \\
\hline Agropecuaria & 2.30 & 3,693 \\
\hline Ambiente & 1.70 & 2,691 \\
\hline Vivienda y Desarrollo Urbano & 1.50 & 2,420 \\
\hline Industria & 0.10 & 229 \\
\hline Trabajo & 0.40 & 602 \\
\hline Energía & 0.60 & 996 \\
\hline Justicia & 3.40 & 5,364 \\
\hline Comunicaciones & 0.50 & 856 \\
\hline Salud & 10.20 & 16,027 \\
\hline Comercio & 0.30 & 508 \\
\hline Pesca & 0.30 & 463 \\
\hline Cultura y Deporte & 1.90 & 2,941 \\
\hline Minería & 0.10 & 189 \\
\hline Planeamiento, Gestión y Reserva de & & \\
\hline Contingencia & 16.80 & 26,364 \\
\hline Legislativa & 0.40 & 553 \\
\hline Previsión Social & 8.00 & 12,604 \\
\hline Deuda Pública & & 11,780 \\
\hline Total & $\mathbf{1 5 7 , 1 5 9}$ \\
\hline
\end{tabular}

Elaboración Propia

Fuentes: MEF. Nov 2017 
De acuerdo a $\mathrm{APEIM}^{4}$ y CPI ${ }^{5}$, en la zona 5 de Lima existe un mayor porcentaje de hogares con NSE C+ que B y A como se muestra en la figura 12, por otro lado dada la idiosincrasia de la población de esta zona, estos segmentos presentan en su mayoría hábitos y costumbres similares siendo el poder adquisitivo lo que los diferencia.

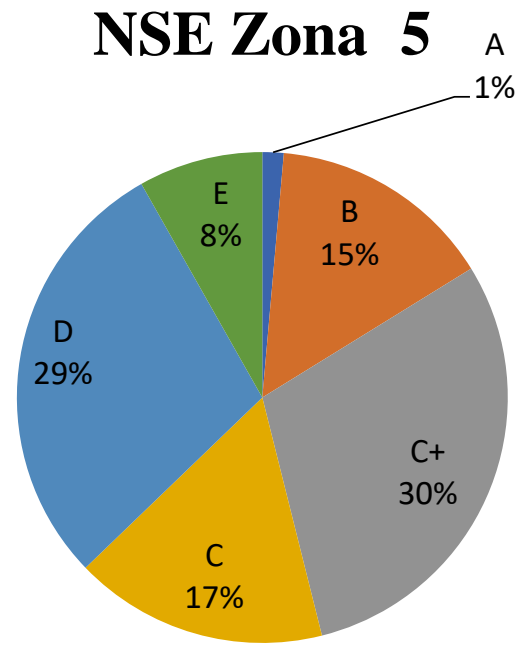

Figura 12. Distribución por NSE Zona 5 Lima Metropolitana

4 APEIM 2017: Data ENAHO 2016

5 CPI Compañía Peruana de Estudios de Mercados y Opinión pública- Market Report Agosto 2017. 
Ate y Santa Anita son distritos altamente comerciales, con fuerte presencia de inversión privada promovida por las pequeñas y medianas empresas. En el 2018 se estima que la inversión privada crece en $4.7 \%$ respecto del año anterior, de ello el 26\% está destinada a infraestructura del transporte y el 3\% a inversión diversificada, de acuerdo a la publicación de Apoyo Consultores ${ }^{6}$.

Uno de los proyectos más relevantes que impactará en el crecimiento económico es el nuevo centro comercial Real Plaza en Puruchuco (S/.480 millones) a inaugurarse en el 2018, generando un gran potencial de consumo que hay en la zona, además estará ubicado a una cuadra de la sede de Ate.

Según confirma un estudio de Ipsos para Real Plaza, el gasto promedio, sin considerar supermercados, de una familia de Lima este en una visita a un centro comercial asciende a S/.200. (Diario El Comercio "Ate se convierte en el imán de inversiones de Lima Este“) y el gasto promedio anual en salud y servicios médicos es alrededor de S/. 302 y para el 2018 se estima en S/. 431 como se muestra en la tabla 12. 
Tabla 12. Proyección de Gastos e Ingresos Zona 5 NSE A, B, C+

\begin{tabular}{|l|c|c|c|}
\hline Indicadores de la Zona 5* & 2016 & 2017 & 2018 \\
\hline $\begin{array}{l}\text { Cuidado, Conservación de la Salud y } \\
\text { Servicios Médicos - gasto promedio } \\
\text { anual /2 /3 }\end{array}$ & S/. 153.66 & S/. 302 & S/. 431 \\
\hline $\begin{array}{l}\text { PROMEDIO GENERAL DE } \\
\text { GASTO FAMILIAR MENSUAL /2 } \\
\text { /3 }\end{array}$ & S/. 3,476.78 & S/. 3,942 & S/. 5,632 \\
\hline $\begin{array}{l}\text { PROMEDIO GENERAL DE } \\
\text { INGRESO FAMILIAR MENSUAL } \\
\text { /2 /3/ }\end{array}$ & S/. 4,580.49 & S/. 5,733 & S/. 8,191 \\
\hline
\end{tabular}

Elaboración Propia

Fuentes:

1/ Informe Técnico Nro. 02. Mayo 2017.

Cuentas Nacionales año Base 2007 Instituto

Nacional de Estadística e Informática con

información disponible al 10-05-2017.

2/ APEIM 2016: Data ENAHO 2015

3/ APEIM 2017: Data ENAHO 2016

*Zona 5 : Ate, Chaclacayo, Lurigancho,

Santa Anita, San Luis, El Agustino

En el Perú existen diferentes mecanismos de acceso a la salud: el SIS brinda cobertura a 17 millones de personas, EESALUD a 11 millones y las aseguradoras privadas a 2 millones. Tenemos aproximadamente 6,632 puestos de salud, 2,981 centros de salud y 628 hospitales y Lima concentra el $24,8 \%$ de centros de salud.

"El Perú es uno de los países de la región con mayores gastos de bolsillo de los hogares en salud. Ello se debe a la deficiencia del servicio de salud pública que obliga 
a las familias a acudir a centros privados para satisfacer estas necesidades", sostuvo Hernán Pena, Superintendente Adjunto de Supervisión de SuSalud ${ }^{7}$ (Publicación Diario Gestión, 28 de agosto del 2017)

Principalmente los afiliados al SIS, ESSALUD y no asegurados son los que acuden a centros privados, dado que los establecimientos públicos no resuelven sus necesidades.

En Lima Metropolitana, cerca de 3 millones de habitantes realizan un gasto de bolsillo al no estar afiliado a algún sistema de salud como se muestra en la tabla 13.

\footnotetext{
${ }^{7}$ Publicación Diario Gestión, 28 de agosto del 2017
} 
Tabla 13. Proyección de afiliación a los sistemas de salud en Lima Metropolitana

\begin{tabular}{|c|c|c|c|}
\hline & 2016 & 2017 & 2018 \\
\hline \multicolumn{4}{|c|}{ Afiliación a algún sistema de salud (millones de habitantes) 3/4/5/ } \\
\hline ESSALUD & 4.13 & 4.19 & 4.25 \\
\hline Sistema Privado de Pensiones & 0.43 & 0.44 & 0.44 \\
\hline EPS & 0.34 & 0.35 & 0.35 \\
\hline Seguro FFAA-PNP & 0.39 & 0.40 & 0.40 \\
\hline Seguro Integral de salud & 2.33 & 2.36 & 2.40 \\
\hline Seguro Universitario & 0.06 & 0.06 & 0.06 \\
\hline Seguro Escolar Privado & 0.01 & 0.01 & 0.01 \\
\hline \multirow[t]{2}{*}{ Otro } & & & \\
\hline & 0.02 & 0.02 & 0.02 \\
\hline \multirow[t]{2}{*}{ No afiliado } & & & \\
\hline & 2.89 & 2.94 & 2.98 \\
\hline
\end{tabular}

Elaboración propia

Fuente:

3/ Proyecciones poblacionales para lima metropolitana a los años horizonte 2018 -

2021 - 2025 y 2035 a nivel distrital. Instituto Metropolitano de planificación.

26/02/2014

4/ APEIM 2016: Data ENAHO 2015

5/ APEIM 2017: Data ENAHO 2016 
Según APEIM 2017 el 76\% del NSE A,B,C de Lima metropolitana recibe una atención de salud privada, no están afiliados a ningún sistema de salud o el sistema de Salud no satisface sus necesidades.

Con respecto a la salud dental en Perú, el gasto por familia es alrededor de los S/. 1,500 al año y por persona llega a los $\mathrm{S} / 300$ como se muestra en la tabla 14, que es un valor bastante bajo si lo comparamos con Chile y Colombia quienes gastan por familia entre 30\% y $40 \%$ más que el presupuesto en el Perú.

Tabla 14. Gasto Promedio de la Salud Bucal Perú, Chile, Colombia

\begin{tabular}{|l|l|l|r|}
\hline Gasto promedio en Salud Bucal & Perú & Chile & \multicolumn{1}{l|}{ Colombia } \\
\hline Gasto por familia (anual) & $\$ 454.55$ & $\$ 700.00$ & $\$ 800.00$ \\
\hline Gasto por persona (anual) & $\$ 93.75$ & $\$ 121.88$ & $\$ 131.25$ \\
\hline
\end{tabular}

Elaboración propia

Fuente:

Publicación Diario Gestión 31 Enero 2017. Salud dental: ¿Cuánto gastan los peruanos cada año en su salud bucal? 
Entre el 60 y $90 \%$ de niños en edad escolar y casi el 100\% de adultos presentan caries, generalmente acompañados de dolor o sensación de molestia ${ }^{8}$ (CD Cesar Torres 2017).

De acuerdo con un estudio de investigación sobre Gastos de Atención Odontológica de Niños con Caries de Infancia Temprana, ocasionados a la Familias y al Estado Peruano, representado por el Instituto Nacional de Salud del Niño, podemos identificar en la tabla 15 que las familias de pacientes sanos gastan por encima de S/.30.00 en tratamientos de prevención y las familias de los pacientes enfermos gastan por encima de $\mathrm{S} / .113$ en tratamientos restaurativos. Al aplicarse un tratamiento restaurativo con anestesia general, más de la mitad de las familias gastan por encima de S/.639.00 lo que equivale a 20 veces más que lo gastado en procedimientos de prevención. Si la familia no se encuentra afiliada a un seguro de salud pública, este gasto se incrementa al doble.

\footnotetext{
${ }^{8}$ CD Cesar Torres 2017
} 
Tabla 15. Gastos de atención odontológica de niños con caries de infancia temprana.

\begin{tabular}{|l|c|c|c|c|}
\cline { 2 - 5 } \multicolumn{1}{c|}{} & \multicolumn{2}{c|}{ Familia } & \multicolumn{2}{c|}{ Estado } \\
\hline Condición Clínica & Gasto Promedio & Media & $\begin{array}{c}\text { Gasto } \\
\text { Promedio }\end{array}$ & Media \\
\hline Sanos 6/ & S/. 39.21 & S/. 30.00 & S/. 310.36 & S/. 260.00 \\
\hline Enfermos 6/ & N/A & N/A & S/. 1,269.08 & S/. 600.00 \\
\hline Manejo de Conducta 6/ & S/. 63.87 & S/. 49.00 & N/A & N/A \\
\hline Sedación 6/ & S/. 87.58 & S/. 98.00 & N/A & N/A \\
\hline Anestesia General 6/ & S/. 637.03 & S/. 639.00 & N/A & N/A \\
\hline
\end{tabular}

Elaboración propia

Fuente:

6/ Revista Estomatológica. Herediana vol.25 no.1

Lima ene. 2015 


\subsubsection{Matriz de Competitividad de Porter}

\subsubsection{Poder de negociación de los Clientes.}

Número de clientes importantes

A partir del análisis sobre la base de datos de pacientes acumulados desde el 2012, se ha identificado que del total de pacientes nuevos que llegan cada año, un $60 \%$ inicia un tratamiento en el mismo período. Sólo un 23\% regresa al año siguiente para otro tratamiento o control recomendado por el especialista. Y año tras año se observa el incremento de pacientes existentes que no reciben ningún tratamiento. Uno de los mayores medios de referencia de nuevos clientes es por recomendación de otros pacientes que señalan la buena atención y servicio de calidad que recibieron en Multident, por ello se determina que los clientes tienen poco nivel de negociación. Las cantidades de pacientes en el transcurso de los años se muestra en la tabla 16. 
Tabla 16. Distribución de pacientes del 2012-2017

\begin{tabular}{|l|r|r|r|r|r|r|}
\hline & \multicolumn{1}{|c|}{2012} & \multicolumn{1}{|c|}{2013} & \multicolumn{1}{c|}{2014} & \multicolumn{1}{c|}{2015} & \multicolumn{1}{c|}{2016} & \multicolumn{1}{c|}{2017} \\
\hline Pacientes existentes & 0 & 1,917 & 4,009 & 5,623 & 7,574 & 10,074 \\
\hline Pacientes nuevos & 1,917 & 2,092 & 1,614 & 1,951 & 2,500 & 2,832 \\
\hline Total Pacientes & 1,917 & 4,009 & 5,623 & 7,574 & 10,074 & 12,906 \\
\hline $\begin{array}{l}\text { Pacientes con } \\
\text { facturación }\end{array}$ & 1,150 & 2,301 & 1,775 & 2,146 & 2,750 & 3,115 \\
\hline
\end{tabular}

Elaboración propia

Fuente: Base de Datos de la empresa

Importancia del costo de servicio en los costos totales de los clientes

Siendo el servicio de odontopediatría una necesidad vital en la salud integral del niño ya sea por planificación o por emergencia, el gasto es realizado por los padres si su hijo necesita la atención, el poder de negociación es alta frente a los clientes.

Grado de estandarización del producto

En cuanto a los tratamientos ofrecidos en Multident, por estar en un rubro de salud, son medianamente personalizables al caso del paciente en aspectos como: periodicidad, horarios de citas, duración de citas, ajuste de precio y control, siempre que esté dentro de las posibilidades de la capacidad instalada. 
En este aspecto, los odontopediatras de Multident tienen esta herramienta de personalización como herramienta para negociar y dar valor agregado. Sin embargo, aunque los pacientes tienen facilidades para iniciar el tratamiento según sus requerimientos y financiamiento, cambiarse o continuar en otra clínica no es difícil.

Costo de cambio

El cambio o continuación del tratamiento dental puede ser fácil para cualquier paciente que lo requiera, ellos tienen derecho a solicitar su historia clínica, así como las radiografías auxiliares para el diagnóstico y control del tratamiento. "El establecimiento de salud queda obligado a proporcionar copia de la historia clínica al paciente en caso de que éste o su representante lo solicite. El interesado asume el costo que supone el pedido.” (Señalado en el tercer párrafo del artículo $29^{\circ}$ de la Ley General de Salud, Ley $N^{\circ} 26842$, modificado por la Ley $\mathrm{N}^{\circ} 29414$ )

Además, los consultorios particulares de odontología reciben sin muchos requisitos un paciente que desee continuar por diversos motivos en un establecimiento diferente al que inició. El servicio al cliente y la lealtad del mismo juegan un papel muy importante en este aspecto, la negociación mayor la tiene el cliente debido a las facilidades por la competencia. 
Amenaza de integración hacia atrás

La posibilidad que los pacientes puedan brindar servicios odontológicos por su propia cuenta es difícil pues requiere de unos estudios de odontología para que puedan ser reemplazados.

\section{Amenaza de integración hacia adelante}

La recordación de citas es un proceso que se realiza de manera constante con la finalidad de evitar la inasistencia y mejorar la relación con el paciente, el nivel de negociación en este aspecto es medio.

Importancia del servicio para asegurar la calidad de los clientes

Un aspecto difícil de encontrar en la zona es la atención especializada que sí se brinda en Multident y que genera confianza, mejores resultados y un mayor valor económico para el paciente. El valor que una buena atención odontológica añade a la calidad de vida de los pacientes es variable, pues podríamos encontrar casos con un alivio para ingerir alimentos hasta un cambio radical en la personalidad y autoestima debido a la seguridad que una sonrisa les puede agregar a las personas por lo que el nivel de negociación que tienen los clientes es bajo.

Además de los pacientes que llegan por un tratamiento específico, la empresa maneja como clientes influenciadores a las empresas con las que se realizan programas corporativos. Los convenios no involucran un gasto económico por parte de la empresa, sin embargo, la calidad del servicio y el respaldo de la marca juegan un papel muy importante para su aceptación. 
Actualmente existen convenios corporativos con 22 empresas ubicadas en Lima Este, es decir los distritos de Santa Anita, Ate, Chaclacayo y Lurigancho mencionadas en el Anexo 1. Según datos del área de Convenios el $84 \%$ de los trabajadores viven en estos distritos.

El rubro de empresas que aceptan en su mayoría concretar un acuerdo con Multident son colegios e institutos de la zona como se identifica en la tabla 17. Al cierre del 2017 se realizaron 24 campañas en el año y ninguna de ellas tuvo un convenio formal firmado de por medio, pero si un acuerdo de palabra para llevarse a cabo. Es preciso mencionar que a pesar de realizar estas acciones de comunicación mediante empresas y colegios el ciclo se encuentra incompleto por falta de seguimiento.

Tabla 17. Actividades realizadas por el área de Marketing en el año 2017.

\begin{tabular}{|l|c|}
\hline Tipo de institución & Cantidad \\
\hline Colegios & 24 \\
\hline Empresas & 7 \\
\hline Total de Campañas & 31 \\
\hline
\end{tabular}

Elaboración propia

Fuente: Base de Datos de la empresa 


\section{Información que manejan}

Una importante característica de los clientes interesados en algún tratamiento es que van muy informados sobre ello. Gracias al fácil acceso de información en internet y en la propia página web donde se pueden encontrar información sobre tratamientos, beneficios de la atención por un especialista en odontopediatría y todas las sedes cercanas para la atención.

La información que obtienen es mucho más valiosa y pueden aprovechar mejor la consulta con un especialista que es la principal herramienta para poder exponer el tratamiento a seguir según el caso y negociar la aceptación de este.

\subsubsection{Poder de negociación con proveedores.}

\section{Número de proveedores importantes}

El principal proveedor de Multident es el staff de doctores, quienes son considerados socios de la empresa ya que lo hacen mediante un contrato asociativo de consorcio que significa una retribución del $50 \%$ de los pagos efectuados de los pacientes por tratamientos odontológicos, con un horario flexible de acuerdo con la disponibilidad, previa emisión de factura y con igualdad de responsabilidades.

El staff de doctores especialistas en odontopediatría en las sedes de Ate y Santa Anita es de 18 en total. 
El segundo tipo de proveedor importante comprende a los equipos dentales como: unidades dentales, equipos de radiografías, esterilización y compresora de aire que son sumamente necesarios para cumplir con la atención odontológica; se cuenta con buena relación con los proveedores de equipos, servicio de mantenimiento periódico de los equipos y dan prioridad a Multident. En el caso que se presente alguna contingencia con los equipos se dificultaría la atención a los pacientes.

El tercer y último proveedor de productos de cepillos, pastas dentífricas y colutorios dentales promociona sus productos a los doctores por medio de visitadores médicos quienes lo recomiendan para los pacientes. Estos se colocarán en la vitrina de la clínica para disposición de los clientes como una compra complementaria. La relación con estos laboratorios y sus visitadores es muy buena pues en varias oportunidades se han creado acuerdos para que dejen muestras de sus productos que son entregadas gratuitamente en la clínica, en eventos y campañas de despistaje.

\section{Costo del cambio}

Cambiar del principal proveedor, es decir del especialista en odontopediatría genera un costo alto para la imagen de la clínica pues se estaría reflejando una inestabilidad en la administración de la empresa y poca confianza para los pacientes. Por ello, la empresa dedica recursos a mantener un buen clima laboral y a los especialistas a gusto en su centro de trabajo. Para este aspecto los especialistas tienen mayor nivel de negociación frente a la empresa. 
Importancia del proveedor en la cadena de valor

En cuanto a los especialistas de odontopediatría quienes se encargan de realizar el tratamiento dental para niños y tiene el mayor trato directo con ellos, la importancia en la cadena de valor es tan alta que sin ellos el servicio no sería posible. Para este aspecto también son los especialistas quienes tienen mayor nivel de negociación.

\section{Amenaza de integrarse hacia adelante}

Un factor tentador para los doctores es la posibilidad de llevar a los pacientes que van a Multident Kids a sus consultorios particulares, es un riesgo que puede darse en el caso de pacientes con menor poder adquisitivo y que valoren más por lo que si representa un valor importante cuidar este aspecto.

\section{Amenaza de integrarse hacia atrás}

Siendo los especialistas de odontopediatría quienes tienen el conocimiento sobre los tratamientos dentales específicos existe la posibilidad que implementen sus consultorios e incluso clínicas propias. Sin embargo, el conocimiento para poder desarrollar toda una administración enfocada en el cliente requiere de un nivel mayor de compromiso y disciplina, así como un equipo para realizarlo. Actualmente no se ha identificado iniciativa en la mayoría de ellos para poder formar su propia clínica sino lo contrario. 
Importancia del proveedor para asegurar la calidad de los servicios

Dado que el servicio es el tratamiento dental, la importancia de los especialistas en odontopediatría es fundamental para concluir todo el ciclo de atención al paciente, el mayor nivel de negociación la tienen los doctores especialistas.

Importancia en la rentabilidad del proveedor

Para los especialistas en odontopediatría, su principal fuente de ingreso la obtienen en Multident porque les asegura una mejor rentabilidad de su tiempo a comparación de otros consultorios o clínicas, un buen clima laboral y posibilidades de capacitación constante de su especialidad. Por lo que Multident tiene mayor nivel de negociación sobre ellos.

Amenaza de proveedores sustitutos

Siendo imprescindible para Multident que los doctores sean especialistas en odontopediatría y la cantidad de odontopediatras no es abundante, el poder de negociación frente a ellos es media. 


\subsubsection{Amenaza de nuevos competidores}

Economía de escala

La marca Multident es bastante reconocida por su participación en más del $80 \%$ de los distritos de Lima, sin embargo, existe otros inversionistas de clínicas que trabajan con públicos similares como San Juan de Lurigancho y es el caso de las principales clínicas odontológicas como "Dr. Sonrisa" y "Clínicas Odam" quienes tienen años de experiencia significando una amenaza alta.

Diferenciación del producto o servicio

Multident Kids se caracteriza por su calificado staff de profesionales especialistas con amplio conocimiento y experiencia. Mantiene óptimos niveles de calidad tanto en el servicio del tratamiento, como en los insumos que utiliza.

La empresa posee la infraestructura, tecnología y ambientes diseñados para niños, que muy pocas clínicas presentan en la zona, pero podrían replicarla en el tiempo. Su ubicación en avenidas principales representa una fortaleza pues tienen mejor acceso y visibilidad en comparación a la competencia. Por lo que la amenaza frente a los nuevos competidores en este aspecto es media. 


\section{Identificación de marcas}

El público al que va dirigido prefiere la confianza que le da la marca y la calidad del servicio. Teniendo en cuenta que existen marcas con presencia en distritos periféricos similares como "Dr. Sonrisa” y "Clínicas Odam” que cuentan con mayor experiencia que Multident en estos distritos, buena situación financiera y buena acogida del público, su posible ingreso a los distritos de Ate y Santa Anita pueden representar una amenaza media para Multident Kids.

\section{Costo de Cambio}

La población aún es poco consciente de su salud bucal y las consecuencias posteriores que podría generar un tratamiento no adecuado, siendo susceptible todavía al precio bajo y fácilmente cambia de centro odontológico. El ingreso de un nuevo competidor similar en zona representa una alta amenaza para Multident.

\section{Requerimiento de Capital}

La inversión para la apertura de un Clínica odontológica y pediátrica requiere de una inversión no menor a S/. 300,000, lo que dificulta el ingreso de competidores directos a la marca, sin embargo, la apertura de un

consultorio dental particular no es muy elevada: S/. 30,000. Para llegar a brindar un servicio como el de Multident en la zona la amenaza resulta baja. 


\section{Acceso a canales de distribución}

Debido a la que el servicio de tratamientos dentales es de distribución directa en la clínica, la amenaza frente a los competidores es alta, todos los centros odontológicos tendrían las mismas de posibilidades de distribución.

\section{Acceso a insumos}

En el mercado existen múltiples marcas y niveles de calidad de los insumos que pueden encarecer o abaratar finalmente el tratamiento. Todos los centros odontológicos de la zona pueden tener fácil acceso a adquirirlas e igualar a la empresa en cuanto a calidad de insumos si lo quisieran, por lo que la amenaza en este aspecto es alta.

\section{Tasa de Crecimiento del Sector}

De acuerdo con las proyecciones macroeconómicas del país, el sector salud está en crecimiento y la empresa no mantiene el mismo ritmo que el sector por lo que la amenaza frente a otros competidores es alta.

\section{Reacción esperada}

Los principales centros odontológicos en la zona suelen realizar promociones de precio cuando ingresa un nuevo competidor, pero se regularizan en poco tiempo, por lo que la amenaza frente a la reacción es media. 
Protección del gobierno o legal

La clínica compite igual que otros centros odontológicos ubicados en la zona pues no tiene ninguna ley de exclusividad por lo que la amenaza es alta.

\subsubsection{Amenaza de productos o servicios sustitutos}

Precio relativo de los sustitutos

Consideramos como servicios sustitutos a los consultorios odontológicos particulares formales e informales, que, si bien prestan una atención odontológica, muchas veces carecen de la especialidad de odontopediatría y todos los servicios relacionados que caracteriza una atención integral de la salud dental y emocional del niño. Los precios en consultorios odontológicos son menores a Multident hasta por un 50\% por lo que la amenaza es alta.

\section{Precio/Calidad}

La relación entre calidad y precio de los consultorios no representa una fuerte amenaza ya que, si bien es cierto que los precios son menores, la calidad de los servicios prestados en Multident es superior.

\section{Disponibilidad de sustitutos cercanos}

Los consultorios ubicados se encuentran cerca de las sedes de Santa Anita y Ate, sin embargo, el acceso a ellos es limitado pues cuentan con horarios reducidos y poco personal para la atención por lo que la amenaza es media. 
Costo de cambio para el cliente

La posibilidad de cambiar o continuar el tratamiento dental en otro consultorio odontológico es muy fácil pero poco recomendable para la salud del paciente por lo que resulta una amenaza media para Multident.

Preferencia del cliente hacia el sustituto

Debido a que algunas personas pueden inclinar su preferencia por el precio menor y atención en otros consultorios odontológicos de la zona, la amenaza por su preferencia es alta.

\subsubsection{Rivalidad entre los competidores existentes.}

\section{Concentración}

En el distrito de Ate existe más de 195 centros odontológicos concentrados en la zona comercial de Ceres y en Santa Anita más de 60 centros. Se ha identificado que la principal competencia se encuentra a pocos minutos de distancia de las sedes y son pocos centros que se consideran competidores directos como se muestra en las figuras 13 y 14. Aunque las sedes estén ubicadas en avenidas principales del distrito, la identificación en la zona no es la más alta y se considera una rivalidad media. 


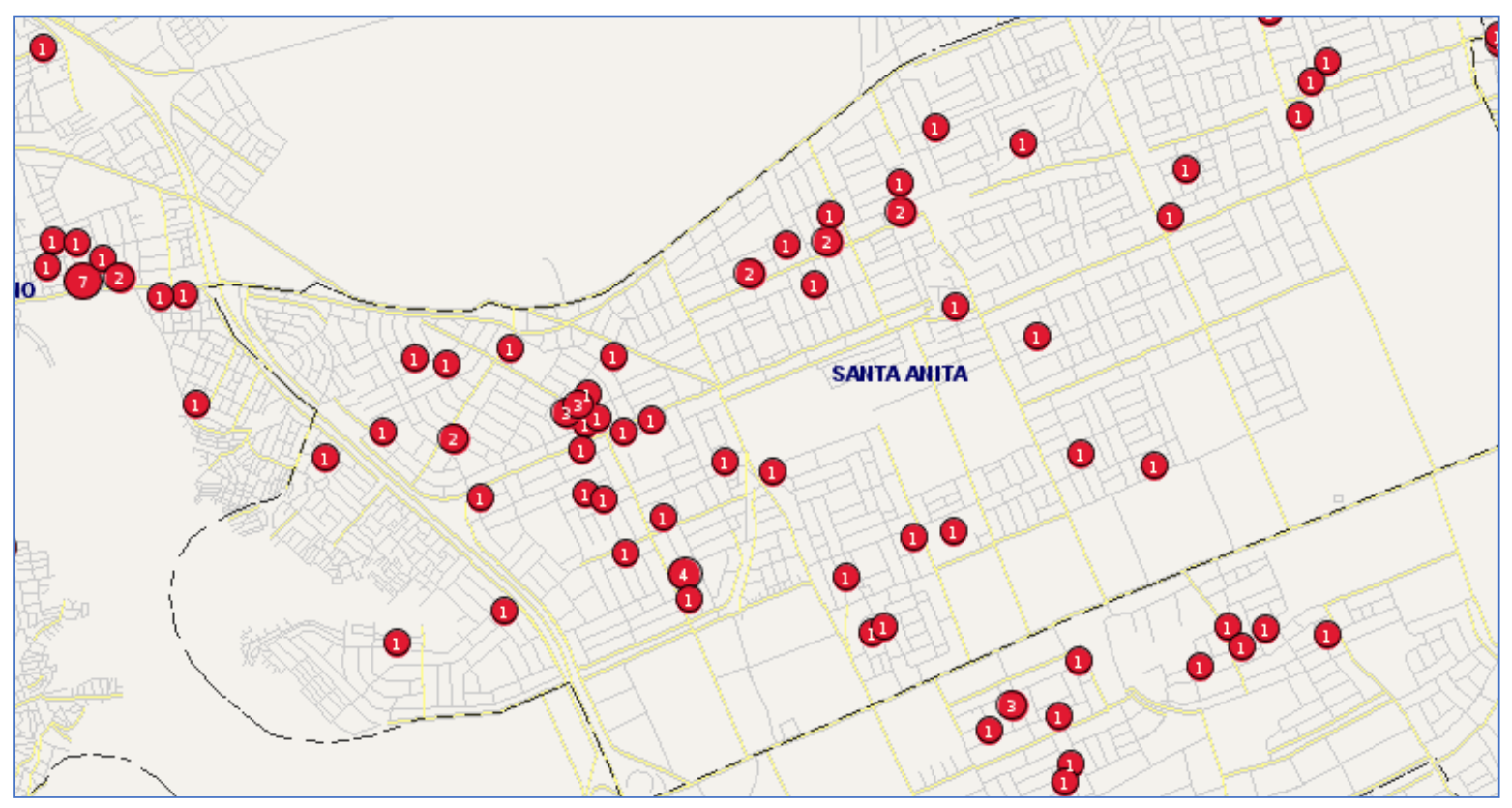

Figura 13. Mapa de ubicación de centros odontológicos en Santa Anita

Fuente: Sistema de Información Geográfica para Emprendedores- SIGE I-NEI

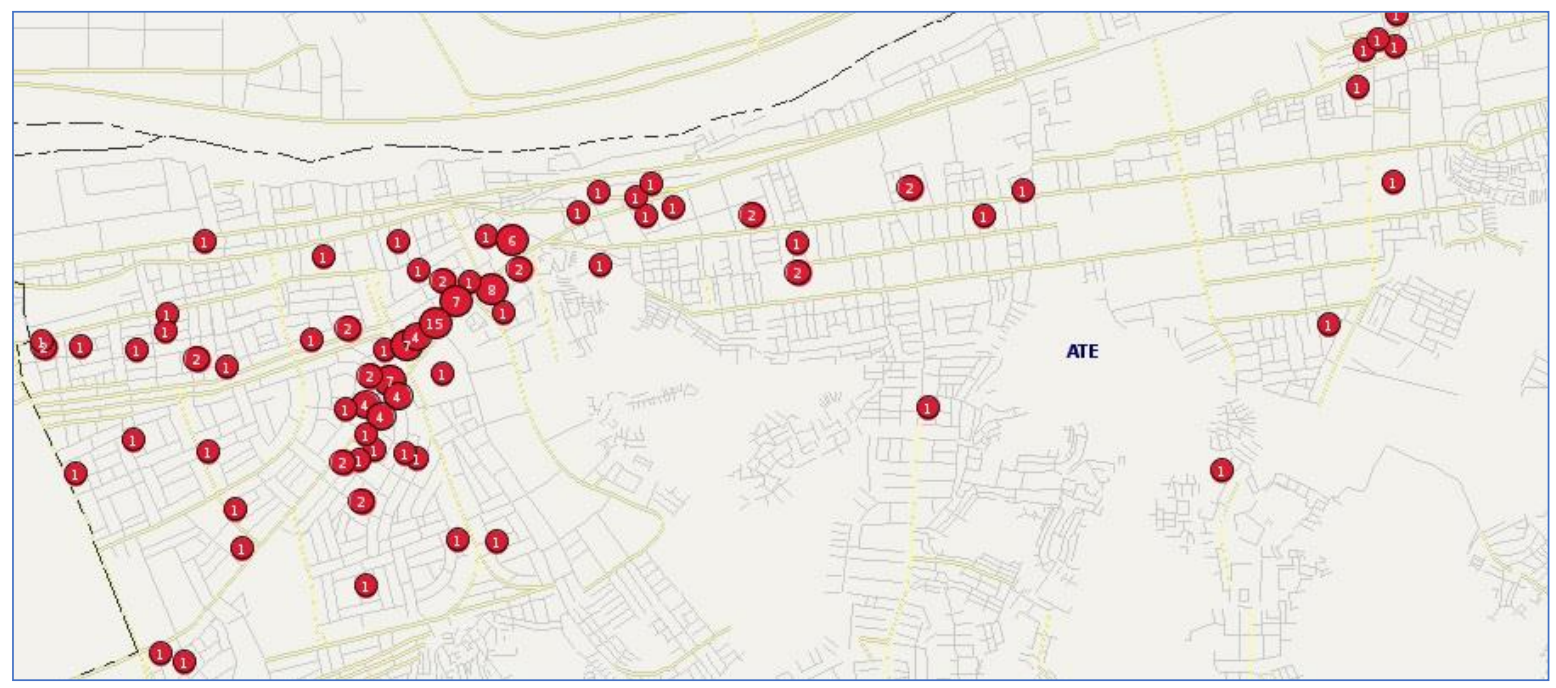

Figura 14.Mapa de ubicación de centros odontológicos en Ate

Fuente: Sistema de Información Geográfica para Emprendedores- SIGE I-NEI 
Diversidad de competidores

La única clínica dental con servicios similares a Multident existente en los distritos de Ate es Clínica La Merced que cuenta con 5 sedes en este distrito, siendo la que cuenta con la mayor numero de sedes. Además, existen 3 consultorios principales como Brilloral, Santa Apolonia y Dental Gutarra que ofrecen servicios similares a menor precio como se muestra en la figura 15 y alguna de las especialidades odontológicas. Debido a que las características llegan a ser muy similares, la rivalidad entre ellos es alta. Multident cuenta con una participación de mercado del $22 \%$ de la zona, información estimada en base a proporción de sedes por zona.

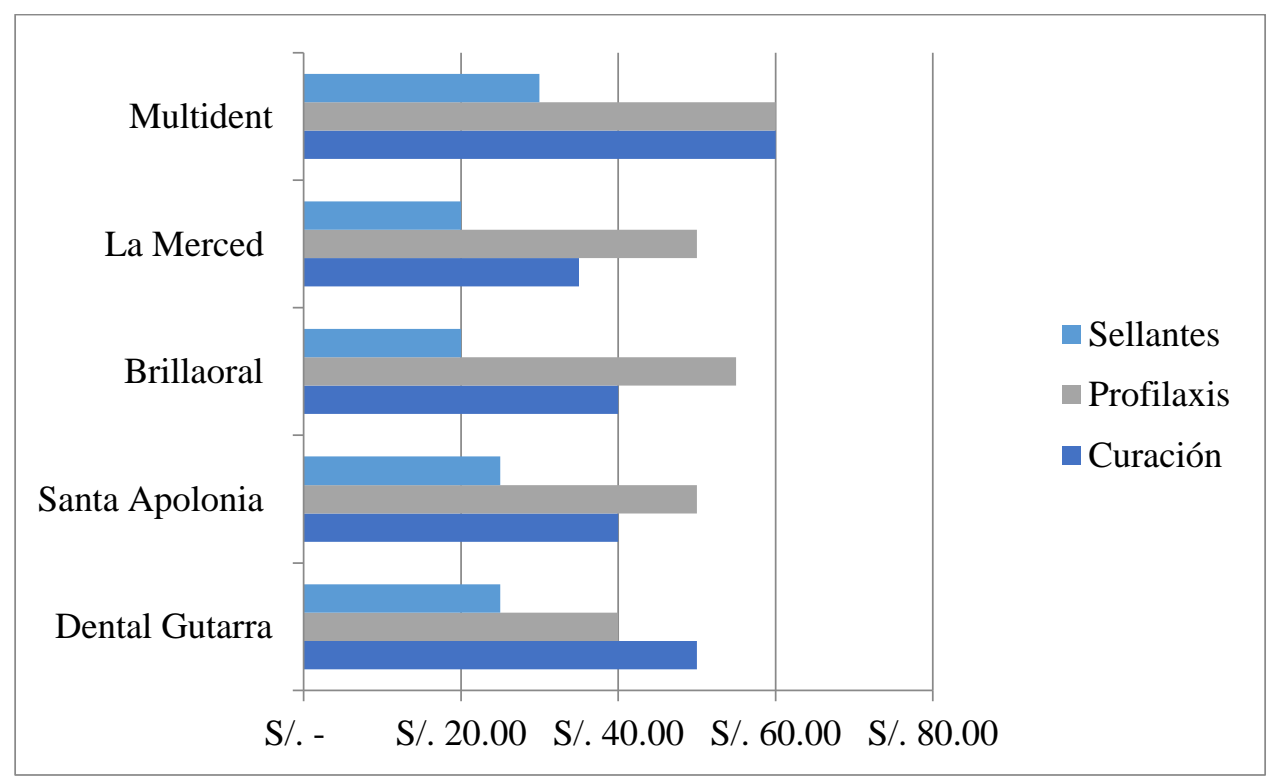

Figura 15. Precios de competencia respecto a MULTIDENT. Elaboración propia 


\section{Diferenciación del producto o servicio}

Existen pocos centros odontopediátricos en la zona que cuenten con especialistas en odontopediatría y infraestructura con áreas lúdicas diseñadas para niños. Sin embargo, la clínica "La Merced" tiene algunas adecuaciones para niños que pueden representar una rivalidad media para Multident.

Barreras de salida

Todo empresario debe realizar un trámite que demanda exigencias económicas y documentarias para optar por la licencia de funcionamiento para equipar un consultorio odontológico. A ello le sumamos los trámites ante la Municipalidad del distrito la cual demanda mayores gastos, por lo que se incrementan las barreras para culminar con la operatividad y legalización del consultorio y una ventaja de Multident sobre sus rivales.

Los requisitos para solicitar la apertura de un centro odontológico en Lima son:

- Tramitar su autorización en el Registro Nacional de Establecimientos de Salud - Renaes

- Tramitar su categorización de establecimiento de salud

- Contar con licencia de IPEN

- Licencia de funcionamiento del establecimiento tramitado en la Municipalidad respectiva

- Contar con RUC 


\section{Costo de cambio}

Siendo fácil la continuación del tratamiento en otro centro odontológico, se hace aún más alta la rivalidad cuando se trata de una clínica similar a Multident pues tiene estándares de calidad similares.

Tasa de crecimiento del sector

El gasto en sector salud refleja un incremento bastante superior respecto de años anteriores, el gasto promedio de Muldident Kids ha crecido sin superarlo, estando por debajo en $20 \%$, por lo que frente a los competidores representa una alta rivalidad. La evolución del gasto y sus porcentajes se muestra en la tabla 11 y en la figura 16.

Tabla 18. Gasto promedio anual de pacientes vs Gasto promedio del sector en los NSE A,B,C+ en Lima Este

\begin{tabular}{|l|r|r|r|}
\hline & 2015 & 2016 & \multicolumn{1}{|c|}{2017} \\
\hline $\begin{array}{l}\text { Porcentaje de pacientes con Gasto mayor al } \\
\text { Promedio del sector }\end{array}$ & $20 \%$ & $20 \%$ & $29 \%$ \\
\hline Gasto anual promedio Multident Kids & $\mathrm{S} / 190.00$ & $\mathrm{~S} / 208.14$ & $\mathrm{~S} / 240.34$ \\
\hline Gasto anual promedio sector NSE A,B,C+ & $\mathrm{S} / 167.00$ & $\mathrm{~S} / 166.00$ & $\mathrm{~S} / 302.00$ \\
\hline Porcentaje con respecto al Gasto del sector & $14 \%$ & $25 \%$ & $-20 \%$ \\
\hline
\end{tabular}

Elaboración propia

Fuente: Base de Datos de la empresa 


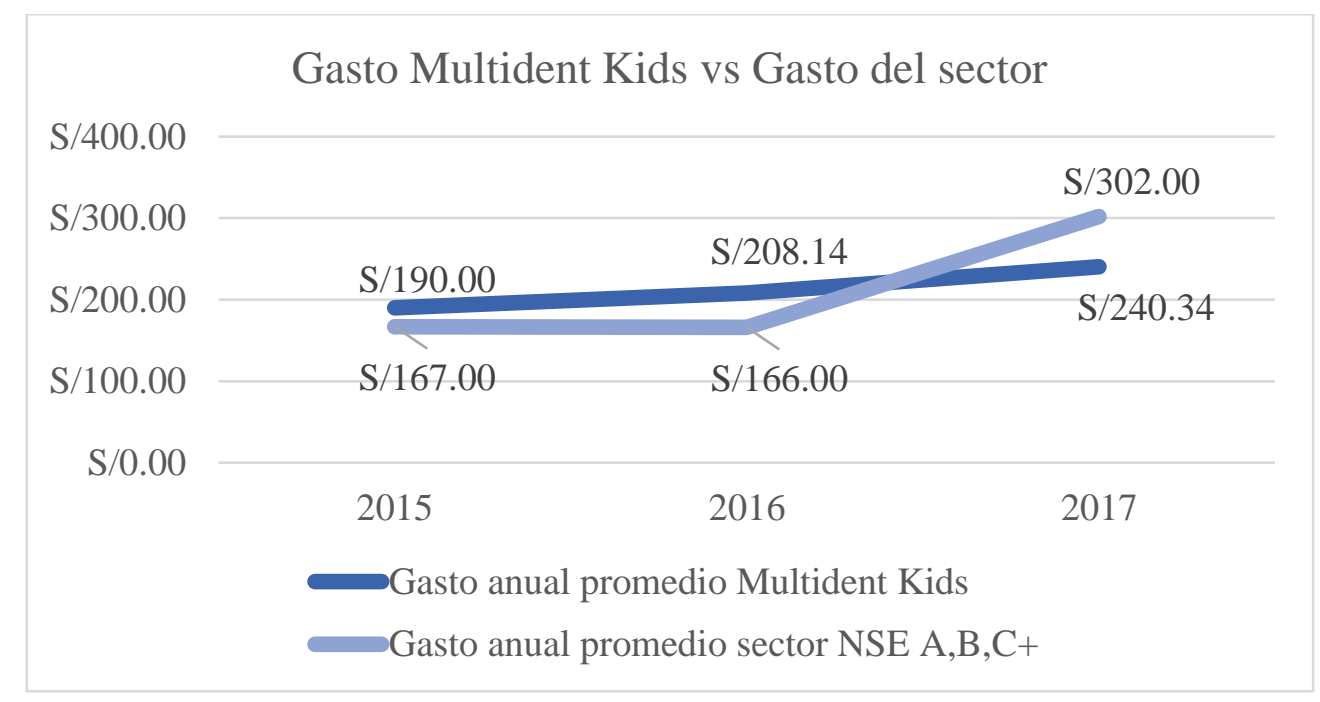

Figura 16. Gasto anual paciente Multident Kids vs Gasto anual del sector 


\subsubsection{Evaluación Matriz Porter}

Realizamos la evaluación para determinar el grado en que afecta a Multident Kids cada una de las 5 fuerzas analizadas.

A: alto, M: medio, B: bajo

\begin{tabular}{|l|c|}
\hline \multicolumn{2}{|c|}{ Poder de Negociación de los Clientes } \\
\hline Número de clientes importantes & B \\
\hline Importancia del costo de servicio en los costos totales de los clientes. & A \\
\hline Grado de estandarización del producto & B \\
\hline Costos de cambio & A \\
\hline Amenaza de integración hacia atrás & B \\
\hline Amenaza de integración hacia delante & M \\
\hline $\begin{array}{l}\text { Importancia del producto o servicio para asegurar la calidad de los } \\
\text { clientes. }\end{array}$ & B \\
\hline Información que manejen & A \\
\hline
\end{tabular}




\begin{tabular}{|l|c|}
\hline \multicolumn{2}{|c|}{ Poder de negociación de los proveedores } \\
\hline Número de proveedores importantes & A \\
\hline Costo de cambio & A \\
\hline Importancia del proveedor en la cadena de valor & A \\
\hline Amenaza de integrarse hacia adelante & A \\
\hline Amenaza de Integrarse hacia atrás & M \\
\hline Importancia del proveedor para asegurar la calidad de los productos & A \\
o servicios & \\
\hline Importancia en la rentabilidad del proveedor & B \\
\hline Amenaza de proveedores sustitutos & M \\
\hline \multicolumn{1}{|c|}{ La amenaza de nuevos competidores } & \\
\hline Economías de escala & A \\
\hline Diferenciación del servicio & M \\
\hline Identificación de marcas & M \\
\hline Costo de cambio & A \\
\hline Requerimiento de capital & A \\
\hline Acceso a canales de distribución & \\
\hline Acceso a insumos & \\
\hline
\end{tabular}




\begin{tabular}{|l|c|}
\hline Tasa de crecimiento del sector & A \\
\hline Reacción esperada & M \\
\hline Protección del gobierno o legal & A \\
\hline \multicolumn{2}{|c|}{ Amenaza de productos o servicios sustitutos } \\
\hline Precio relativo de los sustitutos & A \\
\hline Precio / Calidad & M \\
\hline Disponibilidad de sustitutos cercanos & $\mathrm{M}$ \\
\hline Costo de cambio para el cliente & $\mathrm{M}$ \\
\hline Preferencia del cliente hacia el sustituto & $\mathrm{A}$ \\
\hline \multicolumn{1}{|c|}{ Rivalidad entre los competidores existentes } & \\
\hline Concentración & $\mathrm{M}$ \\
\hline Diversidad de competidores & $\mathrm{A}$ \\
\hline Diferenciación del servicio & $\mathrm{M}$ \\
\hline Barreras de salida & $\mathrm{B}$ \\
\hline Costo de cambio & $\mathrm{A}$ \\
\hline Tasa de crecimiento del sector & \\
\hline
\end{tabular}


Mientras más alto sea el grado de cada fuerza, menos rentable resultará el mercado.

Valorizamos A (5 puntos), M (3 puntos) y B (1 punto), y concluimos que el poder de negociación de los proveedores y la amenaza de nuevos competidores son las fuerzas más influyentes sobre Multident Kids y la menor es el poder de negociación de los clientes.

\begin{tabular}{|l|c|}
\hline \multicolumn{1}{|c|}{ Fuerza } & Puntaje \\
\hline Poder de Negociación de los Clientes & 2.8 \\
\hline Poder de negociación de los proveedores & 4 \\
\hline La amenaza de nuevos competidores & 4 \\
\hline Amenaza de productos o servicios sustitutos & 3.8 \\
\hline Rivalidad entre los competidores existentes & 3.7 \\
\hline
\end{tabular}




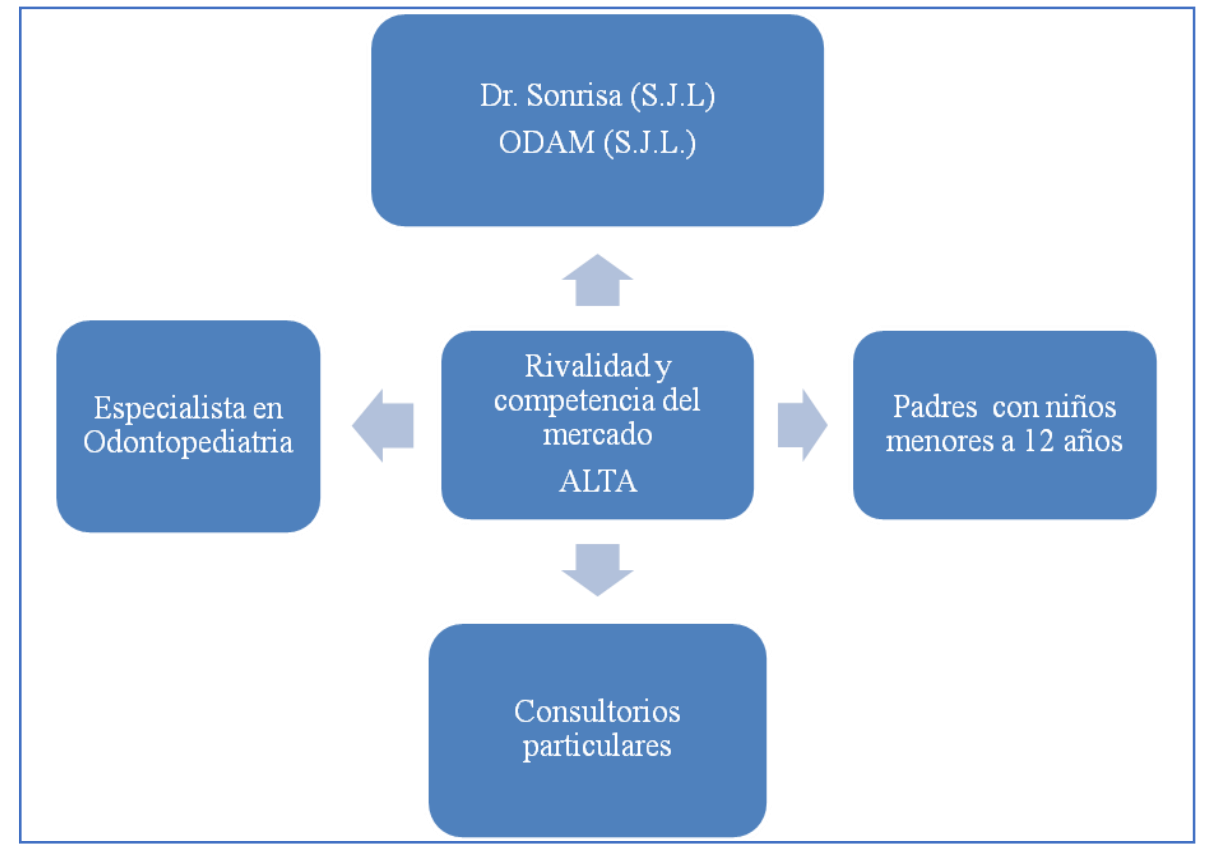

Figura 17. Fuerzas de Porter - Multident (Ate, Santa Anita) 


\subsubsection{Matriz de Perfil Competitivo}

Hemos considerado como factores críticos de éxito cuestiones tanto internas como externas y las clasificaciones se refieren a las fortalezas y debilidades, donde 4 recibe la fortaleza principal, 3 la fortaleza menor, 2 la debilidad menor y $1^{\mathrm{a}}$ debilidad principal.

\begin{tabular}{|c|c|c|c|c|c|c|c|c|}
\hline & & & \multicolumn{2}{|c|}{ Multident } & \multicolumn{2}{|c|}{ La Merced } & \multicolumn{2}{|c|}{ Consultorios Particulares } \\
\hline & Factores Críticos para el éxito & Ponderación & Calificación. & $\begin{array}{l}\text { Puntuación. } \\
\text { Ponderación. }\end{array}$ & Calificación. & $\begin{array}{l}\text { Puntuación. } \\
\text { Ponderación. }\end{array}$ & Calificación. & $\begin{array}{l}\text { Puntuación. } \\
\text { Ponderación. }\end{array}$ \\
\hline 1 & Servicio de atención al cliente & 0.15 & 4 & 0.6 & 2 & 0.3 & 3 & 0.45 \\
\hline 2 & Infraestructura (tecnología) & 0.15 & 4 & 0.6 & 2 & 0.3 & 1 & 0.15 \\
\hline 3 & Ubicación & 0.1 & 3 & 0.3 & 2 & 0.2 & 1 & 0.1 \\
\hline 4 & Competitividad de precios & 0.12 & 2 & 0.24 & 4 & 0.48 & 3 & 0.36 \\
\hline 5 & Lealtad del cliente & 0.1 & 3 & 0.3 & 2 & 0.2 & 4 & 0.4 \\
\hline 6 & Especialistas en odontopediatría & 0.1 & 4 & 0.4 & 3 & 0.3 & 2 & 0.2 \\
\hline 7 & Identificación en la zona & 0.15 & 2 & 0.3 & 4 & 0.6 & 2 & 0.3 \\
\hline 8 & Comunicación y promoción & 0.13 & 3 & 0.39 & 4 & 0.52 & 1 & 0.13 \\
\hline & & 1 & & 3.13 & & 2.9 & & 2.09 \\
\hline
\end{tabular}




\subsubsection{Matriz de Evaluación de Factores Externos}

\begin{tabular}{|c|c|c|c|c|}
\hline & \multicolumn{4}{|l|}{ Matriz de evaluación de factores externos } \\
\hline & Factores externos clave & Ponderación & Calificación & $\begin{array}{l}\text { Puntuación } \\
\text { ponderada }\end{array}$ \\
\hline & Oportunidades & & & \\
\hline 1 & Zona altamente comercial con presencia de pymes y trabajadores independientes. & 0.11 & 2 & 0.22 \\
\hline 2 & El gasto promedio familiar en salud va en incremento. & 0.12 & 2 & 0.24 \\
\hline 3 & Amplio campo educacional, terapéuticos y atención a gestantes en la zona con clientes potenciales. & 0.10 & 2 & 0.20 \\
\hline 4 & Estilo de vida apresurado de los padres requiere servicios con mayor asistencia. & 0.08 & 1 & 0.08 \\
\hline 5 & Cliente potencial demanda más opciones de horarios. & 0.10 & 3 & 0.30 \\
\hline 6 & $\begin{array}{l}\text { Las madres en la etapa de gestación y los padres primerizos presentan una mayor recepción para la salud } \\
\text { preventiva. }\end{array}$ & 0.06 & 1 & 0.06 \\
\hline 7 & $\begin{array}{l}\text { Padres en busca de progreso, en su mayoría hijos de inmigrantes que demandan servicios diferenciados para } \\
\text { sus hijos, a los que ellos no pudieron acceder. }\end{array}$ & 0.09 & 2 & 0.18 \\
\hline & Amenazas & & & \\
\hline 1 & Baja fiscalización genera alta aglomeración de consultorios dentales en zonas cercanas. & 0.11 & 3 & 0.33 \\
\hline 2 & Clínica La Merced con mayor número de sucursales en la zona. & 0.09 & 2 & 0.18 \\
\hline 3 & Alta dependencia del proveedor más importante (odontopediatra) & 0.07 & 3 & 0.21 \\
\hline 4 & Desconocimiento de los beneficios del servicio especializado & 0.07 & 2 & 0.14 \\
\hline & & 1 & & 2.14 \\
\hline
\end{tabular}




\subsubsection{Conclusiones del Análisis del Sector}

Del análisis realizado al sector salud y específicamente la salud dental en niños, podemos concluir lo siguiente:

- Nueva ley en la práctica odontológica que permite la descentralización regional y autonomía jurídica y la obligatoriedad de condición de colegiado y habilitado.

- Mayor fiscalización de SUSALUD frente a la alta aglomeración de consultorios dentales en la zona que compiten con precio muy bajos.

- Crecimiento de sector salud de acuerdo con las proyecciones macroeconómicas, incremento del 16\% en el presupuesto respecto del 2017. Es el tercer sector de mayor presupuesto.

- Crecimiento del $4.2 \%$ en inversión privada y 3.2\% inversión diversificada, siendo Ate y Santa Anita, distritos altamente comerciales de fuerte presencia de pequeñas y medianas empresas, a su vez alberga a dos grandes obras la Linea 2 del Metro y el Mall Real Plaza Puruchuco, incrementando aun más su potencial.

- Las principales redes de clínicas concentran su inversión para el 2018 en innovación tecnológica y remodelaciones.

- Gasto promedio familiar en salud en centros privados viene incrementándose. Cerca del $80 \%$ de la población realiza un gasto de bolsillo para atención de salud al no estar afiliado a ningún sistema de salud o por la deficiencia de los sistemas públicos.

- El proveedor más importante en el sector es el mismo profesional odontólogo, lo que crea una alta dependencia de éste con el lugar donde realiza la práctica y con el paciente. 
- La odontopediatría es una especialidad que no solo exige la presencia de un profesional que maneje adecuadamente la conducta del paciente, sino la existencia de un entorno físico-psicológico para la práctica con los niveles adecuados de calidad en el servicio.

- Existen barreras de entrada al mercado por la alta inversión para la apertura de clínicas dentales, sin embargo, para consultorios la barrera disminuye dado que la inversión es la décima parte.

- Referente a la idiosincracia de Lima Este, encontramos a los padres que son hijos de inmigrantes y progresistas que anhelan para sus hijos, aquello a lo que no pudieron acceder. 


\subsection{Análisis Interno}

\subsubsection{Análisis de la empresa}

\subsubsection{Historia}

En Lima Este, Multident inició en el 2012 pues identificó una oportunidad en los distritos de Ate y Santa Anita que se encontraban parcialmente desatendidos. La única opción cercana para los potenciales clientes era la sede de La Molina pero que al encontrarse en el centro de este distrito era poco accesible para la población.

Las sedes de Santa Anita y Ate trabajan bajo una misma dirección, administración y equipo de Marketing. Geográficamente, Santa Anita tiene límite con Ate por el noreste, este y sur, son distritos colindantes como se muestra en la figura 18.

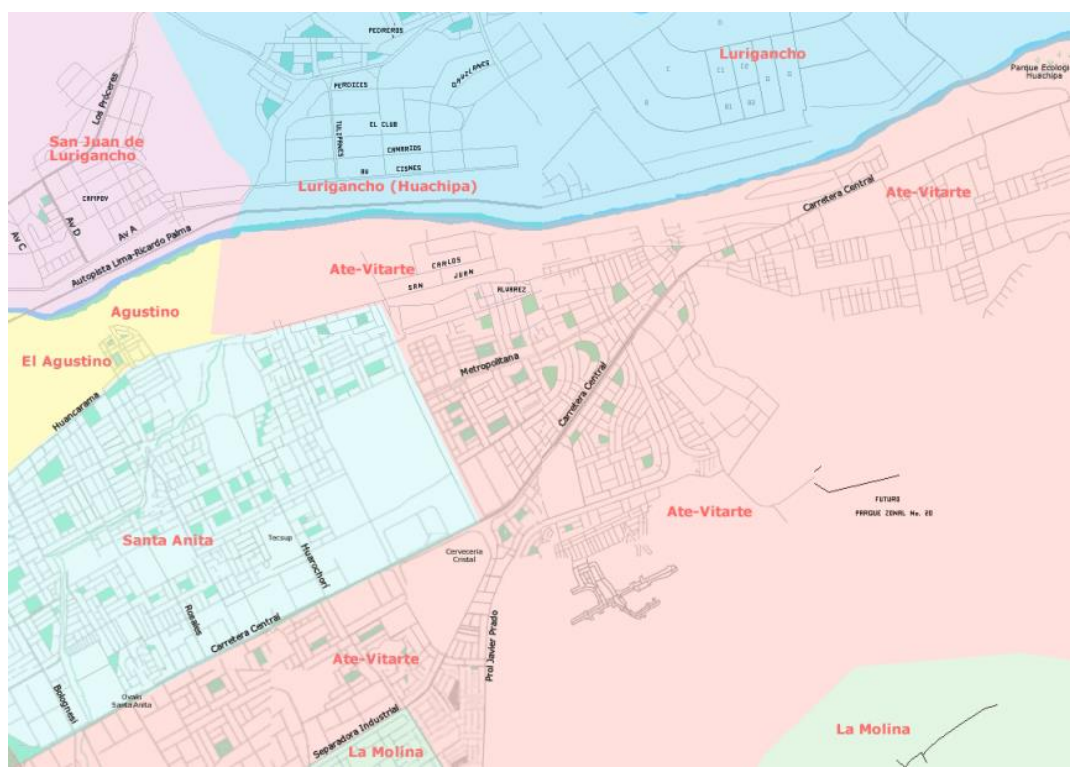

Figura 18. Mapa de Lima Este de Guía de Calles de Lima 
La sede de Santa Anita fue la primera de Lima Este, desde sus inicios tuvo una buena aceptación de los clientes y rápidamente fue creciendo. Actualmente cuenta con un staff de odontólogos, administrativos y mantenimiento que trabajan en equipo para brindar una atención de calidad a los pacientes. La sede se encuentra ubicada en la Av. Ruiseñores, que es una avenida principal por donde la mayor parte de las personas que ingresan o salen del distrito obligatoriamente transitan, por lo que cual ha ganado visibilidad durante los años. Sin embargo, para las personas de otras zonas de distrito donde el acceso es por vías secundarias no reconocen la sede aún.

Dos años más tarde la administración identificó que más del 50\% de los pacientes que consultaban provenían del distrito de Ate y es así como decidió abrir una sede en este distrito, ubicada en la Carretera Central y a pocos minutos de la sede de Santa Anita. Sus inicios fueron similares hasta un año después cuando las obras por la construcción de la Línea 2 del Metro de Lima iniciaron y se vió fuertemente afectada por la falta accesibilidad para los pacientes. Actualmente, las obras siguen en proceso y se espera que a fines del 2018 concluyan y la afluencia por la zona incremente. Ambas sedes han tenido un incremento en el ausentismo de las citas de los pacientes por la dificultad para la accesibilidad, los cambios de ruta en avenidas principales y congestión vehicular debido a las obras de la Línea 2 del Metro de Lima. 


\subsubsection{Estructura Organizacional de la empresa}

La administración de Multident Santa Anita y Ate reciben la misma dirección por la cercanía y se encuentra organizado de la siguiente forma:

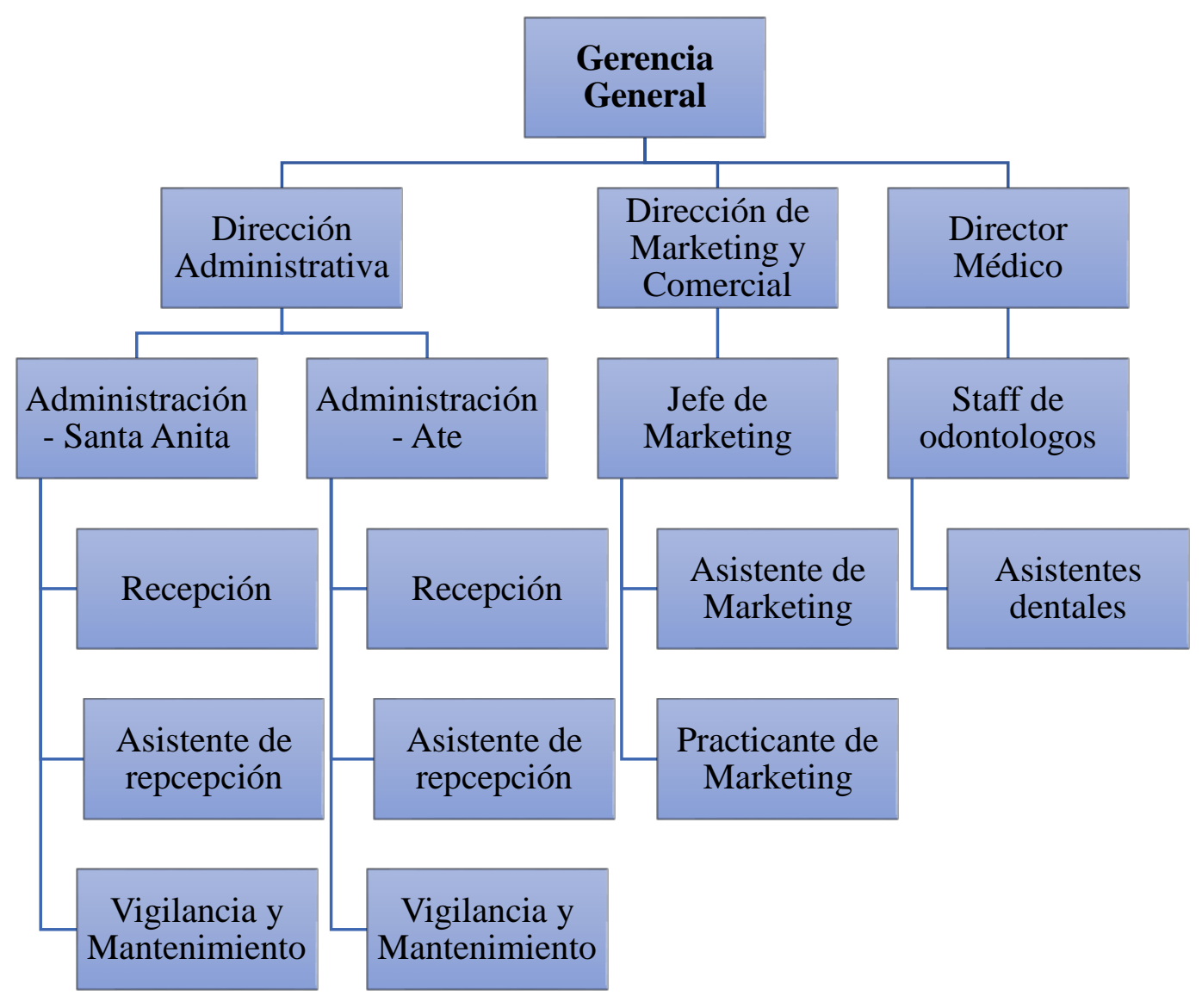

Los lineamientos generales vienen de la administración central de todas las sedes y se replica en cada una de las sedes, el área de contabilidad, sistemas y legal son proporcionados por la sede central como un servicio tercerizado. 


\subsubsection{Productos.}

Los productos de Multident Kids son tratamientos dentales para niños.

Son 25 tratamientos que se ofrecen dentro de la especialidad de odontopediatría que han sido clasificados por su naturaleza siendo ellos:

1. Exámenes auxiliares: Evaluaciones, toma de modelos y tomas radiográficas.

2. Tratamientos preventivos: Profilaxis, fluorización y sellantes. En estos se pone mayor énfasis y se ha creado un paquete preventivo básico como gancho para atraer a nuevos pacientes, el valor original es de S/.240.00 y es ofrecido al público por S/.90.00.

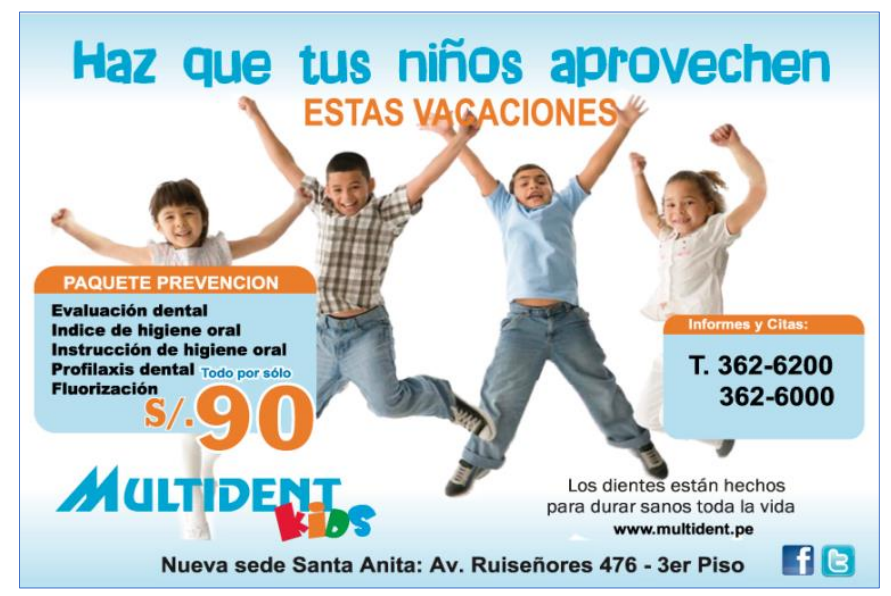

Figura 19. Paquete preventivo actual

3. Tratamientos restaurativos: Restauraciones con resina o curaciones, simples, complejas, compuestas e incrustaciones.

4. Tratamientos de conductos: Pulpotomía y Pulpectomía. 
5. Tratamientos de cirugía oral: Cirugías de tejidos blandos y duros. y el tratamiento más común de extracción o exodoncia.

6. Tratamientos de rehabilitación oral: Coronas de acetato y acero, ferulizaciones y mantenedores de espacio.

7. Sedación consciente que funcionan como un tratamiento adicional según el requerimiento de la conducta del paciente.

Además, gran aporte de la consulta y tratamiento con un odontopediatra es el valor agregado del conocimiento y recomendaciones que le puedan otorgar, por lo que se tiene a disposición La Vitrina Multident que ofrece los productos recomendados como pastas dentales, cepillos, hilos, enjuagatorios y otros accesorios.

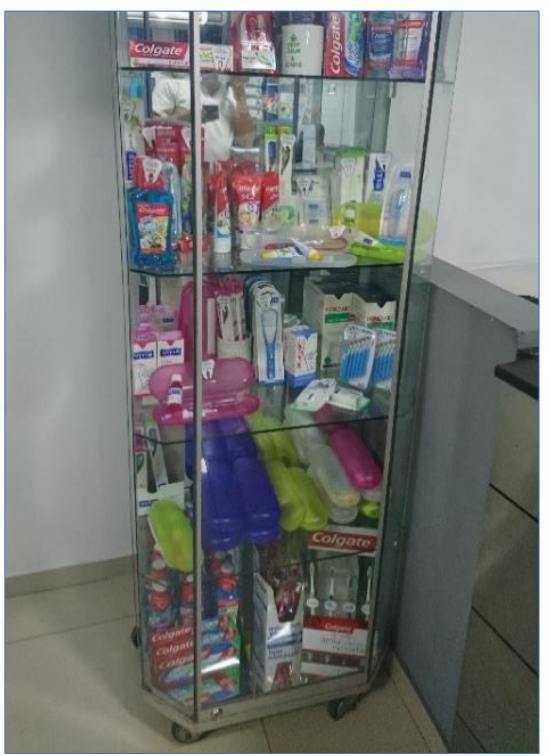

Figura 20. La Vitrina Multident 


\subsubsection{Ciclo de vida.}

Dentro de Odontopediatría identificamos lo siguiente:

Los tratamientos preventivos y restaurativos son los de mayor facturación en ventas como se muestra en la figura 21.

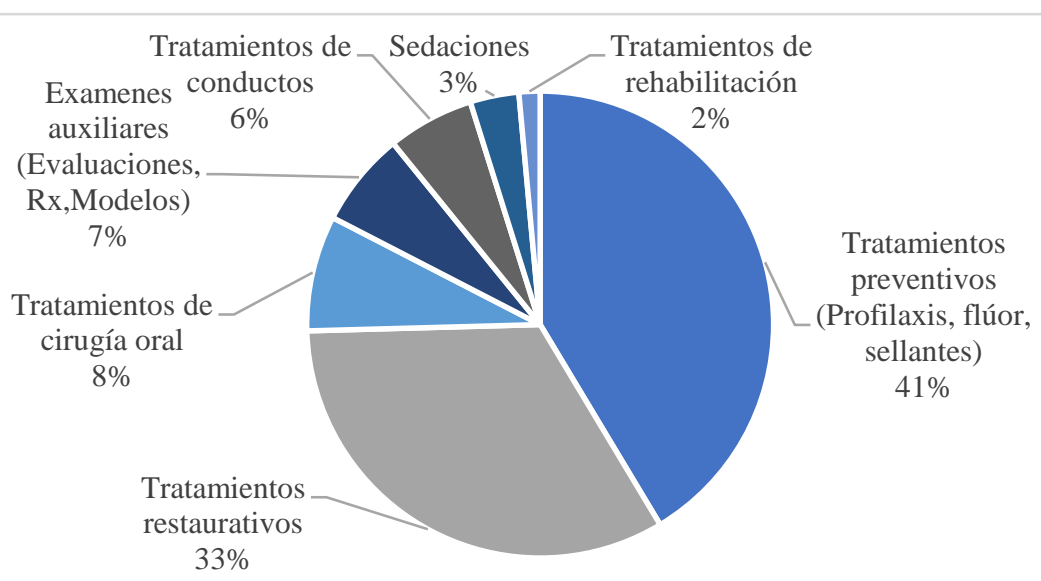

Figura 21. Participación de ventas por tipo de tratamiento

Dentro del análisis del ciclo de vida de los productos que se muestra e la figura 22 , se observa que los tratamientos de rehabilitación como "Ortopedia Maxilar" están entrando recién al mercado y hasta el momento representan poca facturación.

Los tratamientos de fluorización en sus dos modalidades se ubican en diferentes etapas, el primero "Fluorización con barniz" se encuentra en 
crecimiento porque es un método moderno y con mayores ventajas sobre el último "Fluorización con gel" que se encuentra al final del ciclo de vida.

En auge encontramos a los tratamientos preventivos de "Sellantes dentales" por su necesidad para evitar enfermedades dentales graves.

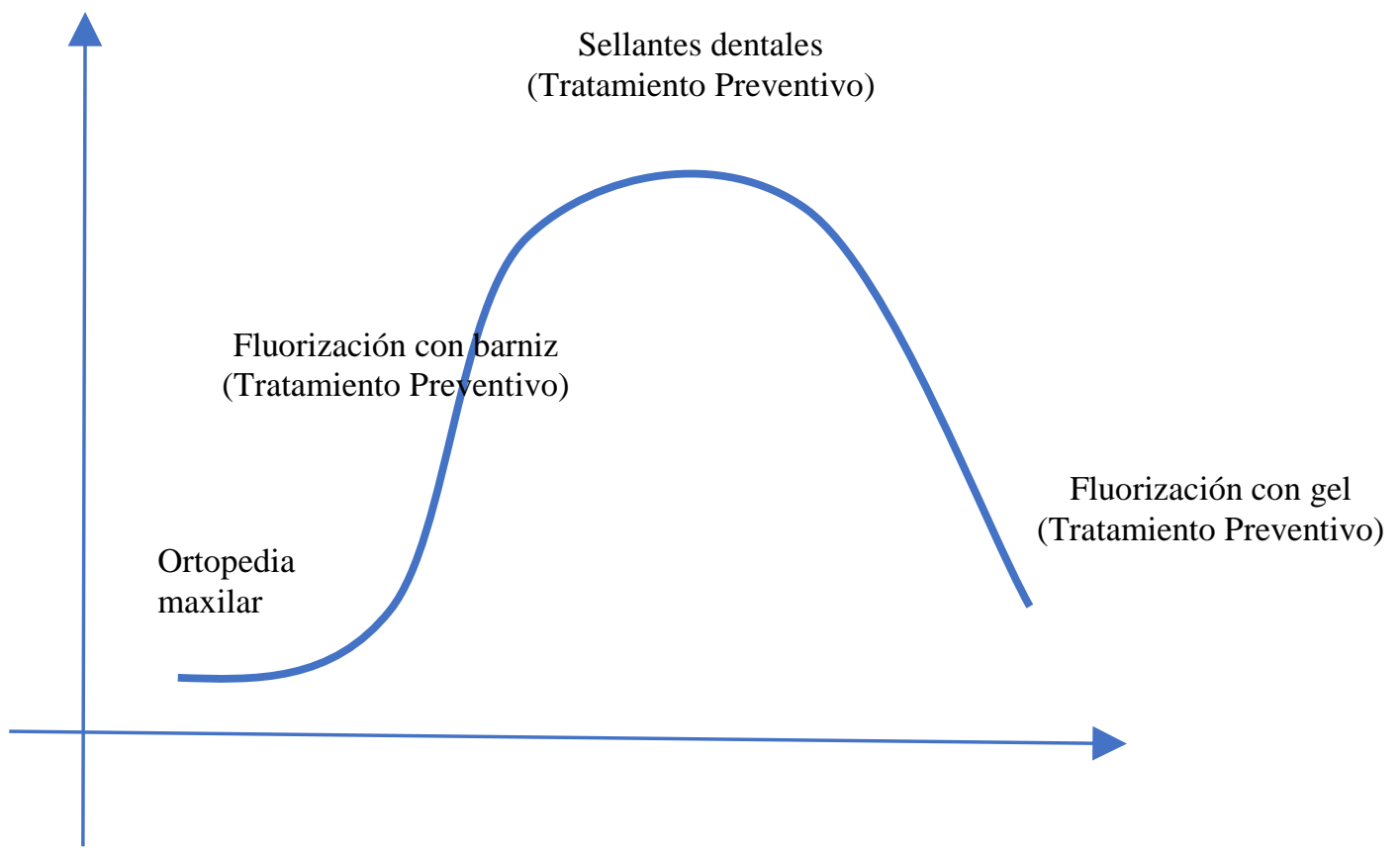

Figura 22. Ciclo de vida de las especialidades odontológicas en Multident 
Mediante la matriz BCG se han analizado los productos que se ofrecerán para proponer estrategias exitosas:

Matriz BCG para Multident Kids - Odontopediatría

\begin{tabular}{|l|l|}
\hline Estrellas & Incógnitas \\
Tratamientos Preventivos & Tratamientos Restaurativos \\
(Fluorización + Sellantes) & $\begin{array}{l}\text { Tratamientos de Conductos } \\
\text { Tratamientos de Cirugía }\end{array}$ \\
\hline $\begin{array}{l}\text { Vacas Lecheras } \\
\text { Oratamiento de Rehabilitación } \\
\text { Sedación }\end{array}$ & $\begin{array}{l}\text { Tratamientos Preventivos } \\
\text { educativos (Fisioterapia e } \\
\text { Índice de higiene) }\end{array}$ \\
\hline
\end{tabular}




\subsubsection{Precios.}

El tarifario de precios contiene 25 tratamientos dentales. En esta parte describiremos los tratamientos más comunes de la especialidad de odontopediatría que se detallan en la tabla 19:

\section{Precios de Odontopediatría.}

Los tratamientos están expresados en unidades y nuevos soles

Tabla 19. Tarifario de tratamientos más comunes

\begin{tabular}{|l|c|}
\hline Tratamientos & Precio S/. \\
\hline Flúor Gel Por Arcada & $\mathrm{S} / 60.00$ \\
\hline Flúor Barniz & $\mathrm{S} / .200 .00$ \\
\hline Restauración Con Ionomero De Vidrio & $\mathrm{S} / .120 .00$ \\
\hline Sedación Consciente Oral & $\mathrm{S} / .250 .00$ \\
\hline Sedación Consciente Óxido Nitroso & $\mathrm{S} / .500 .00$ \\
\hline Resina Por Superficie Niños & $\mathrm{S} / 60.00$ \\
\hline Sellantes De Surcos Y Fisuras & $\mathrm{S} / .30 .00$ \\
\hline Pulpotomía & $\mathrm{S} / .150 .00$ \\
\hline Pulpectomia & $\mathrm{S} / .250 .00$ \\
\hline
\end{tabular}




\subsubsection{Distribución.}

La estrategia de distribución se basa en la atención al paciente y sigue

los siguientes pasos:

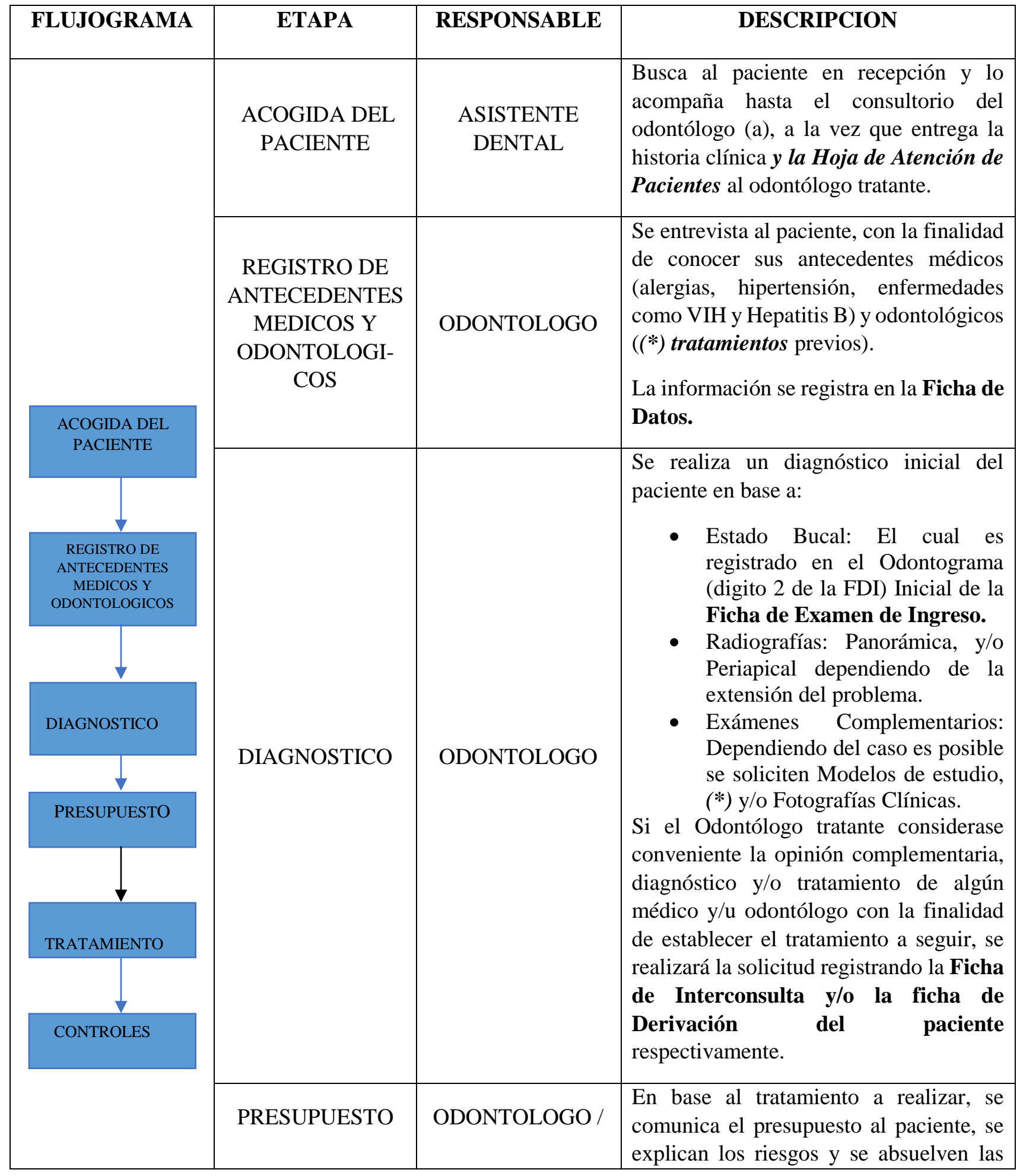




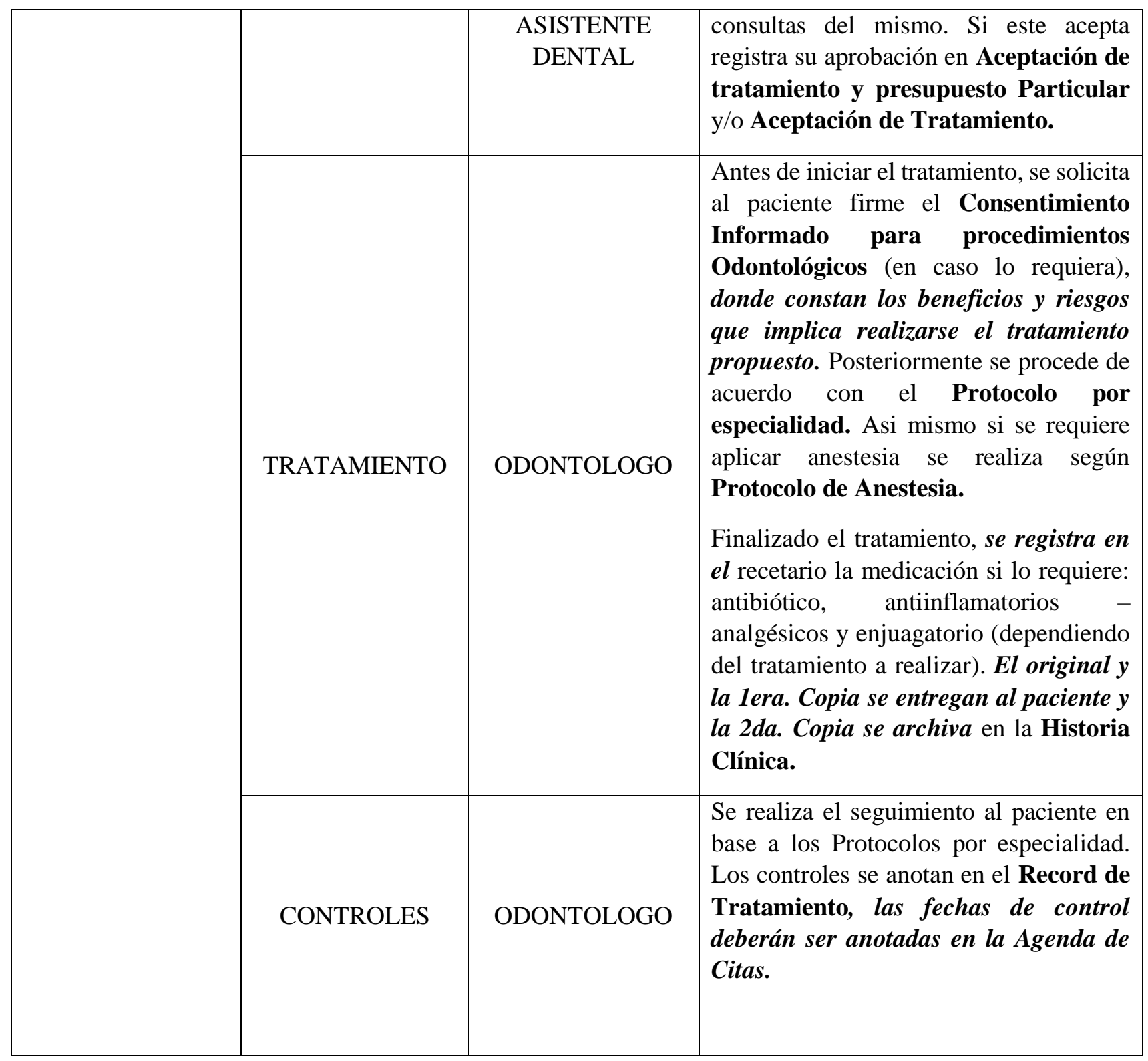




\subsubsection{Comunicación.}

Actualmente la empresa maneja una comunicación directa con los pacientes mediante el uso constante de mensajes por WhatsApp, de texto y llamadas telefónicas para comunicar algún evento importante o recordación de citas.

El personal de turno se comunica mediante el uso de correos electrónicos, intercomunicadores y un grupo específico de trabajo en WhatsApp para dar solución a impases y generar un buen ambiente de trabajo.

\subsubsection{Fuerza de ventas.}

En Multident la fuerza de ventas está constituida por los odontopediatras, quienes explican a los padres el tratamiento recomendado para sus hijos.

Los odontopediatras realizan una evaluación con odontograma, cámara intraoral y radiografías auxiliares para determinar un diagnóstico completo de la salud dental del paciente, luego de ello proceden a hacer una explicación del caso que puede durar entre 30 a 60 minutos según la complejidad del mismo y disponibilidad del paciente. 
Es en la etapa de explicación donde se usan las mejores herramientas de ventas para poder captar a un paciente que proceda a iniciar su tratamiento. Entre las herramientas que se utilizan tenemos:

1. Explicación con maquetas dentales

2. Explicación con cámara intraoral

3. Explicación con vídeos de tratamientos

4. Explicación de métodos de descuentos con la tarjeta Multident Card.

\subsubsection{Descripción del producto de la empresa}

Los tratamientos odontológicos se realizan después de un correcto diagnóstico de los pacientes, una explicación del caso y aceptación del tratamiento.

El servicio se realiza a partir de una cita generada con el tiempo indicado por el odontólogo según el tipo de tratamiento. Los procesos de atención son estandarizados para garantizar una buena atención. 


\subsubsection{Competencias básicas de la empresa}

\subsubsection{Servicio de garantía.}

Todos los tratamientos son realizados por odontopediatra titulados, colegiados, hábiles y especialistas con RNE (Registro Nacional de Especialidad) lo que garantiza el éxito del tratamiento siempre que el paciente siga las recomendaciones dadas por cada odontólogo, como asistir a sus controles e ingerir alimentos adecuados según el tratamiento.

\subsubsection{Infraestructura adecuada.}

Cada sede de Multident cuenta con una sala de espera para adultos y otra para niños con aire acondicionado, buen aroma e higiene para que los pacientes puedan sentirse tranquilos durante su estadía como se muestra en la figura 23.

En cuanto a equipos médicos se cuentan con unidades dentales modernas, televisores, pantallas y equipos radiográficos para brindar una buena explicación del caso y del tratamiento a seguir. La capacidad instalada actualmente está diseñada para atender a más 4,000 pacientes al año. 

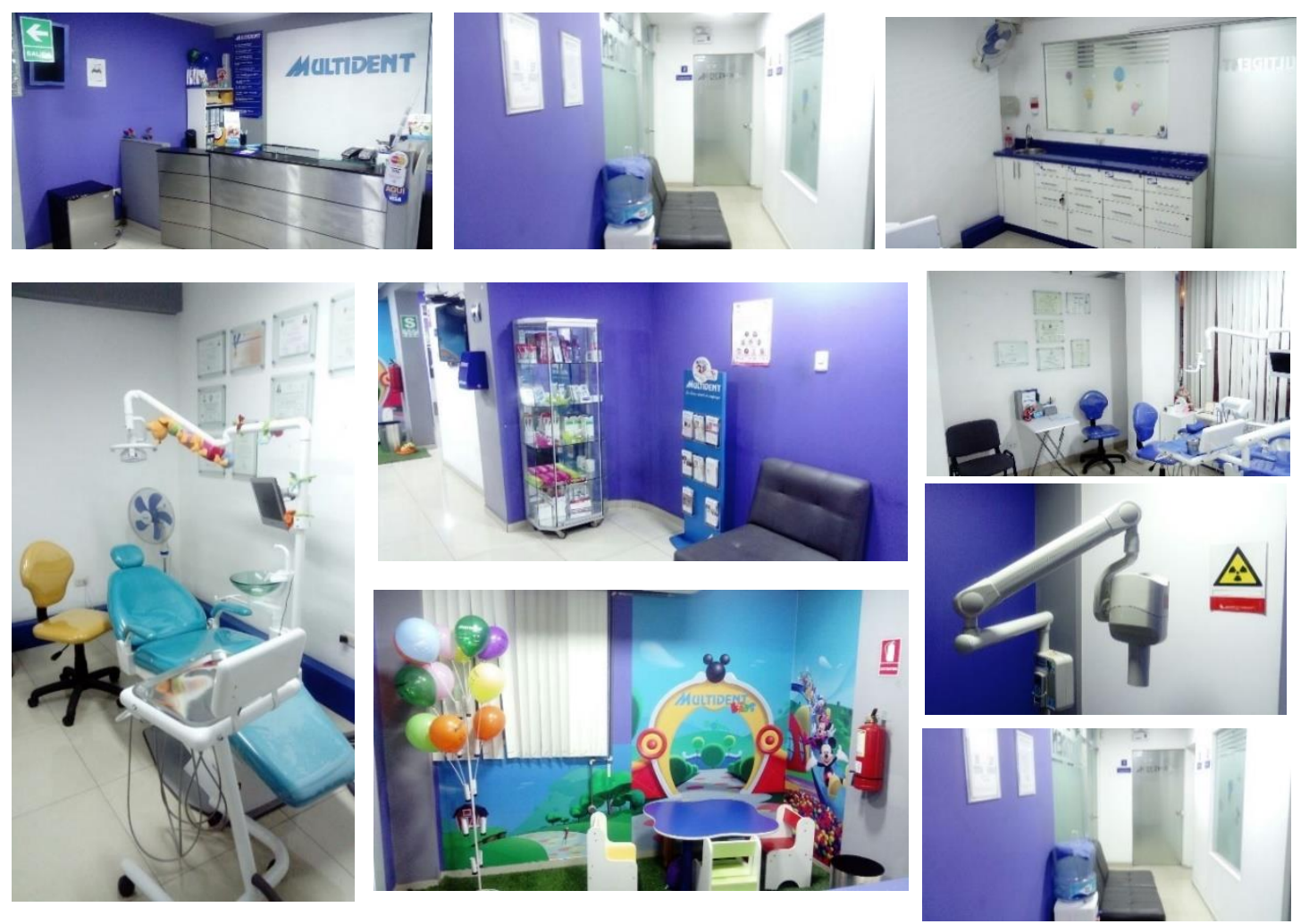

Figura 23. Fotografías de infraestructura actual

\subsubsection{Clima laboral.}

El trabajo del área administrativa y de recursos humanos considera como parte importante el bienestar de los trabajadores tanto de la parte administrativa como del staff de odontólogos, es por ello que se invierte tiempo y dinero en mantener un buen clima laboral en Multident. El clima laboral es bueno debido al trabajo que se realiza en equipo, la confianza y respeto que siempre se práctica a todos niveles, lo que se ve reflejado en el nivel de satisfacción del personal que actualmente se encuentra en el $83 \%$ como se calcula en el Anexo 2. 
Dentro del presupuesto mensual se considera un porcentaje para ambientar y realizar compras de las actividades que se muestran en la figura 24 como: cumpleaños de trabajadores, actividades extralaborales entre almuerzos, aniversarios, intercambios navideños y reuniones con todo el personal.
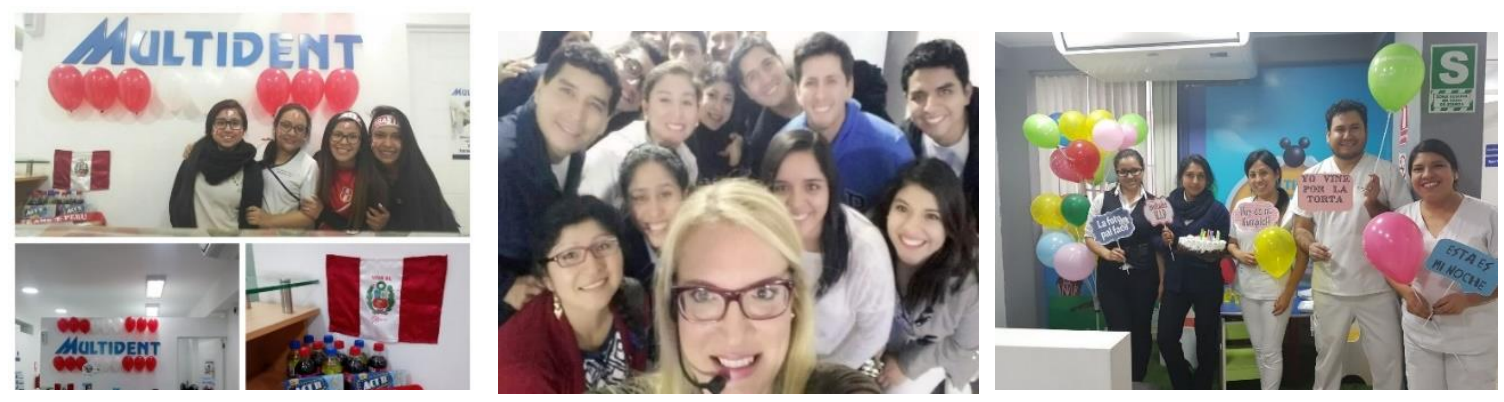

Figura 24. Actividades del equipo de trabajo

\subsubsection{Capacidades de marketing de la empresa}

La empresa tiene como principales capacidades

- Generar confianza en los pacientes y sus padres aprovechando la tecnología superior que posee frente a otras opciones en la zona como el uso de cámara intraoral para la explicación y venta del tratamiento, así como el equipamiento durante el proceso de tratamiento al paciente.

- El posicionamiento de Multident y su slogan "Su clínica de Confianza”, refuerza con acciones durante 23 años su posicionamiento en base a la confianza. 
- Saber comunicar a los padres adecuadamente los beneficios de la atención especializada frente a otras opciones.

- Capacitar a los especialistas en odontopediatria en técnicas de venta además de su actualización constante en la especialidad.

- Mantenerse a la vanguardia en tecnología odontológica. 


\subsubsection{Matriz de Evaluación de Factores Interno}

\begin{tabular}{|c|c|c|c|c|}
\hline & Matriz de evaluación de factores internos & & & \\
\hline & Factores internos clave & Ponderación & Calificación & $\begin{array}{l}\text { Puntuación } \\
\text { ponderada }\end{array}$ \\
\hline & Fortalezas & & & \\
\hline 1 & Reconocimiento de la marca en el rubro de salud dental. & 0.11 & 4 & 0.44 \\
\hline 2 & $\begin{array}{l}\text { Staff de odontopediatras calificados y con título de especialista validado por el Colegio } \\
\text { Odontológico del Perú. }\end{array}$ & 0.10 & 4 & 0.40 \\
\hline 3 & $\begin{array}{l}\text { Uso de tecnología novedosa en la zona (cámara intraoral y ultrasonido) que aumenta la } \\
\text { confianza y transparencia en los padres. }\end{array}$ & 0.09 & 4 & 0.36 \\
\hline 4 & $\begin{array}{l}\text { La duración de la cita se personaliza de acuerdo al comportamiento del paciente y sus } \\
\text { padres. }\end{array}$ & 0.06 & 3 & 0.18 \\
\hline 5 & $\begin{array}{l}\text { Ubicación estratégica en avenidas principales cercana a centros comerciales, empresas y } \\
\text { centros de trabajo/estudio. }\end{array}$ & 0.08 & 3 & 0.24 \\
\hline \multirow{2}{*}{6} & La empresa mantiene un buen clima organizacional. & 0.06 & 3 & 0.18 \\
\hline & Debilidades & & & \\
\hline 1 & Falta de identificación de las sedes de Ate y Santa Anita. & 0.13 & 2 & 0.26 \\
\hline 2 & Precios más elevados que la competencia. & 0.10 & 1 & 0.10 \\
\hline 3 & No está afiliada a una entidad prestadora de servicio. & 0.06 & 1 & 0.06 \\
\hline 4 & $\begin{array}{l}\text { Incremento de ausentismo a las citas debido el proceso de construcción de la Línea } 2 \text { del } \\
\text { Metro de Lima. }\end{array}$ & 0.08 & 2 & 0.16 \\
\hline 5 & Sus programas de campañas no están dirigidas al decisor de la compra. & 0.07 & 2 & 0.14 \\
\hline \multirow[t]{2}{*}{6} & Baja tasa de retorno de pacientes de un año a otro $23 \%$ & 0.06 & 2 & 0.12 \\
\hline & & $\mathbf{1 . 0 0}$ & & 2.64 \\
\hline
\end{tabular}




\subsubsection{Conclusiones del Análisis Interno}

- A pesar de que Multident es una marca reconocida en Lima, no es fácilmente identificada en la zona, y el precio de los tratamientos es uno de los más altos, ello debido a los especialistas y tecnología que no se encuentran fácilmente en la competencia. La empresa no está afiliada a una entidad prestadora de servicios (EPS), sin embargo, se realizan campañas con empresas de la zona.

- Siendo los odontopediatras la principal fuerza de venta y principal proveedor, la empresa mantiene preocupación constante por su capital humano y se refleja en los indicadores de satisfacción del personal.

- La duración de la cita se personaliza de acuerdo con la complejidad del caso del paciente y la disponibilidad de los padres.

- Multident utiliza diversas estrategias de marketing, sin embargo, no ha logrado posicionar la marca en la zona. 


\section{CAPÍTULO IV}

\section{Investigación de Mercado}

\subsection{Problema de Investigación}

El programa Multident Kids dirigido a gestantes y niños entre 0 y 12 años, no ha crecido sostenidamente en la Clínica como si lo han conseguido otras especialidades tales como: implantes, ortodoncia y estética dental. Inicialmente el programa contaba con un $8 \%$ de la facturación de la empresa y, en la actualidad el porcentaje ha decrecido a un 5\%, dado el mayor énfasis puesto por la empresa en las demás especialidades.

En una entrevista con el director médico de Lima Este de Multident manifestó su preocupación por el programa ya que, a pesar de poner esfuerzos en el área de marketing mediante campañas, charlas y actividades en colegios de las zonas cercanas, los resultados no reflejan un importante incremento en las ventas para Multident Kids. Sin embargo, dada las oportunidades que presenta el sector y el mercado de Lima este y las fortalezas de la clínica, consideramos que presenta potencial para crecer, además que puede significar el primer paso para que toda una familia considere atenderse en Multident y retribuya al crecimiento de toda la empresa.

Consideramos que el reto está en acceder de una forma más eficiente al público objetivo y en cómo lograr que los padres valoren la salud dental de sus hijos y accedan al servicio odontopediátrico que Multident Kids ofrece. 
Planteamos como principales problemas de investigación lo siguiente:

a) Conocer el comportamiento de los padres en la salud dental de sus hijos.

b) Identificar las características del mercado de odontopediatría en los distritos de Ate y Santa Anita.

c) Apreciación del servicio de salud odontológica que ofrece Multident Kids.

\subsection{Necesidades de Información}

Hemos desarrollado el detalle de los componentes y las hipótesis para cada uno de ellos considerado en la investigación. La hipótesis según Naresh K. Malhotra (2003) “son una afirmación o proposición aún no comprobada acerca de un factor o fenómenos que es de interés para el investigador" (p.53), razón por la cual han sido adecuadas para comprobar la veracidad o falsedad de las ideas percibidas antes de la investigación. 


\subsubsection{Componente A: Conocer el comportamiento de los padres en la salud dental de sus hijos.}

A.1. Hábitos de la salud dental de los hijos: Motivo, limpieza y frecuencia.

A.2. Nivel de información en salud dental.

A.3. Atributos que más valora del servicio ofrecido a sus hijos.

A.4. Elementos que más influyen negativamente en sus hijos del servicio ofrecido.

\section{Hipótesis del componente A:}

- Hipótesis 1: Los padres de familia prefieren tratar de manera preventiva la salud dental de sus hijos.

- Hipótesis 2: Las madres gestantes son más receptivas a las indicaciones del especialista.

\subsubsection{Componente B: Identificar las características del mercado de odontopediatría en el distrito de Ate, Santa Anita.}

B.1. Nivel de conocimiento de los beneficios de la especialidad de odontopediatría frente al servicio de un odontólogo.

B.2. Preferencia sobre sistemas de atención dental odontopediátrica: Eps, clínicas y consultorios.

B.3. Grado de satisfacción y tiempo de permanencia con el centro odontológico más relevante.

B.4.Atributos considerados para la elección del servicio. 
B.5. Medios que influyen en su decisión de elección del servicio.

Hipótesis del componente B:

- Hipótesis 1: El nivel de conocimiento de los beneficios del servicio especializado es bajo.

- Hipótesis 2: Los padres de familia no encuentran en el mercado los atributos que más valoran en un centro odontológico.

- Hipótesis 3: Los padres de familia son fieles al especialista en odontología.

\subsubsection{Componente C: Apreciación del servicio de salud odontológica que ofrece Multident Kids.}

C.1. Nivel de recordación de la marca.

C.2. Nivel de reconocimiento de las sedes de Ate y/o Santa Anita.

C.3. Atributos más valorados de la marca y del servicio de odontopediatría.

Hipótesis del componente C:

- Hipótesis 1: La marca Multident es menos reconocida en Lima Este.

- Hipótesis 2: El atributo más valorado del programa Multident Kids es la confianza. 


\subsection{Diseño de investigación}

Para la investigación, utilizamos el diseño investigación exploratoria y el diseño descriptivo transversal simple. Según Naresh K. Malhotra la investigación exploratoria, nos sirve para analizar el problema, brindando conocimiento y comprensión de la situación.

Nuestro trabajo requiere realizar un análisis de los datos obtenidos, para contrastar las variables que más valoran los padres y los pacientes de centros odontológicos donde son atendidos, de manera que las estrategias a proponer estén de acuerdo con los resultados de la investigación.

Para la investigación nos apoyamos en las siguientes fuentes de información:

Conversaciones con quienes toman las decisiones: Reuniones con el director de Multident de Lima Este.

Entrevistas con los expertos del sector: Entrevistas a odontopediatras de las diferentes sedes de Multident, odontopediatras de otras clínicas y profesionales que trabajen con padres.

\section{Entrevistas con padres con hijos hasta 12 años y madres gestantes.}

Análisis de datos Secundarios: Se ha llevado a cabo la investigación usando la información estadística del INEI para determinar el alcance de la población y determinar el mercado potencial, objeto del estudio.

Asimismo, nos hemos apoyado en la información de la base de datos de la empresa para determinar algunas tendencias y preferencias de los pacientes de Multident. 


\subsection{Método de investigación cualitativa}

\subsubsection{Proceso de muestreo}

Se aplicará el muestreo no probabilístico a través de entrevistas a profundidad que nos permitirá comprender qué es lo que realmente buscan los padres en el servicio de una atención odontológica para sus hijos menores a 12 años y por parte de la entrevista a expertos, conocer las percepciones y visión de la clínica sobre el sector.

La finalidad es comprender a profundidad sus pensamientos y sensaciones para que Multident Kids tenga una oferta y comunicación competitiva.

\section{Definición del Target.}

El programa Multident Kids tiene como mercado potencial a los padres con hijos de 0 a 12 años y a las madres gestantes que viven principalmente en los distritos de Ate, Santa Anita y aledaños como Lurigancho y Chaclacayo. Además, considera un precio accesible para un NSE A, B y C+. Por otro lado, considera que los padres que muestran más preocupación por la salud de sus hijos oscilan entre 25 y 45 años, dado que el $80 \%$ de los que retornan por un tratamiento continuo estuvieron en ese rango. 
Hemos considerado las siguientes variables:

Entrevistas a profundidad a los padres con hijos hasta 12 años (24 entrevistas).

- Tienen hijos entre 0 y 12 años.

- Viven en los distritos de Ate, Santa Anita, Chaclacayo, Lurigancho.

- Edad entre 25 y 45 años.

- Nivel de ingreso familiar: Desde 5000 soles

- Profesión u ocupación: Grado superior y/o técnico.

- Condición de trabajo: Independiente/ dependiente.

Entrevistas a profundidad a Madres gestantes.

- Tienen desde 3 meses de gestación.

- Edad entre 25 y 45 años.

- Viven en los distritos de Ate, Santa Anita, Chaclacayo, Lurigancho

- Nivel de ingreso familiar: Desde 5000 soles.

- Profesión u ocupación: Grado superior y/o técnico.

- Condición de trabajo: Independiente/ dependiente.

La metodología que se emplea es la siguiente:

- Reclutamiento de participantes que sean padres con hijos hasta 12 años, pertenezcan a un NSE A, B, C+ y vivan en Ate, Santa Anita, Lurigancho y Chaclacayo.

- Duración: El tiempo de la entrevista es de 1 hora. 
- Condiciones: En la vivienda de la persona entrevistada y se le entrego un presente por su participación.

- Análisis a cargo del grupo que cuenta con experiencia previa en análisis cualitativo y de datos.

- Respaldo de información: Audio

Para determinar los segmentos, la población de padres con hijos la hemos clasificado por distrito, mas no por NSE dado que la mayor diferencia es el poder adquisitivo y el costo es accesible para los 3 NSE, tal como se explicó anteriormente. 


\subsubsection{Diseño muestral de las entrevistas a profundidad}

Para la presente investigación se realizaron entrevistas a profundidad personales a conveniencia a padres y expertos.

\section{Tabla 20.Estructura Distribución Muestral}

\begin{tabular}{|c|c|c|c|c|c|}
\hline & $\begin{array}{l}\text { Característica } \\
1\end{array}$ & $\begin{array}{l}\text { Característica } \\
2\end{array}$ & $\begin{array}{l}\text { Característica } \\
3\end{array}$ & $\begin{array}{l}\text { Característica } \\
4\end{array}$ & $\begin{array}{l}\text { Característica } \\
5\end{array}$ \\
\hline \multirow{5}{*}{$\begin{array}{l}\text { Entrevista a } \\
\text { profundidad }\end{array}$} & $\begin{array}{l}\text { Padres con } \\
\text { hijos }\end{array}$ & 25 a 45 años & $\begin{array}{l}\text { Hijos de } 0 \text { a } \\
12 \text { años }\end{array}$ & $\mathrm{A}, \mathrm{B}, \mathrm{C}+$ & Ate \\
\hline & $\begin{array}{l}\text { Padres con } \\
\text { hijos }\end{array}$ & 25 a 45 años & $\begin{array}{l}\text { Hijos de } 0 \text { a } \\
12 \text { años }\end{array}$ & $\mathrm{A}, \mathrm{B}, \mathrm{C}+$ & Santa Anita \\
\hline & $\begin{array}{l}\text { Padres con } \\
\text { hijos }\end{array}$ & 25 a 45 años & $\begin{array}{l}\text { Hijos de } 0 \text { a } \\
12 \text { años }\end{array}$ & $\mathrm{A}, \mathrm{B}, \mathrm{C}+$ & Lurigancho \\
\hline & $\begin{array}{l}\text { Padres con } \\
\text { hijos }\end{array}$ & 25 a 45 años & $\begin{array}{l}\text { Hijos de } 0 \text { a } \\
12 \text { años }\end{array}$ & $\mathrm{A}, \mathrm{B}, \mathrm{C}+$ & Chaclacayo \\
\hline & $\begin{array}{l}\text { Madres } \\
\text { gestantes }\end{array}$ & 25 a 45 años & N.A. & $\mathrm{A}, \mathrm{B}, \mathrm{C}+$ & $\begin{array}{l}\text { Ate, Santa } \\
\text { Anita, } \\
\text { Lurigancho y } \\
\text { Chaclacayo }\end{array}$ \\
\hline \multirow{3}{*}{$\begin{array}{l}\text { Entrevistas } \\
\text { a Expertos }\end{array}$} & \multicolumn{5}{|l|}{ Odontólogos } \\
\hline & \multicolumn{5}{|l|}{ Relacionados } \\
\hline & \multicolumn{5}{|l|}{ Director } \\
\hline
\end{tabular}


Se realizaron las entrevistas a profundidad a las siguientes personas:

1. Profesionales odontólogos (4):

a. Dra. Giselle Silva Román, de Multident - Santa Anita

b. Dra. Paola Sánchez Conde, de Multident - Ate

c. Dra. Danitza Mayca de Dental House Kids - Ate

d. Dr. César Huerta Munaya, de Multident - Ate

2. Profesional relacionado (2):

a. Rosa Maria Alvarez Rueda, profesora de Happy Days - Ate

b. Nilton Bedriñana, gerente de Agencia Mi Banco - Ate

3. Padres de familia (24):

a. Magaly Arquiñigo Castellano, mamá de niño de 2 años - Ate

b. Marina Hurtado Gómez, mamá de bebé de 9 meses - Ate

c. Victoria Delgado Marín, mamá de niños de 3 y 10 años - Ate

d. Carlos Chirinos, papá de Raimundo de 10 años - Ate

e. Maribel Llatas, mamá de Diego Vásquez de 12 años - Ate

f. Vannesa Rouillón, mamá de Milagros de 9 años - Ate

g. Maria Luisa, mama de niño de 12 años - Ate

h. Jenny Salina, mamá de 2 niños de 6 y 8 años - Ate 
i. Pilar Vasquez, mamá de niño de 1 año - Santa Anita

j. Karen Astocondor, mamá de niño de 6 años - Santa Anita

k. Guisela Aguilera, mamá de niño de 10 años - Santa Anita

1. Janet Maguiña, mama niño de 5 años - Santa Anita

m. Giuliana Cordova, mama niña de 5 años - Santa Anita

n. Paola Illara, mama niño de 5 años - Santa Anita

o. Rosa Vigo, mamá de 1 niño de 10 años - Chaclacayo

p. Angela Campusano, mamá de niño de 6 años - Chaclacayo

q. Maribel Tapia, mamá de niña de 5 años - Chaclacayo

r. Nelly manchego, mama de niña de 5 años - Chaclacayo

s. Diana Mori, mama de niña de 6 años - Chaclacayo

t. Gisselle Carpio, mama de niña de 5 años - Chaclacayo

u. Mónica Tarco Salazar, mamá de niño de 1 año - Lurigancho

v. Karla Huilca, mamá de niña de 6 años - Lurigancho

w. Karina Fabian, mamá de niño de 6 años - Lurigancho

x. Blanca Joo, mamá de niña de 5 años - Lurigancho

y. Maria Zarate, mama niña de 5 años - Lurigancho

z. Patricia Dolorier, mama niño de 6 años - Lurigancho 
4. Madres Gestantes (6):
a. Carmen García - Ate
b. Sheila Altez Giraldo-Ate
c. Janet Huaman - Chaclacayo
d. Rosario Aguilar - Lurigancho
e. Ana Sanchez - Santa Anita
f. Giuliana Cardenas - Santa Anita

Las guías aplicadas en las entrevistas a profundidad a profesionales odontólogos, relacionados y padres de familia se encuentran detallados en los Anexos 5,6 y 7. A continuación se menciona los hallazgos más importantes:

\section{$\underline{\text { De los profesionales odontólogos }}$}

- Conclusión 1: El NSE no es un determinante, no se encuentran diferencias significativas en sus opiniones y tiene mayor influencia la preocupación y receptividad de los padres para seguir recomendaciones de doctores.

- Conclusión 2: Existe un escaso conocimiento de los padres sobre el cuidado de salud dental y buenos hábitos.

- Conclusión 3: Los padres más jóvenes son más receptivos a las indicaciones dadas por los especialistas, lo mismo que las madres gestantes. 
- Conclusión 4: Las edades más difíciles son hasta los 3 años, donde la mayoría de los niños va acompañado por ambos padres.

- Conclusión 5: El uso de cámara intraoral y materiales didácticos tiene un efecto positivo en los pacientes atendidos y aumenta la credibilidad de los padres.

- Conclusión 6: La marca Multident es considerada como una de las mejores en la zona de estudio, pero la de más alto precio.

$\underline{\text { De los profesionales relacionados }}$

- Conclusión 7: Los comportamientos de los niños están muy relacionados a la tecnología como celulares, tablets y playstation y la influencia de internet.

- Conclusión 8: Los niños en edad preescolar tienen mayor atención y participación de sus padres en cuanto a las actividades y reuniones que el colegio organiza.

- Conclusión 9: Los colegios se encuentran interesados en brindarles servicios adicionales para sus estudiantes que permitan mejorar su bienestar.

- Conclusión 10: Los padres de la zona buscan opciones de financiamiento cuando se trata de la salud de su familia para poder brindarles lo mejor.

$\underline{\text { De los padres de familia }}$ 
- Conclusión 11: Los padres desconocen los beneficios de un odontopediatra frente a un odontólogo general, sin embargo, considera muy importante que el profesional que atienda a sus hijos tenga paciencia, buen trato y no lo asuste.

- Conclusión 12: Los padres de la zona desconocen opciones en el mercado que les garantice confianza y calidad, declaran desconfiar de los consultorios que se ubican en la zona, indicando que son informales.

- Conclusión 13: Si pertenecen a un sistema EPS o un seguro de salud integral particular, en su mayoría no utilizan los servicios dentales de la red, sino buscan otras opciones. Indican que deben esperar un plazo prolongado por una cita, el tiempo de la cita es corta y no les explican detenidamente, los horarios no se acomodan.

- Conclusión 14: Sobre las propuestas de acceder a un programa de ahorro dental y a un plan preventivo sin caries, los padres mostraron mayor interés por la segunda opción por ser de uso casi inmediato, a diferencia de la primera opción donde encontraron mayores ventajas los padres con hijos entre 10 y 12 años o que previamente sus hijos han tenido diversos tratamientos.

- Conclusión 15: Ante la propuesta del Odontologo Delivery, manifestaron que prefieren una atención definitiva realizada en la misma clínica, especialmente los padres con niños pequeños, ello ante la posibilidad de presentarse una emergencia o inconveniente en la atención en casa. 
- Conclusión 16: Las propuestas Multilandia para niños y el mejor aliado para la salud de tus hijos genero gran acogida y expectativa, indicaron no encontrar ninguna clínica con esas características en la zona que les otorgue un área apropiada para el entretenimiento de acuerdo con la edad, resaltaron la importancia de que la clínica se preocupe por recordarles los próximos controles y haga seguimiento a la salud de sus hijos.

- Conclusión 17: Los pacientes valoran y se interesan por el posttratamiento o seguimiento del tratamiento. 


\subsection{Método de investigación Cuantitativo}

Para la investigación cuantitativa usamos un muestreo no probabilístico, por conveniencia y selección de entrevistados a juicio del investigador. Elaboramos un cuestionario en formato físico.

Tiene el siguiente criterio de segmentación:

- La población que está a los alrededores de los colegios, nidos y centros de salud ubicados en los distritos de Ate, Santa Anita, Chaclacayo y Lurigancho. Esto constituyó una estratificación por defecto.

El Muestreo por conveniencia se caracteriza "por un esfuerzo deliberado de obtener muestras representativas mediante la inclusión en la muestra de grupos supuestamente típicos. Es frecuente el utilizar como muestra los individuos a los que se tiene fácil acceso". Tipos de Muestreo, Jordi Casal, Enric Mateu. Rev. Epidem. Med. Prev. (2003), 1.

En este caso nuestro procedimiento de muestreo al ser No probabilístico depende fuertemente del tamaño de muestra, el que fue calculado a través de la fórmula de tamaño de muestra para población finita, por tratarse de una población menor a 100,000 elementos.

Se realizó una prueba piloto con las 20 primeras encuestas para determinar el grado de aceptación o rechazo de la pregunta filtro que es la número 19 del cuestionario y se refiere al grado de familiaridad con Multident. Como resultado de la prueba obtuvimos los valores para $\mathrm{p}=90 \%$ y $\mathrm{q}=10 \%$. 


\section{Definición del Target.}

Hemos seleccionado las siguientes variables para definir el target:

Filtro:

- Padres con hijos hasta 12 años.

- Edad de los padres entre 25 y 45 años.

- NSE: A, B, C+

- Lugar donde viven: Ate, Santa Anita, Lurigancho, Chaclacayo

Para la determinación de la población, hemos considerado a los padres que tienen hijos entre 0 y 12 años, viven en de Ate y Santa Anita y en el caso de los distritos aledaños como Lurigancho y Chaclacayo, hemos considerado por cercanía y afluencia de vías principales como la Carretera Central, es importante precisar que los distritos elegidos están unidos por esta vía y ambas sedes están a metros de esta.

Considerando lo mencionado, en las tablas 21 y 22 podemos apreciar que existen alrededor de 10,667 padres de 25 a 45 años con hijos de 0 a 12 años y 3,374 madres gestantes. 
Tabla 21. Índices Utilizados para el cálculo del Mercado Potencial

\begin{tabular}{|c|c|c|c|c|}
\hline & $\begin{array}{l}\text { Índices utilizados para el cálculo del Mercado } \\
\text { Potencial }\end{array}$ & NSE A & NSE B & NSE C + \\
\hline I & $\% \mathrm{NSE} \quad 1 /$ & $4.40 \%$ & $24.50 \%$ & $27.30 \%$ \\
\hline II & $\begin{array}{l}\text { \% Población Ate, Santa Anita, Chaclacayo, } \\
\text { Lurigancho 1/ }\end{array}$ & $2.20 \%$ & $7.10 \%$ & $11.30 \%$ \\
\hline III & $\begin{array}{l}\text { \% Niños de } 0 \text { a } 12 \text { años Ate, Santa Anita, } \\
\text { Chaclacayo, Lurigancho } 1 /\end{array}$ & $14.20 \%$ & $14.30 \%$ & $16.50 \%$ \\
\hline IV & $\begin{array}{l}\text { Número promedio de hijos por familia en zona } \\
\text { urbana de Lima } 2 /\end{array}$ & \multicolumn{3}{|c|}{2.30} \\
\hline $\mathrm{V}$ & $\begin{array}{l}\text { \% Población entre } 25 \text { y } 45 \text { años en Lima } \\
\text { metropolitana } 3 / 5 /\end{array}$ & \multicolumn{3}{|c|}{$30.7 \%$} \\
\hline VI & $\%$ Población mujeres entre 25 y 45 años $3 /$ & \multicolumn{3}{|c|}{$15.9 \%$} \\
\hline VII & \% Población gestantes esperados en Lima 4/ & \multicolumn{3}{|c|}{$0.7 \%$} \\
\hline
\end{tabular}

Elaboración Propia

Fuente:

1/ APEIM 2017: Data ENAHO 2016

2/ Encuesta Demográfica y de Salud familiar (Endes) 2016

3/ Market Report Nro 7 Agosto 2017 CPI - Compañía Peruana de Estudios de Mercado y Opinión Pública. Cuadro 10

4/ Boletines Especiales de Estimaciones y Proyecciones de Población Nro 17 al 20 INEI

5/ Población Total al 30 Junio por grupos quinquenales de edad, según departamento, provincia, distrito. INEI 
Tabla 22. Cálculo del Mercado Potencial

\begin{tabular}{|l|r|r|r|}
\hline \multicolumn{1}{|c|}{ Cálculo del Mercado Potencial } & \multicolumn{1}{c|}{$\mathbf{2 0 1 6}$} & \multicolumn{1}{c|}{$\mathbf{2 0 1 7}$} & \multicolumn{1}{c|}{$\mathbf{2 0 1 8}$} \\
\hline Población Lima Metropolitana 1/ & $10,012,437$ & $10,190,922$ & $10,347,422$ \\
\hline $\begin{array}{l}\text { Población Niños entre 0 y 12 años, NSE A, B, C+ de } \\
\text { Ate, Santa Anita, Chaclacayo, Lurigancho 2/ }\end{array}$ & 70,157 & 78,623 & 79,831 \\
\hline $\begin{array}{l}\text { Población familias (padres) con hijos entre 0 y 12 } \\
\text { años, NSE A, B, C+ de Ate, Santa Anita, Chaclacayo, } \\
\text { Lurigancho 3/ }\end{array}$ & 30,503 & 34,184 & 34,709 \\
\hline $\begin{array}{l}\text { Población familias (padres entre 25 y 45 años) con } \\
\text { hijos entre 0 y 12 años, NSE A, B, C+ de Ate, Santa } \\
\text { Anita, Chaclacayo, Lurigancho 4/ }\end{array}$ & & & 10,667 \\
\hline $\begin{array}{l}\text { Población gestantes entre 25 y 45 años, NSE A, B, } \\
\text { C+ de Ate, Santa Anita, Chaclacayo, Lurigancho 5/ }\end{array}$ & 3,265 & 3,323 & 3,374 \\
\hline
\end{tabular}

Elaboración Propia

Fuente:

1/ APEIM 2017: Data ENAHO 2016 proyectado al 2018

2/ Utiliza los índices I, II, III

3/ Utiliza el índice IV

4/ Utiliza el índice V

5/ Utiliza los índices VI y VII 
Se calculó el mercado potencial y la muestra según como se muestra en las tablas 23,24 y 25 .

Tabla 23.Mercado Potencial

\begin{tabular}{|l|r|}
\hline Población & $\begin{array}{c}\text { Cantidad de } \\
\text { personas }\end{array}$ \\
\hline $\begin{array}{l}\text { Familias (padres entre 25 y 45 años) con hijos } \\
\text { entre 0 y } 12 \text { años, NSE A, B, C+ de Ate, Santa } \\
\text { Anita, Chaclacayo, Lurigancho }\end{array}$ & 10,667 \\
\hline $\begin{array}{l}\text { Gestantes entre 25 y 45 años, NSE A, B, C+ } \\
\text { de Ate, Santa Anita, Chaclacayo, Lurigancho }\end{array}$ & 3,374 \\
\hline
\end{tabular}

Para una población finita con $\mathrm{N}$ conocido aplicamos lo siguiente:

$$
n=\frac{N \times Z_{a}^{2} \times p \times q}{d^{2} \times(N-1)+Z_{a}^{2} \times p \times q}
$$


Tabla 24. Muestra gestantes entre 25 y 45 años, NSE A, B, C+ de Ate, Santa Anita, Chaclacayo, Lurigancho

\begin{tabular}{|c|r|}
\hline Variables & Valores \\
\hline $\mathrm{N}$ & 3,374 \\
\hline $\mathrm{Z}$ & 1.96 \\
\hline $\mathrm{P}$ & 0.9 \\
\hline $\mathrm{Q}$ & 0.1 \\
\hline $\mathrm{D}$ & $5 \%$ \\
\hline Muestra & 133 \\
\hline
\end{tabular}

Tabla 25. Muestra Familias (padres entre 25 y 45 años) con hijos entre 0 y 12 años, NSE A, B, C+ de Ate, Santa Anita, Chaclacayo, Lurigancho

\begin{tabular}{|c|r|}
\hline Variables & Valores \\
\hline $\mathrm{N}$ & 10,667 \\
\hline $\mathrm{Z}$ & 1.96 \\
\hline $\mathrm{P}$ & 0.9 \\
\hline $\mathrm{Q}$ & 0.1 \\
\hline $\mathrm{D}$ & $5 \%$ \\
\hline Muestra & 137 \\
\hline
\end{tabular}


Se analizó 270 encuestas. La encuesta fue aplicada en la semana del 1 al 7 de octubre en los distritos antes mencionados según la distribución indicada en la tabla 26 y 27.

Tabla 26. Distribución de la muestra para madres gestantes

\begin{tabular}{|c|r|c|}
\hline & Muestra & $\%$ \\
\hline Ate & 73 & $55 \%$ \\
\hline Santa Anita & 28 & $21 \%$ \\
\hline Lurigancho & 26 & $19 \%$ \\
\hline Chaclacayo & 6 & $5 \%$ \\
\hline
\end{tabular}

Fuente: Market Report CPI Compañía de estudios de Mercado y Opinión Publica. Agosto 2017.

Tabla 27. Distribución de la muestra para padres con niños de 0 a 12 años

\begin{tabular}{|c|r|c|}
\hline & Muestra & $\%$ \\
\hline Ate & 77 & $56 \%$ \\
\hline Santa Anita & 28 & $20 \%$ \\
\hline Lurigancho & 27 & $20 \%$ \\
\hline Chaclacayo & 5 & $4 \%$ \\
\hline
\end{tabular}

Fuente: Market Report CPI Compañía de estudios de Mercado y Opinión Publica. Agosto 2017. 
El cuestionario se detalla en el Anexo 8 y se ha tomado en consideración lo siguiente:

- Las alternativas de respuesta múltiple se obtuvieron a partir de las opiniones vertidas durante la investigación cualitativa.

- Las preguntas de opción múltiple tienen un contenido sesgado (lo que no presenta la pregunta abierta) sin embargo, son las más fáciles de tabular e indicadas para un estudio cuantitativo con una muestra de tamaño regular.

- La redacción de nuestras preguntas de alternativa múltiple cumple con la regla metodológica de que son colectivamente exhaustivas y mutuamente excluyentes.

- A excepción de la pregunta 1 y 2, nuestras alternativas de respuesta múltiple recogen datos de carácter nominal razón por la cual fueron tabuladas con porcentajes como estadístico permisible (además de la moda), dado que solo se puede realizar un recuento de las ocurrencias y elecciones.

- A nivel de contenido, las preguntas dirigidas a los padres de familia (número 20 y 22) orientadas a si conocen o no las sedes de Ate/Santa Anita y aquella que indaga sobre la opinión del negocio, nos ayudan a explorar las soluciones del problema de investigación que buscamos resolver: ¿porque Multident no presenta un crecimiento sostenido? 


\subsection{Análisis del producto}

Como resultado de la investigación cualitativa y cuantitativa se detectó una aceptación del programa Multident Kids con las siguientes características:

"Plan de ahorro por S/.39.00" que consiste en incentivar el ahorro en los padres para utilizarlo en cualquier tratamiento odontológico en el momento necesario. La mayoría de los padres coincidieron que era un monto mensual manejable y se mostraron más interesados los que tenían hijos con edades entre 10 y 12 años o que ya habían recibido algún tratamiento.

"Multilandia para niños" es una propuesta aceptada por la totalidad de los padres para una forma de entretenimiento mientras esperan, siempre que consiga estándares de seguridad para ellos. Además, una observación interesante de ellos es que llevan a sus hijos “a donde más les llame la atención”. Las atracciones con mayor aceptación son: juegos didácticos, manualidades, juegos de mesa y una zona de lectura.

"El mejor aliado para la salud de tus hijos" es lo más valioso que encontraron los padres porque la mayoría tiene muchas actividades que le impiden estar al pendiente de cada control de sus hijos, y, por lo tanto, valoran tener un seguimiento constante y recordación de controles.

“Odontólogo delivery" fue una propuesta rechazada por la mayoría de los padres, sobre todo por aquellos con hijos pequeños ya que en caso de presentarse una emergencia o inconveniente prefieren que lo solucionen de manera inmediata y 
definitiva. Algunos mostraron un interés medio si es que la propuesta llega a cumplirse en el tiempo ofrecido y con la solución del problema odontológico.

"Plan Sin Caries" fue la propuesta mejor aceptada como se muestra en la figura 25 por la simplicidad y promesa ofrecida, debido a que incentiva una cultura preventiva de los padres hacia sus hijos desde pequeños que no sólo cuidará su salud, sino también su bolsillo.

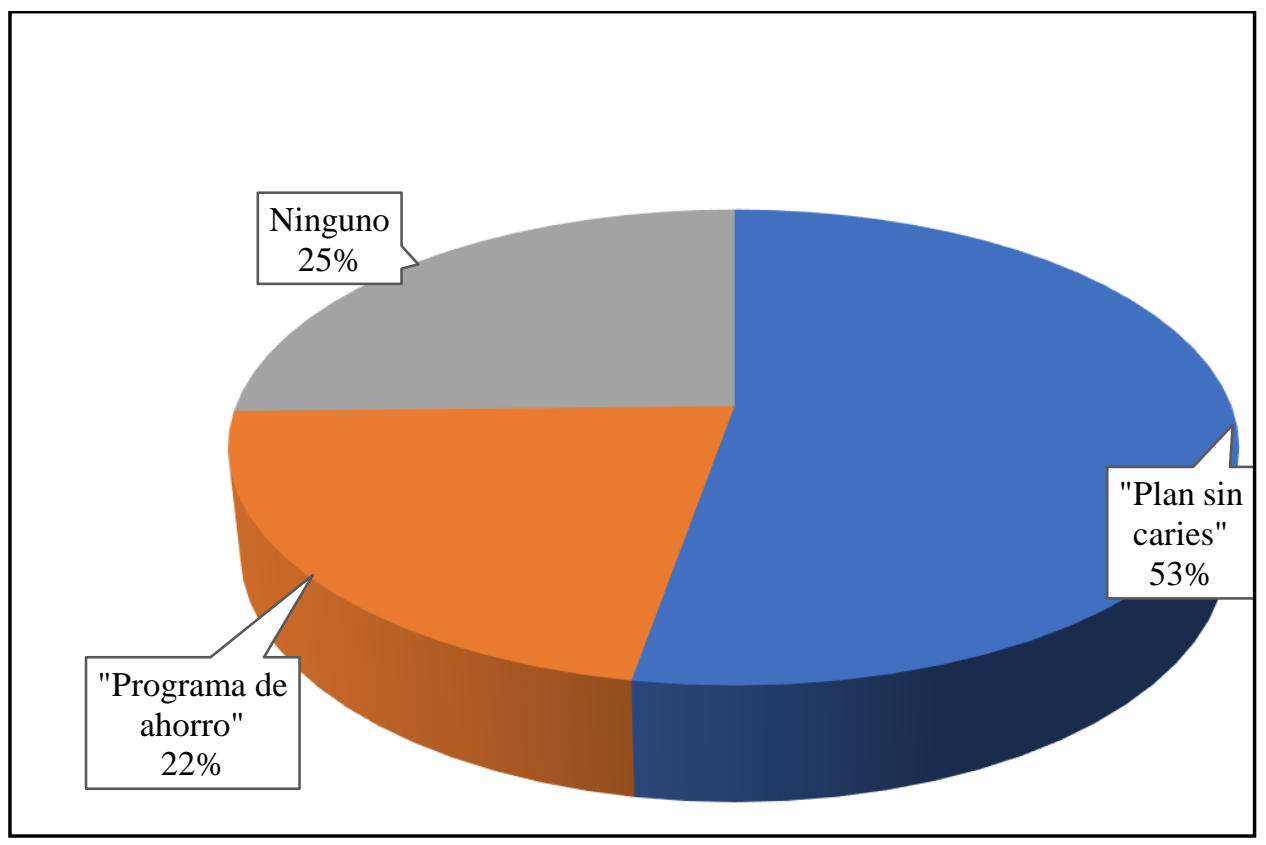

Figura 25. Preferencia de programas dentales para Multident Kids 
Las opciones preferidas de actividades en una sala de espera para niños se muestran según su clasificación por edades en las figuras 26, 27 y 28.

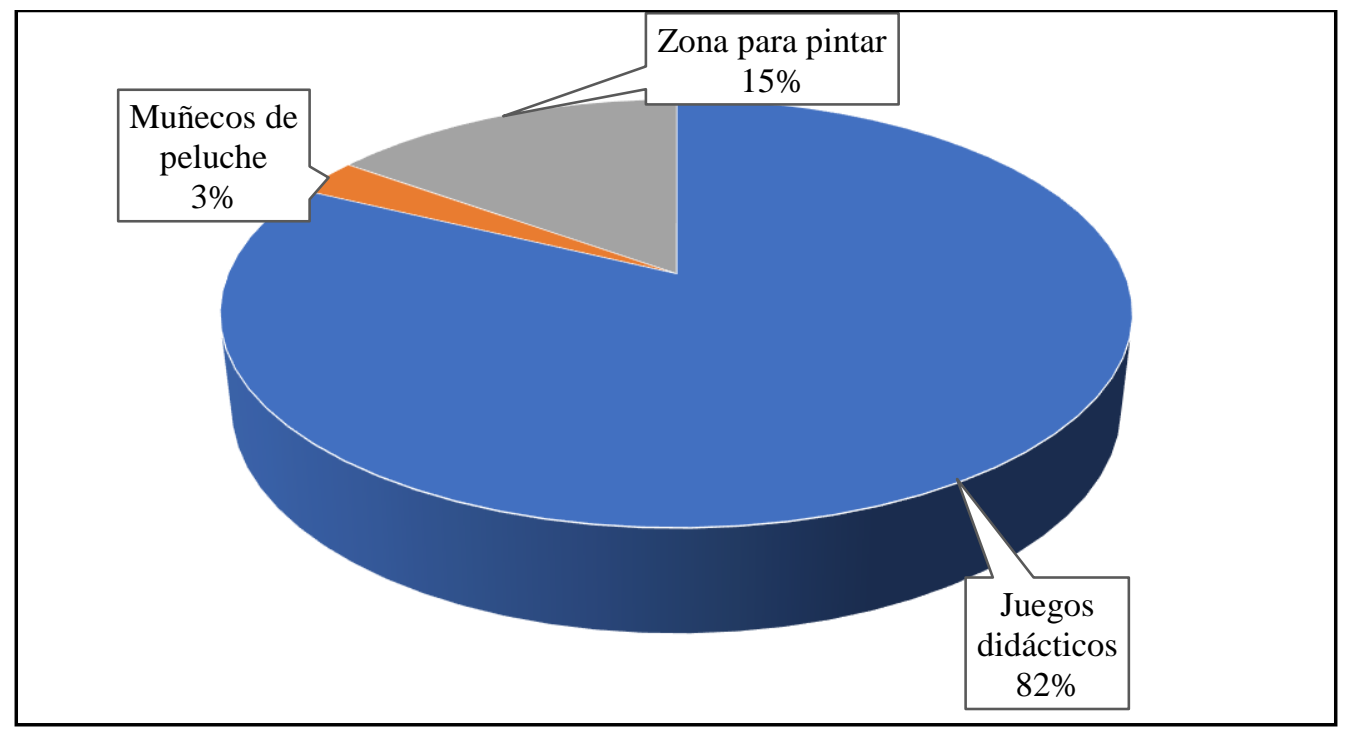

Figura 26. Preferencia para sala de espera para niños de 0-2 años

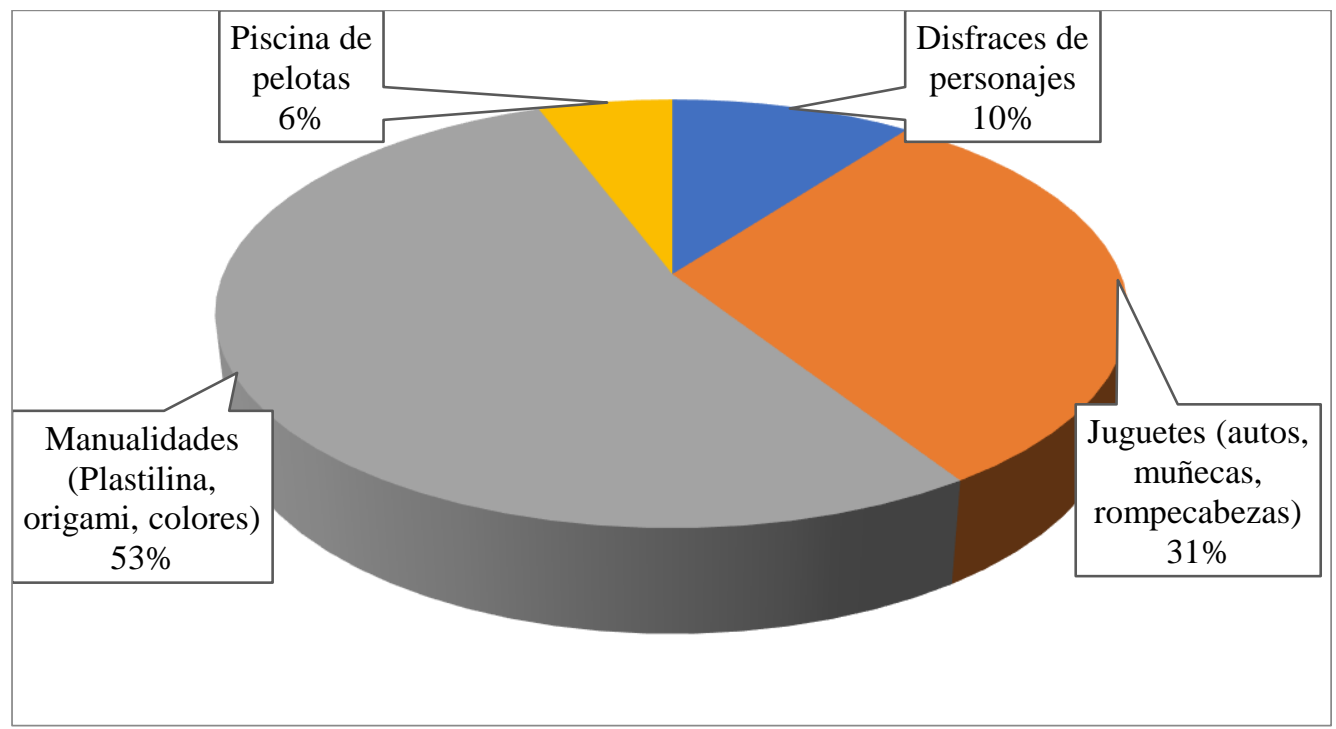


Figura 27. Preferencia para sala de espera para niños de 3-5 años

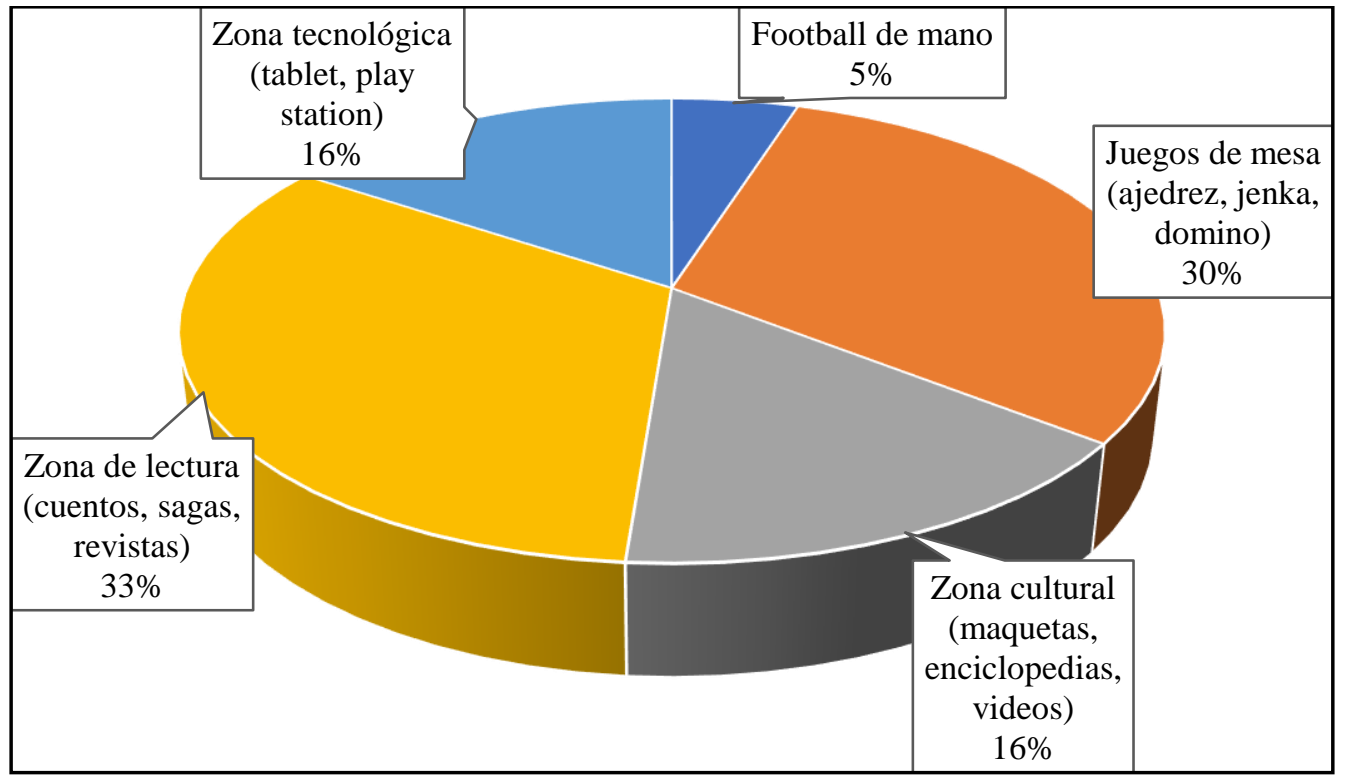

Figura 28. Preferencia para sala de espera para niños de 6-12 años 


\subsection{Tendencias del producto}

En general, los padres muestran un interés por un servicio odontológico con beneficios para sus hijos siempre que mantenga los mejores estándares de servicio y lo principal sea la mejor atención y trato del especialista. Además, encontramos que una característica importante en los padres es que no soportan ver a sus hijos llorar o en pánico, y en muchas ocasiones ha sido un determinante para no continuar con el servicio.

\subsubsection{Características del servicio}

El principal motivo para la descontinuación de tratamientos es el tiempo reflejado en los horarios disponibles en el mercado. Los horarios más solicitados son de lunes a viernes por las tardes, sábados y domingos como se muestra en la figura 29. Actualmente las sedes cuentan con los horarios más solicitados excepto los domingos.

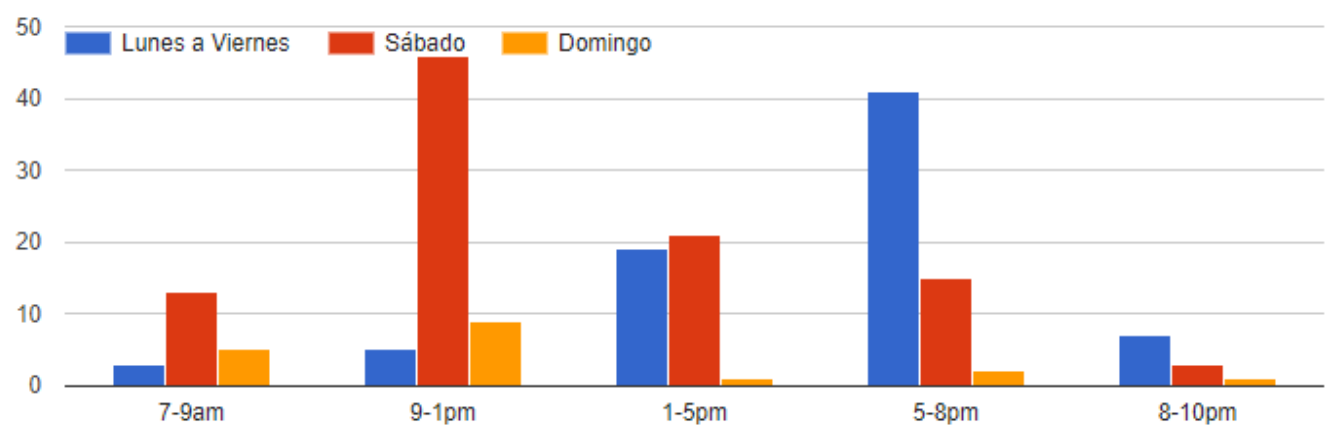

Figura 29. Preferencia sobre horarios de atención 
Una de las facilidades más valoradas por los encuestados es la del estacionamiento y valet parking; y el segundo el bazar o vitrina de productos dentales recomendados por los odontólogos como se muestra en la figura 30.

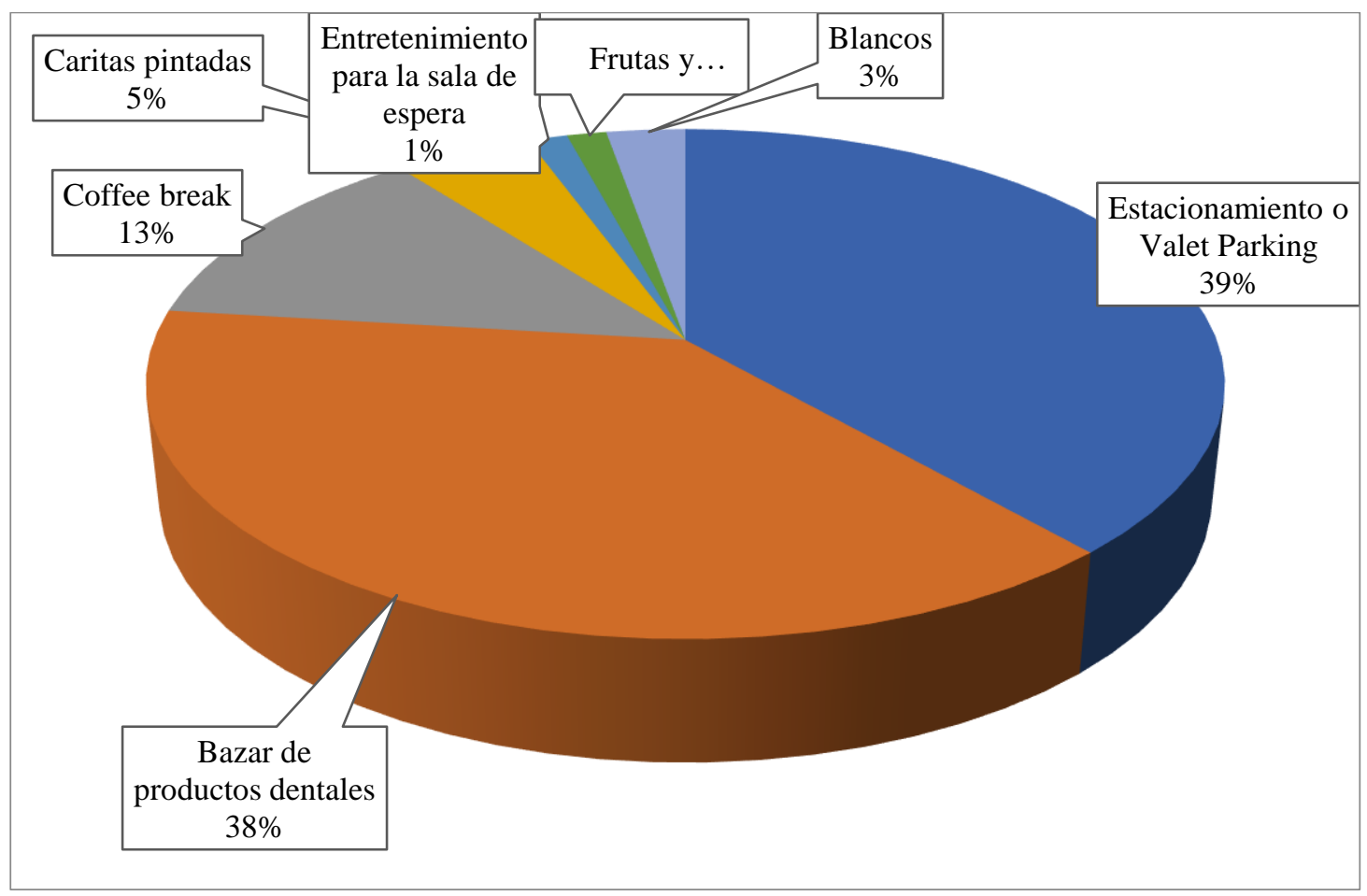

Figura 30. Preferencia de servicios adicionales esperados

Sobre la pregunta abierta para conocer la opinión que le inspira Multident a los padres, existen diversas características, entre los más destacados están la Confianza, Buenos dentistas y Calidad en los insumos. 


\subsection{Tendencias del Comportamiento del Consumidor}

Como resultado de la investigación exploratoria hemos identificado que la tendencia va hacia tratamientos sin dolor para los niños, los padres no soportan ver llorar a sus hijos o que se asusten. Adicionalmente se identifico que los atributos que más valoran los padres son los que se muestran en la figura 31:

- Recordación y seguimiento del tratamiento.

- Cercanía a casa o trabajo.

- Amplio horario de atención.

- Sala de entretenimiento y consultorio temático.

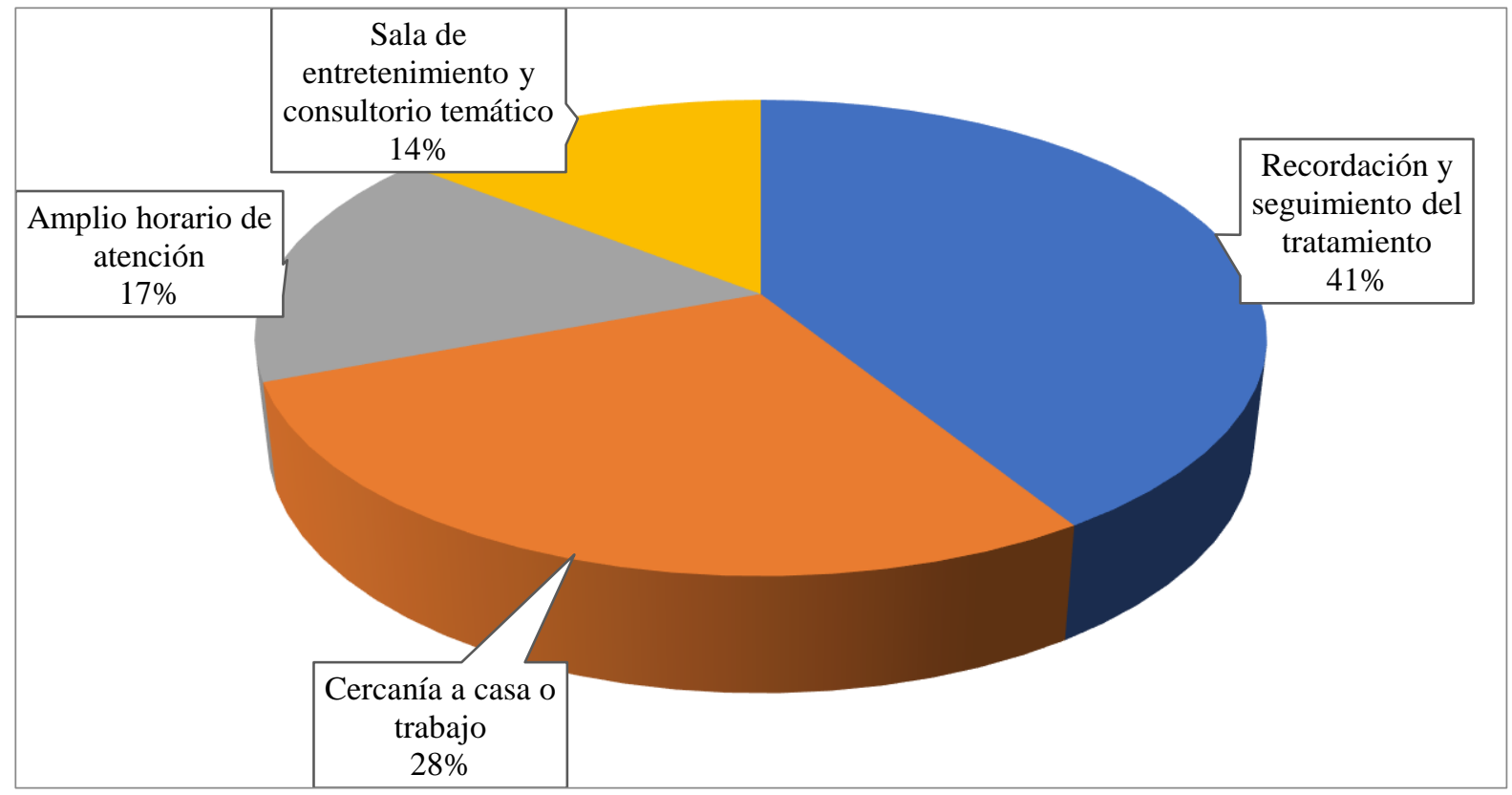

Figura 31.Aspectos valorados en un centro odontológico 
Los padres manifiestan que llevan a sus hijos principalmente por prevención y en su mayoría más de una vez al año como se muestra en la figura 32.

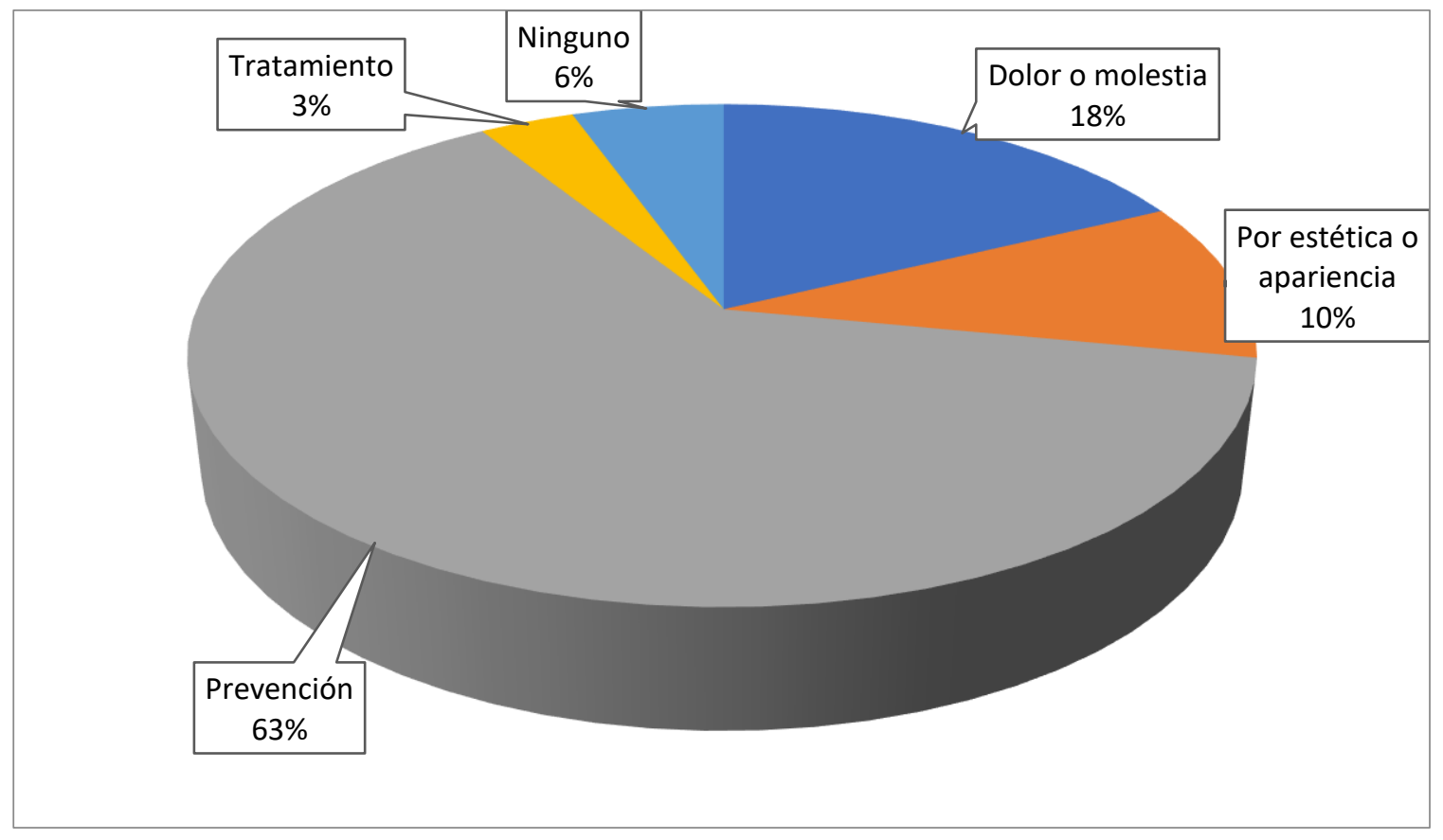

Figura 32. Motivo por el que llevó a su hijo a su última atención

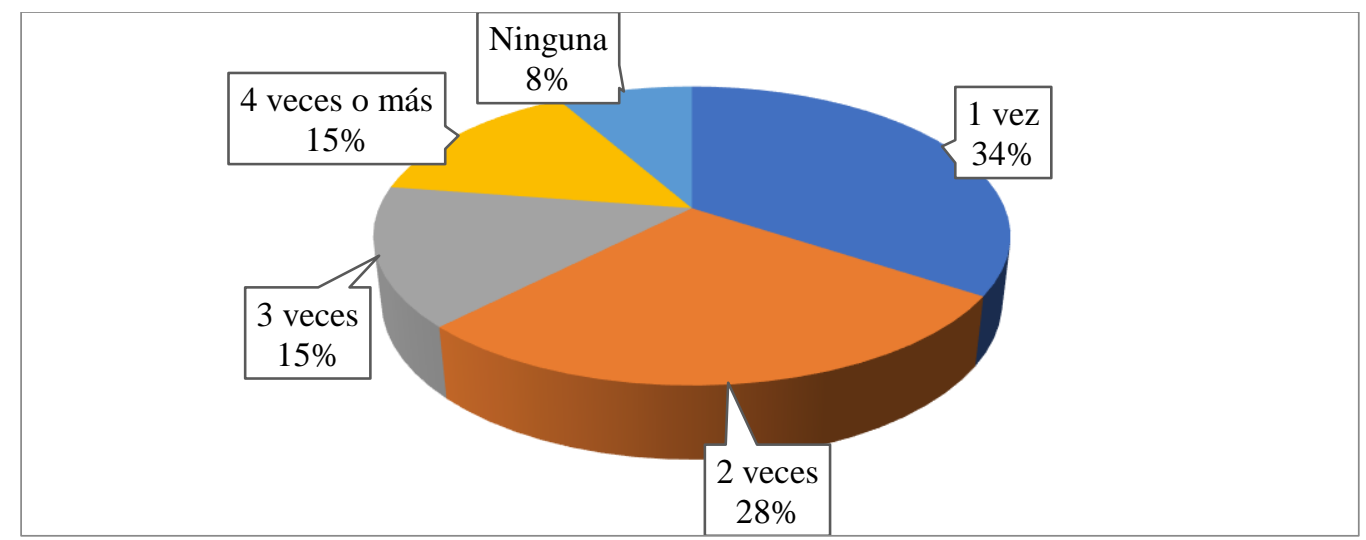

Figura 33. Cantidad de veces que llevó a su hijo al dentista en el último año 
La mayoría asiste a consultorios dentales particulares por recomendación de otras personas principalmente familiares y donde se atienden la mayor parte de la familia, el segundo factor importante es la cercanía del centro a su lugar de trabajo o domicilio como se muestra en la figura 34.

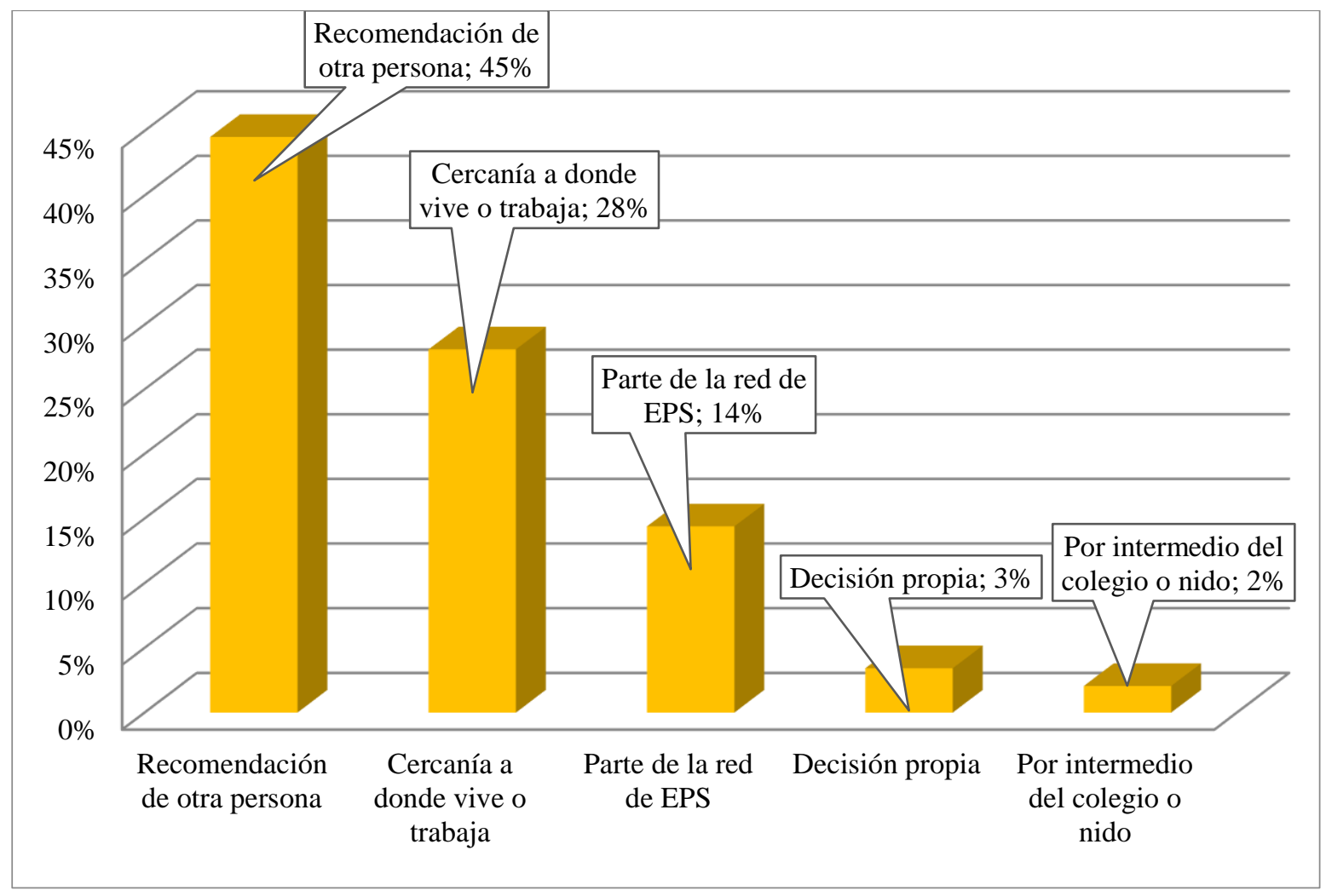

Figura 34. Motivo de elección del centro odontológico 
EL $80 \%$ de los encuestados prefiere una atención particular ya sea en consultorio o en una clínica como se muestra en la figura 35.

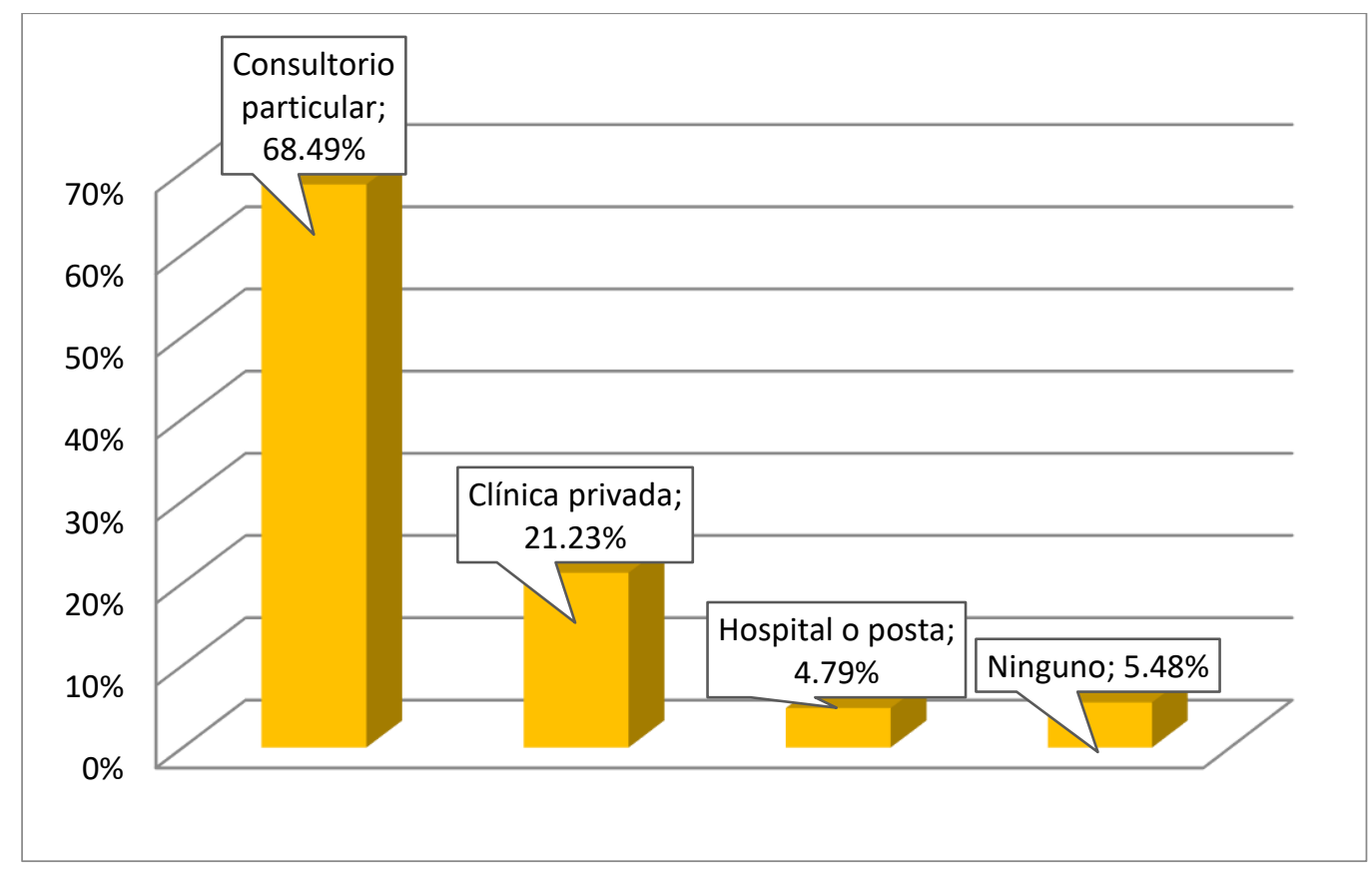

Figura 35.Lugar de la última atención dental

El $82 \%$ de los encuestados manifiesta que sus hijos concluyen sus tratamientos odontológicos y los dos factores más importantes por los que no concluyen el tratamiento son la falta de tiempo de los padres que representa el 35\% y la falta de seguimiento o recordación que representa el 38\%, los cuales, en conjunto, son más de la mitad de los motivos de abandono: $73 \%$ como se muestran en las figuras 36 y 37. 


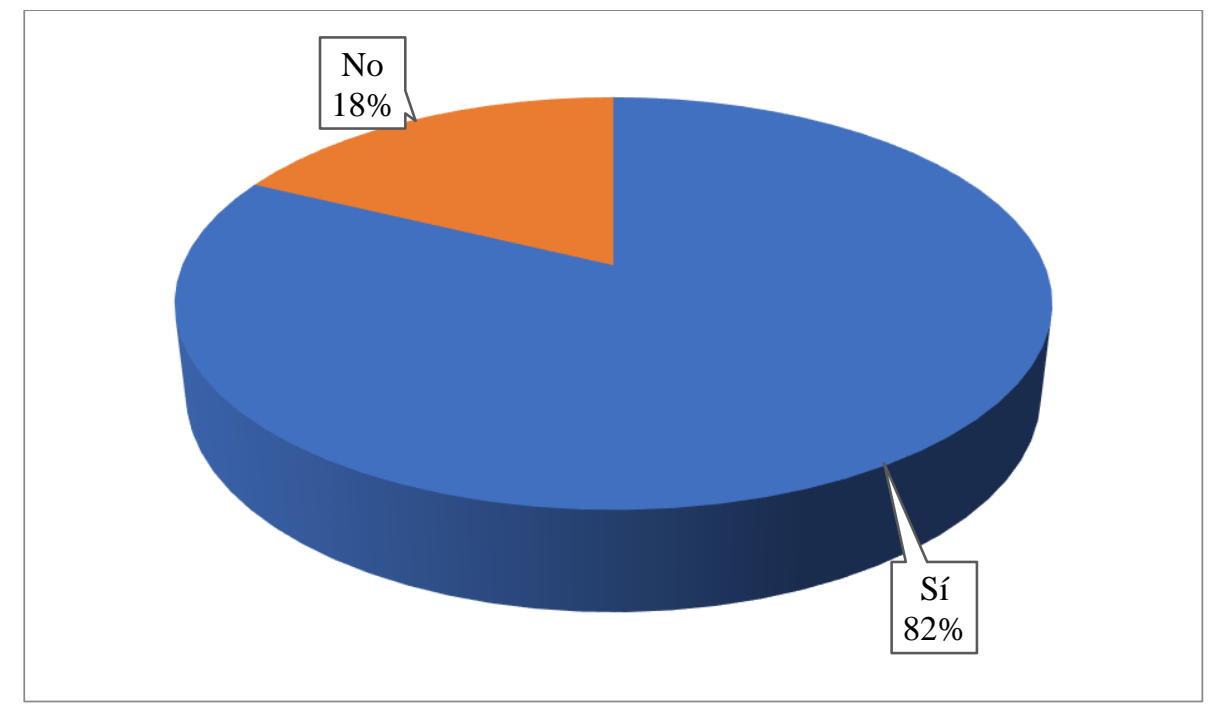

Figura 36. Padres cuyos hijos concluyen sus tratamientos

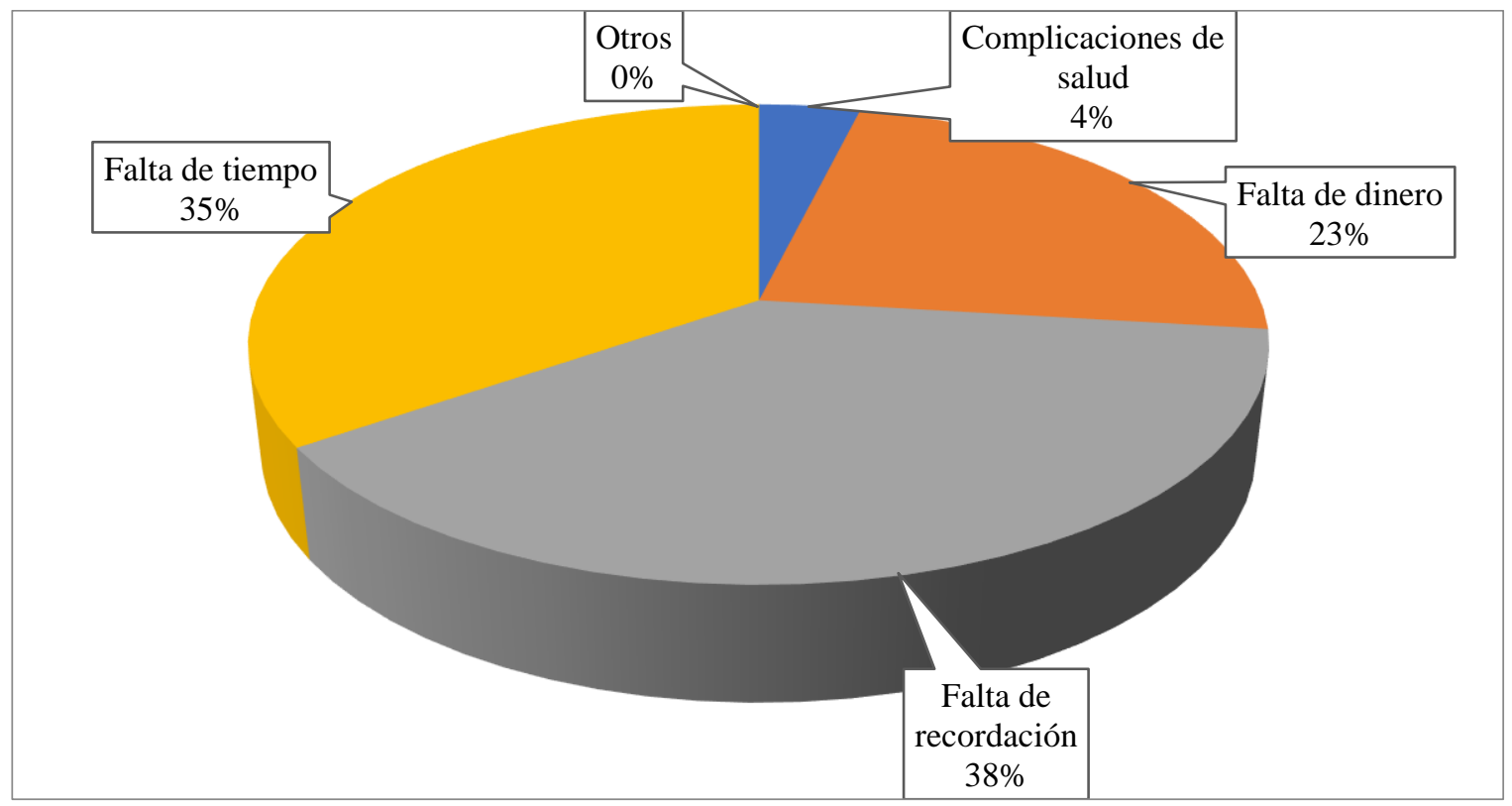

Figura 37. Motivos de abandono del tratamiento 


\subsection{Tendencia de medios, distribución, precio.}

El reconocimiento de la marca es del 82\%, sin embargo, sólo el $34 \%$ conoce que la Clínica tiene sedes en los distritos de Ate y Santa Anita como se muestran en las figuras 38 y 39, lo que demuestra un gran desconocimiento de la ubicación de las sedes, a pesar de estar ubicadas en avenidas principales.

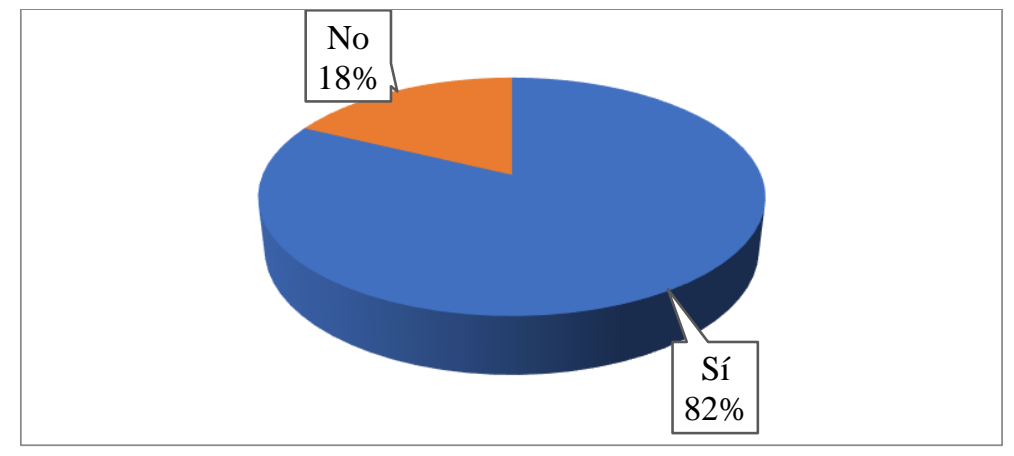

Figura 38.Recordación de la marca "Multident"

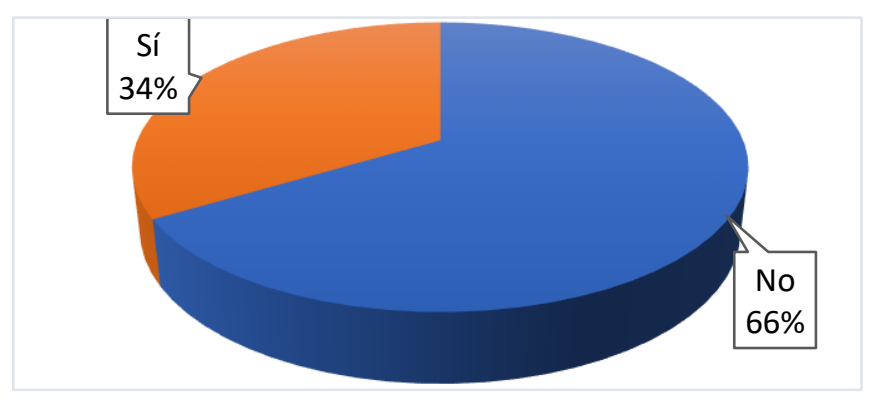

Figura 39. Reconocimiento de la marca "Multident" en Ate y Santa Anita 
Sin duda la mayoría de los padres prefiere la comunicación por WhatsApp y un porcentaje menor (21\%) por llamadas telefónicas como se muestra en la figura 40.

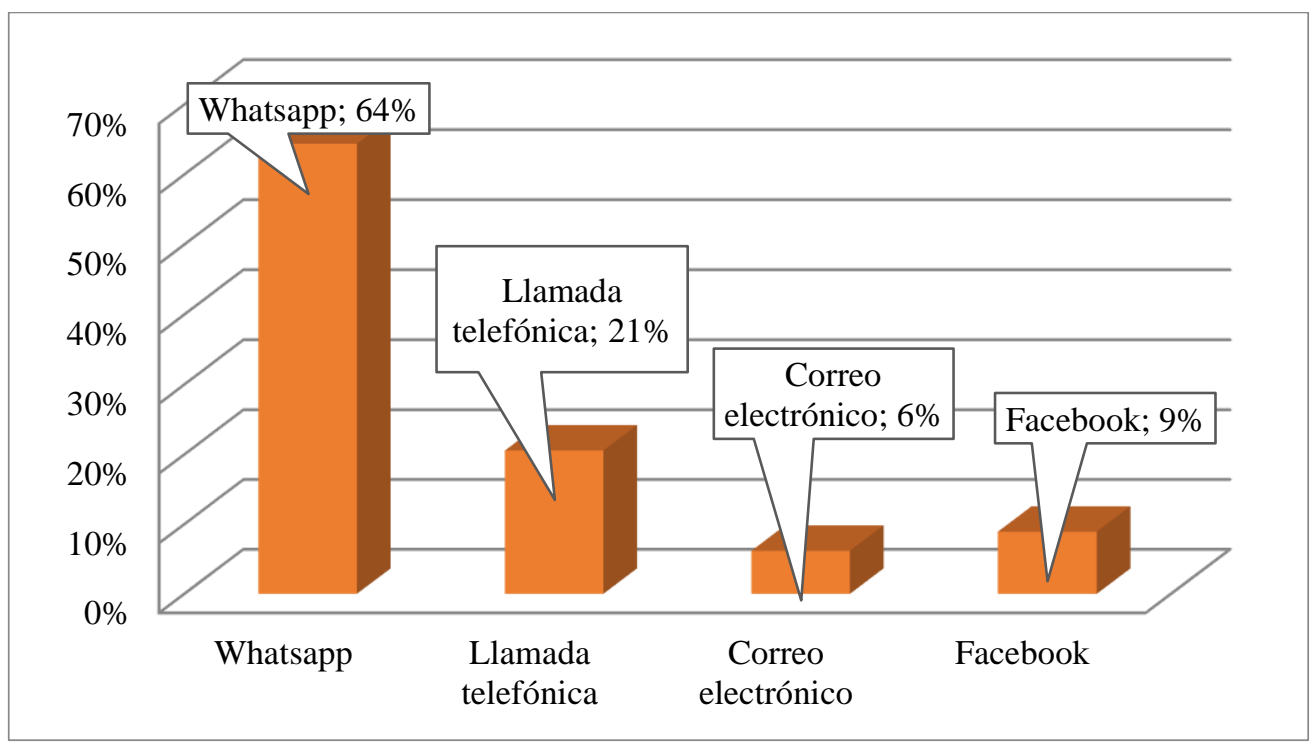

Figura 40. Medio preferido para mantener comunicación 
Las aceptaciones de los servicios propuestos incluían el componente precio y se observó el resultado como se muestra en la figura 41.

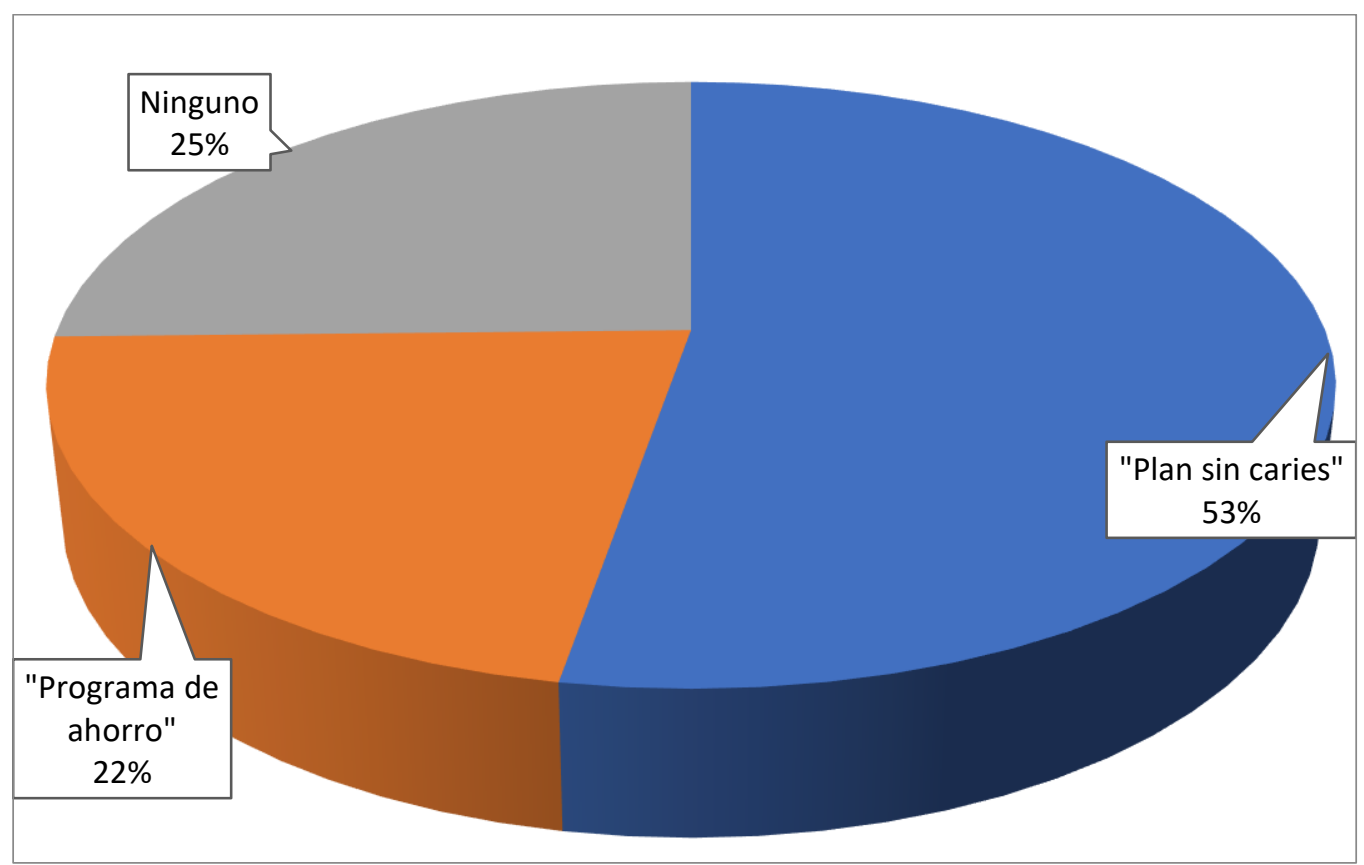

Figura 41. Preferencia sobre planes propuestos y sus características

\subsection{Segmentos del mercado que compran el producto}

Como resultado de las tendencias identificadas del análisis cualitativo y confirmadas con el estudio cuantitativo podemos concluir que los padres y madres gestantes entre 25 a 45 años son más receptivos a planes y programas continuos con la clínica, el $75 \%$ de estos acepta alguna de las dos propuestas y en relación con la edad de sus hijos están entre 3 y 12 años (65\%). 
Ellos han llevado una o dos veces a sus hijos a un dentista, lo hicieron de manera preventiva, su primera opción para la atención es un consultorio particular y por lo general, concluyen sus tratamientos.

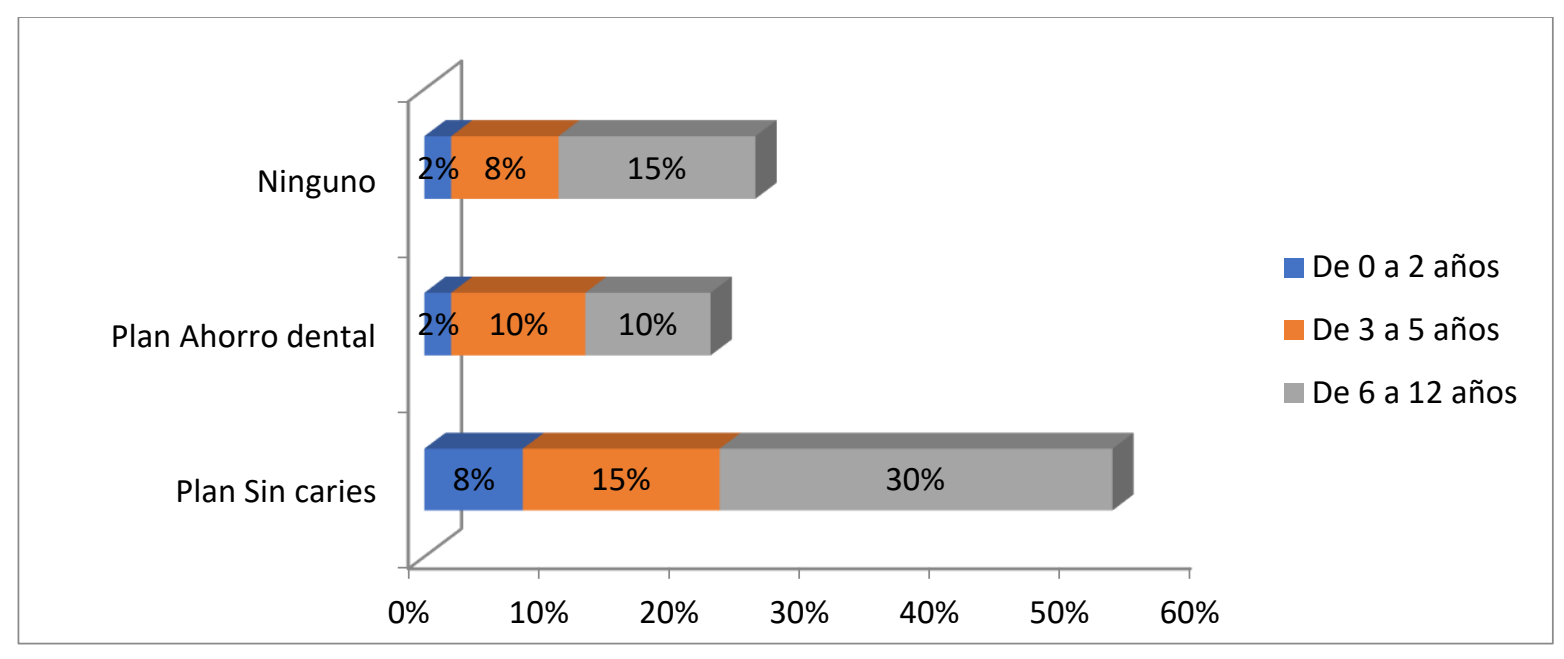

Figura 42. Edades de los padres en la aceptación de las propuestas 


\subsection{Análisis DAFO}

Como resultados del análisis macro y microentorno y el análisis interno tenemos identificadas las oportunidades, amenazas, fortalezas y debilidades que a través de la matriz DAFO nos permitirán determinar algunos lineamientos estratégicos.

\begin{tabular}{|c|c|}
\hline Oportunidades & Amenazas \\
\hline $\begin{array}{l}\text { 1. Zona altamente comercial con } \\
\text { presencia de pymes y trabajadores } \\
\text { independientes. } \\
\text { 2. El gasto promedio familiar en salud va } \\
\text { en incremento. } \\
\text { 3. Amplio campo educacional y atención } \\
\text { a gestantes en la zona con clientes } \\
\text { potenciales. } \\
\text { 4. Estilo de vida apresurado de los padres } \\
\text { requiere servicios con mayor } \\
\text { asistencia. } \\
\text { 5. Cliente potencial demanda más } \\
\text { opciones de horarios. } \\
\text { 6. Padres valoran altamente la paciencia } \\
\text { y buen trato, no soportan ver llorar a } \\
\text { sus hijos. } \\
\text { 7. Padres en busca de progreso, en su } \\
\text { mayoría hijos de inmigrantes que } \\
\text { demandan servicios diferenciados para } \\
\text { sus hijos, a los que ellos no pudieron } \\
\text { acceder. }\end{array}$ & $\begin{array}{l}\text { 1. Baja fiscalización genera alta } \\
\text { aglomeración de consultorios } \\
\text { dentales en zonas cercanas. } \\
\text { 2. Clínica La Merced con mayor } \\
\text { número de sucursales en la zona. } \\
\text { 3. Alta dependencia del proveedor más } \\
\text { importante: El odontopediatra. } \\
\text { 4. Desconocimiento de los beneficios } \\
\text { de un servicio especializado. }\end{array}$ \\
\hline
\end{tabular}




\begin{tabular}{|c|c|}
\hline Fortalezas & Debilidades \\
\hline $\begin{array}{l}\text { 1. Reconocimiento de la marca en el rubro de } \\
\text { salud dental. } \\
\text { 2. Staff de odontopediatras calificados y con } \\
\text { título de especialista validado por el } \\
\text { Colegio Odontológico del Perú. } \\
\text { 3. Uso de tecnología novedosa en la zona } \\
\text { (cámara intraoral y ultrasonido) que } \\
\text { aumenta la confianza y transparencia en los } \\
\text { padres. } \\
\text { 4. La duración de la cita se personaliza de } \\
\text { acuerdo con el comportamiento del } \\
\text { paciente y sus padres. } \\
\text { 5. Ubicación estratégica en avenidas } \\
\text { principales cercana a centros comerciales, } \\
\text { empresas y centros de trabajo/estudio. } \\
\text { 6. La empresa mantiene un buen clima } \\
\text { organizacional. }\end{array}$ & $\begin{array}{l}\text { 1. Falta de identificación de las sedes de Ate } \\
\text { y Santa Anita. } \\
\text { 2. Precios más elevados que la competencia. } \\
\text { 3. No está afiliada a una entidad prestadora } \\
\text { de servicio. (EPS) } \\
\text { 4. Incremento de ausentismo a las citas } \\
\text { debido el proceso de construcción de la } \\
\text { Línea } 2 \text { del Metro de Lima. } \\
\text { 5. Las campañas no están dirigidas al decisor } \\
\text { de la compra. } \\
\text { 6. Baja tasa de retorno de pacientes de un } \\
\text { año a otro } 23 \% \text {. }\end{array}$ \\
\hline
\end{tabular}




\subsubsection{DAFO Cruzado}

\begin{tabular}{|c|c|c|}
\hline & OPORTUNIDADES & AMENAZAS \\
\hline 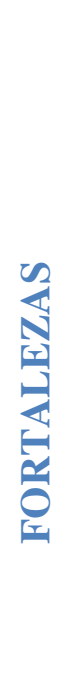 & $\begin{array}{l}\text { (F 2,3 - } 0 \text { 2,6) Añadir atributos al servicio } \\
\text { creando la experiencia Multident Kids. } \\
\text { (F } 1,2-0 \text { 3) Diversificar los canales de venta } \\
\text { con empresas que presentan el mismo público } \\
\text { objetivo en otros servicios relacionados. } \\
\text { (F } 1 \text { - O 1) ) Diversificar los canales de venta } \\
\text { con Pymes y trabajadores independientes. }\end{array}$ & $\begin{array}{l}\text { (F } 1 \text { - A 4) Potenciar la presencia en } \\
\text { medios digitales. } \\
\text { (F } 5 \text { - A 1) Promocionar las sedes con } \\
\text { publicidad convencional. } \\
\text { (F } 6 \text { - A 3) Desarrollar acciones para } \\
\text { mantener la satisfacción del cliente interno. }\end{array}$ \\
\hline
\end{tabular}




\begin{tabular}{|l|l|l|}
\hline \multicolumn{1}{|c|}{ OPORTUNIDADES } & AMENAZAS \\
(D 6 - O 4) Convertir la clínica en el mejor & \\
aliado de la salud de sus hijos. & (D 2 - A 1,2,4) Difundir los beneficios de los \\
(D 4 - O 5) Añadir atributos al servicio con & programas actuales. \\
más opciones en el horario. & \\
(D 5 - O 7) Difundir la preocupación por & \\
la salud dental de la comunidad como una & \\
cualidad de la marca. & \\
(D 1 - O 1) Promocionar las características &
\end{tabular}




\section{CAPÍTULO V}

\section{OBJETIVOS}

Presentaremos los objetivos estratégicos de la compañía, así como los objetivos de Marketing alineados con la misma.

En base a los resultados de la investigación de fuentes primarias y secundarias tanto cualitativas y cuantitativas que nos han brindado un análisis de Multident Kids, comportamiento del consumidor, el mercado y la competencia, variables fundamentales para diseñar el siguiente plan y darle a la Clínica las pautas y acciones que sugerimos desarrollar.

\subsection{Relación entre el Plan estratégico y el Plan de marketing}

Multident actualmente no cuenta con un plan estratégico establecido, pero sí tiene claro que su visión es ser el sistema de atención dental líder en el país con la más avanzada tecnología, en manos de un equipo integrado por odontólogos de primer nivel, técnicos y administrativos, comprometidos con el mejoramiento continuo en busca de un país que sonría sanamente.

Busca la expansión y creación de nuevos formatos en los próximos 5 años. Esencialmente, la marca pretende tener una presencia en todo el país con un total de 55 sedes.

Cada área y sede tiene objetivos independientes que no se relacionan entre sí; esta falta de integración de sus acciones ha generado que las ventas y el 
posicionamiento de su marca se debilite anualmente y que no aproveche las fortalezas que posee ni las oportunidades que se presentan en el mercado.

Consideramos que Multident Kids debe buscar la optimización de sus recursos y fortalezas con la finalidad de posicionar las sedes de Ate y Santa Anita como un servicio de confianza y diferenciado en la zona, y de esta manera incrementar sus ventas en concordancia el crecimiento de este mercado.

Considerando los siguientes criterios:

- Multident es un modelo de franquicias odontológicas, y estas pueden generar ganancias de hasta $500 \%$ de acuerdo a un artículo publicado en Gestión por el director de Clínicas Dentales Dr. Sonrisa ${ }^{9}$,

- La participación de mercado de las sedes de Ate y Santa Anita es del $22 \%$ y el gasto promedio anual en salud bucal por peruano es de 300 soles (Diario Gestión 2017) ${ }^{10}$ por lo que concluimos que el mercado potencial de Multident medido en valores supera 934,561 soles.

\section{$\underline{\text { Escenario Pesimista - Formulación de Objetivo }}$}

\begin{tabular}{|l|r|r|r|r|}
\cline { 2 - 5 } \multicolumn{1}{c|}{} & $\begin{array}{c}\text { Participacion } \\
\text { de Mercado }\end{array}$ & \begin{tabular}{c} 
Pacientes del \\
Mercado Meta \\
\multicolumn{1}{c|}{}
\end{tabular} & $\begin{array}{c}\text { Gasto Bucal } \\
\text { promedio } \\
\text { Anual }\end{array}$ & Valor de mercado \\
\hline Actual & $22 \%$ & 3,115 & 240 & 747,649 \\
\hline Propuesto & $27 \%$ & 3,823 & 240 & 917,569 \\
\hline
\end{tabular}

${ }^{9}$ Publicación Diario Gestión, Clínicas odontológicas apuntan a franquicias: genera ganancias de hasta $500 \%$. Febrero 2017.

${ }^{10}$ Publicación Diario Gestión, Clínicas odontológicas apuntan a franquicias: genera ganancias de hasta $500 \%$. Febrero 2017.

Publicación Diario Gestión 31 Enero 2017. Salud dental: ¿Cuánto gastan los peruanos cada año en su salud bucal? 
(*) Mercado Meta explicado en el capítulo VI

Escenario Medio - Formulación de Objetivo

\begin{tabular}{|l|r|r|r|r|}
\cline { 2 - 5 } \multicolumn{1}{c|}{} & $\begin{array}{c}\text { Participacion } \\
\text { de Mercado }\end{array}$ & $\begin{array}{c}\text { Pacientes del } \\
\text { Mercado Meta } \\
(*)\end{array}$ & $\begin{array}{c}\text { Gasto Bucal } \\
\text { promedio } \\
\text { Anual }\end{array}$ & Valor de mercado \\
\hline Actual & $22 \%$ & 3,115 & 300 & 934,561 \\
\hline Propuesto & $27 \%$ & 3,823 & 300 & $1,146,962$ \\
\hline
\end{tabular}

(*) Mercado Meta explicado en el capítulo VI

Escenario Optimista - Formulación de Objetivo

\begin{tabular}{|l|r|r|r|r|}
\cline { 2 - 5 } \multicolumn{1}{c|}{} & $\begin{array}{c}\text { Participacion } \\
\text { de Mercado }\end{array}$ & $\begin{array}{c}\text { Pacientes del } \\
\text { Mercado Meta } \\
(*)\end{array}$ & $\begin{array}{c}\text { Gasto Bucal } \\
\text { promedio } \\
\text { Anual }\end{array}$ & Valor de mercado \\
\hline Actual & $22 \%$ & 3,115 & 300 & 934,561 \\
\hline Propuesto & $30 \%$ & 4,248 & 300 & $1,274,402$ \\
\hline
\end{tabular}

(*) Mercado Meta explicado en el capítulo VI 
En base a ello hemos planteado el siguiente objetivo estratégico para Multident Kids para el periodo 2018.

- Incrementar la participación de mercado de $22 \%$ a $27 \%$ para el cierre del año 2018, manteniendo un margen de utilidad neta superior al 5\%.

\subsection{Formulación de Objetivos}

En concordancia con el objetivo estratégico, antes planteado, hemos desarrollado los siguientes objetivos de marketing al cierre del año 2018:

\subsubsection{Objetivos de Venta}

Incrementar la facturación del programa Multident Kids en $59 \%$ en el 2018.

\begin{tabular}{|l|c|c|c|}
\hline & $\mathbf{2 0 1 7}$ & $\mathbf{2 0 1 8}$ & Crecimiento \\
\hline Ventas Multident Kids & S/. 733,200 & S/. 1165,847 & $59 \%$ \\
\hline
\end{tabular}

\subsubsection{Objetivos de Margen}

Mantener el margen neto sobre las ventas como mínimo en $5 \%$ en el 2018.

\begin{tabular}{|l|c|c|}
\hline & $\mathbf{2 0 1 7}$ & $\mathbf{2 0 1 8}$ \\
\hline Margen Neto & $5 \%$ & $5 \%$ \\
\hline
\end{tabular}




\subsubsection{Objetivos Comerciales}

Incrementar en $25 \%$ la cantidad de pacientes que facturan y en $25 \%$ el gasto promedio de facturación anual para el año 2018

\begin{tabular}{|l|c|c|}
\hline & $\mathbf{2 0 1 7}$ & $\mathbf{2 0 1 8}$ \\
\hline Pacientes en tratamiento & 3,055 & 3,823 \\
\hline & $\mathbf{2 0 1 7}$ & $\mathbf{2 0 1 8}$ \\
\hline Gasto promedio anual & S/. 240 & S/. 300 \\
\hline
\end{tabular}

\subsubsection{Objetivos de Distribución}

Ampliar la cobertura de convenios con presencia en 3\% de las empresas ubicadas en los distritos de Ate, Santa Anita, Lurigancho y Chaclacayo para el 2018.

\begin{tabular}{|l|c|c|}
\hline & $\mathbf{2 0 1 7}$ & $\mathbf{2 0 1 8}$ \\
\hline Cantidad de Empresas en & & \\
convenio con la clínica & 22 & 74 \\
\hline
\end{tabular}




\subsubsection{Objetivos de Comunicación}

Aumentar la notoriedad de la marca en Ate y Santa Anita de 34\% a 50\% en el 2018.

\begin{tabular}{|l|c|c|}
\hline & $\mathbf{2 0 1 7}$ & $\mathbf{2 0 1 8}$ \\
\hline Notoriedad de marca & $34 \%$ & $50 \%$ \\
\hline
\end{tabular}




\section{CAPÍTULO VI}

\section{ESTRATEGIAS DE MARKETING}

Presentaremos las estrategias de marketing que han sido creadas con la finalidad de que los objetivos de la compañía se cumplan, estas estrategias están enfocadas en diferentes aspectos y divididas en macro estrategias y estrategias funcionales: producto, precio, distribución, ventas y comunicación.

\subsection{Seleccionar Mercado Objetivo}

\subsection{Mercado potencial}

Padres con hijos cuyas edades oscilan entre 0 y 12 años y madres gestantes que viven en Ate, Santa Anita, Lurigancho y Chaclacayo, por cercanía y afluencia de vías principales como la carretera Central y la definición del radio de acción para las sedes en estudio. Padres y madres gestantes que pertenecen a un nivel socioeconómico $\mathrm{A}, \mathrm{B}$ o $\mathrm{C}+$ entre las edades de 25 a 45 años. Este mercado representa alrededor de 14,041 consumidores. 


\subsection{Mercado disponible}

El mercado disponible se calcula en base al mercado potencial conformado por padres y madres gestantes que a la pregunta 4 del cuestionario

¿Donde se atendió por última vez?”, respondieron “una atención odontológica particular para sus hijos“ (89\%). Según APEIM 2017 el 76\% del NSE A,B,C de Lima metropolitana recibe una atención odontológica privada, no están afiliados a ningún sistema de salud o el sistema de Salud no satisface sus necesidades, por lo que tomaremos como valor a $83 \%$, promedio de $89 \%$ y $76 \%$ antes escritos. Este mercado representa a 11,584 consumidores.

\subsection{Mercado efectivo}

Calculado en base al mercado disponible, considerando que muestran su intención de afiliación a uno de los 2 programas dentales propuestos (pregunta 12 del cuestionario, con la consigna para el entrevistador de asociarlo verbalmente a Multident). En función de que estos programas son planes dentales para personas con predisposición a recurrir periódicamente a los tratamientos. Realizamos una tabulación cruzada en base a las preguntas 12 y 19 del cuestionario ¿Cuál de estos planes de salud dental elegirías? y ¿Ha escuchado sobre Multident?, el 62\% elige uno de los planes y ha escuchado sobre Multident. 


\begin{tabular}{|l|r|}
\hline Eligieron un plan & $75 \%$ \\
\hline $\begin{array}{l}\text { Han escuchado de } \\
\text { Multident }\end{array}$ & $82 \%$ \\
\hline & $62 \%$ \\
\hline
\end{tabular}

Este mercado efectivo representa a 7,124 consumidores.

\subsection{Mercado meta}

Considerando que actualmente Multident tiene una actual participación de mercado del $22 \%$ en la zona y tiene como objetivo un incremento del 5\% para obtener una participación del 27\% para el año 2018. La capacidad instalada de Multident permite sin limitación este crecimiento, por otro lado los planes de marketing que proponemos sustentan dicho incremento.

Este mercado meta representa el $27 \%$ del mercado efectivo y se compone de 1,461 padres y 462 madres gestantes. 


\section{Resumen del Cálculo de los Mercados}

\begin{tabular}{|c|c|c|c|c|c|}
\hline & Padres & Gestantes & Valor & $\%$ & \multicolumn{1}{c|}{ Descripción } \\
\hline $\begin{array}{c}\text { Mercado } \\
\text { Potencial }\end{array}$ & $10,667.22$ & $3,373.78$ & $14,041.00$ & & $\begin{array}{l}\text { Familias (padres entre 25 y 45 } \\
\text { años) con hijos entre 0 y 12 años o } \\
\text { gestantes entre 25 y 45 años, NSE } \\
\text { A, B, C+ de Ate, Santa Anita, } \\
\text { Chaclacayo, Lurigancho }\end{array}$ \\
\hline $\begin{array}{c}\text { Mercado } \\
\text { Disponible }\end{array}$ & $8,800.46$ & $2,783.37$ & $11,583.83$ & $83 \%$ & $\begin{array}{l}\text { Aplicación de \% promedio entre la } \\
\text { pregunta 4 (89\%) y el ratio } \\
\text { indicado en APEIM (76\%) }\end{array}$ \\
\hline $\begin{array}{c}\text { Mercado } \\
\text { Efectivo }\end{array}$ & $5,412.28$ & $1,711.77$ & $7,124.05$ & $62 \%$ & $\begin{array}{l}\text { Aplicación de tabulación cruzada } \\
\text { entre las preguntas 12 y 19 }\end{array}$ \\
\hline $\begin{array}{c}\text { Mercado } \\
\text { Meta }\end{array}$ & $1,461.32$ & 462.18 & $1,923.49$ & $27 \%$ & $\begin{array}{l}\text { 27\% de Participación de mercado } \\
\text { (incremento de 5\% ) }\end{array}$ \\
\hline
\end{tabular}

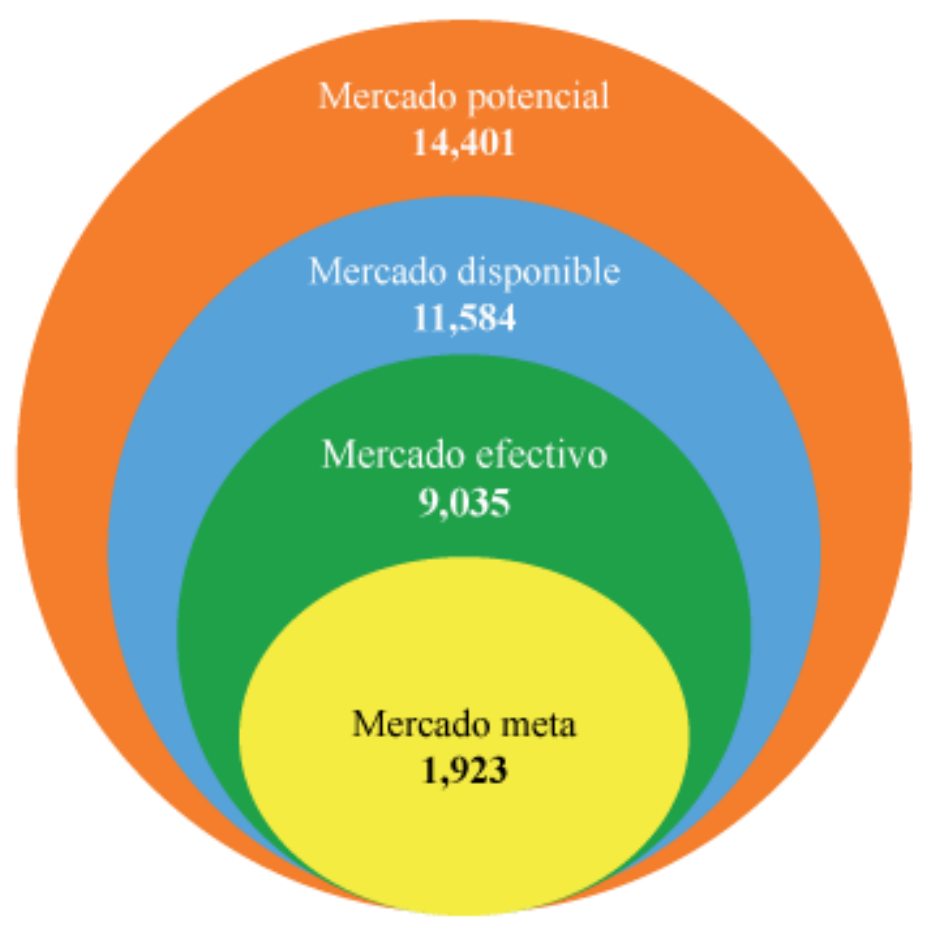

Figura 43. Selección de mercado meta 


\subsection{Estrategias Genéricas}

“Las estrategias genéricas están basadas en las ventajas competitivas presentadas por Porter" (Rivera y Garcillan Lopez Rua, 2012).

Proponemos que Multident aplique la estrategia de diferenciación basada en el “Servicio personalizado que construya y mantenga el vínculo paciente -clínica en el tiempo"

\begin{tabular}{|c|c|c|}
\hline \multirow{2}{*}{ Mercado } & Producto & Menor Precio \\
\hline & Diferenciado & \\
\hline Todo el sector & Diferenciación & Liderazgo en costos \\
\hline Un segmento & Enfoque en & Enfoque en costos \\
\hline & diferenciación & \\
\hline
\end{tabular}

Figura 44. Matriz estrategias genéricas de Porter 


\subsection{Estrategias de Cartera}

Analizamos los productos de Multident en odontopediatría utilizando la matriz BCG y la matriz de priorización de líneas de productos.

\section{Matriz BCG}

\begin{tabular}{|c|l|}
\hline Estrellas & Incógnitas \\
\hline Tratamientos Preventivos & Tratamientos Restaurativos \\
\hline Vacas Lecheras & Tratamientos de Conductos \\
\hline Tratamientos de & Tratamientos de Cirugía \\
\hline Rehabilitación oral & Tratamientos preventivos educativos \\
\hline
\end{tabular}

Figura 45. Matriz BCG 
Matriz de Priorización de Líneas de Productos

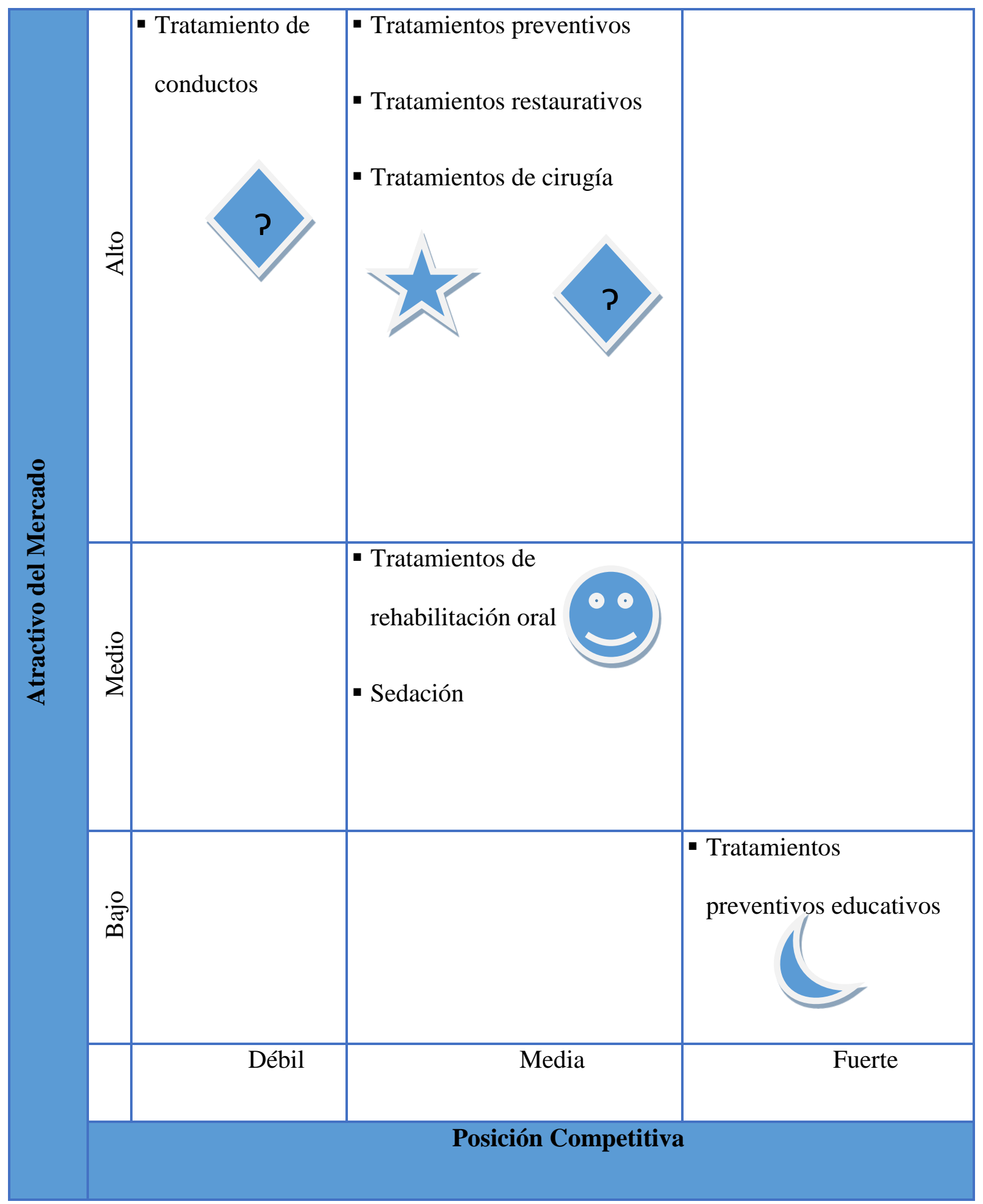

Figura 46. Matriz priorización Líneas de productos 
La estrategia de cartera que utilizaremos es de Penetración (EP): Mejorar el servicio de atención al paciente y sus padres para atraer los clientes de la competencia principalmente en tratamientos preventivos por calificarse como el producto estrella y tratamientos restaurativos. 


\subsection{Estrategias de Segmentación}

El público objetivo para Multident Kids son los niños de 0 a 12 años de las zonas de Santa Anita y Ate, sin embargo, al no ser los decisores finales de compra la segmentación propuesta se determinará con las características de sus padres según los segmentos definidos en la tabla 28:

Tabla 28. Estrategia de Segmentación

\begin{tabular}{|c|c|c|l|}
\hline Segmentos & Descripción & $\begin{array}{c}\text { Aspectos que } \\
\text { valoran }\end{array}$ & $\begin{array}{c}\text { Estrategia de } \\
\text { segmentación }\end{array}$ \\
\hline Madres gestantes & $\begin{array}{l}\text { Madres en etapa } \\
\text { de gestación }\end{array}$ & $\begin{array}{l}\text { - Información } \\
\text { - Facilidad de } \\
\text { acceso }\end{array}$ & $\begin{array}{l}\text { Segmento } \\
\text { estratégico }\end{array}$ \\
\hline $\begin{array}{l}\text { Padres con hijos } \\
\text { de primera edad }\end{array}$ & $\begin{array}{c}\text { Con niños de } \\
0 \text { años }\end{array}$ & $\begin{array}{l}\text {-Trato y } \\
\text { amabilidad } \\
\text {-Calidad del } \\
\text { servicio }\end{array}$ & $\begin{array}{l}\text { Segmento } \\
\text { estratégico }\end{array}$ \\
\hline $\begin{array}{l}\text { Padres con hijos } \\
\text { de segunda edad }\end{array}$ & 3 a 5 años niños de & $\begin{array}{c}\text { - Trato y } \\
\text { amabilidad } \\
\text { - Amplio } \\
\text { horario } \\
\text { - Proximidad }\end{array}$ & $\begin{array}{l}\text { Segmento } \\
\text { prioritario }\end{array}$ \\
\hline $\begin{array}{l}\text { Padres con hijos } \\
\text { de tercera edad }\end{array}$ & $\begin{array}{l}\text { Con niños de } 6 \text { a } \\
12 \text { años }\end{array}$ & $\begin{array}{l}\text { - Amplio horario } \\
\text {-Seguimiento } \\
\text { - Proximidad }\end{array}$ & $\begin{array}{l}\text { Segmento } \\
\text { estratégico } \\
\text { prioritario }\end{array}$ \\
\hline $\begin{array}{l}\text { Padres con } \\
\text { experiencia }\end{array}$ & $\begin{array}{l}\text { Con más de 1 } \\
\text { hijo }\end{array}$ & $\begin{array}{l}\text { - Amplio horario } \\
\text { - Seguimiento } \\
\text { - Precio y ofertas }\end{array}$ & $\begin{array}{l}\text { No es segmento } \\
\text { estratégico }\end{array}$ \\
\hline
\end{tabular}

Elaboración propia 
Las madres gestantes pertenecen a un segmento estratégico por ser más receptivas a todas las indicaciones de expertos en salud y buscan el bienestar de sus hijos desde la etapa de gestación. Además, presenta una gran posibilidad para que su futuro hijo pueda recibir en la clínica todos los tratamientos odontopediátricos que requiera.

Los padres con hijos de primera edad (entre 0 a 2 años) son un segmento estratégico porque son este tipo de padres que recepcionan bien todas las indicaciones y son más constantes en los controles de sus hijos, sin embargo, al ser niños pequeños no representa un porcentaje importante de facturación, pero sí la posibilidad de mantenerlos como pacientes desde temprana edad.

Los padres con hijos en la segunda edad (3-5 años) son un segmento interesante pues en esas edades se empiezan a presentar enfermedades y mal posiciones que pueden detectarse y tratarse desde niños para minimizar la complejidad de tratamientos a futuro y que siguen siendo rentables para la clínica.

Los padres con hijos en la tercera edad (6- 12 años) son un segmento estratégico prioritario ya que es en esta etapa donde se puede mantener probablemente una relación casi de por vida con el paciente determinando si continuará un tratamiento de ortodoncia que tiene una duración mínima de 1 año y medio. Y, los padres con experiencia, que por lo general cuentan con más de 1 hijo siguen siendo un segmento al que debe darse atención, pero no de manera prioritaria ya que son los que pasaron por alguna experiencia de salud odontológica y pueden ser menos receptivos a indicaciones de controles o tratamientos sugeridos. 


\subsection{Estrategias de Posicionamiento}

Posicionamiento de acuerdo al segmento:

Tabla 29. Estrategia de Posicionamiento

\begin{tabular}{|c|c|c|c|c|}
\hline $\begin{array}{l}\text { Estrategia de } \\
\text { segmentación }\end{array}$ & Segmentos & Descripción & $\begin{array}{l}\text { Aspectos que } \\
\text { valoran }\end{array}$ & $\begin{array}{ll}\text { Estrategia de } \\
\text { posicionamiento }\end{array}$ \\
\hline $\begin{array}{l}\text { Segmento } \\
\text { estratégico }\end{array}$ & $\begin{array}{l}\text { Madres } \\
\text { gestantes }\end{array}$ & $\begin{array}{l}\text { Madres en } \\
\text { etapa de } \\
\text { gestación }\end{array}$ & $\begin{array}{l}\text {-Sugerencias } \\
\text { puntuales } \\
\text {-Facilidad } \\
\text { acceso }\end{array}$ & $\begin{array}{l}\text { - Calidad de servicio } \\
\text { diferenciado } \\
\text { proximidad }\end{array}$ \\
\hline $\begin{array}{l}\text { Segmento } \\
\text { estratégico } \\
\text { prioritario }\end{array}$ & $\begin{array}{l}\text { Padres con hijos } \\
\text { de primera edad }\end{array}$ & $\begin{array}{l}\text { Con niños } \\
\text { de } 0 \text { a } 2 \text { años }\end{array}$ & $\begin{array}{l}\text {-Trato } \\
\text { amabilidad } \\
\text {-Calidad } \\
\text { servicio }\end{array}$ & $\begin{array}{l}\text {-Calidad de servicio } \\
\text { diferenciado, } \\
\text { confianza } \\
\text { proximidad. }\end{array}$ \\
\hline $\begin{array}{l}\text { Segmento } \\
\text { estratégico } \\
\text { prioritario }\end{array}$ & $\begin{array}{l}\text { Padres con hijos } \\
\text { de segunda edad }\end{array}$ & $\begin{array}{l}\text { Con niños } \\
\text { de } 3 \text { a } 5 \text { años }\end{array}$ & $\begin{array}{l}\text {-Trato y } \\
\text { amabilidad } \\
\text { - Amplio horario } \\
\text { - Proximidad }\end{array}$ & $\begin{array}{l}\text {-Calidad de servicio } \\
\text { diferenciado, } \\
\text { confianza } \\
\text { proximidad. }\end{array}$ \\
\hline $\begin{array}{l}\text { Segmento } \\
\text { estratégico }\end{array}$ & $\begin{array}{l}\text { Padres con hijos } \\
\text { de tercera edad }\end{array}$ & 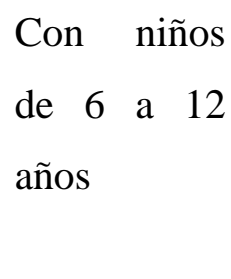 & $\begin{array}{l}\text { - Amplio horario } \\
\text {-Seguimiento } \\
\text { - Proximidad }\end{array}$ & $\begin{array}{l}\text {-Calidad de servicio } \\
\text { diferenciado, } \\
\text { confianza } \\
\text { proximidad. }\end{array}$ \\
\hline $\begin{array}{l}\text { Resto } \\
\text { segmentos }\end{array}$ & $\begin{array}{l}\text { Padres con } \\
\text { experiencia }\end{array}$ & $\begin{array}{l}\text { Con más de } \\
1 \text { hijo }\end{array}$ & $\begin{array}{l}\text { - Amplio horario } \\
\text { - Precio y ofertas }\end{array}$ & -Calidad de servicio \\
\hline
\end{tabular}

Elaboración propia 


\subsection{Estrategias de Fidelización}

"La gestión valor percibido trata de aumentar el valor de la compra realizada para el cliente" (Jose Maria Sainz de Vicuña Ancin, 2016).

A partir de los datos recogidos en las encuestas aplicadas, podremos analizar las necesidades, expectativas y deseos de los pacientes para interpretar la información y poder elegir la estrategia más adecuada que se muestra en las tablas 30 y 31 .

Tabla 30. Evaluación de calidad percibida

(Servicio adquirido + proceso de servicio)

\begin{tabular}{|c|c|c|c|c|c|}
\hline Atributos & Pond. & $\begin{array}{l}\text { Calificación } \\
\text { de Multident }\end{array}$ & $\begin{array}{l}\text { Calificación } \\
\text { Competidor }\end{array}$ & Ratio & $\begin{array}{l}\text { Ratio } \\
\text { ponderado }\end{array}$ \\
\hline Horarios flexibles & 15 & 5 & 6 & 0.83 & 12.50 \\
\hline Nivel profesional & 20 & 7 & 4 & 1.75 & 35.00 \\
\hline Infraestructura & 16 & 6 & 3 & 2.00 & 32.00 \\
\hline Ubicación & 10 & 4 & 5 & 0.80 & 8.00 \\
\hline Identificación en la zona & 16 & 3 & 5 & 0.60 & 9.60 \\
\hline Nivel de lealtad cliente & 10 & 4 & 4 & 1.00 & 10.00 \\
\hline $\begin{array}{l}\text { Comunicación } \\
\text { promoción }\end{array}$ & 13 & 3 & 2 & 1.50 & 19.50 \\
\hline Total & 100 & 32 & 29 & & 126.60 \\
\hline
\end{tabular}

Elaboración propia 
Tabla 31. Evaluación del coste/precio percibido

(Precio + otros costes)

\begin{tabular}{|l|c|c|c|c|c|}
\hline $\begin{array}{c}\text { Elementos de } \\
\text { costo para el } \\
\text { cliente }\end{array}$ & Ponderación & $\begin{array}{c}\text { Calificación } \\
\text { de Multident }\end{array}$ & $\begin{array}{c}\text { Calificación } \\
\text { del } \\
\text { Competidor }\end{array}$ & Ratio & $\begin{array}{c}\text { Ratio } \\
\text { ponderado }\end{array}$ \\
\hline Precio del servicio & 40 & 9 & 6 & 1.50 & 60.00 \\
\hline Forma de pago & 20 & 5 & 6 & 0.83 & 16.67 \\
\hline Descuentos /Ofertas & 30 & 8 & 4 & 2.00 & 60.00 \\
\hline $\begin{array}{l}\text { Desplazamiento } \\
\text { desde pto. } \\
\text { Domicilio }\end{array}$ & 10 & 4 & 2 & 2.00 & 20.00 \\
\hline \multicolumn{1}{|c|}{ Total } & $\mathbf{1 0 0}$ & $\mathbf{2 6}$ & $\mathbf{1 8}$ & & 156.67 \\
\hline
\end{tabular}

Elaboración propia

Ratio de calidad percibida por el mercado: $126.60 \%=1.26$

Ratio de coste percibido por el mercado: $156.67 \%=1.57$ 
La estrategia es incrementar beneficios y comunicarlos adecuadamente para que sean percibidos por el cliente según los resultados que muestran en la figura 48 .

MAPA DEL VALOR PARA EL CLIENTE

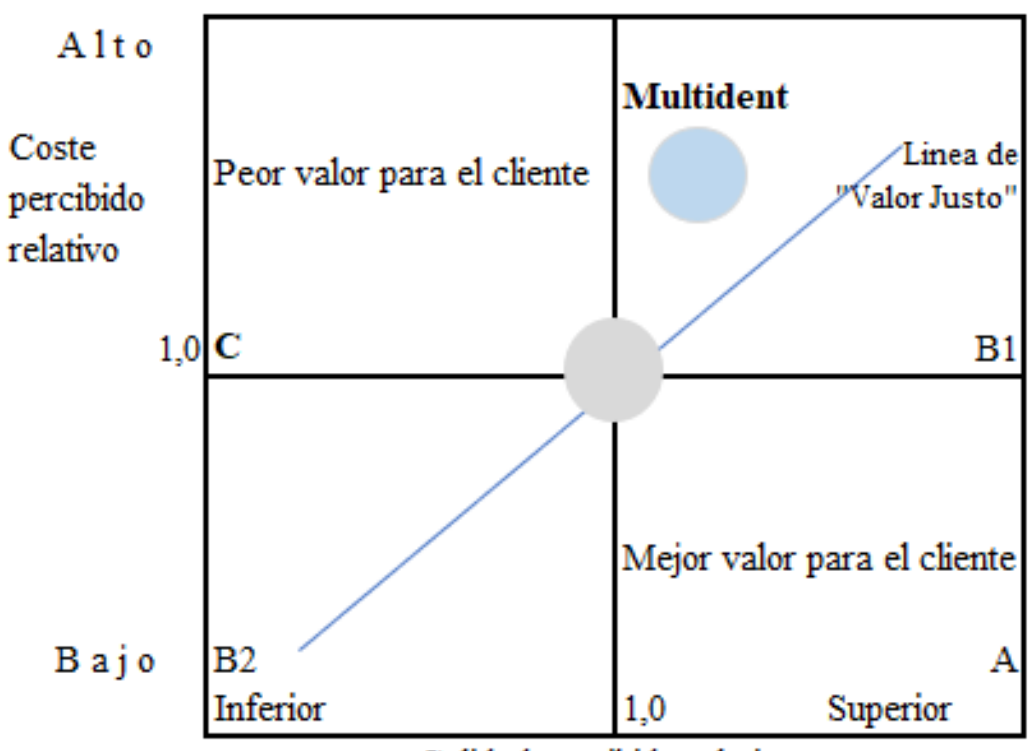

Calidad percibida relativa

Figura 47. Mapa del Valor para el Cliente 


\subsection{Estrategia de Posición de mercado (LRS)}

Según Philip Kotler, en la estrategia del líder del mercado, la empresa es un punto de orientación para los competidores a la cual desafiar, imitar o evitar, dirige a los demás en introducciones de nuevos productos e intensidad de la promoción.

Proponemos que Multident mantenga su estrategia de liderazgo en Confiabilidad debido al slogan de la marca "Su clínica dental de confianza", lo cual aunado a la cantidad de locales ( 35 a nivel nacional) y los 23 años de experiencia en el mercado, han reforzado la recordación en la variable "confianza". Por otro lado, en nuestra investigación exploratoria (entrevistas a profundidad), los padres manifestaron qué esperan de un centro odontológico:

a) Que sus hijos sean tratados con mucha paciencia

b) Sin dolor

c) Evitando que se asusten

Lo cual vuelve a recaer en la variable confianza pues de otra manera no entregarían a sus niños para el cuidado de su salud dental.

Esta es una ventaja competitiva difícil de replicar en el tiempo, a diferencia del precio y la tecnología. 


\subsection{Estrategias Funcionales}

\subsubsection{Estrategias de Producto}

Añadir atributos al servicio

a. Desarrollar la relación paciente - clínica como una experiencia sin dolor, confianza en los especialistas y divertida.

b. Ampliar las opciones en horarios, incluyendo los domingos.

c. Desarrollar la relación padres - clínica como el mejor aliado en el cuidado de la salud dental de sus hijos.

\subsubsection{Estrategias de Precios}

a. Potenciar "Multident Card" y sus beneficios de afiliación de la tarjeta de descuentos

\subsubsection{Estrategia de Distribución y Ventas}

\section{Diversificar los canales de venta con empresas}

a. Implementar el plan de tratamiento preventivo para los hijos de trabajadores de Pymes y trabajadores independientes, que viven en la zona.

b. Desarrollar alianzas con instituciones que presenten el mismo consumidor objetivo. 


\subsubsection{Estrategia de Comunicación}

Difundir las características y cualidades de la marca, creando confianza y servicio diferenciado en los segmentos estratégicos prioritarios.

Online

a. Generar contenido de interés para los padres a través de medios no convencionales.

Offline

b. Crear un programa educativo "Guerra a las caries" con difusión en Ate, Santa Anita, Lurigancho y Chaclacayo

c. Promocionar las sedes en centros estratégicos de alto tránsito, referencia a cercanía, a través de publicidad exterior.

d. Difusión en distritos. 


\section{CAPÍTULO VII}

\section{EJECUCIÓN DE LA ESTRATEGIA}

\subsection{Planes de acción}

Las siguientes acciones tienen como finalidad otorgar a nuestros clientes mayores alternativas que le permitan acceder a un servicio de salud dental diferenciado y que se ajuste a sus necesidades.

En cuanto al producto, se propone diseñar alternativas que mejoren la experiencia de los pacientes añadiendo atributos al servicio actual y siendo para los padres el mejor aliado de la salud dental de sus hijos.

Las estrategias de precio están dirigidas a demostrar que la inversión en los tratamientos no es costosa como los pacientes lo perciben.

Por otro lado, las estrategias de distribución y ventas están enfocadas en atraer nuevos clientes provenientes de pymes, trabajadores independientes y otras empresas que prestan servicios al mismo público objetivo. 


\section{Objetivo General}

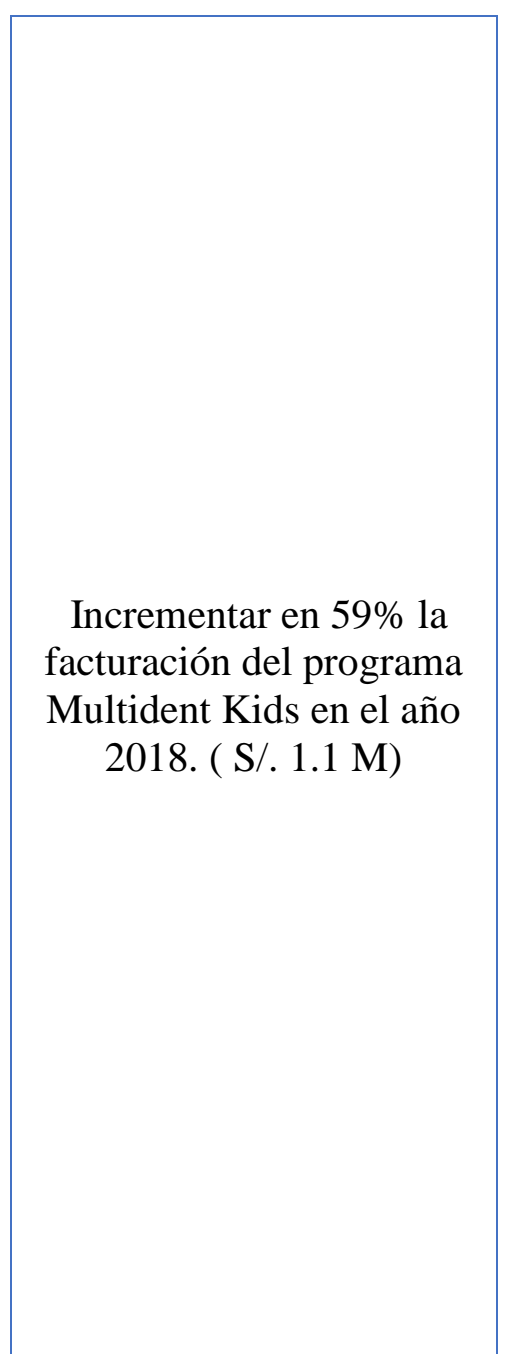

\section{Objetivos específicos}

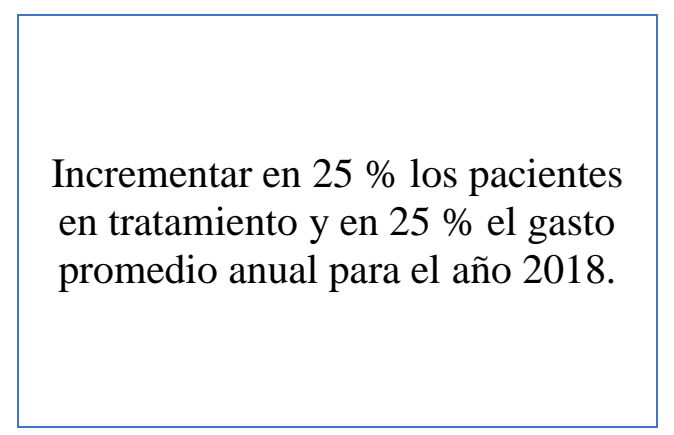

Ampliar la cobertura de convenios con presencia en $3 \%$ de empresas en Lima Este para el 2018.

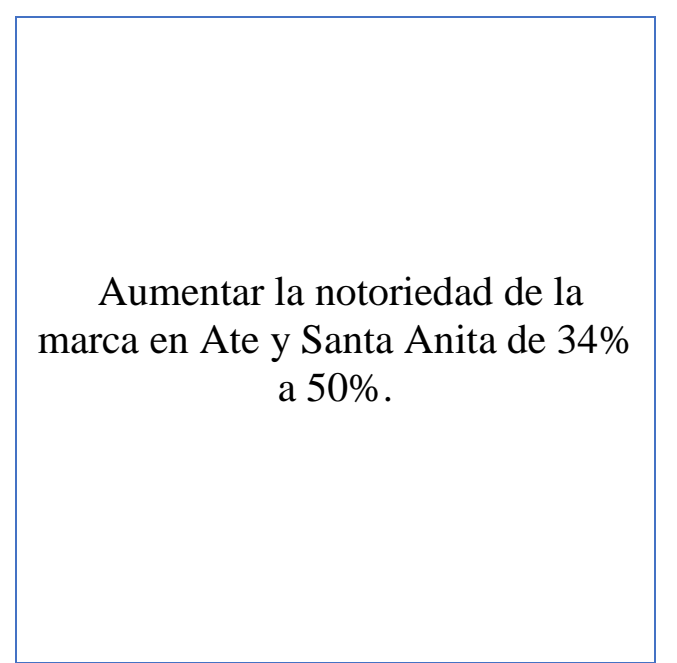

\section{Estrategias}
Ser el mejor aliado de la salud de tus hijos.

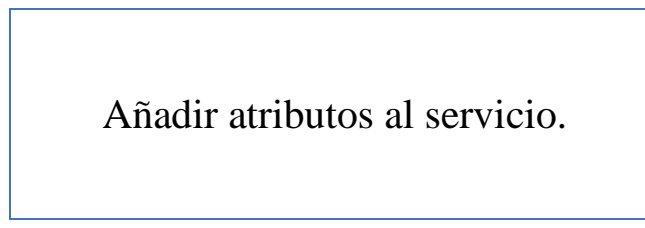

Diversificar los canales de venta con empresas.

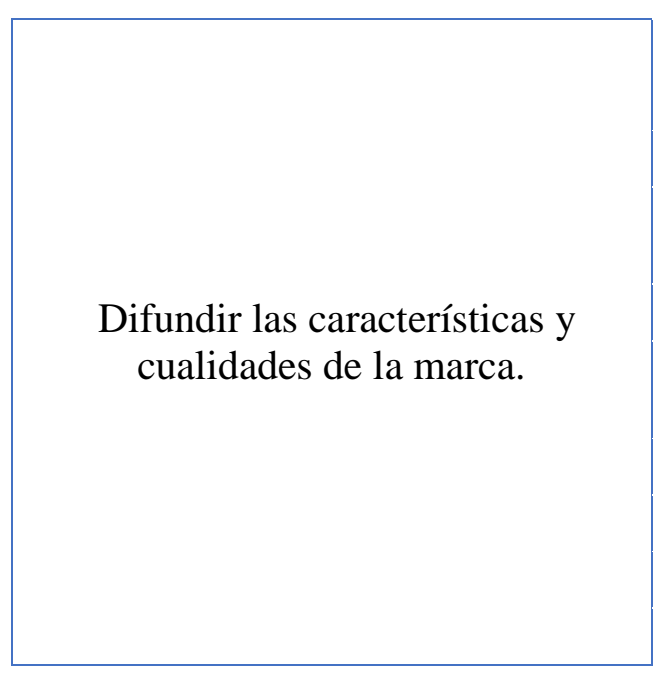

Acciones

\begin{tabular}{c}
\hline Multident te \\
recuerda:"Plan de \\
seguimiento"
\end{tabular}

"Los domingos contigo"

\section{"Experiencia Multident} Kids"

\section{"Alianzas"}

"Plan sin caries".

"Programa guerra a las Caries"

\section{Multilandia Cerca de ti: \\ Referencia a la Cercanía}

"Potenciar Multident Card"

Estrategias Digitales

Publicidad Offline 


\begin{tabular}{|c|c|c|c|c|c|c|}
\hline Estrategia & Cod & Acción & Responsable & Cronograma & Pri & ipuesto \\
\hline $\begin{array}{l}\text { Ser el mejor aliado de la salud de } \\
\text { tus hijos. }\end{array}$ & A1 & $\begin{array}{l}\text { Multident te recuerda: "Plan de } \\
\text { seguimiento" }\end{array}$ & $\begin{array}{l}\text { Director } \\
\text { Comercial }\end{array}$ & $\begin{array}{l}\text { I: Ene18 - } \\
\text { Mar18 } \\
\text { C: Abr18 - Dic18 }\end{array}$ & $\mathrm{S} /$. & 30,000 \\
\hline \multirow[b]{2}{*}{ Añadir atributos al servicio. } & $\mathrm{A} 2$ & "Los domingos contigo" & $\begin{array}{l}\text { Director } \\
\text { Administrativo }\end{array}$ & Mar18 -Nov18 & $\mathrm{S} /$. & 34,276 \\
\hline & A3 & "Experiencia MultidentKids" & $\begin{array}{l}\text { Director } \\
\text { Administrativo }\end{array}$ & $\begin{array}{l}\text { Ene18 - Dic } 18 \\
\text { C: Abr18 - Dic18 }\end{array}$ & \multicolumn{2}{|r|}{89,650} \\
\hline \multirow[b]{2}{*}{$\begin{array}{l}\text { Diversificar los canales de venta } \\
\text { con empresas. }\end{array}$} & A4 & "Alianzas" & $\begin{array}{l}\text { Director } \\
\text { Comercial }\end{array}$ & $\begin{array}{l}\text { I: Ene18 } \\
\text { C: Feb18 - Dic18 }\end{array}$ & $\mathrm{S} /$. & 5,000 \\
\hline & A5 & "Plan sin caries". & $\begin{array}{l}\text { Director } \\
\text { Comercial }\end{array}$ & $\begin{array}{l}\text { I: Ene18 - } \\
\text { Mar18 } \\
\text { C: Abr18 - Dic18 }\end{array}$ & $\mathrm{S} /$. & 33,000 \\
\hline \multirow{5}{*}{$\begin{array}{l}\text { Difundir las características y } \\
\text { cualidades de la marca. }\end{array}$} & A6 & "Programa guerra a las Caries" & Jefe de Marketing & Feb18, Jul18 & $\mathrm{S} /$. & 34,060 \\
\hline & A7 & $\begin{array}{l}\text { Multilandia cerca de ti: } \\
\text { Referencia a la Cercanía }\end{array}$ & Jefe de Marketing & Ene18 - Dic 18 & S/. & 15,000 \\
\hline & A8 & "Potenciar Multident Card" & Jefe de Marketing & Ene18 - Dic 18 & $\mathrm{~S} /$. & 7,000 \\
\hline & A9 & Estategias Digitales & Jefe de Marketing & Ene18 - Dic 18 & $\mathrm{~S} /$. & 20,000 \\
\hline & A10 & Publicidad Off line & Jefe de Marketing & Ene18 - Dic 18 & $\mathrm{~S} /$. & 12,000 \\
\hline
\end{tabular}




\section{A1. Multident te recuerda: "Plan de seguimiento"}

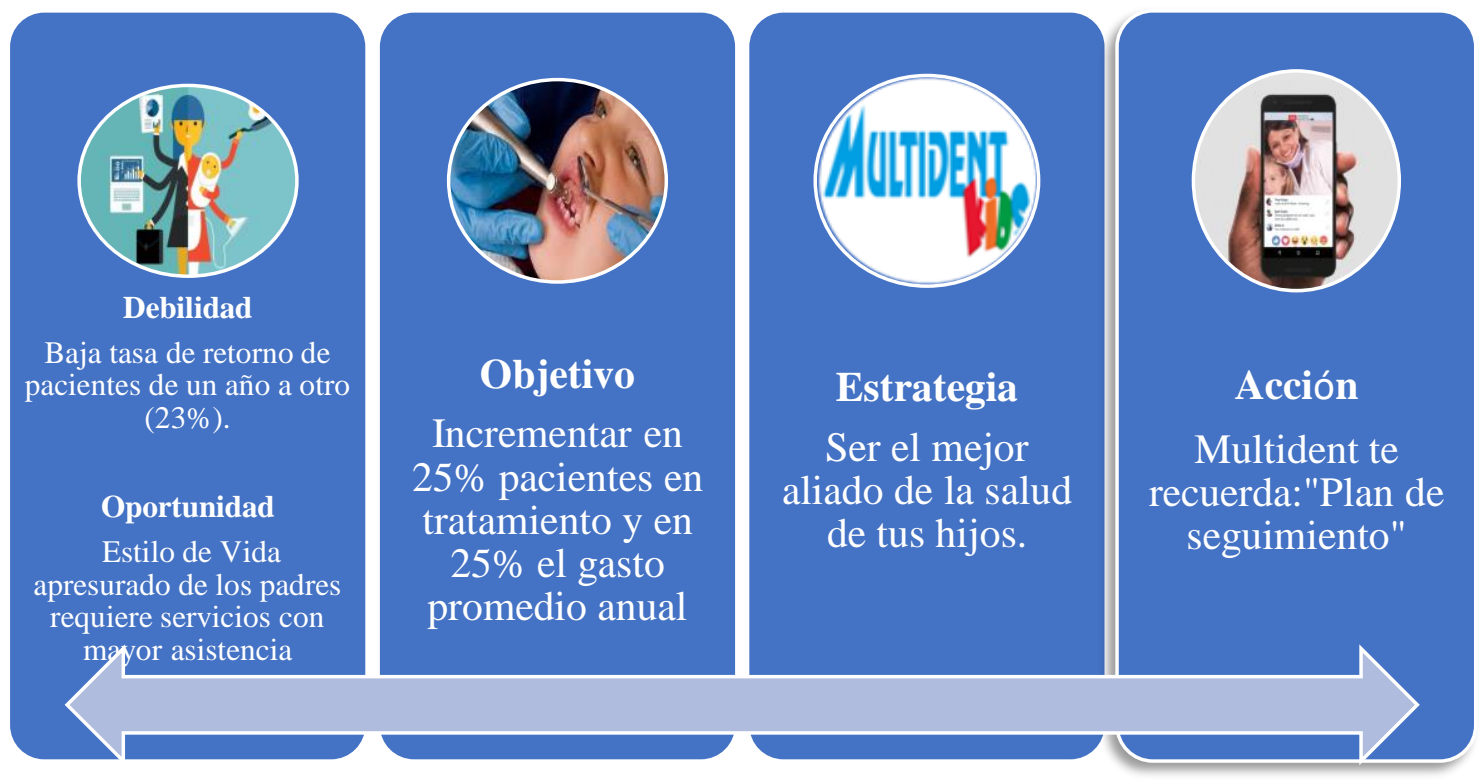

\section{Descripción de la acción}

La implementación de la acción tendrá las siguientes tareas:

- Rediseñar la base de información necesaria para el workflow, como atributos del cliente, su tipificación o clasificación, programas a los que está afiliado, detalle de tratamientos y origen de los descuentos.

- Diseñar un workflow de atención de tratamientos para que genere las alertas en cada etapa del tratamiento.

- Generar las listas y mensajería asociada para su comunicación vía WhatsApp o llamadas telefónicas.

- Generar reporte de indicadores de seguimiento. 
El seguimiento se realizará a cada una de las listas generadas como:

- Prospectos de citas producto de las campañas, acciones de difusión publicitaria.

- Recuperación de pacientes existentes en la base de datos.

- Control de pacientes con planes con frecuencia mínima de tres meses.

- Control de pacientes en tratamiento y de alta.

- Reprogramación de pacientes con citas cancelada.

\section{Comunicación}

La comunicación con el cliente se realizará a través de llamadas telefónicas y mensajería de WhatsApp, dado que son los medios preferidos por los pacientes para mantener la comunicación con la clínica como se muestra en la figura 49.

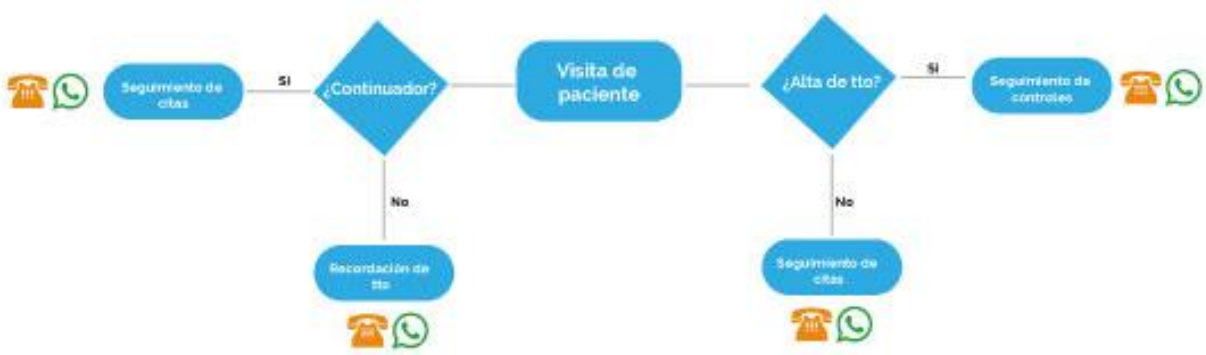

Figura 48. Worflow propuesto para Plan de Seguimiento

\begin{tabular}{|c|c|c|}
\hline Responsable & Cronograma & \multicolumn{2}{|c|}{ Presupuesto } \\
\hline Director Comercial & $\begin{array}{l}\text { I: Ene18 - Mar18 } \\
\text { C: Abr18 - Dic18 }\end{array}$ & S/. 30,000 \\
\hline
\end{tabular}




\section{A2. "Los domingos contigo"}

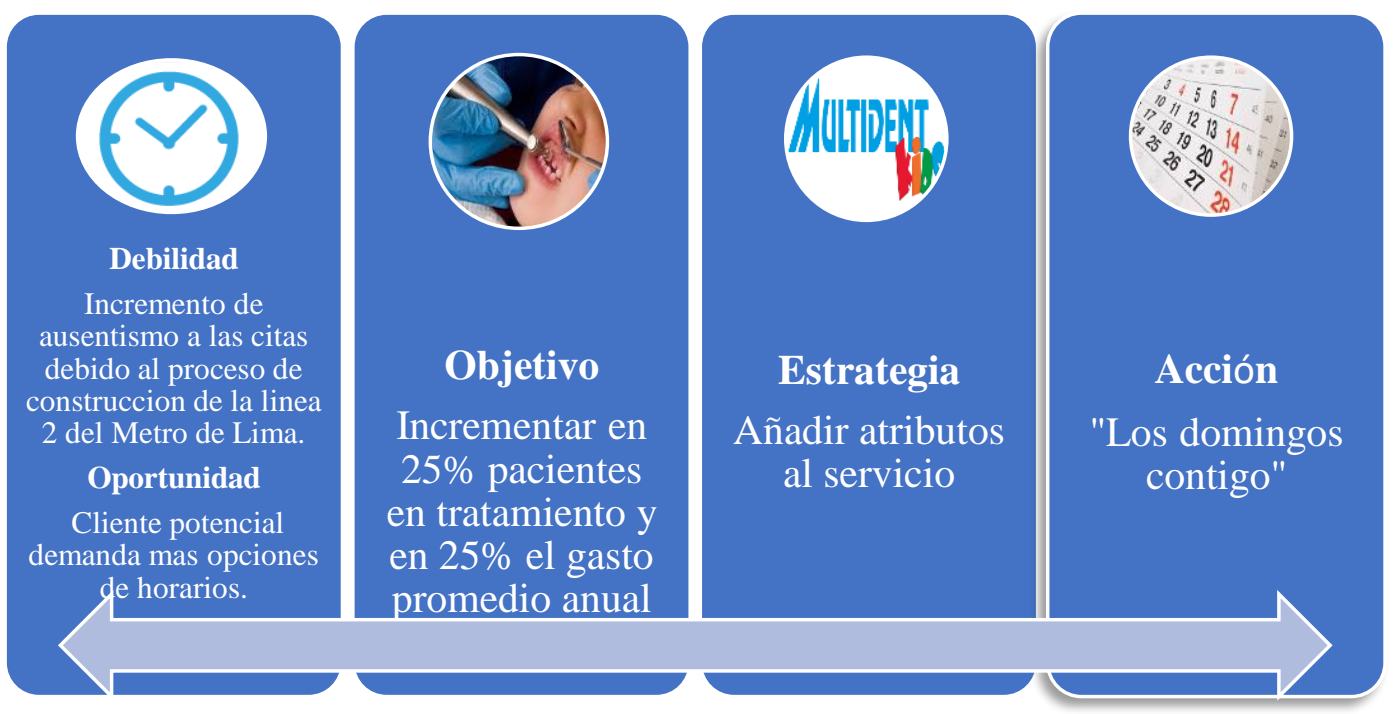

\section{Descripción de la acción}

Según los resultados de la investigación proponemos adicionar más opciones en los horarios de atención, incluyendo el día domingo. Dado que este es un día familiar es importante generar un ambiente amigable y divertido tanto para el paciente y sus familiares, se considera a personal de recepción, limpieza y una sección de actividades de distracción familiar como: títeres, caritas pintadas, teatro, claun, magia, etc.
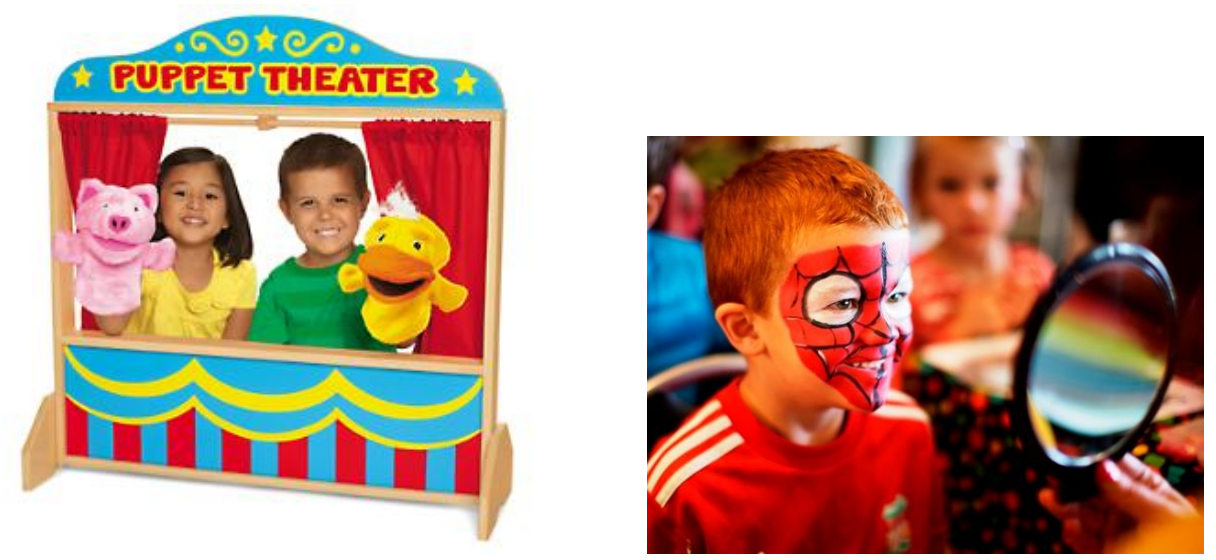
Figura 49. Propuesta para actividades adicionales para atención en domingos

\section{Comunicación}

La comunicación se llevará a cabo a través de publicación de contenidos en Facebook con fotografías de las actividades realizadas semanalmente.

Además, dentro de las instalaciones se difundirá el nuevo horario mediante afiches e invitaciones personales.

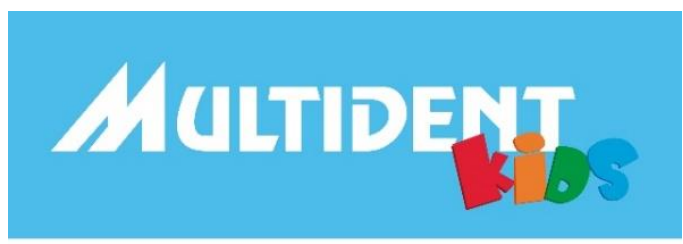

Este domingo:

Show

de

Titeres

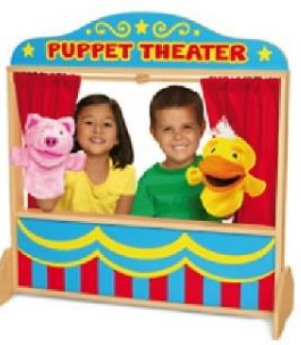

www.multident.pe

Figura 50. Propuesta de afiche para atención dominical

\begin{tabular}{|c|c|c|}
\hline Responsable & Cronograma & Presupuesto \\
\hline Director Administrativo & Mar18-Nov18 & S/. 34,276 \\
\hline
\end{tabular}




\section{A3. "Experiencia Multident Kids"}

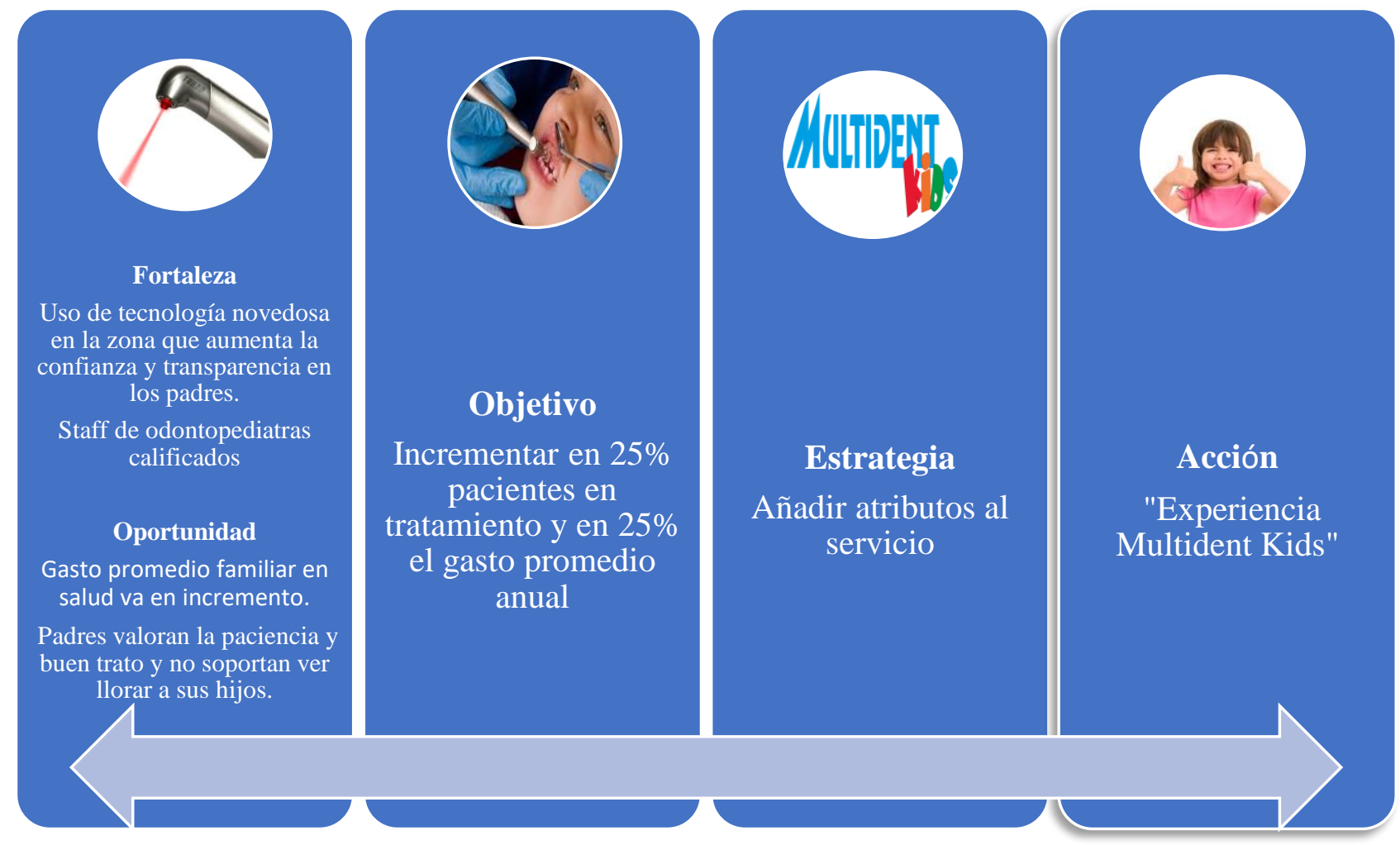

\section{Descripción de la acción}

La experiencia Multident Kids considera tres aspectos importantes para la salud integral (salud dental y emocional) del paciente, siendo los siguientes:

- Sin dolor, concibe el uso de la tecnología para brindarle una experiencia agradable y sin molestia al paciente por dolor o ruidos, como las curaciones con láser y sedación con óxido nitroso.

- Especialistas felices, genera pacientes contentos. Siendo los doctores el principal proveedor del servicio, es indispensable mantener el buen clima organizacional, para ello se realizará las siguientes actividades: 
- Laboratorio de experiencias tiene como finalidad comprometer a una comunicación continua entre todas las especialidades, donde se puedan compartir conocimiento, tratamiento en nuevos casos y proponer mejoras para la atención a los pacientes.

- Tarde de diversión Multident: Una tarde para realizar juegos sencillos como: una búsqueda del tesoro y charada que permita conocer más a todos los participantes.

- Noche de talentos Multident: Una noche para que demuestren sus dotes artísticas, musicales y de canto.
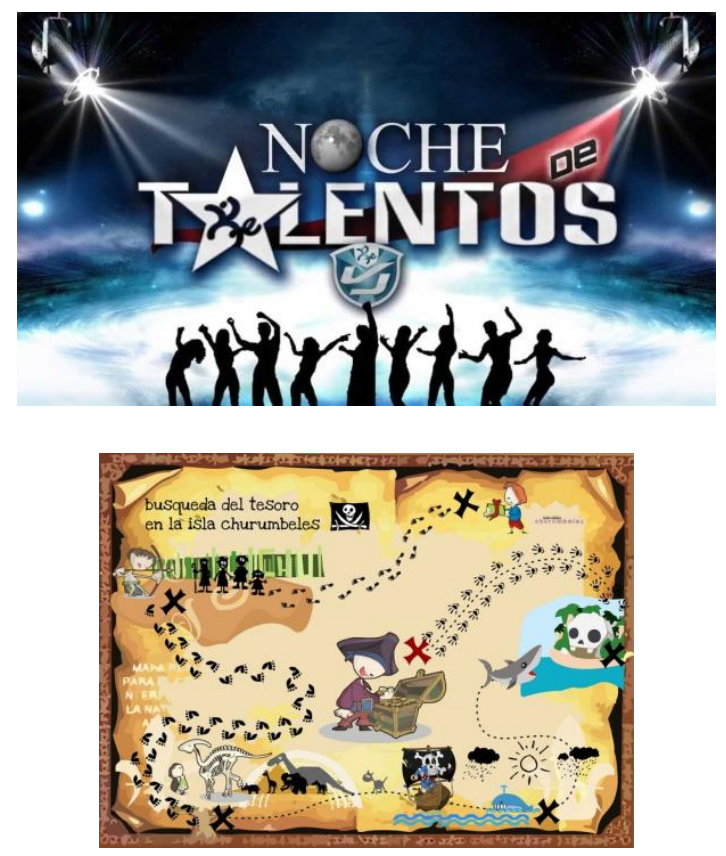

Figura 51. Propuesta de anuncios para actividades 
- Multilandia, consiste en una infraestructura renovada en consultorios, sala de espera y materiales para explicación de tratamiento, haciendo uso de la mayoría de recursos actuales con un diseño diferente:

- Sala de espera con temática por cada segmento de edad:

\begin{tabular}{l}
$\begin{array}{l}\text { Espacio para bebés } \\
\text { hasta } 2 \text { años: incluye } \\
\text { zona de juegos } \\
\text { didácticos y zona } \\
\text { para pintar. }\end{array}$ \\
\hline $\begin{array}{l}\text { Espacio para niños } \\
\text { de } 3 \text { a } 5 \text { años: } \\
\text { incluye zona de } \\
\text { manualidades } \\
\text { (Plastilina, origami, } \\
\text { colores) y zona de } \\
\text { juguetes (autos, } \\
\text { muñecas, } \\
\text { rompecabezas). }\end{array}$ \\
$\begin{array}{l}\text { Espacio para niños } \\
\text { de } 6 \text { a } 12 \text { años: } \\
\text { incluye una zona de } \\
\text { lectura, de juegos de } \\
\text { mesa. }\end{array}$
\end{tabular}


- Consultorios amigables

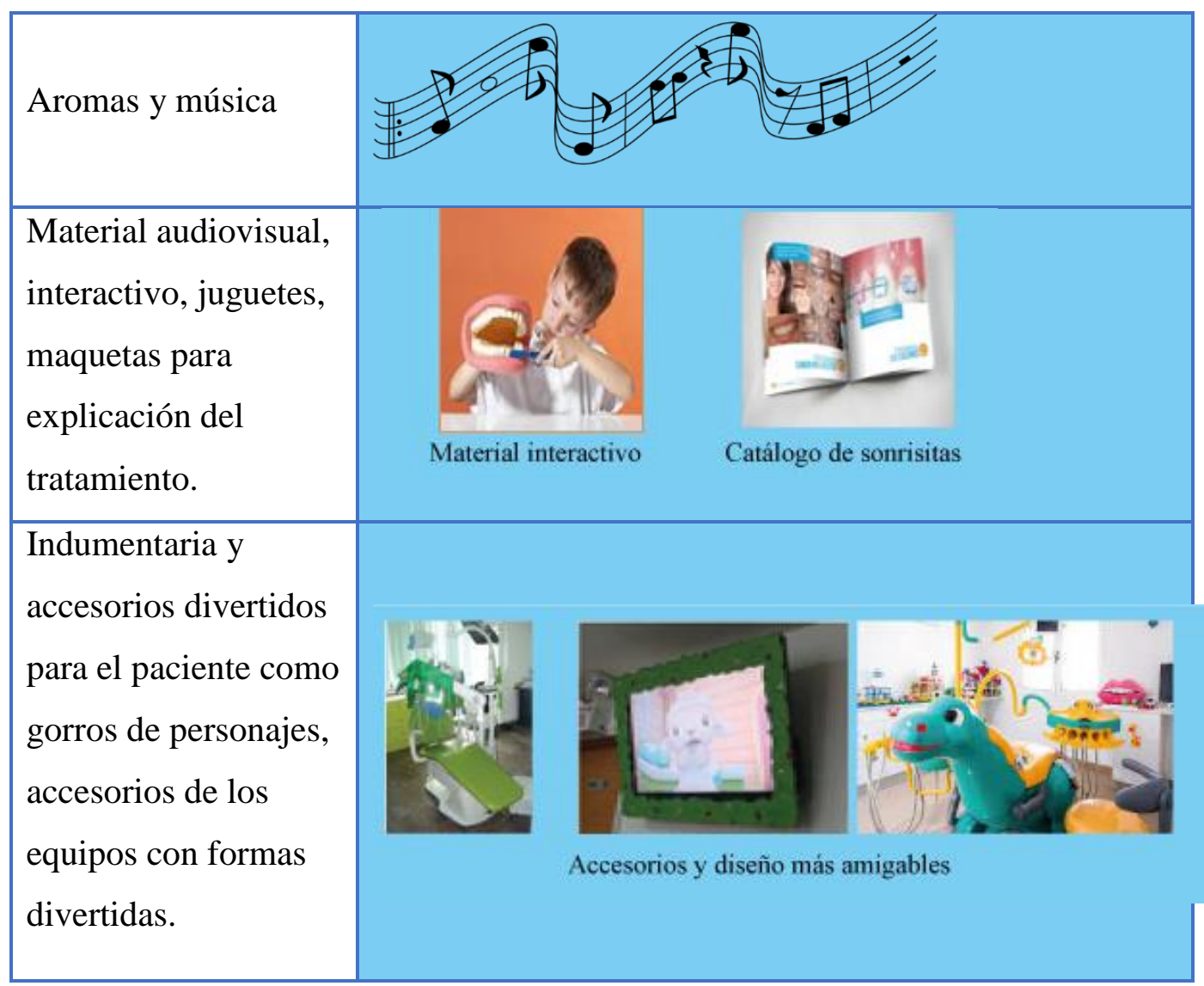

\section{Comunicación}

La comunicación se llevará a cabo a través de publicación de contenidos en Facebook como se propone en la figura 53, con álbumes de fotos de experiencias, imágenes 360 que permitan visualizar un tour rápido de las instalaciones y videos cortos de las visitas. 


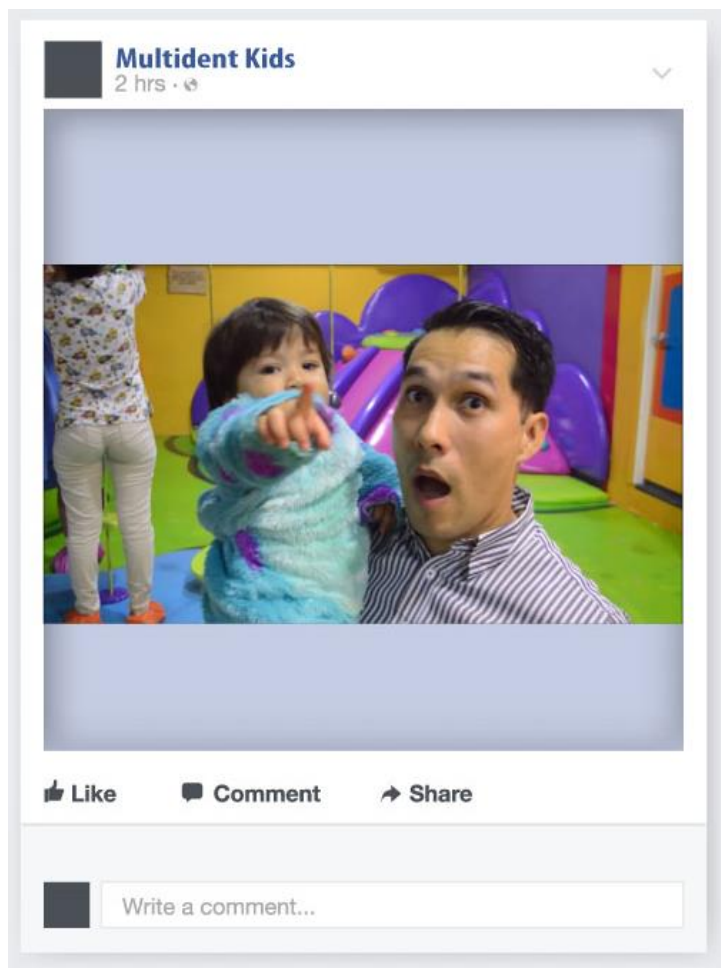

Figura 52. Propuesta de publicación de experiencia en Facebook

\begin{tabular}{|c|c|c|}
\hline Responsable & Cronograma & Presupuesto \\
\hline Director Administrativo & $\begin{array}{c}\text { Ene18-Dic18 } \\
\text { C: Abr18-Dic18 }\end{array}$ & S/. 89,650 \\
\hline
\end{tabular}




\section{A4. "Alianzas"}

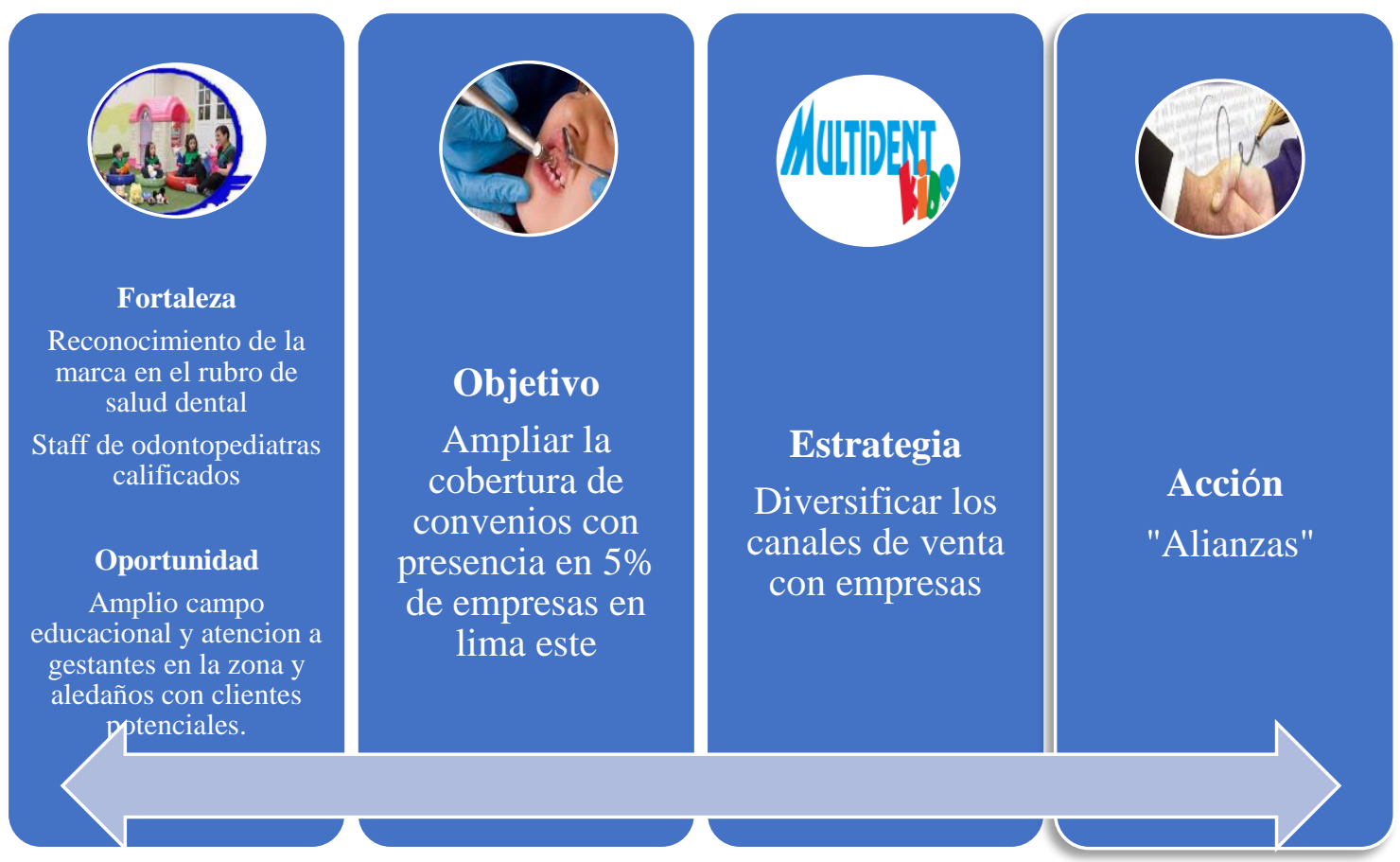

\section{Descripción de la acción}

En atención a las necesidades de los padres y proximidad a ellos, buscamos concentrar nuestros esfuerzos en aquellas instituciones a donde nuestros clientes asisten con frecuencia y se ubican en los mismos distritos en los que viven. La captación se realizará a través de las instituciones con paquetes que incluyen:

- Consulta odontológica gratuita del paciente y para madres gestantes además la de su bebé a la salida del primer diente. 
- Descuento en tratamientos preventivos y restaurativos autorizados, presentando el carnet vigente de la institución o vale de descuento.

- Acceso a programas de educación sobre salud dental: eventos, talleres, charlas al suscribirse en la página.

Los paquetes diseñados de acuerdo al tipo de institución:

a. Pack odontológico para alianza con consultorios ginecológicos dirigido a madres gestantes.

b. Pack odontológico para alianza con centros de estimulación y guarderías dirigido a bebés

c. Pack odontológico para alianza con centros pre - escolares dirigidos a bebés y niños

d. Pack odontológico para alianza con tiendas de ropa y zapatos exclusivos para bebes y niños

\section{Comunicación}

Se entregará a cada institución material publicitario, obsequios, folletos y vales para ser canjeados por la atención en la clínica. La institución brindará la información de los padres interesados en la alianza y las facilidades de acercamiento entre la clínica y los padres para la ejecución de charlas dentro de las actividades de la institución, a cambio la clínica promocionará la alianza con las instituciones en sus redes sociales. 


\section{Colloky. \\ ayudándote a ser mamá y papá

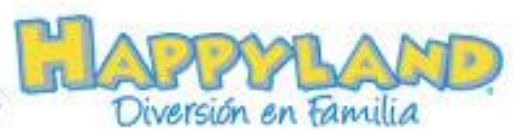 \\ KiDS \\ CREATE!}

Figura 53. Empresas propuestas para alianzas

\begin{tabular}{|c|c|c|}
\hline Responsable & Cronograma & \multicolumn{2}{|c|}{ Presupuesto } \\
\hline Director Comercial & I: Ene18 & S/. 5,000 \\
& C: Feb18-Dic18 & \\
\hline
\end{tabular}

\section{A5. "Plan sin caries"}

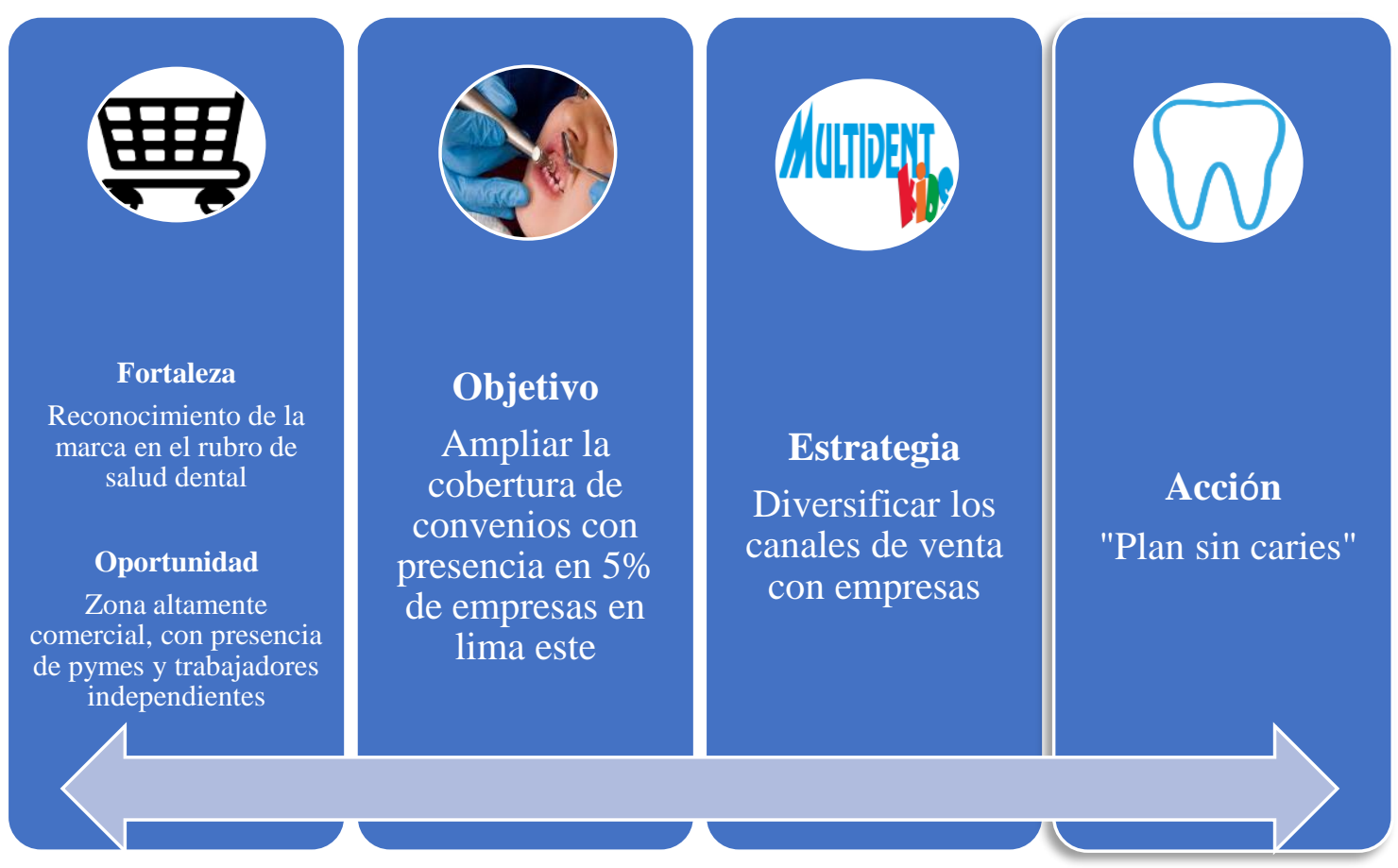




\section{Descripción de la acción}

El plan está orientado a los trabajadores de empresas no afiliadas a ningún sistema con EPS y a independientes. Específicamente a los padres que viven y trabajan en la zona con hijos comprendidos en las edades de nuestra investigación teniendo en consideración que uno de los atributos más valorados es la cercanía. Esto se basa principalmente en la información histórica de las campañas Multident que presentan un mayor porcentaje de clientes que trabajan y viven en la zona de estudio.

El plan sin caries permite a los padres cuidar eficientemente la salud dental de sus hijos contribuyendo a su salud emocional e integral a través de la prevención. Los beneficios son los siguientes:

- Consulta odontológica y control cada 3 meses

- Acceso a tratamiento preventivo cada 3 meses según frecuencia recomendada por el especialista.

- Acceso a programas de educación sobre salud dental: eventos, talleres, charlas.

- Acceso a descuentos en las empresas que forman alianza con Multident

- Regalo porta dientes, para niños que aún no mudan los dientes en el control que le corresponde.

Costo: S/30 mensuales. 


\section{Comunicación}

La comunicación se realizará a los trabajadores de las empresas Ate, Santa Anita, Lurigancho y Chaclacayo, con las que se ha firmado un convenio entre la clínica y esta. El convenio permitirá difundir los beneficios del plan, y la pyme gestionará la afiliación de sus trabajadores.
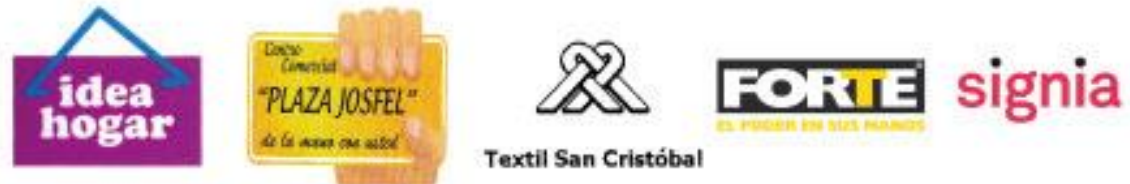

Textil San Cristóbal

Figura 54. Empresas propuestas para convenios de Plan Sin Caries

\begin{tabular}{|c|c|c|}
\hline Responsable & Cronograma & Presupuesto \\
\hline Director Comercial & $\begin{array}{l}\text { I: Ene18-Mar18 } \\
\text { C: Abr18-Dic18 }\end{array}$ & S/. 33,000 \\
\hline
\end{tabular}




\section{A6. "Programa Guerra a las Caries"}

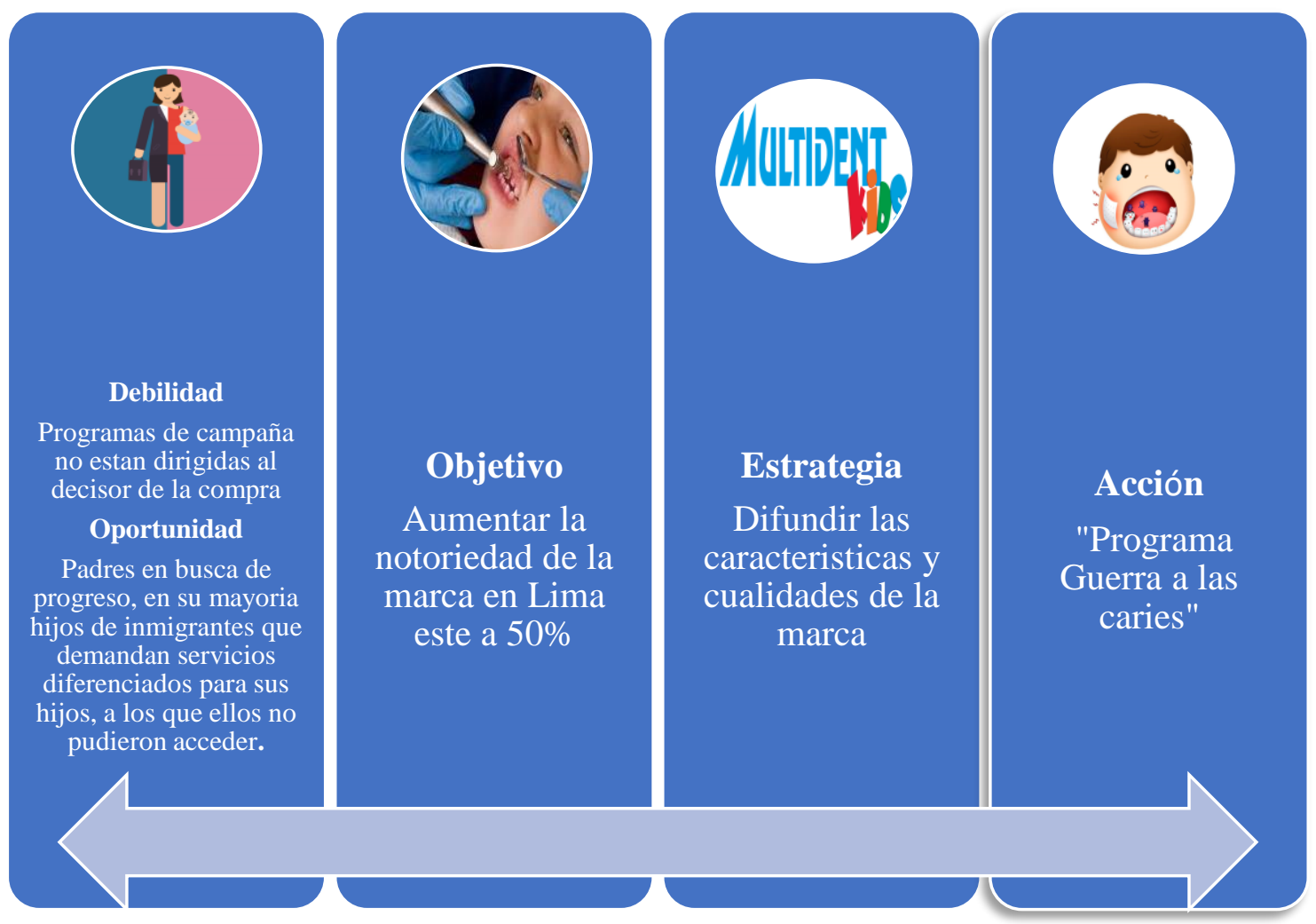

\section{Descripción de la acción}

Campaña que permitirá un acercamiento entra la clínica y la comunidad mediante juegos interactivos en los puntos más concurridos de los principales centros comerciales como el Mall Aventura Plaza Santa Anita y el Real Plaza Santa Clara. 
Dentro de estos centros comerciales se instalará por 4 días un módulo informativo con un muñeco de material mdf que represente un niño con caries para iniciar el juego.

El juego consiste en que los niños puedan eliminar las caries del muñeco con unas pelotas de plástico, lo que generará entusiasmo e interés por los transeúntes. Para poder participar del juego gratuito y tener la oportunidad de ganar vales o cepillos, los padres tendrán que inscribirse mediante un formulario con sus principales datos.

Al finalizar el juego, mediante una invitación se difundirá las charlas de salud preventiva en niños, la que se realizará en el cine del mismo centro comercial.

\section{Comunicación}

La comunicación tendrá tres etapas importantes:

1. Campaña de intriga por medio de clips de video en el espacio para tráilers de los cines del centro comercial y publicaciones en redes sociales.

2. La propia campaña del juego mediante publicidad impresa en los lugares cercanos y publicaciones en redes sociales sectorizadas para la zona.

3. Y finalmente la puesta en escena de la charla informativa con material audiovisual llamativo, dinámica de juegos para los padres y premios por participación. 


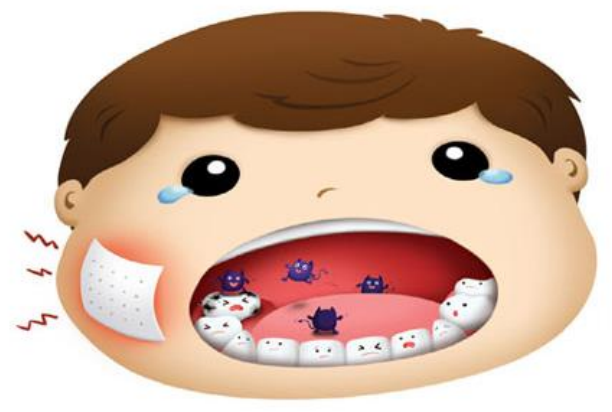

Figura 55. Propuesta de muñeco en material mdf para juegos en centro comerciales

\begin{tabular}{|c|c|c|}
\hline Responsable & Cronograma & Presupuesto \\
\hline Jefe de Marketing & Feb18-Jul18 & S/. 34,060 \\
\hline
\end{tabular}




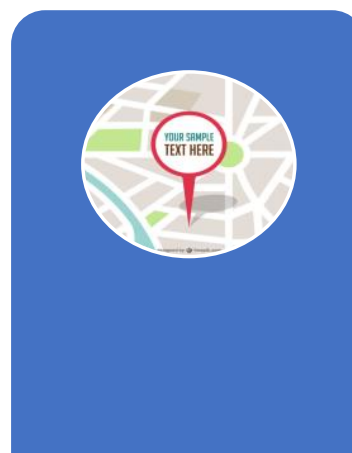

Debilidad

Falta de identificacion de las sedes de Ate y Santa Anita

Oportunidad

Zona altamente

comercial, con presencia

de pymes y trabajadores independientes

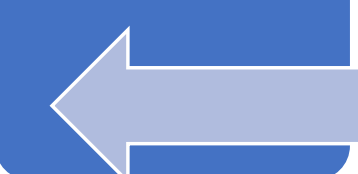

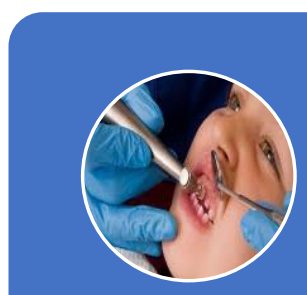

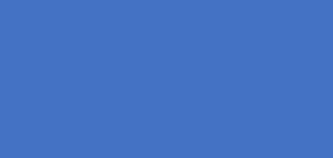

Objetivo

Aumentar la notoriedad de la marca en Lima este a $50 \%$

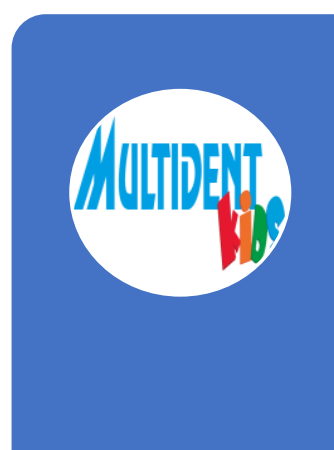

Estrategia

Difundir las caracteristicas y cualidades de la marca

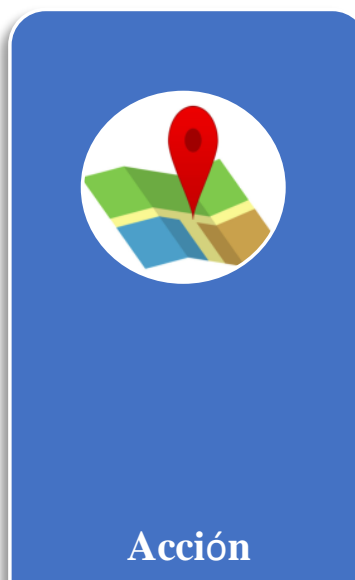

Multilandia cerca de ti: "Referencia a la cercanía"

\section{Descripción de la acción}

Se identificará las zonas de mayor afluencia para la contratación de publicidad exterior resaltando la cercanía de la sede a su lugar de trabajo o domicilio.

- En el distrito de Chaclacayo: Cerca a centros de esparcimientos y la avenida principal de la carretera central donde se encuentran grandes comercios como Metro, Plaza Vea y restaurantes con mucha afluencia.

- En el distrito de Lurigancho: Cerca de la Plaza de Armas de Chosica y galerías principales. 


\section{Comunicación}

Para cada uno de estos espacios y puntos publicitarios se incluye un arte diferente y muy específico enfatizando la cercanía del punto hacia la sede más próxima. Además de la ruta más rápida para llegar y tiempo en minutos.

Para Chosica: Conoce Multident Ate, a 30 min por la carretera central.

Para Chaclacayo: Cada vez más cerca de Multident Ate, sólo faltan 20 min.

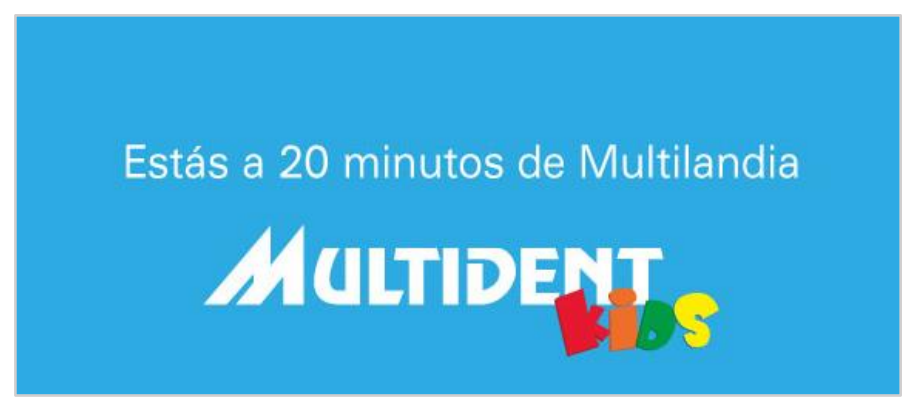

Figura 56. Prototipo de Banner relativa a la cercanía.

\begin{tabular}{|c|c|c|}
\hline Responsable & Cronograma & Presupuesto \\
\hline Jefe de Marketing & Ene18-Dic18 & S/. 15,000 \\
\hline
\end{tabular}




\section{A8. "Potenciar Multident Card"}

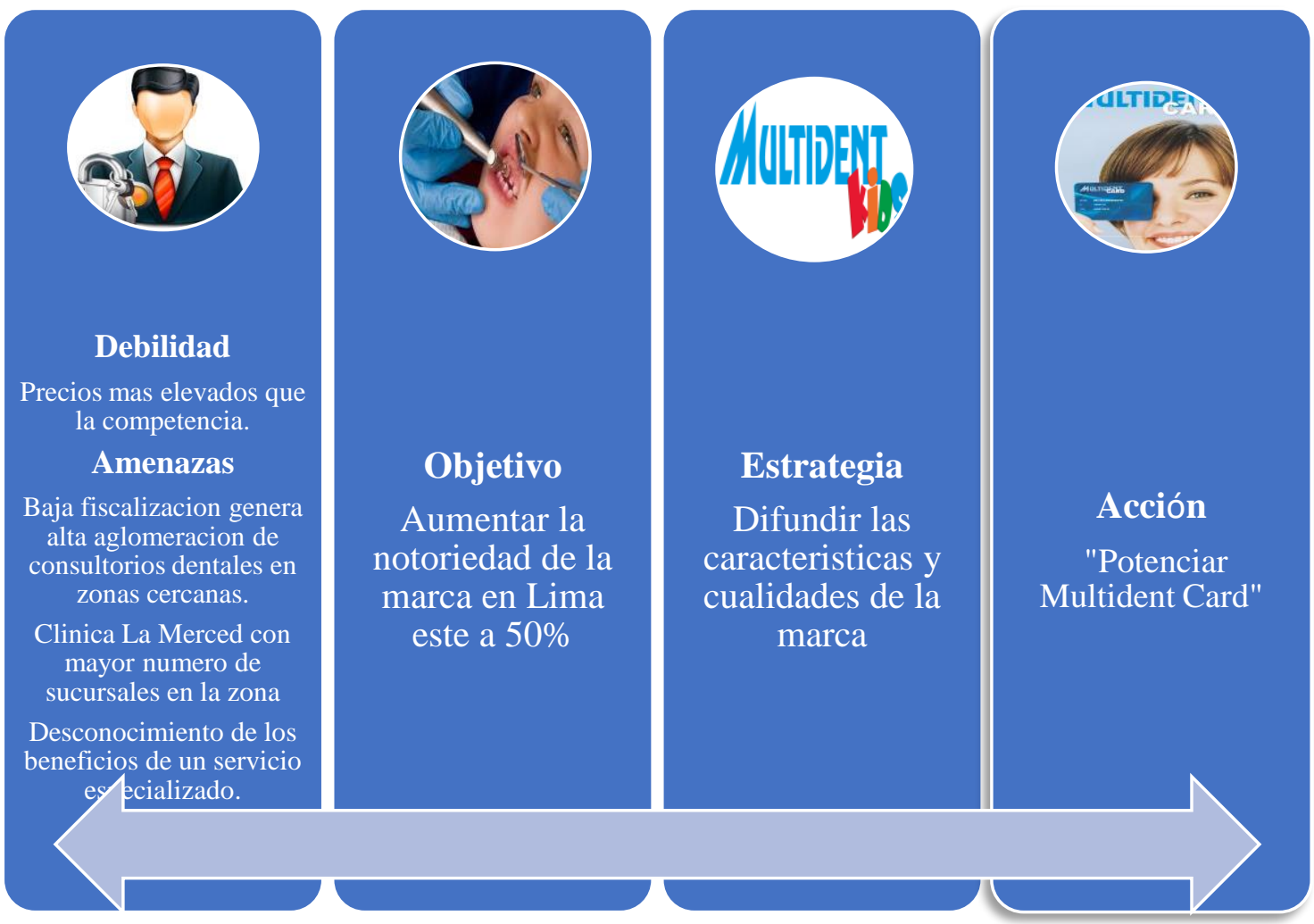

\section{Descripción de la acción}

Con el objetivo de aumentar la difusión de los beneficios y teniendo en cuenta la percepción sobre el costo que tiene el mercado en la zona, es necesario realizar un comparativo de precios de los tratamientos más solicitados con la tarjeta Multident Card. Diseñar la comunicación y difundirla en centros estratégicos. 


\section{Comunicación}

La comunicación se llevará a cabo a través de publicación de contenidos en

Facebook con información de los principales beneficios de la adquisición de la tarjeta: los descuentos.

Además, dentro de las instalaciones se difundirá con afiches impresos y digitales.

Tabla 32.Tarifario comparativo de precios regulares y con tarjeta Multident Card (nuevos soles)

\begin{tabular}{|l|r|r|}
\hline \multicolumn{2}{|c|}{ ODONTOPEDIATRIA } \\
\hline \multicolumn{1}{|c|}{ Tratamiento } & P.Regular & P. Mcard \\
\hline Arco linguaVPlaca de Hawley (odontopediatría) & 700.00 & 700.00 \\
\hline Corona preformada de acero (odontopediatria) & 180.00 & 150.00 \\
\hline Destartraje con ultrasonido niños & 180.00 & 162.00 \\
\hline Exodoncia compleja (odontopediatría) & 80.00 & 80.00 \\
\hline Fluor barniz & 120.00 & 108.00 \\
\hline Flúor por arcada & 60.00 & 60.00 \\
\hline Flúor total & 120.00 & 120.00 \\
\hline Frenectomia & 300.00 & 270.00 \\
\hline Lavado + drenaje de niños & 100.00 & 90.00 \\
\hline Mantenedor de espacio (banda ansa, corona ansa: odontopediatría) & 400.00 & 400.00 \\
\hline Operculectomia & 280.00 & 252.00 \\
\hline Profilaxis (odontopediatría) & 60.00 & 60.00 \\
\hline Pulpectomía & 200.00 & 180.00 \\
\hline Pulpotomía & 120.00 & 100.00 \\
\hline Recubrimiento pulpar indirecto (odontopediatría) & 80.00 & 70.00 \\
\hline Resina por superficie niños & 60.00 & 54.00 \\
\hline Restauración con ionomero de vidrio & 100.00 & 80.00 \\
\hline Sedación consciente (odontopediatria) & 250.00 & 200.00 \\
\hline Sellante por pieza & 30.00 & 30.00 \\
\hline Sellantes total x 16 & 480.00 & 480.00 \\
\hline
\end{tabular}




\begin{tabular}{|c|c|c|}
\hline Responsable & Cronograma & Presupuesto \\
\hline Jefe de Marketing & Ene18-Dic18 & S/. 7,000 \\
\hline
\end{tabular}

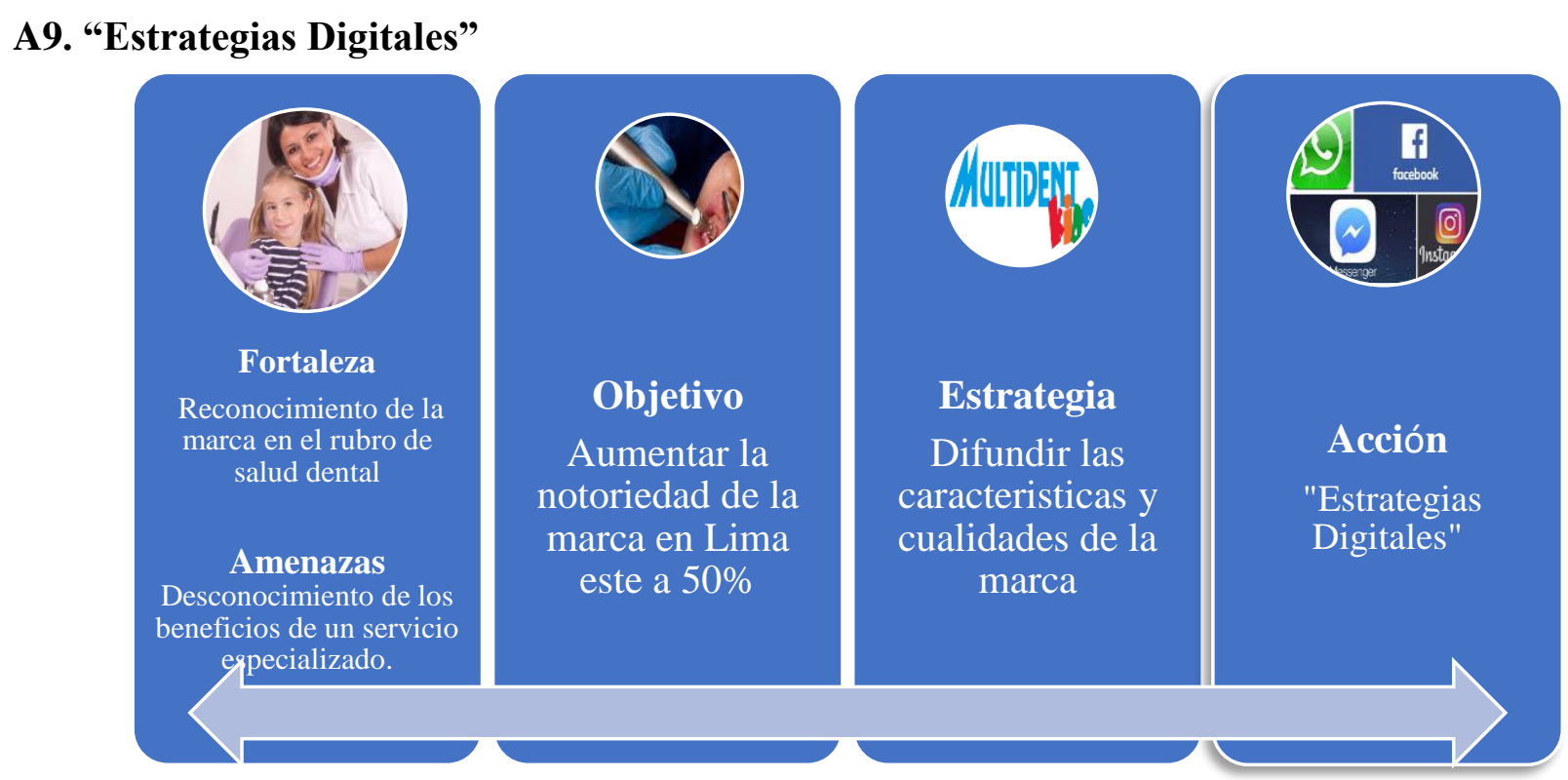

\section{Descripción de la acción}

Las estrategias digitales se realizarán durante todo el periodo del plan para fortalecer cada una de las estrategias antes mencionadas, pero además las nuevas ideas propuestas a implementar en el transcurso del año son las siguientes:

- Transmitir videos en vivo para que los odontopediatras interactúen con los padres: Se propone realizar una transmisión mensual en vivo con los odontopediatras abarcando temas recurrentes según calendario en el Anexo 9 siguiendo la estructura: 
○ Conexión, saludo y bienvenida: $10 \mathrm{~min}$.

- Importancia del tema a tratar:10 min

○ Recomendaciones principales del tema a tratar: 5 min

- Preguntas y respuestas: $25 \mathrm{~min}$

- Despedida y referencias de la sede: $5 \mathrm{~min}$

- Comunicar las experiencias de los pacientes que concluyan sus tratamientos: Mediante testimonios en video, boomerang o fotografías de pacientes con sonrisas sanas. Publicar el contenido en las redes sociales para comunicar que son pacientes felices y sanos luego de todo su tratamiento.

- Difusión de momentos de diversión de los niños en los espacios creados: Para dar a conocer el renovado espacio para niños denominado "Multilandia" se realizarán toma de fotografías a los niños mientras estén en el espacio interactuando, previa autorización de sus apoderados, para usar las herramientas más actuales en redes sociales se utilizarán:

○ Imágenes completas: 360

○ Imágenes en movimiento: Boomerangs

- Fotografías con emojis felices

- Difusión de artículos con recomendaciones de salud dental para los niños: Mediante artículos trimestrales con recomendaciones de salud dental para niños siendo los títulos escogidos: 
○ Marzo 2018: "Loncheras saludables para el año escolar"

○ Junio 2018: "Reglas de oro para niños"

○ Setiembre 2018: "Alternativas de dulces para Halloween"

○ Diciembre 2018: "Navidad sin caries"

El boletín distribuido tendrá un espacio para pintar o llenar un crucigrama para que los niños tengan la curiosidad por el documento.

- Difusión de eventos realizados en la clínica o donde participa la clínica: fechas importantes en el año como Día del Niño, día de la madre, aniversario, conferencias, viajes, eventos diversos, etc

- Difusión novedades en productos y servicios, alianzas y nuevos convenios.

\section{Comunicación}

La comunicación de las propuestas descritas se difundirá en Facebook utilizando los nuevos formatos de imagen y video de esta herramienta para generar mayor atención de la audiencia.

\begin{tabular}{|c|c|c|}
\hline Responsable & Cronograma & Presupuesto \\
\hline Jefe de Marketing & Ene18-Dic18 & S/. 20,000 \\
\hline
\end{tabular}




\section{A10. "Publicidad Offline"}

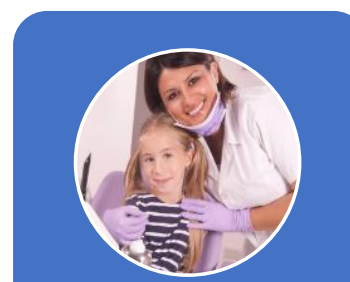

Fortaleza

Ubicación estratégica en

avenidas principales

cercana a centros

comerciales, empresas y

centros de trabajo/estudio

Amenazas

Baja fiscalización genera

alta aglomeración de

consultorios dentales en

zolas cercanas.

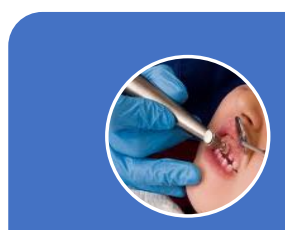

Objetivo

Aumentar la notoriedad de la

marca en Lima

este a $50 \%$

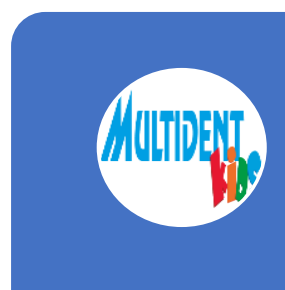

Estrategia

Difundir las

caracteristicas y

cualidades de la

marca

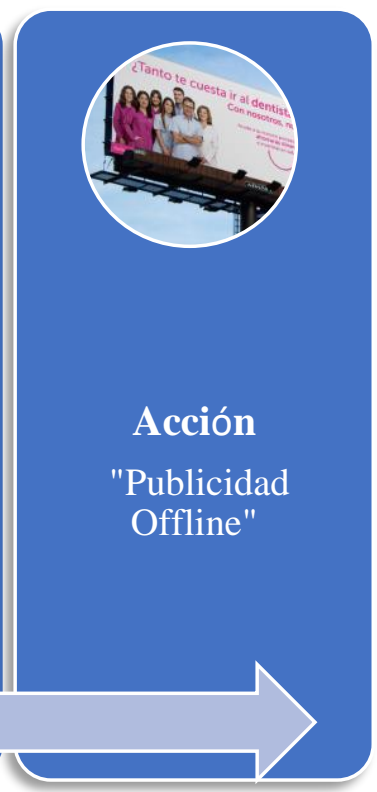

\section{Descripción de la acción}

La publicidad offline a utilizar son las vallas y paneles en puntos de mayor afluencia. Y publicidad impresa en formato de volantes y afiches que serán distribuidos en las zonas:

- Urbanización Los Ficus y Santa Anita.

- Urbanización Santa Clara, Los Portales, Mayorazgo.

- Urbanizaciones principales en Chaclacayo, Chosica.

\section{Comunicación}

Los diseños de la publicidad impresa además de seguir con los lineamientos de la empresa, tendrán una opción de interacción mediante un juego de 
habilidad mental o colorear para que la información tenga una mayor relevancia.

\begin{tabular}{|c|c|c|}
\hline Responsable & Cronograma & Presupuesto \\
\hline Jefe de Marketing & Ene18-Dic18 & S/. 12,000 \\
\hline
\end{tabular}




\subsection{Calendario de ejecución del Plan}

\begin{tabular}{|c|c|c|c|c|c|c|c|c|c|c|c|c|c|c|c|c|c|c|c|c|c|c|c|c|c|c|c|}
\hline \multirow[b]{2}{*}{ Cod } & \multirow[b]{2}{*}{ Acciones } & \multicolumn{2}{|c|}{ Presupuesto } & \multicolumn{4}{|c|}{ Enero } & \multicolumn{4}{|c|}{ Febrero } & \multicolumn{4}{|c|}{ Marzo } & \multicolumn{4}{|c|}{ Abril } & \multicolumn{4}{|c|}{ Mayo } & \multicolumn{4}{|c|}{ Junio } \\
\hline & & $\begin{array}{c}\text { Gastos } \\
\text { (Miles S/.) }\end{array}$ & $\begin{array}{l}\text { Inversión } \\
\text { (Miles S/.) }\end{array}$ & 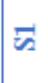 & $\approx$ & 2 & 洪 & $\approx$ & ש & 5 & 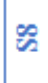 & $\approx$ & 离 & $\bar{\nabla}$ & $\underset{\sim}{\tilde{N}}$ & $\frac{m}{\pi}$ & $\vec{\nabla}$ & $\frac{n}{2}$ & $\frac{0}{2}$ & $\bar{r}$ & $\frac{\infty}{\infty}$ & $\vec{\nabla}$ & 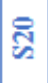 & 党 & đ্ঠু & ฟู & 忩 \\
\hline Al & "Plan de seguimiento" & $\mathrm{S} /$. & $\mathrm{S} / . \quad 30,000.0$ & & & & & & & & & & & & & & & & & & & & & & & & \\
\hline A2 & "Horario domingo" & S/. $\quad 34,276.00$ & & & & & & & & & & & & & & & & & & & & & & & & & \\
\hline A3 & "Experiencia MultidentKids" & S/. $\quad 24,700.00$ & S/. $\quad 64,950.0$ & & & & & & & & & & & & & & & & & & & & & & & & \\
\hline A4 & "Alianzas" & S/. $\quad 5,000.00$ & & & & & & & & & & & & & & & & & & & & & & & & & \\
\hline A5 & "Plan sin caries". & & $\mathrm{S} / . \quad 33,000.0$ & & & & & & & & & & & & & & & & & & & & & & & & \\
\hline A6 & "Programa guerra a las caries" & S/. $\quad 34,060.00$ & & & & & & & & & & & & & & & & & & & & & & & & & \\
\hline A7 & Referencia a la Cercania & S/. $\quad 15,000.00$ & & & & & & & & & & & & & & & & & & & & & & & & & \\
\hline A8 & "Potenciar Multident Card" & S/. $\quad 7,000.00$ & & & & & & & & & & & & & & & & & & & & & & & & & \\
\hline A9 & Estategias Digitales & S/. $\quad 20,000.00$ & & & & & & & & & & & & & & & & & & & & & & & & & \\
\hline Al0 & Publicidad Off line & S/. $\quad 12,000.00$ & & & & & & & & & & & & & & & & & & & & & & & & & \\
\hline & & S/. $\quad 152,036.00$ & S/. $127,950.00$ & & & & & & & & & & & & & & & & & & & & & & & & \\
\hline
\end{tabular}

\begin{tabular}{|c|c|c|c|c|c|c|c|c|c|c|c|c|c|c|c|c|c|c|c|c|c|c|c|c|c|c|}
\hline \multirow[b]{2}{*}{ Cod } & \multirow[b]{2}{*}{ Acciones } & \multicolumn{2}{|c|}{ Presupuesto } & \multicolumn{4}{|c|}{ Julio } & \multicolumn{4}{|c|}{ Agosto } & \multicolumn{3}{|c|}{ Setiembre } & \multicolumn{4}{|c|}{ Octubre } & \multicolumn{4}{|c|}{ Noviembre } & \multicolumn{4}{|c|}{ Diciembre } \\
\hline & & $\begin{array}{c}\text { Gastos } \\
\text { (Miles S/.) }\end{array}$ & $\begin{array}{l}\text { Inversión } \\
\text { (Miles S/.) }\end{array}$ & ปู & 岕 & 공 & 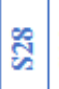 & స్రి & 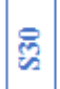 & $\bar{\delta}$ & 乩 & $\mathscr{c}$ & 总 & 忞 & $\hat{s}$ & $\mathscr{m}$ & ल्ठू⿹ & 奉 & 焉 & 㞼 & 箈 & 声 & 嗮 & 㛬 & 落 & 照 \\
\hline Al & "Plan de seguimiento" & $\mathrm{S} /$. & S/. $\quad 30,000.0$ & & & & & & & & & & & & & & & & & & & & & & & \\
\hline A2 & "Horario domingo" & S/. $\quad 34,276.00$ & & & & & & & & & & & & & & & & & & & & & & & & \\
\hline A3 & "Experiencia MultidentKids" & S/. $\quad 24,700.00$ & S/. $\quad 64,950.0$ & & & & & & & & & & & & & & & & & & & & & & & \\
\hline A4 & "Alianzas" & S/. $\quad 5,000.00$ & & & & & & & & & & & & & & & & & & & & & & & & \\
\hline A5 & "Plan sin caries". & & $33,000.0$ & & & & & & & & & & & & & & & & & & & & & & & \\
\hline A6 & "Programa guerra a las caries" & S/. $\quad 34,060.00$ & & & & & & & & & & & & & & & & & & & & & & & & \\
\hline A7 & Referencia a la Cercania & S/. $\quad 15,000.00$ & & & & & & & & & & & & & & & & & & & & & & & & \\
\hline A8 & "Potenciar Multident Card" & S/. $\quad 7,000.00$ & & & & & & & & & & & & & & & & & & & & & & & & \\
\hline A9 & Estategias Digitales & S/. $\quad 20,000.00$ & & & & & & & & & & & & & & & & & & & & & & & & \\
\hline Al0 & Publicidad Off line & $\mathrm{S} / . \quad 12,000.00$ & & & & & & & & & & & & & & & & & & & & & & & & \\
\hline & & S/. $152,036.00$ & S/. $127,950.00$ & & & & & & & & & & & & & & & & & & & & & & & \\
\hline
\end{tabular}




\subsection{Presupuesto de Marketing}

El plan supone una inversión de S/. 361,986, de los cuales, el 35\% es para adquisición de tecnología y la diferencia son gastos en marketing.

\begin{tabular}{|c|c|c|}
\hline Acción & Gasto & $\begin{array}{c}\text { Inversión } \\
\text { Activos }\end{array}$ \\
\hline "Plan de seguimiento" & & S/. $30,000.00$ \\
\hline "Horario domingo" & S/. $34,276.00$ & \\
\hline "Experiencia Multident Kids" & S/. $24,700.00$ & S/. $64,950.00$ \\
\hline "Alianzas" & S/. $\quad 5,000.00$ & \\
\hline "Plan sin caries". & S/. $21,000.00$ & S/. 33,000.00 \\
\hline "Programa guerra a las caries" & S/. 34,060.00 & \\
\hline "Referencia a la cercanía" & S/. $15,000.00$ & \\
\hline "Potenciar Multident Card" & S/. $\quad 7,000.00$ & \\
\hline "Estrategias Digitales" & S/. $20,000.00$ & \\
\hline "Publicidad Off line" & S/. $12,000.00$ & \\
\hline Total & S/. $152,036.00$ & S/. $127,950.00$ \\
\hline & \multicolumn{2}{|c|}{ S/. 279,986.00 } \\
\hline
\end{tabular}




\subsection{Estado de Resultados}

\subsubsection{Previsión de ventas}

De acuerdo con el histórico de ventas del programa Multident Kids, para los próximos 3 años tendríamos la siguiente proyección de ventas sin la aplicación del presente plan como se muestra en la tabla 33.

Tabla 33. Proyección de Ventas sin plan de marketing propuesto

\begin{tabular}{|l|r|r|r|r|r|}
\cline { 2 - 6 } \multicolumn{1}{c|}{} & \multicolumn{1}{c|}{2016} & \multicolumn{1}{c|}{2017} & 2018 & \multicolumn{1}{c|}{2019} & \multicolumn{1}{c|}{2020} \\
\hline $\begin{array}{l}\text { Pacientes con facturacion } \\
\text { (en tratamiento) }\end{array}$ & 2,750 & 3,055 & 3,115 & 3,338 & 3,521 \\
\hline Gasto promedio Annual & 208 & 240 & 240 & 260 & 300 \\
\hline Total Ventas & 572,000 & 733,200 & 747,600 & 867,967 & $1,056,250$ \\
\hline
\end{tabular}

Las ventas del 2018 están calculadas en base a la participación de mercado actual $22 \%$

El plan considera para la previsión de ventas como se muestra en la tabla 34, la distribución del mercado meta por cada acción de acuerdo con las preferencias y hábitos analizados en el mismo.

Tabla 34. Previsión de Ventas del plan de marketing propuesto

\begin{tabular}{|l|r|r|r|}
\hline Plan de seguimiento & \multicolumn{1}{|c|}{2018} & \multicolumn{1}{c|}{2019} & \multicolumn{1}{c|}{2020} \\
\hline Pacientes en tratamiento & 1,567 & 1,756 & 1,976 \\
\hline Gasto promedio anual & $\mathrm{S} / .300$ & $\mathrm{~S} / .320$ & $\mathrm{~S} / .350$ \\
\hline Ventas & $\mathrm{S} / .470,229$ & $\mathrm{~S} / .561,842$ & $\mathrm{~S} / .691,503$ \\
\hline
\end{tabular}




\begin{tabular}{|c|c|c|c|}
\hline Horario Domingo & 2018 & 2019 & 2020 \\
\hline Pacientes en tratamiento & 650 & 728 & 819 \\
\hline Gasto promedio anual & $\mathrm{S} / .300$ & $\mathrm{~S} / .320$ & $\mathrm{~S} / .350$ \\
\hline Ventas & S/.194,973 & S/.232,959 & $\mathrm{S} / .286,721$ \\
\hline Experiencia MultidentKids & 2018 & 2019 & 2020 \\
\hline Pacientes en tratamiento & 535 & 600 & 675 \\
\hline Gasto promedio anual & $\mathrm{S} / .300$ & $\mathrm{~S} / .320$ & $\mathrm{~S} / .350$ \\
\hline Ventas & S/.160,566 & $\mathrm{S} / .191,849$ & $\mathrm{~S} / .236,123$ \\
\hline
\end{tabular}

\begin{tabular}{|c|c|c|c|}
\hline Alianzas & 2018 & 2019 & 2020 \\
\hline Plan sin caries & 2018 & 2019 & 2020 \\
\hline Pacientes en tratamiento & 503 & 564 & 634 \\
\hline Gasto promedio anual & $\mathrm{S} / .360$ & $\mathrm{~S} / .360$ & $\mathrm{~S} / .360$ \\
\hline Ventas & $\mathrm{S} / .135,839$ & S/.163,431 & $\mathrm{S} / .202,931$ \\
\hline
\end{tabular}


Tabla 35. Resumen previsión de ventas

\begin{tabular}{|c|c|c|c|}
\hline & 2018 & 2019 & 2020 \\
\hline Pacientes en tratamiento & 3,055 & 3,823 & 4,282 \\
\hline Nuevos & 1,925 & 2,256 & 2,527 \\
\hline Existentes & 1,130 & 1,567 & 1,756 \\
\hline Ventas & S/.733,200 & S/.1,165,847 & S7.1,378,860 \\
\hline
\end{tabular}

7.4.2. Proyección de estado de resultados

La inversión en el plan Marketing es financiada al 60\% bajo la siguiente estructura de pagos.

\begin{tabular}{|l|r|}
\hline Financiamiento & $60 \%$ \\
\hline Deuda & $167,991.60$ \\
\hline Tasa & $16 \%$ \\
\hline Plazo & 3.00 \\
\hline
\end{tabular}

\begin{tabular}{|c|r|c|c|}
\hline Periodo & Amortización & Interes & Cuota \\
\hline 1 & $61,955.61$ & $34,750.66$ & $96,706.27$ \\
\hline 2 & $71,868.51$ & $24,837.76$ & $96,706.27$ \\
\hline 3 & $83,367.47$ & $13,338.80$ & $96,706.27$ \\
\hline
\end{tabular}


El programa Multident Kids presenta un incremento del 59\% de las ventas para el 2018 respecto del año anterior y un margen neto del 5\% en el 2018 y $19 \%$ hacia el 2020.

Tabla 36. Proyección de Estado de Ganancias y Pérdidas del programa Multident Kids

\begin{tabular}{|c|c|c|c|c|}
\hline Expresado en S/. & 2017 & 2018 & 2019 & 2020 \\
\hline Ventas & $733,200.00$ & $1,165,846.79$ & $1,378,859.95$ & $1,674,718.06$ \\
\hline Costo de ventas & $278,616.00$ & $443,021.78$ & $523,966.78$ & $636,392.86$ \\
\hline Utilidad Bruta & $454,584.00$ & $722,825.01$ & $854,893.17$ & $\mathbf{1 , 0 3 8 , 3 2 5 . 2 0}$ \\
\hline Gastos administrativos y de ventas & $403,260.00$ & $555,296.00$ & $532,796.00$ & $529,636.00$ \\
\hline Depreciacion del ejercicio & & $42,650.00$ & $42,650.00$ & $42,650.00$ \\
\hline Utilidad Operacional & $51,324.00$ & $124,879.01$ & $279,447.17$ & $466,039.20$ \\
\hline Gastos financieros & $1,154.43$ & $34,750.66$ & $24,837.76$ & $13,338.80$ \\
\hline Utilidad antes de impuestos & $50,169.57$ & $90,128.35$ & $254,609.41$ & $452,700.40$ \\
\hline Impuesto a la renta & $15,050.87$ & $27,038.51$ & $76,382.82$ & $135,810.12$ \\
\hline Utilidad Neta & $35,118.70$ & $63,089.85$ & $178,226.59$ & $316,890.28$ \\
\hline & 2017 & 2018 & 2019 & 2020 \\
\hline Margen Bruto & $62 \%$ & $62 \%$ & $62 \%$ & $62 \%$ \\
\hline Margen Operativo & $7 \%$ & $11 \%$ & $20 \%$ & $28 \%$ \\
\hline Margen Neto & $5 \%$ & $5 \%$ & $13 \%$ & $19 \%$ \\
\hline
\end{tabular}




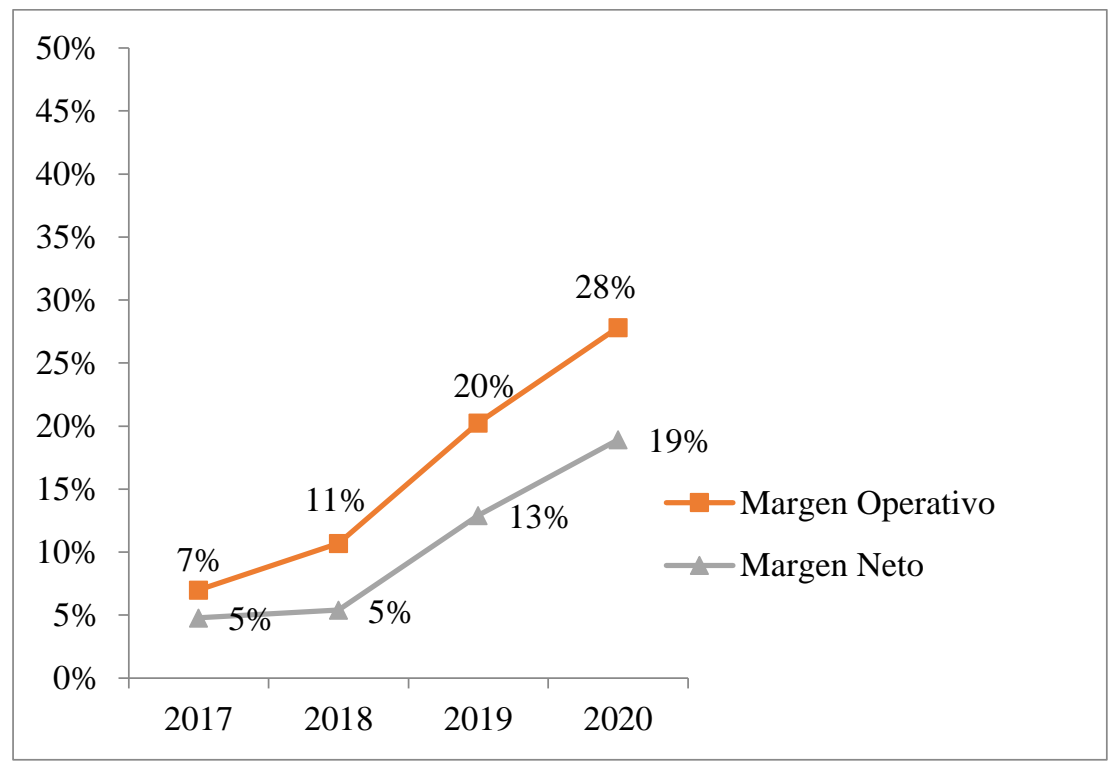

Figura 57. Proyección de Resultados 


\section{CAPÍTULO VIII}

\section{EVALUACIÓN DE LA ESTRATEGIA}

\subsection{Sistema de Información y Control}

Los sistemas de información se basarán en información de fuentes internas y externas que usaremos según la etapa a analizar del plan de marketing, definimos la periodicidad en que se deberá obtener y el nivel de confianza que se debe asumir.

Para cada estrategia hemos definido uno o más indicadores de control, ver tabla 37.

\begin{tabular}{|c|c|c|c|c|}
\hline \multicolumn{5}{|c|}{ Sistema de Información sobre el entorno } \\
\hline Información & Fuente & $\begin{array}{l}\text { Period } \\
\quad \text { o }\end{array}$ & $\begin{array}{c}\text { Confian } \\
\text { za }\end{array}$ & Etapa Plan \\
\hline $\begin{array}{l}\text { - Lineamientos } \\
\text { estratégicos de la } \\
\text { empresa } \\
\text { - Tamaño y } \\
\text { evolución del } \\
\text { sector } \\
\text { odontológico } \\
\text { - Análisis de } \\
\text { productos, precio, } \\
\text { publicidad y } \\
\text { distribución de la } \\
\text { competencia en } \\
\text { odontopediatria } \\
\text { - Ventas anuales de } \\
\text { la competencia } \\
\text { - Participación del } \\
\text { mercado }\end{array}$ & $\begin{array}{l}\text { Superintendencia de } \\
\text { Salud (SuSalud) } \\
\text { Colegio odontológico } \\
\text { del Perú } \\
\text { Medios especializados } \\
\text { (Gestión, D1, Canal N) }\end{array}$ & Anual & $90 \%$ & $\begin{array}{l}\text { Análisis del } \\
\text { entorno } \\
\text { Mercado } \\
\text { Fuerzas } \\
\text { competitivas } \\
\text { Posicionamien } \\
\text { to }\end{array}$ \\
\hline
\end{tabular}


- Posicionamiento

Sistema de información sobre Marketing

\begin{tabular}{|l|l|l|l|l|}
\hline $\begin{array}{l}\text { - Costos de Ventas } \\
\text { - Staff de } \\
\text { profesionales }\end{array}$ & Gestión Humana & Anual & $100 \%$ & $\begin{array}{l}\text { Definición del } \\
\text { precio, } \\
\text { producto, } \\
\text { distribución y } \\
\text { promoción }\end{array}$ \\
\hline - Mercados actuales & Estudios cualitativos & mensu & $80 \%$ & Selección del \\
\hline
\end{tabular}

y potenciales.

- Selección del producto objetivo.

- Identificación de productos similares $y / 0$ sustitutos

- Proveedores y alianzas estratégicas (entrevistas)

Técnicas de proyección

Definición de precio, productos y promoción.

\section{Sistema de información sobre Comercial}

\begin{tabular}{|l|l|l|l|l|}
\hline $\begin{array}{l}\text { Proyección de } \\
\text { ventas en base al } \\
\text { histórico del } \\
\text { mercado }\end{array}$ & $\begin{array}{l}\text { MINSA } \\
\text { SuSalud }\end{array}$ & $\begin{array}{l}\text { mensu } \\
\text { al }\end{array}$ & $70 \%$ & $\begin{array}{l}\text { Estimación de } \\
\text { las ventas }\end{array}$ \\
\hline
\end{tabular}




\subsection{Plan de Contingencia}

El Plan de Contingencia nos permite responder de forma alternativa ante la ocurrencia

de amenazas y debilidades del programa, de forma que los objetivos definidos se cumplan.

Se han divido en 3 bloques principales según las estrategias planteadas. Pero, además, los indicadores propuestos tienen una periodicidad mensual que permite el control del avance de la ejecución del plan como se muestra en la tabla 32.

Debido a lo importante que es el cumplimiento de los objetivos para el éxito del plan se consideran tanto acciones para escenarios positivos como negativos. 
Tabla 37. Indicadores de Control y Plan de Contingencia

\begin{tabular}{|c|c|c|c|c|c|c|c|c|}
\hline Objetivo & \# & Acción & Indicador & Previsto & Real & \multicolumn{3}{|c|}{ Plan de Contingencia } \\
\hline \multirow{8}{*}{$\begin{array}{l}\text { Incrementar en } \\
25 \% \text { los } \\
\text { pacientes en } \\
\text { tratamiento y en } \\
25 \% \text { el gasto } \\
\text { promedio anual }\end{array}$} & \multirow[b]{2}{*}{$\mathbf{A 1}$} & \multirow{2}{*}{$\begin{array}{c}\text { "Plan de } \\
\text { seguimiento" }\end{array}$} & $\begin{array}{l}\text { Tasa de recupero de } \\
\text { pacientes }\end{array}$ & $12 \%$ & & Exceso & $\begin{array}{l}\text { Ventas > } \\
57,000 \\
\text { mensuales }\end{array}$ & $\begin{array}{c}\text { Ampliación de la cobertura } \\
\text { horaria diaria. }\end{array}$ \\
\hline & & & Gasto promedio anual & 300 & & Defecto & $\begin{array}{c}\text { Pacientes } \\
\text { recuperados < } \\
191 \text { mensuales }\end{array}$ & $\begin{array}{c}\text { Campaña de evaluación } \\
\text { odontológica gratuita durante } 1 \\
\text { mes, para pacientes sin } \\
\text { tratamiento en el último año. }\end{array}$ \\
\hline & & & $\begin{array}{l}\text { Cantidad de pacientes } \\
\text { nuevos }\end{array}$ & 650 & & Exceso & $\begin{array}{c}\text { Ventas > } \\
23,000 \\
\text { mensuales }\end{array}$ & Ofrecer Plan Sin caries. \\
\hline & A2 & $\begin{array}{l}\text { Horar10 } \\
\text { domingo" }\end{array}$ & Gasto promedio anual & 300 & & Defecto & $\begin{array}{c}\text { Pacientes } \\
\text { nuevos en } \\
\text { tratamiento < } \\
191 \text { mensuales }\end{array}$ & $\begin{array}{l}\text { Reducción de las horas de } \\
\text { atención los dias domingos. }\end{array}$ \\
\hline & & & $\%$ Nivel de & 800 & & Exceso & NSP $>80 \%$ & $\begin{array}{l}\text { Concurso en redes sociales para } \\
\text { generar recomendación }\end{array}$ \\
\hline & & & $\begin{array}{l}\text { satistaccion del cliente } \\
\text { (padre-niño) }\end{array}$ & $80 \%$ & & Defecto & NSP $<80 \%$ & $\begin{array}{c}\text { Recopilar las acciones de } \\
\text { mejora. }\end{array}$ \\
\hline & $\mathbf{A 3}$ & $\begin{array}{l}\text { "Experiencia } \\
\text { Multident Kids" }\end{array}$ & $\begin{array}{l}\text { Cantidad de pacientes } \\
\text { nuevos }\end{array}$ & 650 & & Exceso & $\begin{array}{c}\text { Ventas }> \\
23,000 \\
\text { mensuales }\end{array}$ & Ofrecer Plan Sin caries. \\
\hline & & & Gasto promedio anual & 300 & & Defecto & $\begin{array}{c}\text { Pacientes } \\
\text { nuevos en } \\
\text { tratamiento }< \\
191 \text { mensuales }\end{array}$ & $\begin{array}{c}\text { Campaña de evaluación } \\
\text { odontológica gratuita durante } 1 \\
\text { semana y/o fechas especiales del } \\
\text { mes. }\end{array}$ \\
\hline
\end{tabular}




\begin{tabular}{|c|c|c|c|c|c|c|c|}
\hline \multirow{4}{*}{$\begin{array}{c}\text { Ampliar la } \\
\text { cobertura de } \\
\text { convenios con } \\
\text { presencia en el } \\
3 \% \text { de empresas } \\
\text { en lima este }\end{array}$} & \multirow{2}{*}{ A4 } & \multirow{2}{*}{ "Alianzas" } & $\begin{array}{l}\text { \# de afiliados promedio } \\
\text { por convenio }\end{array}$ & 25 & Exceso & $\begin{array}{c}\quad \# \text { de } \\
\text { afiliaciones } \\
\text { provenientes de } \\
\text { convenios > } 84 \\
\text { mensuales }\end{array}$ & Entregar incentivos al convenio \\
\hline & & & \# convenios suscritos & 40 & Defecto & $\begin{array}{c}\text { \# de } \\
\text { afiliaciones } \\
\text { provenienes de } \\
\text { convenios < } \\
84 \text { mensuales }\end{array}$ & $\begin{array}{l}\text { Charlas a los clientes de la } \\
\text { empresa en sus instalaciones }\end{array}$ \\
\hline & \multirow{2}{*}{ A5 } & \multirow{2}{*}{ "Plan sin caries" } & $\begin{array}{l}\text { \# de afiliados promedio } \\
\text { por convenio }\end{array}$ & 20 & Exceso & $\begin{array}{c}\text { \# de } \\
\text { afiliaciones al } \\
\text { plan sin caries } \\
>54 \text { mensuales }\end{array}$ & Entregar incentivo a la empresa \\
\hline & & & \# convenios suscritos & 34 & Defecto & $\begin{array}{l}\quad \# \text { de } \\
\text { afiliaciones al } \\
\text { plan sin caries } \\
<54 \text { mensuales }\end{array}$ & $\begin{array}{c}\text { Campaña de evaluación } \\
\text { odontológica gratuita durante } 1 \\
\text { semana por fecha de aniversario } \\
\text { de la empresa }\end{array}$ \\
\hline
\end{tabular}




\begin{tabular}{|c|c|c|c|c|c|c|c|}
\hline \multirow{11}{*}{$\begin{array}{c}\text { Aumentar la } \\
\text { notoriedad de la } \\
\text { marca en Lima } \\
\text { este de } 34 \% \text { a } \\
50 \%\end{array}$} & \multirow[b]{2}{*}{ A6 } & \multirow{2}{*}{$\begin{array}{l}\text { "Guerra a las } \\
\text { caries" }\end{array}$} & \multirow{2}{*}{$\begin{array}{l}\text { \# Prospecto de citas } \\
\text { agendadas }\end{array}$} & \multirow[b]{2}{*}{1,343} & \multirow{2}{*}{$\begin{array}{l}\text { Exceso } \\
\text { Defecto }\end{array}$} & $\begin{array}{l}\text { \# prospectos } \\
\text { conseguidos }> \\
672 \text { por evento }\end{array}$ & Seguimiento de la cita \\
\hline & & & & & & $\begin{array}{c}\text { \# prospectos } \\
\text { conseguidos < } \\
1,343 \text { por } \\
\text { evento }\end{array}$ & $\begin{array}{c}\text { Reforzar actividades de difusion } \\
\text { en colegios, centros preescolares } \\
\text { y empresas relacionadas al } \\
\text { mismo público. }\end{array}$ \\
\hline & \multirow{2}{*}{ A7 } & \multirow{2}{*}{$\begin{array}{l}\text { "Referencia a la } \\
\text { cercanía" }\end{array}$} & \multirow{2}{*}{$\begin{array}{l}\text { \# Pacientes } \\
\text { informados por } \\
\text { publicidad exterior }\end{array}$} & \multirow[b]{2}{*}{2,163} & \multirow[t]{2}{*}{ Exceso } & $\begin{array}{c}\text { Clientes } \\
\text { impactados > } \\
2,163\end{array}$ & $\begin{array}{l}\text { Intensificar la acción en puntos } \\
\text { estratégicos }\end{array}$ \\
\hline & & & & & & $\begin{array}{c}\text { Clientes } \\
\text { impactados }< \\
2,163\end{array}$ & $\begin{array}{c}\text { Entrega de afiches y volantes en } \\
\text { puntos estrategicos }\end{array}$ \\
\hline & \multirow[t]{2}{*}{ A8 } & \multirow[t]{2}{*}{$\begin{array}{c}\text { "Potenciar } \\
\text { Multident Card" }\end{array}$} & \multirow[t]{2}{*}{$\begin{array}{l}\text { \# Pacientes que } \\
\text { refieren a la Multident } \\
\text { Card }\end{array}$} & \multirow[t]{2}{*}{1923} & Exceso & $\begin{array}{c}\text { Clientes } \\
\text { impactados > } \\
2,019\end{array}$ & Intensificar la acción \\
\hline & & & & & Defecto & & Reformular la politica de precio \\
\hline & \multirow{3}{*}{ A9 } & \multirow{3}{*}{$\begin{array}{l}\text { "Estrategias } \\
\text { Digitales" }\end{array}$} & $\begin{array}{l}\% \text { Aumento de } \\
\text { seguidores en redes } \\
\text { sociales }\end{array}$ & $70 \%$ & Exceso & $\begin{array}{c}\text { Interacciones > } \\
41,530\end{array}$ & $\begin{array}{c}\text { Concurso para generar } \\
\text { vinculación de marcas de } \\
\text { servicios complementarios }\end{array}$ \\
\hline & & & $\begin{array}{l}\% \text { Alcance de las } \\
\text { publicaciones }\end{array}$ & $50 \%$ & \multirow{2}{*}{ Defecto } & \multirow{2}{*}{$\begin{array}{c}\text { Interacciones }< \\
41,530\end{array}$} & \multirow{2}{*}{$\begin{array}{l}\text { Reformular contenido de las } \\
\text { publicaciones }\end{array}$} \\
\hline & & & $\begin{array}{l}\text { \# Interacciones en } \\
\text { redes sociales }\end{array}$ & 41,530 & & & \\
\hline & \multirow{2}{*}{ A10 } & \multirow{2}{*}{$\begin{array}{l}\text { "Publicidad } \\
\text { Offline" }\end{array}$} & \multirow{2}{*}{ \# Personas impactadas } & \multirow[b]{2}{*}{3600} & Exceso & $\begin{array}{c}\text { Clientes } \\
\text { impactados > } \\
3600\end{array}$ & $\begin{array}{l}\text { Intensificar la acción en puntos } \\
\text { estratégicos }\end{array}$ \\
\hline & & & & & Defecto & $\begin{array}{c}\text { Clientes } \\
\text { impactados < } \\
3600\end{array}$ & $\begin{array}{l}\text { Reformular los puntos de } \\
\text { distribucion }\end{array}$ \\
\hline
\end{tabular}




\subsection{Evaluación Financiera}

En la evaluación financiera, el flujo de caja solo considera el diferencial de las ventas producto de la aplicación del plan y su proyección para los años 2018 al 2020.

La inversión en el plan S/ 279,986 tiene un retorno de 1.9 años. El Valor presente neto es de S/.48,040.81 que hace viable el proyecto a un costo de oportunidad del $20 \%$, siendo la tasa interna de retorno económica del $33.3 \%$ y la tasa interna de retorno financiero de $40.5 \%$ que lo hace atractivo frente a otras alternativas de inversión superior al WACC de $15 \%$.

El índice de retorno sobre la inversión es de 49\%.

\section{Tabla 38. Flujo de Fondos}

\begin{tabular}{|c|c|c|c|c|}
\hline Expresado en S/. & 0 & 1 & 2 & 3 \\
\hline$(+)$ Ingresos & & $418,246.79$ & $510,893.28$ & $618,468.06$ \\
\hline (-)Costo de ventas & & $158,933.78$ & $194,139.45$ & $235,017.86$ \\
\hline $\begin{array}{l}\text { (-)Gastos Administrativos y de } \\
\text { ventas }\end{array}$ & & $21,526.15$ & $21,526.15$ & $21,526.15$ \\
\hline (-)Gastos Plan MKT & & $130,509.85$ & $108,009.85$ & $104,849.85$ \\
\hline (-)Licencias y equipos & $127,950.00$ & - & - & - \\
\hline Resultado antes de impuestos & & $107,277.01$ & $187,217.83$ & $257,074.20$ \\
\hline Impuesto a la renta & & $32,183.10$ & $56,165.35$ & $77,122.26$ \\
\hline Capital de trabajo & $152,036.00$ & & & \\
\hline Inversión & $279,986.00$ & & & \\
\hline Flujo de Fondos Operativo & & $75,093.91$ & $131,052.48$ & $179,951.94$ \\
\hline (+)Depreciación & & $42,650.00$ & $42,650.00$ & $42,650.00$ \\
\hline Flujo de Fondos Económico & - 279,986.00 & $117,743.91$ & $173,702.48$ & $222,601.94$ \\
\hline (-)Amortizacion & & $61,955.61$ & $71,868.51$ & $83,367.47$ \\
\hline
\end{tabular}




\begin{tabular}{|l|r|r|r|r|} 
& & & & \\
(-)Intereses & & $34,750.66$ & $24,837.76$ & $13,338.80$ \\
\hline (+)Credito fiscal & & $10,425.20$ & $7,451.33$ & $4,001.64$ \\
\hline Prestamo & 167991.6 & & & \\
Flujo de Fondos Financiero & $-111,994.40$ & $\mathbf{3 1 , 4 6 2 . 8 3}$ & $\mathbf{8 4 , 4 4 7 . 5 4}$ & $\mathbf{1 2 9 , 8 9 7 . 3 1}$ \\
\hline
\end{tabular}

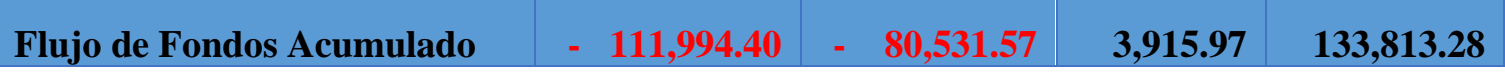

\begin{tabular}{|l|r|r|}
\hline & \multicolumn{1}{|c|}{ Deuda } & \multicolumn{1}{c|}{ Capital } \\
\hline Inversión & $167,991.60$ & $111,994.40$ \\
\hline Peso & $60 \%$ & $40 \%$ \\
\hline Costo & $11 \%$ & $20 \%$ \\
\hline WACC & \multicolumn{2}{|c|}{$15 \%$} \\
\hline
\end{tabular}

Tabla 39.Indicadores del Proyecto

\begin{tabular}{|l|r|}
\hline \multicolumn{2}{|c|}{ Indicadores del Proyecto } \\
\hline Costo de Oportunidad & $20 \%$ \\
\hline TIRE & S/. 48,040.81 \\
\hline TIRF & $33.3 \%$ \\
\hline Años de retorno & $40.5 \%$ \\
\hline ROI & 1.95 \\
\hline
\end{tabular}




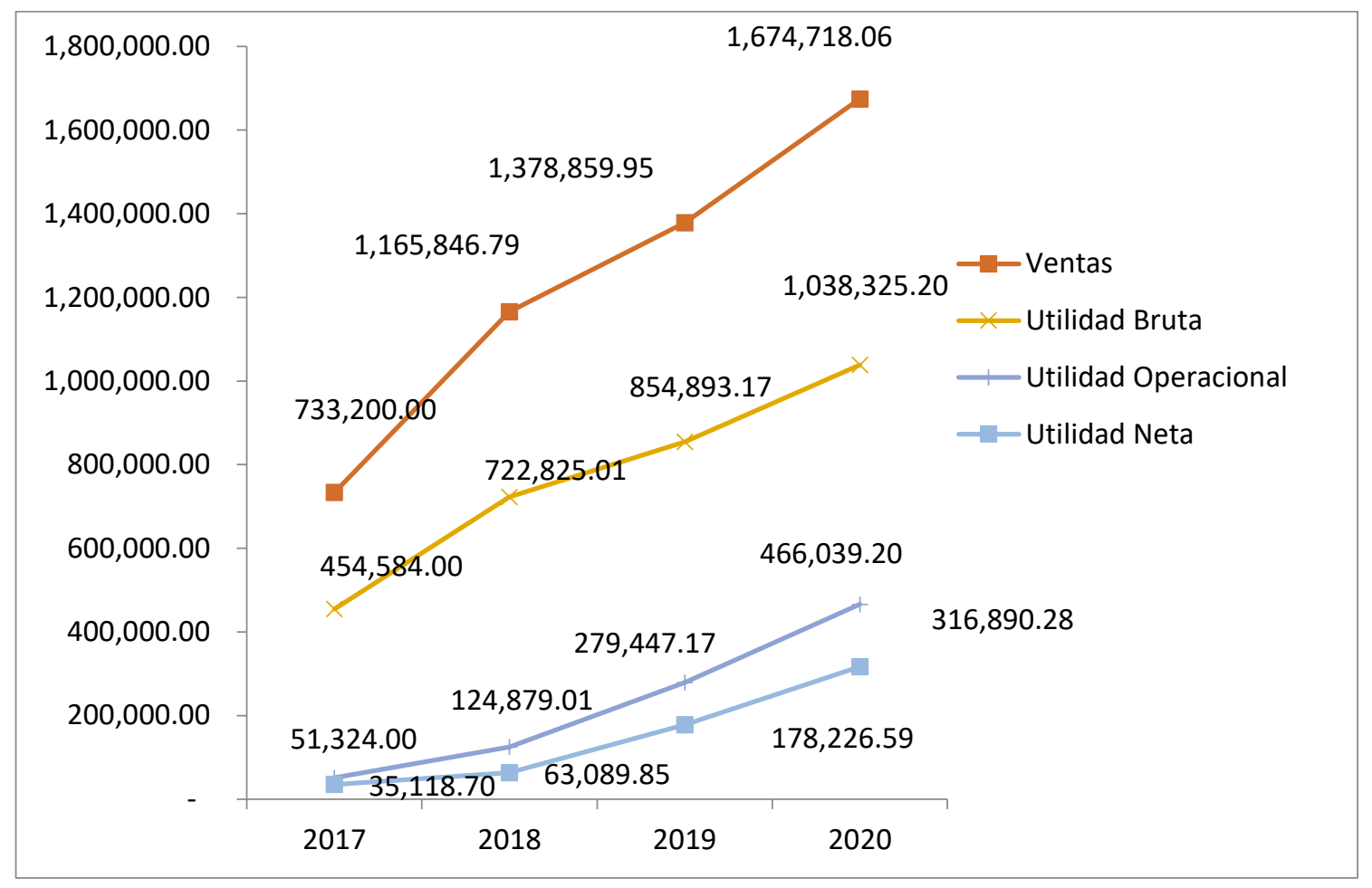

Figura 58. Evaluación Financiera 


\section{CONCLUSIONES Y RECOMENDACIONES}

El desarrollo del trabajo de investigación nos lleva a las siguientes conclusiones:

1. La población perteneciente al NSE A, B y C+ de los distritos de Ate y Santa Anita se caracteriza por mantener una misma idiosincrasia, mantienen hábitos y preferencias similares, lo que varía entre segmentos es el poder adquisitivo. El plan propuesto considera mecanismos para potenciar los beneficios y transmitir adecuadamente la relación calidad-precio.

2. El mercado de Ate y Santa Anita experimenta un constante crecimiento y un sector comercial muy activo. Ate se ha convertido en el tercer distrito más poblado de la capital y ha hecho de esta zona de Lima este, un destino altamente atractivo para las inversiones privadas. El presente plan propone la generación de alianzas con comercios que tengan el mismo público objetivo y de mayor rotación a diferencia de colegios en los que se enfoca actualmente, a fin de aprovechar esta oportunidad.

3. Producto de la investigación se identificó que independientemente del tipo de seguro al que estén afiliados, los padres optan por una atención particular que les genere confianza y buen trato hacia sus hijos, por tanto, los principales aspectos influyentes son la recomendación y cercanía al lugar donde viven. El plan 
propuesto comprende mecanismos para que los padres de los actuales pacientes de la clínica sientan confianza en el servicio y generen más y mejores recomendaciones sobre su experiencia.

4. El principal motivo por el cual los niños no concluyen sus tratamientos es la falta de tiempo de los padres y falta de seguimiento, es prioritario incluir la atención en horarios flexibles y acorde a las necesidades de los pacientes.

5. Actualmente vivimos inmersos en un sin número de actividades entorno a la profesión, hogar, educación y familia, y un aspecto muy valorado por los padres es que alguien pueda recordarles los tratamientos y controles de sus hijos, siendo este un aspecto no trabajado en Multident Kids, por ello, el plan propone un seguimiento continuo que permita a los padres reconocer a Multident Kids como un aliado en la salud de sus hijos, mejorar su bienestar y la satisfacción de los padres contribuyendo a su economía a largo plazo. Además, buscan información inmediata por lo que tienen gran interacción con redes sociales y el plan propone estrategias digitales están dirigidas a ellos.

6. Como resultado de la investigación existe una tendencia de los padres hacia la salud preventiva por eso los planes diseñados están orientados a cubrir esa necesidad. 
7. Los principales pacientes de la clínica son los niños y madres gestantes por ser los más jóvenes constituyen el primer eslabón de la cadena para la atención de los tratamientos futuros del paciente a lo largo de su vida y el de su familia. Es sumamente importante que tanto el paciente odontopediátrico y sus padres estén satisfechos por el servicio recibido.

8. El plan de Marketing propuesto para el 2018 se desarrolla de acuerdo a los resultados del análisis de los servicios valorados por los padres y niños en salud dental, que si bien la empresa tenía algunas acciones encaminadas, carecían de una comunicación adecuada de las características del servicio y sus diferenciales por lo que todo lo planteado asegura una mejora para Multident Kids. 
Las recomendaciones que consideramos más importante para futuros estudios o implementaciones:

1. El segundo motivo por el cual los niños no completan sus tratamientos diagnosticados es cuando excede considerablemente el presupuesto familiar previsto. Como resultado de las entrevistas a los padres acogieron con gran aceptación un programa de "ahorro para salud dental" que les permita planificar los gastos de la salud dental de sus hijos y tratamientos futuros sin restricción de edad y tipo de tratamiento.

El programa incluiría los siguientes beneficios:

- 1 consulta odontológica gratuita para diagnóstico al año

- 1 tratamiento preventivo gratuito al año: profilaxis

- Acceso a tratamientos preventivos y restaurativos con un descuento según tipo de tratamiento.

- Acceder al programa de beneficios por puntos.

- Acceso a programas de educación sobre salud dental: eventos, talleres, charlas

- Acceso a descuentos en las empresas que forman alianza con Multident.

El depósito mínimo exigido mensualmente sería de S/.39

2. Considerando que la ortodoncia es un tratamiento altamente demandado y que inicia en los últimos años de la niñez, es una oportunidad que la clínica puede 
explotar para mantener la fidelidad de los clientes que van dejando la odontopediatría y se convierten en los futuros clientes de cualquiera de las especialidades de la clínica.

3. Si bien el presente plan atiende las preferencias y valoraciones en el servicio de los padres y niños de los distritos en estudio, muchas de estas acciones responden a necesidades generalizadas no atendidas en diversas clínicas de Lima en la especialidad de odontopediatría. Recomendamos replicar el presente plan en las demás sedes de Multident de aquellos distritos con características similares.

4. Finalmente, para los próximos estudios se sugiere analizar la información historial de los pacientes, que bajo la implementación del plan se consigue información codificada y estructurada, para evaluar en detalle las frecuencias de tratamiento de la familia, el costo de tratamiento familiar, los motivos de abandono o irregularidad en la continuación de tratamientos, servicios adicionales que consume, etc. Actualmente muchas clínicas, dedican sus esfuerzos en obtener nuevos pacientes y dejan de lado a los que ya tienen. 


\section{ANEXOS}

Anexo 1: Lista de empresas con convenios corporativos vigentes.

\begin{tabular}{|l|l|}
\multicolumn{1}{|c|}{ EMPRESAS } & \multicolumn{1}{c|}{ DISTRITO } \\
\hline AJEPER & Ate \\
\hline ALAMACENES SANTA CLARA & Santa Anita \\
\hline ATENTO PERÚ & Ate \\
\hline CAJA HUANCAYO & Ate/Santa Anita \\
\hline COLEGIO PAMER & Santa Anita \\
\hline DUPREE & Santa Anita \\
\hline FINANCIERA RAIZ & Santa Anita \\
\hline GRAFIPAPEL S.A. & Chaclacayo \\
\hline INCOT & Ate \\
\hline LIMTEK SERVICIOS INTEGRALES & Ate \\
\hline S.A. & Santa Anita \\
\hline NESTLE PERU & Santa Anita \\
\hline PEPSI & \\
\hline PERUANA DE COMBUSTIBLE \\
(PECSA) & Santa Anita \\
\hline PLAZA VEA & Ate/Santa Anita \\
\hline PRIMAX S.A. & Ate/Santa Anita \\
\hline PROMART & Ate/Santa Anita \\
\hline REPSOL & Ate/Santa Anita \\
\hline SODIMAC & Santa Anita \\
\hline TAY LOY & Ate/Santa Anita \\
\hline TEVA PERÚ & Ate \\
\hline TOTTUS & Santa Anita \\
\hline TRANSPORTE 77 & Ate \\
\hline & \\
\hline
\end{tabular}




\section{Anexo 2: Nivel de satisfacción del cliente interno}

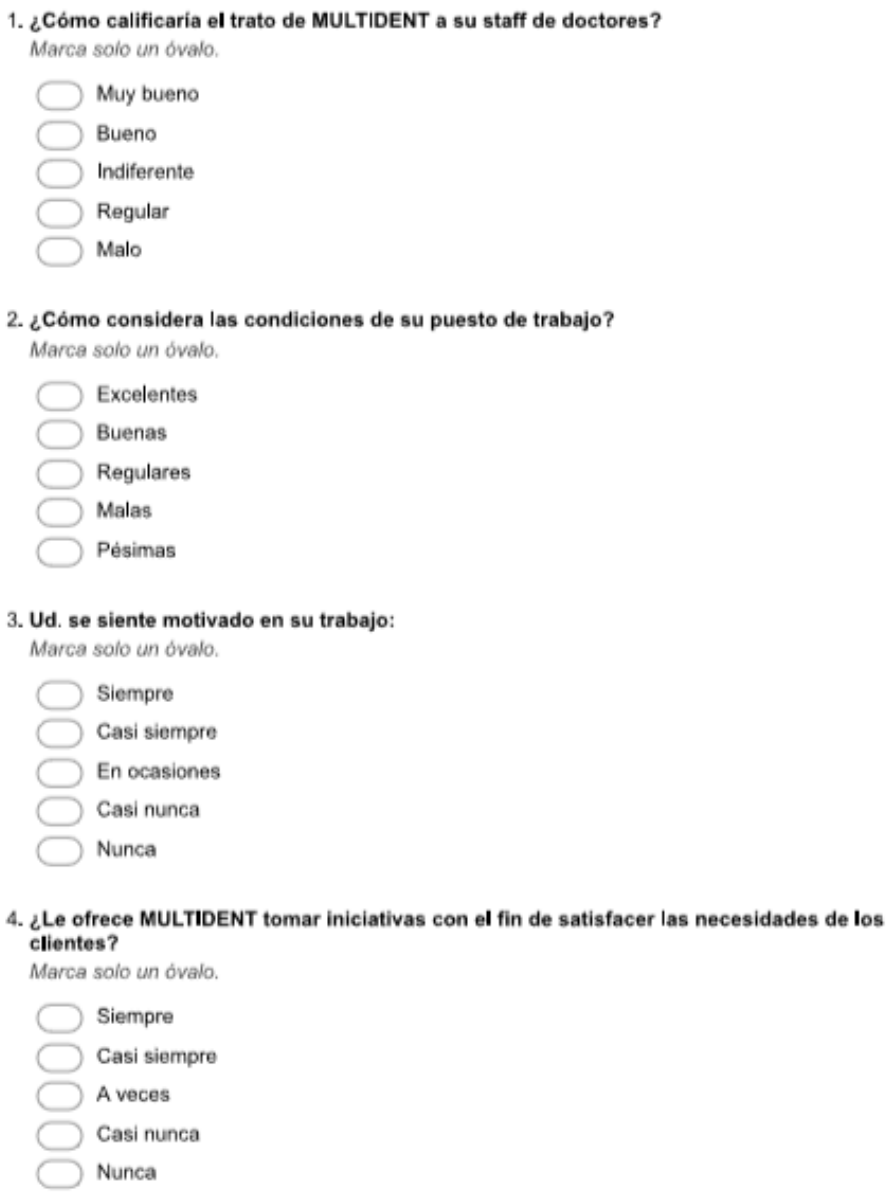

\begin{tabular}{|c|c|c|c|c|c|}
\hline \multirow{2}{*}{$\begin{array}{l}\text { Resultado de encuestas a staff de doctores } \\
\text { Atributos }\end{array}$} & \multicolumn{4}{|c|}{ Calificación } & \multirow[b]{2}{*}{ NSP } \\
\hline & $\begin{array}{l}\text { Muy } \\
\text { Bueno }\end{array}$ & Bueno & Regular & Malo & \\
\hline $\begin{array}{l}\text { ¿Cómo calificaría el trato de MULTIDENT a su staff de } \\
\text { doctores? }\end{array}$ & $56 \%$ & $39 \%$ & $6 \%$ & & $89 \%$ \\
\hline ¿Cómo considera las condiciones de su puesto de trabajo? & $17 \%$ & $78 \%$ & $6 \%$ & & $89 \%$ \\
\hline Ud. se siente motivado en su trabajo: & $56 \%$ & $33 \%$ & $11 \%$ & & $78 \%$ \\
\hline $\begin{array}{l}\text { ¿Le ofrecen tomar iniciativas con el fin de satisfacer las } \\
\text { necesidades de los clientes? }\end{array}$ & $56 \%$ & $33 \%$ & $11 \%$ & & $78 \%$ \\
\hline \multicolumn{5}{|c|}{ Nivel de Satisfacción del cliente } & $83 \%$ \\
\hline
\end{tabular}




\section{Anexo 3: Nivel de satisfacción del cliente externo}

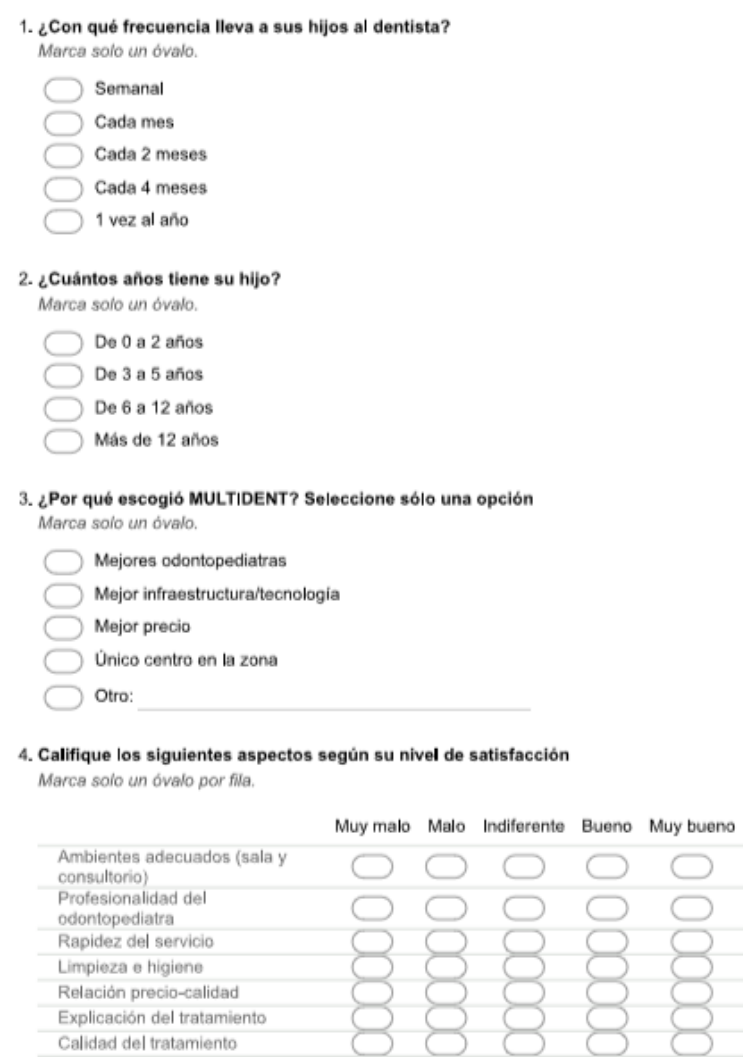

\begin{tabular}{|c|c|c|c|c|c|}
\hline \multirow{2}{*}{$\begin{array}{l}\text { Resultados de } 72 \text { encuestas } \\
\text { Atributo }\end{array}$} & \multicolumn{4}{|c|}{ Calificación } & \multirow[b]{2}{*}{ NSP } \\
\hline & Muy Bueno & Bueno & Regular & Malo & \\
\hline Ambientes adecuados (sala y consultorio) & $14 \%$ & $71 \%$ & $14 \%$ & & $71 \%$ \\
\hline Profesionalidad del odontopediatra & $21 \%$ & $71 \%$ & $7 \%$ & & $86 \%$ \\
\hline Rapidez del servicio & $21 \%$ & $43 \%$ & $36 \%$ & & $29 \%$ \\
\hline Limpieza e higiene & $29 \%$ & $57 \%$ & $14 \%$ & & $71 \%$ \\
\hline Relación precio-calidad & $29 \%$ & $36 \%$ & $29 \%$ & & $36 \%$ \\
\hline Explicación del tratamiento & $29 \%$ & $50 \%$ & & $21 \%$ & $57 \%$ \\
\hline Calidad del tratamiento & $43 \%$ & $50 \%$ & $7 \%$ & & $86 \%$ \\
\hline \multicolumn{5}{|c|}{ Nivel de Satisfacción del cliente } & $62 \%$ \\
\hline
\end{tabular}


Anexo 4: Resultado de trabajo de campo de competencia directa

\begin{tabular}{|l|c|c|c|c|c|}
\hline $\begin{array}{c}\text { Servicios } \\
\text { odontológicos }\end{array}$ & $\begin{array}{c}\text { Dental } \\
\text { Gutarra }\end{array}$ & $\begin{array}{c}\text { Santa } \\
\text { Apolonia }\end{array}$ & Brillaoral & La Merced & Multident \\
\hline Ubicación & Santa Anita & Ate & Santa Anita & Ate & $\begin{array}{c}\text { Santa Anita y } \\
\text { Ate }\end{array}$ \\
\hline Curación & 50.00 & 40.00 & 40.00 & 35.00 & S/. \\
Profilaxis & $\mathrm{S} /$. & $\mathrm{S} /$. & $\mathrm{S} /$. & $\mathrm{S} /$. & $\mathrm{S} /$. \\
\hline & 40.00 & 50.00 & 55.00 & 50.00 & 60.00 \\
\hline Sellantes & $\mathrm{S} /$. & $\mathrm{S} /$. & $\mathrm{S} /$. & $\mathrm{S} /$. & $\mathrm{S} /$. \\
\hline
\end{tabular}

Fuente: propia 


\title{
Anexo 5: Guía para entrevistas a profundidad a profesional odontólogo
}

\author{
$\underline{\text { Sobre profesional }}$
}

1. ¿Cuál es la diferencia entre un odontopediatra y un odontólogo que atiende a niños? ¿Por qué los padres deberían preferirte? ¿Qué tan importante es la conducta?)

2. ¿Los odontólogos que atienden niños son una competencia para ellos?

3. Entendemos con los avances tecnológicos deben existir sillones diferentes para niños y adultos. ¿Cuál es el beneficio para el profesional? (productividad, comodidad)

4. ¿Cuál debe ser el aporte de una clínica para impulsar en la especialidad de odontopediatría? En Multident, ¿es suficiente el espacio que dispone la clínica para actividades/juegos? ¿Los colores son adecuados? ¿Realizan charlas preventivas?

5. ¿Qué tratamientos/tecnologías no se hacen o llegan Perú? ¿Y creen que están prontas a llegar? ¿Tratamientos de anestesia, sellantes y rehabilitación con láser?

6. ¿Qué tratamientos le interesa realizar más y menos en odontopediatría?

7. ¿Cuenta con herramientas para explicar los tratamientos y una previa demostración de lo que se va a realizar a los padres y niños? ¿Qué recursos utiliza (¿música, material didáctico?)

8. ¿Por qué eligió la carrera? ¿Qué tan seguido va a actualizaciones, qué tan seguido las organizan? ¿Cuándo fue la última vez? 


\section{$\underline{\text { Sobre los padres }}$}

1. En el cono este, ¿Que tanta importancia los padres le dan a la salud de sus hijos?

2. ¿Cuánto es el \% de las consultas por urgencia (dolor, molestia) y prevención? ¿Cómo ha evolucionado?

3. ¿Qué tantos \% vienen desde muy pequeños o en gestación?

4. ¿El precio es un factor importante o imprescindible?

5. ¿Qué diferencias/similitudes encuentra en los padres y niños en los 3 distritos? (Ate, Santa Anita, San Juan de Lurigancho)

6. ¿Qué tratamientos son los que más les interesa o le dan prioridad a los padres?

\section{$\underline{\text { Sobre niños }}$}

7. ¿Qué tanto influye un ambiente diseñado para niños (físico, lúdico, emocional) en la atención del paciente?

8. ¿Cuál es la edad más difícil y fácil de manejar? (\% tranquilos, \% hiperactivos) 


\section{Anexo 6: Guía para entrevistas a profundidad a profesional relacionado}

1. ¿Cuál es la principal preocupación de los padres para su familia?

2. ¿Qué es lo que más valoran los padres de un servicio para sus hijos?

3. ¿Cómo es el principal comportamiento de los padres con respecto a la salud?

4. ¿Considera que cuidan su salud bucal? ¿Tienen buen aspecto, aliento, dientes completos?

5. ¿A dónde llevan a sus hijos con más frecuencia?

6. ¿Qué actividad es la que más disfrutan en familia?

Para profesoras:

7. ¿Con qué frecuencia los niños se enferman o se ausentan por enfermedad? ¿Es el principal motivo de ausencia?

8. ¿Los padres envían útiles de higiene a sus hijos? ¿Cuáles? ¿Qué tan los cumplidos son enviando los útiles de aseo?

9. A partir de qué edad, los niños pueden cepillarse solos según su observación

10. ¿Cuáles son las actividades que más disfrutan los niños? ¿Pintar, jugar con celular, bailar? ¿Y sus padres? 


\section{Anexo 7: Guía para entrevistas a profundidad a padres de familia}

Buenos días

Somos un grupo de estudiantes de la Escuela de Posgrado de la USIL, Maestría en Dir. Marketing y Comercial.

Nos encontramos realizando una investigación de mercados cuyo objetivo es consolidar información útil para el estudio del plan de marketing de un servicio dental para niños y gestantes.

La entrevista tratará sobre los hábitos y temas de importancia para el cuidado de la salud dental de sus hijos, a quienes ustedes cuidan y también se preocupan porque reciban la atención dedicada de un especialista.

Les confirmo que todo tema que hoy ustedes compartan, será tratado con absoluta confidencialidad.

No existen respuestas buenas ni malas, siéntanse libres de expresar sus opiniones sin restricción sus opiniones. Agradecemos su gentil participación.

Pautas: relájense, no tema estar en desacuerdo. Agradecemos su gentil participación en la presente entrevista.

1. ¿En qué momento lleva a sus hijos a un centro odontológico y por qué? (A2,A1)

2. Al momento que decides utilizar un servicio dental para tus hijos ¿Cómo es el proceso de la búsqueda? ¿Qué medios influyen en tu decisión? (A2,B5) 
3. ¿Qué aspectos considera importantes para elegir al centro odontológico para sus hijos? ¿Cómo usted elige al profesional que atenderá a su(s) hijo (s)? ¿Quién toma la decisión del centro elegido? (A3)

4. ¿Qué formas de cuidado en salud dental tienen sus hijos? ¿cuántas veces al día cepillan sus dientes? ¿Qué accesorios utilizan sus hijos en su limpieza diaria? (A1)

5. ¿Qué experiencia tuvo en la última visita realizada a un centro odontológico que asistió? ¿Cuánto tiempo mantuvo el servicio con ese centro? ¿Tuvo alguna experiencia de mayor tiempo anteriormente? ¿Cuál fue el motivo del cambio?

6. ¿Qué centros odontológicos te han referido? (C)

7. ¿En qué centros odontológicos has atendido a tus hijos? ¿Cuál considera que es el mejor centro odontológico en la atención a niños? ¿Por qué? ¿Qué ventajas ofrece este centro odontológico? ¿desventajas? ¿Cómo calificas la atención recibida por el odontopediatra de su hijo? ¿Estuvo contento con el servicio recibido? y usted dejó alguna sugerencia o reclamo por la atención recibida? (B4)

8. ¿A qué centros odontológicos no acudiría con sus hijos? ¿Por qué? (A4)

9. ¿Qué sabes sobre la especialidad de odontopediatría? ¿Encuentras alguna diferencia en relación con el servicio prestado por un odontólogo general? (A2, B1)

10. ¿Consideras importante que el profesional que atiende a sus hijos sea especializado? ¿Por qué? (B1)

11. ¿Con qué frecuencia has recurrido al servicio de un odontopediatra? (A2) 
12. Dentro de la atención dental que reciben sus hijos ¿A qué especialidades ha acudido? (p.e. ortodoncia, odontopediatría, odontología general). (A2)

13. ¿Cuál es el medio de pago que utiliza? (A2)

14. El colegio de su(s) hijo (s) le ha ofrecido alguna campaña dental, con qué centro odontológico se realizó. (B)

15. ¿Cuenta usted con EPS? ¿Se atiende únicamente por EPS o busca otras opciones? ¿Por qué? (B2)

16. ¿Qué servicios adicionales le gustaría que tenga su centro odontológico deseado para usted y para sus hijos? (B4)

17. ¿Qué preferencias de entretenimiento tienen sus hijos? ¿Cuáles les gustaría encontrar en el centro odontológico? (B4)

18. ¿Por qué medio le gustaría recibir las promociones y beneficios? (B5)

19. ¿En qué urbanización vives? ¿Dónde queda el colegio de tu hijo? ¿Dónde queda tu trabajo?

\section{Intención de compra}

Prueba de concepto:

Multident Kids es un servicio especializado para niños de 0 a 12 años de Multident donde serán atendidos por especialistas en odontopediatría y que cuenta con las siguientes características:

1. "Padres informados, hijos sanos y bolsillo controlado" es un programa para padres que consiste en invitarlos a charlas y conferencias preventivas por especialistas y que 
en ellas los hijos puedan acceder a tratamientos odontológicos preventivos gratuitos por un año, de los que se pueden elegir: profilaxis, fluorización y/o sellantes. (Esperar feedback de los padres).

2. "Somos tus asesores dentales" porque valoramos tu tiempo y la salud de tus hijos, nos comprometemos a realizar un seguimiento permanente después de cada atención odontológica y para todos los controles futuros que han sido diagnosticados.

3. "Multilandia para niños" encontrarás una sala de espera renovada según edades y preferencias donde tendremos estaciones para bebés, preescolares y escolares con sus personajes favoritos del momento, vivirán la mejor experiencia en su visita a su odontopediatra.

4. "Odontólogo delivery" donde tendrás a tu disponibilidad un especialista que revise y medique cuando tus hijos no tengan la facilidad o ánimo para trasladarse a la clínica y puedan ser atendidos en la tranquilidad de su hogar.

5. "Programa de ahorro para sonreír de por vida" que es un sistema de ahorro que te permitirá acceder a los tratamientos odontológicos, beneficios exclusivos, puntos y sorteos en Multident sin restricción hasta el monto ahorrado. Todo esto por un aporte mínimo de S/.39.00 mensuales, por medio de un débito automático o un cargo a tu tarjeta.

¿Qué te parece la propuesta? ¿Tendrías la intención de atenderte? ó ¿Cambiarías tu centro odontológico actual por la propuesta de Multident? ¿Qué te gusta o no? ¿Lo recomendarías? 
Los tratamientos preventivos más comunes como profilaxis (limpieza) y fluorización en gel en Multident cuestan S/.60.00 y tratamientos restaurativos como curaciones simples S/.60.00. ¿Estarías dispuesto a pagar?

En cuanto al "Programa de ahorro para sonreír de por vida" ¿Te afiliarías? ¿Prefieres un cargo a tu tarjeta de crédito o débito? ¿Con que banco?

Agradecemos su valiosa participación. 


\title{
Anexo 8: Encuesta de campo
}

\section{Encuesta de salud dental de tus hijos}

\author{
La información que nos pueda brindar es muy valiosa por ello nos gustaria que responda las siguientes \\ reguntas sobre el cuidado y preferencias en la salud dental de sus hijos menores (hasta 12 años) \\ 'Obligatorio
}

1. Su hijo se encuentra entre las siguientes edades:

Marca soilo un óvalo.

De 0 a 2 años

De 3 a 5 años

De 6 a 12 años

2. Durante el último año, ¿cuántas veces llevó a su hijo a un servicio dental? Marca soio un óvalo
Ninguna
1 vez
2 veces
3 veces
4 veces o más

3. ¿Por qué motivo acudió a su última visita?

Marca solo un óvalo.

Prevención

Dolor o molestia

Por estética o apariencial

Otro:

4. ¿Dónde se atendió por última vez? Marca solo un óvalo.

Consultorio particular

Clínica privada

Hospital o posta

Otro: 
5. ¿Por qué eligió el centro odontológico al que asiste su hijo?

Marca solo un óvalo.
Recomendación de otra persona
Cercania a donde vive o trabaja
Por intermedio del colegio o nido
Parte de la red de EPS

Otro:

6. Además de un buen trato de un odontólogo ¿Cuál es una caracteristica importante para usted en un centro odontológico?

Marca solo un óvalo.

Sala de entretenimiento y consultorio temático

Recordación y seguimiento del tratamiento

Amplio horario de atención

Cercania a casa o trabajo

7. ¿Qué actividades extraescolares realiza su hijo?

8. Si el centro odontológico le ofreciera "charlas sobre salud dental y algunos tratamientos preventivos gratuitos" por asistir, ¿dónde estaria dispuesto a recibirlas?

Marca solo un óvalo.

En el centro de estudios de su hijo (colegio, nido o estimulación)

En el centro odontológico

En un centro comercial

En el centro de trabajo

Me es indiferente

Otro:

9. ¿Su hijo siempre concluye los tratamientos diagnosticados en la evaluación odontológica? Marca solio un óvalo.

$\mathrm{Si}$

No

\section{Si marcó SI, continúe a partir de la pregunta 11}

\section{Si marcó NO, continúe a partir de la pregunta 10}


10. De haber respondido NO, ¿cuál es el principal motivo? Marca solo un óvalo.

Falta de tiempo

Falta de dinero

Falta de recordación

Otro:

11. ¿Cuál es el horario de su preferencia para la atención? Marca solo un óvalo por fila.

$7-9 a m$
$9-1 \mathrm{pm}$
$1-5 \mathrm{pm}$
$5-8 \mathrm{pm}$

12. ¿Cuál de estos planes de salud dental eligirias?

Marca solo un óvalo.

'Programa de ahorro para sonreir de por vida". Es un sistema de ahorro para acceder a tratamientos odontólogicos con descuentos y beneficios, con aporte de S/.39.00 mensuales. Pueden ser utilizados sin restricción de tratamientos, edad y la totalidad del monto ahorrado.

-Plan sin caries" Es un programa exclusivo para tratamientos preventivos (controles cada 3 meses) que aseguran la salud dental sin caries con un aporte de $\mathrm{S} / .30 .00$ mensuales.

Ninguno

13. ¿Cuall es el medio de pago de su preferencia?

Marca solo un óvalo.

En efectivo

Tarejta de crédito

Tarejta de débito

14. Si tu hijo tiene entre $\mathbf{0}$ a 2 años, ¿cuál de estas opciones de entretenimiento te gustaria encontrar?

Marca solo un óvalo.

Zona para pintar

Juegos didácticos

Muñecos de peluche

Otro: 
15. Si tu hijo tiene entre 3 a 5 años, ¿cuál de estas opciones de entretenimiento te gustaria encontrar?

Marca solo un óvalo.

Disfraces de personajes

Juguetes (autos, muñecas, rompecabezas, etc)

Manualidades (Plastilina, origami, colores, etc)

Piscina de pelotas

Otro:

16. Si tu hijo tiene entre 6 a 12 años, ¿cuál de estas opciones de entretenimiento te gustaria encontrar?

Marca salo un óvalo.

Zona de lectura (cuentos, sagas, revistas, etc.)

Zona cultural (maquetas, enciclopedias, videos)

Zona tecnológica (tablet, play station, etc.)

Juegos de mesa (ajedrez, jenka, domino etc.)

Football de mano

Otro:

17. ¿Qué servicio adicional es más importante para usted en un centro odontológico? Marca solo un óvalo.

Estacionamiento o Valet Parking

Coffee break

Caritas pintadas

Bazar de productos dentales

Otro:

18. ¿Por qué medio prefiere mantener la comunicación con el centro odontológico? Marca solo un óvalo.

Facebook

Correo electrónico

Whatsapp

Llamada telefónica

Otro:

19. ¿Ha escuchado sobre MULTIDENT?

Marca solo un óvalo.

Si

No 
20. ¿Sabe que MULTIDENT tiene sucursales en Ate y Santa Anita?

Marca soilo un óvalo.

$\longrightarrow \mathrm{Si}$

21. ¿Usted o sus hijos se han atendido en MULTIDENT?

Marca solo un óvalo.

Si

No

22. Si conoce MULTIDENT. Califique en una palabra ¿Qué le inspira?

23. ¿En qué distrito vive?

Marca solo un óvalo.
Santa Anita
El Agustino
La Molina
Chaclayo
Chosica
Ate
Otro:

24. ¿En qué urbanización vive?

25. Indique el nivel educativo alcanzado (papá/mamá)

Marca solo un óvalo.

\section{Educación primaria}

Educación secundaria

Educación profesional técnica

Educación universitaria superior

Educación postgrado

26. ¿Con cuántos baños cuenta en casa? Marca solo un óvalo.
$\longrightarrow 1$
2
3
4
Más de 4 
27. ¿Cuál es su medio de transporte más usado?

Marca solo un óvalo.

$$
\begin{aligned}
& \text { Transporte público } \\
& \text { Bicicleta } \\
& \text { Auto } \\
& \text { Taxi } \\
& \text { Otro: }
\end{aligned}
$$

28. ¿Cuenta con auto propio?

Marca saio un óvalo.

$$
\left\{\begin{array}{l}
\mathrm{Si} \\
\text { No }
\end{array}\right.
$$

29. De haber respondido Si en la pregunta anterior, especifique su uso Marca solio un óvalo.

Uso particular

Uso para taxi

30. Seleccione el rango de su edad * Marca solo un óvalo.
Hasta 24 años
De 25 a 34 años
De 35 a 44 años
) De 45 años a más 


\section{Anexo 9: Cronograma de videos en vivo para estrategia digital en}

Facebook

\begin{tabular}{|c|c|}
\hline Período & Tema a tratar \\
\hline Enero 2018 & Buenos hábitos, técnica del cepillado e higiene básica \\
\hline Febrero 2018 & $\begin{array}{l}\text { Implementos complementarios: Uso del hilo dental, } \\
\text { Cepillos Interproximales }\end{array}$ \\
\hline Marzo 2018 & Loncheras saludables para el año escolar \\
\hline Abril 2018 & $\begin{array}{l}\text { Tratamientos de ortopedia antes de colocación de } \\
\text { brackets }\end{array}$ \\
\hline Mayo 2018 & Caries profundas y posibles tratamientos de conductos \\
\hline Junio 2018 & Experiencias y traumas con dentistas \\
\hline Julio 2018 & Reglas de oro sobre el cuidado dental en niños \\
\hline Agosto 2018 & Emergencias dentales en niños y cómo tratarlas \\
\hline Septiembre 2018 & Inconvenientes de mal aliento en niños \\
\hline Octubre 2018 & Alternativas de dulces para Halloween \\
\hline Noviembre 2018 & $\begin{array}{l}\text { Manejo de comportamientos difíciles en niños } \\
\text { respecto al cepillado }\end{array}$ \\
\hline Diciembre 2018 & $\begin{array}{l}\text { Importancia del cuidado de la salud de niños VS } \\
\text { Gastos en tratamientos }\end{array}$ \\
\hline
\end{tabular}




\section{BIBLIOGRAFÍA}

1. Administración Estratégica. Autor Fred R. David, 10mo cuarta edición, Pearson, México.

2. APEIM 2016: Data ENAHO 2015

3. APEIM 2017: Data ENAHO 2016

4. Estrategias de Marketing. José Luis Munuera Alemán y Ana Isabel Rodríguez Escudero.

5. Fundamentos psicosociales del comportamiento del paciente en la Atención odontopediátrica Autor Dra. Virginia Gugelmeier

6. Gastos de atención odontológica de niños con caries de infancia temprana, ocasionados a la familia y al Estado Peruano, representado por el Instituto Nacional de Salud del Niño. Rev Estomatol Herediana. 2015.

7. Importancia de la salud oral y su conexión con la salud general. Autor Dra. Andrea Bettina Trinchitella

8. Lazo-Gonzales O, Alcalde-Rabanal J, Espinosa-Henao O. El sistema de salud en Perú: situación y desafíos. Lima: Colegio Médico del Perú, REP; 2016.

9. Matus-López M, Prieto Toledo L, Cid Pedraza C. Evaluación del espacio fiscal para la salud en Perú.

Rev Panam Salud Pública. 2016;40(1):64-69.

10. Proyecciones poblacionales para lima metropolitana a los años horizonte 2018 - 2021 - 2025 y 2035 a nivel distrital. Instituto Metropolitano de planificación. 26/02/2014 
11. Perú: Estimaciones y Proyecciones de Población Departamental por Años Calendario y Edades Simples, 1995-2025. Lima, Noviembre 2010. Dirección Técnica de Demografía e Indicadores Sociales. Boletín Especial № 22

12. Perú: Perspectivas económicas al 2018. Servicio de Asesoría Empresarial. Apoyo Consultoría.

13. Publicación del cirujano Dentista Cesar Torres Nonajulca, Marzo 2017. Situación de la salud Bucal 2016. Gerencia Odontología Universidad Nacional de San Marcos. https://issuu.com/cesartorresnonajulca7/docs/situacion_de_la_salud_bucal_2016

14. Publicación Diario Gestión 31 Enero 2017. Salud dental: ¿Cuánto gastan los peruanos cada año en su salud bucal? http://gestion.pe/tu-dinero/salud-dental-cuanto-gastanperuanos-cada-ano-su-salud-bucal-2180932

15. Publicación del informe GFK Internet 2017, Digital Marketing Toolkit Perú. http://www.gfk.com/es-pe/insights/press-release/informe-de-internet-2017-digitalmarketing-toolkit-peru/

16. Revista Estomatológica Herediana versión impresa ISSN 1019-4355. Rev. Estomatol. Herediana vol.25 no.1 Lima ene. 2015

17. Susalud: Hay 60,000 establecimientos médicos informales en Perú, el triple de los formales. Lunes, 28 de agosto del 2017.

18. Sistema de Información Geográfica - INEI http://sige.inei.gob.pe/sige/

19. Tesis "Salud Bucal Materno Infantil”, Facultad de Estomatología Roberto Beltrán, Universidad Peruana Cayetano Heredia, Lima Perú 2011 